Cochrane Database of Systematic Reviews

\title{
lodine supplementation for women during the preconception, pregnancy and postpartum period (Review)
}

Harding KB, Peña-Rosas JP, Webster AC, Yap CMY, Payne BA, Ota E, De-Regil LM

Harding KB, Peña-Rosas JP, Webster AC, Yap CMY, Payne BA, Ota E, De-Regil LM.

lodine supplementation for women during the preconception, pregnancy and postpartum period.

Cochrane Database of Systematic Reviews 2017, Issue 3. Art. No.: CD011761.

DOI: 10.1002/14651858.CD011761.pub2.

www.cochranelibrary.com 
TABLE OF CONTENTS

HEADER

ABSTRACT

PLAIN LANGUAGE SUMMARY

SUMMARY OF FINDINGS

BACKGROUND

OBJECTIVES

METHODS

RESULTS

Figure 1.

Figure 2.

Figure 3.

DISCUSSION

AUTHORS' CONCLUSIONS

ACKNOWLEDGEMENTS

REFERENCES

CHARACTERISTICS OF STUDIES

DATA AND ANALYSES

Analysis 1.1. Comparison 1 Any supplement containing iodine versus same supplement without iodine or no intervention/ placebo, Outcome 1 Maternal hypothyroidism - pregnancy.

Analysis 1.2. Comparison 1 Any supplement containing iodine versus same supplement without iodine or no intervention/ placebo, Outcome 2 Maternal hypothyroidism - postpartum.

Analysis 1.3. Comparison 1 Any supplement containing iodine versus same supplement without iodine or no intervention/ placebo, Outcome 3 Preterm birth.

Analysis 1.4. Comparison 1 Any supplement containing iodine versus same supplement without iodine or no intervention/ placebo, Outcome 4 Maternal adverse effect: elevated thyroid peroxidase antibodies - pregnancy.

Analysis 1.5. Comparison 1 Any supplement containing iodine versus same supplement without iodine or no intervention/ placebo, Outcome 5 Maternal adverse effect: elevated thyroid peroxidase antibodies - postpartum.

Analysis 1.6. Comparison 1 Any supplement containing iodine versus same supplement without iodine or no intervention/ placebo, Outcome 6 Maternal adverse effect: hyperthyroidism - pregnancy.

Analysis 1.7. Comparison 1 Any supplement containing iodine versus same supplement without iodine or no intervention/ placebo, Outcome 7 Maternal adverse effect: hyperthyroidism - postpartum.

Analysis 1.8. Comparison 1 Any supplement containing iodine versus same supplement without iodine or no intervention/ placebo, Outcome 8 Maternal adverse effect: digestive intolerance - pregnancy.

Analysis 1.9. Comparison 1 Any supplement containing iodine versus same supplement without iodine or no intervention/ placebo, Outcome 9 Perinatal mortality.

Analysis 1.10. Comparison 1 Any supplement containing iodine versus same supplement without iodine or no intervention/ placebo, Outcome 10 Low birthweight.

Analysis 1.11. Comparison 1 Any supplement containing iodine versus same supplement without iodine or no intervention/ placebo, Outcome 11 Neonatal hypothyroidism or elevated TSH.

Analysis 1.12. Comparison 1 Any supplement containing iodine versus same supplement without iodine or no intervention/ placebo, Outcome 12 Neonatal adverse effect: elevated thyroid peroxidase antibodies.

Analysis 1.13. Comparison 1 Any supplement containing iodine versus same supplement without iodine or no intervention/ placebo, Outcome 13 Spontaneous miscarriage.

Analysis 1.14. Comparison 1 Any supplement containing iodine versus same supplement without iodine or no intervention/ placebo, Outcome 14 Maternal goitre - pregnancy.

Analysis 1.15. Comparison 1 Any supplement containing iodine versus same supplement without iodine or no intervention/ placebo, Outcome 15 Maternal goitre - postpartum.

Analysis 1.16. Comparison 1 Any supplement containing iodine versus same supplement without iodine or no intervention/ placebo, Outcome 16 Maternal insufficient iodine intake - pregnancy.

Analysis 1.17. Comparison 1 Any supplement containing iodine versus same supplement without iodine or no intervention/ placebo, Outcome 17 Maternal insufficient iodine intake - postpartum.

Analysis 1.18. Comparison 1 Any supplement containing iodine versus same supplement without iodine or no intervention/ placebo, Outcome 18 Maternal excessive iodine intake - pregnancy. 
Analysis 1.19. Comparison 1 Any supplement containing iodine versus same supplement without iodine or no intervention/ placebo, Outcome 19 Small-for-gestational age.

Analysis 1.20. Comparison 1 Any supplement containing iodine versus same supplement without iodine or no intervention/ placebo, Outcome 20 Congenital anomalies.

Analysis 1.21. Comparison 1 Any supplement containing iodine versus same supplement without iodine or no intervention/ placebo, Outcome 21 Neonatal goitre.

Analysis 1.22. Comparison 1 Any supplement containing iodine versus same supplement without iodine or no intervention/ placebo, Outcome 22 Neonatal thyroid volume (in $\mathrm{mL}$ ).

Analysis 1.23. Comparison 1 Any supplement containing iodine versus same supplement without iodine or no intervention/ placebo, Outcome 23 Neonatal insufficient iodine intake.

Analysis 1.24. Comparison 1 Any supplement containing iodine versus same supplement without iodine or no intervention/ placebo, Outcome 24 Child mental or motor development (IQ points).

Analysis 1.25. Comparison 1 Any supplement containing iodine versus same supplement without iodine or no intervention/ placebo, Outcome 25 Child mental or motor development (cognitive score).

Analysis 1.26. Comparison 1 Any supplement containing iodine versus same supplement without iodine or no intervention/ placebo, Outcome 26 Child mental or motor development (language score).

Analysis 1.27. Comparison 1 Any supplement containing iodine versus same supplement without iodine or no intervention/ placebo, Outcome 27 Child mental or motor development (motor score).

Analysis 1.28. Comparison 1 Any supplement containing iodine versus same supplement without iodine or no intervention/ placebo, Outcome 28 Child mental or motor development (social-emotional score).

Analysis 1.29. Comparison 1 Any supplement containing iodine versus same supplement without iodine or no intervention/ placebo, Outcome 29 Child mental or motor development (adaptive behaviour score).

Analysis 1.30. Comparison 1 Any supplement containing iodine versus same supplement without iodine or no intervention/ placebo, Outcome 30 Child mental or motor development (cognitive score $<85$ ).

Analysis 1.31. Comparison 1 Any supplement containing iodine versus same supplement without iodine or no intervention/ placebo, Outcome 31 Child mental or motor development (cognitive score $<70$ ).

Analysis 1.32. Comparison 1 Any supplement containing iodine versus same supplement without iodine or no intervention/ placebo, Outcome 32 Child mental or motor development (language score $<85$ ).

Analysis 1.33. Comparison 1 Any supplement containing iodine versus same supplement without iodine or no intervention/ placebo, Outcome 33 Child mental or motor development (language score $<70$ ).

Analysis 1.34. Comparison 1 Any supplement containing iodine versus same supplement without iodine or no intervention/ placebo, Outcome 34 Child mental or motor development (motor score $<85$ ).

Analysis 1.35. Comparison 1 Any supplement containing iodine versus same supplement without iodine or no intervention/ placebo, Outcome 35 Child mental or motor development (motor score $<70$ ).

Analysis 2.1. Comparison 2 Any oral iodine supplement versus same supplement without iodine or no intervention/placebo, Outcome 1 Maternal hypothyroidism - pregnancy.

Analysis 2.2. Comparison 2 Any oral iodine supplement versus same supplement without iodine or no intervention/placebo, Outcome 2 Maternal hypothyroidism - postpartum.

Analysis 2.3. Comparison 2 Any oral iodine supplement versus same supplement without iodine or no intervention/placebo, Outcome 3 Preterm birth.

Analysis 2.4. Comparison 2 Any oral iodine supplement versus same supplement without iodine or no intervention/placebo, Outcome 4 Maternal adverse effect: elevated thyroid peroxidase antibodies - pregnancy.

Analysis 2.5. Comparison 2 Any oral iodine supplement versus same supplement without iodine or no intervention/placebo, Outcome 5 Maternal adverse effect: elevated thyroid peroxidase antibodies - postpartum.

Analysis 2.6. Comparison 2 Any oral iodine supplement versus same supplement without iodine or no intervention/placebo, Outcome 6 Maternal adverse effect: hyperthyroidism - pregnancy.

Analysis 2.7. Comparison 2 Any oral iodine supplement versus same supplement without iodine or no intervention/placebo, Outcome 7 Maternal adverse effect: hyperthyroidism - postpartum.

Analysis 2.8. Comparison 2 Any oral iodine supplement versus same supplement without iodine or no intervention/placebo, Outcome 8 Maternal adverse effect: digestive intolerance - pregnancy.

Analysis 2.9. Comparison 2 Any oral iodine supplement versus same supplement without iodine or no intervention/placebo, Outcome 9 Perinatal mortality.

Analysis 2.10. Comparison 2 Any oral iodine supplement versus same supplement without iodine or no intervention/placebo, Outcome 10 Low birthweight.

Analysis 2.11. Comparison 2 Any oral iodine supplement versus same supplement without iodine or no intervention/placebo, Outcome 11 Neonatal hypothyroidism or elevated TSH. 
Analysis 2.12. Comparison 2 Any oral iodine supplement versus same supplement without iodine or no intervention/placebo, Outcome 12 Neonatal adverse effect: elevated thyroid peroxidase antibodies.

Analysis 2.13. Comparison 2 Any oral iodine supplement versus same supplement without iodine or no intervention/placebo, Outcome 13 Spontaneous miscarriage.

Analysis 2.14. Comparison 2 Any oral iodine supplement versus same supplement without iodine or no intervention/placebo, Outcome 14 Maternal goitre - pregnancy.

Analysis 2.15. Comparison 2 Any oral iodine supplement versus same supplement without iodine or no intervention/placebo, Outcome 15 Maternal goitre - postpartum.

Analysis 2.16. Comparison 2 Any oral iodine supplement versus same supplement without iodine or no intervention/placebo, Outcome 16 Maternal insufficient iodine intake - pregnancy.

Analysis 2.17. Comparison 2 Any oral iodine supplement versus same supplement without iodine or no intervention/placebo, Outcome 17 Maternal insufficient iodine intake - postpartum.

Analysis 2.18. Comparison 2 Any oral iodine supplement versus same supplement without iodine or no intervention/placebo, Outcome 18 Maternal excessive iodine intake - pregnancy.

Analysis 2.19. Comparison 2 Any oral iodine supplement versus same supplement without iodine or no intervention/placebo, Outcome 19 Small-for-gestational age.

Analysis 2.20. Comparison 2 Any oral iodine supplement versus same supplement without iodine or no intervention/placebo, Outcome 20 Congenital anomalies.

Analysis 2.21. Comparison 2 Any oral iodine supplement versus same supplement without iodine or no intervention/placebo, Outcome 21 Neonatal goitre.

Analysis 2.22. Comparison 2 Any oral iodine supplement versus same supplement without iodine or no intervention/placebo, Outcome 22 Neonatal thyroid volume (in $\mathrm{mL}$ ).

Analysis 2.23. Comparison 2 Any oral iodine supplement versus same supplement without iodine or no intervention/placebo, Outcome 23 Neonatal insufficient iodine intake.

Analysis 2.24. Comparison 2 Any oral iodine supplement versus same supplement without iodine or no intervention/placebo, Outcome 24 Child mental or motor development (cognitive score).

Analysis 2.25. Comparison 2 Any oral iodine supplement versus same supplement without iodine or no intervention/placebo, Outcome 25 Child mental or motor development (language score).

Analysis 2.26. Comparison 2 Any oral iodine supplement versus same supplement without iodine or no intervention/placebo, Outcome 26 Child mental or motor development (motor score).

Analysis 2.27. Comparison 2 Any oral iodine supplement versus same supplement without iodine or no intervention/placebo, Outcome 27 Child mental or motor development (social-emotional score).

Analysis 2.28. Comparison 2 Any oral iodine supplement versus same supplement without iodine or no intervention/placebo, Outcome 28 Child mental or motor development (adaptive behaviour score).

Analysis 2.29. Comparison 2 Any oral iodine supplement versus same supplement without iodine or no intervention/placebo, Outcome 29 Child mental or motor development (cognitive score < 85).

Analysis 2.30. Comparison 2 Any oral iodine supplement versus same supplement without iodine or no intervention/placebo, Outcome 30 Child mental or motor development (cognitive score < 70).

Analysis 2.31. Comparison 2 Any oral iodine supplement versus same supplement without iodine or no intervention/placebo, Outcome 31 Child mental or motor development (language score < 85).

Analysis 2.32. Comparison 2 Any oral iodine supplement versus same supplement without iodine or no intervention/placebo, Outcome 32 Child mental or motor development (language score < 70).

Analysis 2.33. Comparison 2 Any oral iodine supplement versus same supplement without iodine or no intervention/placebo, Outcome 33 Child mental or motor development (motor score $<85$ ).

Analysis 2.34. Comparison 2 Any oral iodine supplement versus same supplement without iodine or no intervention/placebo, Outcome 34 Child mental or motor development (motor score $<70$ ).

Analysis 3.1. Comparison 3 Oral iodine-only supplement versus no intervention or placebo, Outcome 1 Maternal hypothyroidism - postpartum.

Analysis 3.2. Comparison 3 Oral iodine-only supplement versus no intervention or placebo, Outcome 2 Preterm birth. ........... Analysis 3.3. Comparison 3 Oral iodine-only supplement versus no intervention or placebo, Outcome 3 Maternal adverse effect: elevated thyroid peroxidase antibodies - postpartum.

Analysis 3.4. Comparison 3 Oral iodine-only supplement versus no intervention or placebo, Outcome 4 Maternal adverse effect: hyperthyroidism - postpartum.

Analysis 3.5. Comparison 3 Oral iodine-only supplement versus no intervention or placebo, Outcome 5 Perinatal mortality. .... Analysis 3.6. Comparison 3 Oral iodine-only supplement versus no intervention or placebo, Outcome 6 Low birthweight. ...... 
Analysis 3.7. Comparison 3 Oral iodine-only supplement versus no intervention or placebo, Outcome 7 Neonatal hypothyroidism or elevated TSH.

Analysis 3.8. Comparison 3 Oral iodine-only supplement versus no intervention or placebo, Outcome 8 Neonatal adverse effect: elevated thyroid peroxidase antibodies.

Analysis 3.9. Comparison 3 Oral iodine-only supplement versus no intervention or placebo, Outcome 9 Spontaneous miscarriage.

Analysis 3.10. Comparison 3 Oral iodine-only supplement versus no intervention or placebo, Outcome 10 Maternal goitre pregnancy.

Analysis 3.11. Comparison 3 Oral iodine-only supplement versus no intervention or placebo, Outcome 11 Maternal goitre postpartum.

Analysis 3.12. Comparison 3 Oral iodine-only supplement versus no intervention or placebo, Outcome 12 Maternal insufficient iodine intake - postpartum.

Analysis 3.13. Comparison 3 Oral iodine-only supplement versus no intervention or placebo, Outcome 13 Small-for-gestational age.

Analysis 3.14. Comparison 3 Oral iodine-only supplement versus no intervention or placebo, Outcome 14 Congenital anomalies.

Analysis 3.15. Comparison 3 Oral iodine-only supplement versus no intervention or placebo, Outcome 15 Neonatal goitre. .... Analysis 3.16. Comparison 3 Oral iodine-only supplement versus no intervention or placebo, Outcome 16 Neonatal thyroid volume (in $\mathrm{mL}$ ).

Analysis 3.17. Comparison 3 Oral iodine-only supplement versus no intervention or placebo, Outcome 17 Child mental or motor development (cognitive score).

Analysis 3.18. Comparison 3 Oral iodine-only supplement versus no intervention or placebo, Outcome 18 Child mental or motor development (language score).

Analysis 3.19. Comparison 3 Oral iodine-only supplement versus no intervention or placebo, Outcome 19 Child mental or motor development (motor score).

Analysis 3.20. Comparison 3 Oral iodine-only supplement versus no intervention or placebo, Outcome 20 Child mental or motor development (social-emotional score).

Analysis 3.21. Comparison 3 Oral iodine-only supplement versus no intervention or placebo, Outcome 21 Child mental or motor development (adaptive behaviour score).

Analysis 3.22. Comparison 3 Oral iodine-only supplement versus no intervention or placebo, Outcome 22 Child mental or motor development (cognitive score < 85).

Analysis 3.23. Comparison 3 Oral iodine-only supplement versus no intervention or placebo, Outcome 23 Child mental or motor development (cognitive score $<70$ ).

Analysis 3.24. Comparison 3 Oral iodine-only supplement versus no intervention or placebo, Outcome 24 Child mental or motor development (language score $<85$ ).

Analysis 3.25. Comparison 3 Oral iodine-only supplement versus no intervention or placebo, Outcome 25 Child mental or motor development (language score $<70$ ).

Analysis 3.26. Comparison 3 Oral iodine-only supplement versus no intervention or placebo, Outcome 26 Child mental or motor development (motor score < 85).

Analysis 3.27. Comparison 3 Oral iodine-only supplement versus no intervention or placebo, Outcome 27 Child mental or motor development (motor score $<70$ ).

Analysis 4.1. Comparison 4 Oral iodine supplement with other vitamins and/or minerals versus only other vitamins and/or minerals but no iodine, Outcome 1 Maternal hypothyroidism - pregnancy.

Analysis 4.2. Comparison 4 Oral iodine supplement with other vitamins and/or minerals versus only other vitamins and/or minerals but no iodine, Outcome 2 Maternal hypothyroidism - postpartum.

Analysis 4.3. Comparison 4 Oral iodine supplement with other vitamins and/or minerals versus only other vitamins and/or minerals but no iodine, Outcome 3 Preterm birth.

Analysis 4.4. Comparison 4 Oral iodine supplement with other vitamins and/or minerals versus only other vitamins and/or minerals but no iodine, Outcome 4 Maternal adverse effect: elevated thyroid peroxidase antibodies - pregnancy. .................. Analysis 4.5. Comparison 4 Oral iodine supplement with other vitamins and/or minerals versus only other vitamins and/or minerals but no iodine, Outcome 5 Maternal adverse effect: elevated thyroid peroxidase antibodies - postpartum.

Analysis 4.6. Comparison 4 Oral iodine supplement with other vitamins and/or minerals versus only other vitamins and/or minerals but no iodine, Outcome 6 Maternal adverse effect: hyperthyroidism - pregnancy.

Analysis 4.7. Comparison 4 Oral iodine supplement with other vitamins and/or minerals versus only other vitamins and/or minerals but no iodine, Outcome 7 Maternal adverse effect: hyperthyroidism - postpartum. 
Analysis 4.8. Comparison 4 Oral iodine supplement with other vitamins and/or minerals versus only other vitamins and/or minerals but no iodine, Outcome 8 Maternal adverse effect: digestive intolerance - pregnancy.

Analysis 4.9. Comparison 4 Oral iodine supplement with other vitamins and/or minerals versus only other vitamins and/or minerals but no iodine, Outcome 9 Low birthweight.

Analysis 4.10. Comparison 4 Oral iodine supplement with other vitamins and/or minerals versus only other vitamins and/or minerals but no iodine, Outcome 10 Neonatal hypothyroidism or elevated TSH.

Analysis 4.11. Comparison 4 Oral iodine supplement with other vitamins and/or minerals versus only other vitamins and/or minerals but no iodine, Outcome 11 Spontaneous miscarriage.

Analysis 4.12. Comparison 4 Oral iodine supplement with other vitamins and/or minerals versus only other vitamins and/or minerals but no iodine, Outcome 12 Maternal goitre - pregnancy.

Analysis 4.13. Comparison 4 Oral iodine supplement with other vitamins and/or minerals versus only other vitamins and/or minerals but no iodine, Outcome 13 Maternal goitre - postpartum.

Analysis 4.14. Comparison 4 Oral iodine supplement with other vitamins and/or minerals versus only other vitamins and/or minerals but no iodine, Outcome 14 Maternal insufficient iodine intake - pregnancy.

Analysis 4.15. Comparison 4 Oral iodine supplement with other vitamins and/or minerals versus only other vitamins and/or minerals but no iodine, Outcome 15 Maternal insufficient iodine intake - postpartum.

Analysis 4.16. Comparison 4 Oral iodine supplement with other vitamins and/or minerals versus only other vitamins and/or minerals but no iodine, Outcome 16 Maternal excessive iodine intake - pregnancy.

Analysis 4.17. Comparison 4 Oral iodine supplement with other vitamins and/or minerals versus only other vitamins and/or minerals but no iodine, Outcome 17 Small-for-gestational age.

Analysis 4.18. Comparison 4 Oral iodine supplement with other vitamins and/or minerals versus only other vitamins and/or minerals but no iodine, Outcome 18 Neonatal thyroid volume (in $\mathrm{mL}$ ).

Analysis 4.19. Comparison 4 Oral iodine supplement with other vitamins and/or minerals versus only other vitamins and/or minerals but no iodine, Outcome 19 Neonatal insufficient iodine intake.

Analysis 5.1. Comparison 5 Any injected iodine supplement versus same supplement without iodine or no treatment/placebo, Outcome 1 Perinatal mortality.

Analysis 5.2. Comparison 5 Any injected iodine supplement versus same supplement without iodine or no treatment/placebo, Outcome 2 Congenital anomalies.

Analysis 5.3. Comparison 5 Any injected iodine supplement versus same supplement without iodine or no treatment/placebo, Outcome 3 Neonatal goitre.

Analysis 5.4. Comparison 5 Any injected iodine supplement versus same supplement without iodine or no treatment/placebo, Outcome 4 Child mental or motor development (IQ points).

ADDITIONAL TABLES

APPENDICES

CONTRIBUTIONS OF AUTHORS

DECLARATIONS OF INTEREST

SOURCES OF SUPPORT

DIFFERENCES BETWEEN PROTOCOL AND REVIEW

INDEX TERMS

119 
[Intervention Review]

\section{lodine supplementation for women during the preconception, pregnancy and postpartum period}

Kimberly B Harding¹, Juan Pablo Peña-Rosas ${ }^{2}$, Angela C Webster ${ }^{3}$, Constance MY Yap ${ }^{4}$, Brian A Payne ${ }^{5}$, Erika Ota6 ${ }^{6}$ Luz Maria De-Regil ${ }^{1}$

1Research and Evaluation, Micronutrient Initiative, Ottawa, Canada. 2Evidence and Programme Guidance, Department of Nutrition for Health and Development, World Health Organization, Geneva, Switzerland. ${ }^{3}$ Sydney School of Public Health, The University of Sydney, Sydney, Australia. ${ }^{4}$ Department of Diabetes and Endocrinology, Westmead Hospital, Westmead, Australia. ${ }^{5}$ National Nutrition Center, Ministry of Health Barbados, St Michael, Barbados. ${ }^{6} \mathrm{Global}$ Health Nursing, St. Luke's International University, Graduate School of Nursing Sciences, Tokyo, Japan

Contact address: Juan Pablo Peña-Rosas, Evidence and Programme Guidance, Department of Nutrition for Health and Development, World Health Organization, 20 Avenue Appia, Geneva, GE, 1211, Switzerland. penarosasj@who.int, juanpablopenarosas@outlook.com.

Editorial group: Cochrane Pregnancy and Childbirth Group.

Publication status and date: New, published in Issue 3, 2017.

Citation: Harding KB, Peña-Rosas JP, Webster AC, Yap CMY, Payne BA, Ota E, De-Regil LM. lodine supplementation for women during the preconception, pregnancy and postpartum period. Cochrane Database of Systematic Reviews 2017, Issue 3. Art. No.: CD011761. DOI: 10.1002/14651858.CD011761.pub2.

Copyright @ 2017 The Cochrane Collaboration. Published by John Wiley \& Sons, Ltd.

\section{A B S T R A C T}

\section{Background}

lodine is an essential nutrient required for the biosynthesis of thyroid hormones, which are responsible for regulating growth, development and metabolism. lodine requirements increase substantially during pregnancy and breastfeeding. If requirements are not met during these periods, the production of thyroid hormones may decrease and be inadequate for maternal, fetal and infant needs. The provision of iodine supplements may help meet the increased iodine needs during pregnancy and the postpartum period and prevent or correct iodine deficiency and its consequences.

\section{Objectives}

To assess the benefits and harms of supplementation with iodine, alone or in combination with other vitamins and minerals, for women in the preconceptional, pregnancy or postpartum period on their and their children's outcomes.

\section{Search methods}

We searched Cochrane Pregnancy and Childbirth's Trials Register (14 November 2016), and the WHO International Clinical Trials Registry Platform (ICTRP) (17 November 2016), contacted experts in the field and searched the reference lists of retrieved studies and other relevant papers.

\section{Selection criteria}

Randomized and quasi-randomized controlled trials with randomisation at either the individual or cluster level comparing injected or oral iodine supplementation (such as tablets, capsules, drops) during preconception, pregnancy or the postpartum period irrespective of iodine compound, dose, frequency or duration.

\section{Data collection and analysis}

Two review authors independently assessed trial eligibility, risk of bias, extracted data and conducted checks for accuracy. We used the GRADE approach to assess the quality of the evidence for primary outcomes. 
We anticipated high heterogeneity among trials, and we pooled trial results using random-effects models and were cautious in our interpretation of the pooled results.

\section{Main results}

We included 14 studies and excluded 48 studies. We identified five ongoing or unpublished studies and two studies are awaiting classification. Eleven trials involving over 2700 women contributed data for the comparisons in this review (in three trials, the primary or secondary outcomes were not reported).

\section{Maternal primary outcomes}

lodine supplementation decreased the likelihood of the adverse effect of postpartum hyperthyroidism by $68 \%$ (average risk ratio (RR) 0.32 ; $95 \%$ confidence interval $(\mathrm{Cl}) 0.11$ to 0.91 , three trials in mild to moderate iodine deficiency settings, 543 women, no statistical heterogeneity, low-quality evidence) and increased the likelihood of the adverse effect of digestive intolerance in pregnancy by 15 times (average RR $15.33 ; 95 \% \mathrm{Cl} 2.07$ to 113.70 , one trial in a mild-deficiency setting, 76 women, very low-quality evidence).

There were no clear differences between groups for hypothyroidism in pregnancy or postpartum (pregnancy: average RR 1.90; 95\% CI 0.57 to 6.38 , one trial, 365 women, low-quality evidence, and postpartum: average RR $0.44 ; 95 \% \mathrm{Cl} 0.06$ to 3.42 , three trials, 540 women, no statistical heterogeneity, low-quality evidence), preterm birth (average RR $0.71 ; 95 \% \mathrm{Cl} 0.30$ to 1.66 , two trials, 376 women, statistical heterogeneity, low-quality evidence) or the maternal adverse effects of elevated thyroid peroxidase antibodies (TPO-ab) in pregnancy or postpartum (average RR $0.95 ; 95 \% \mathrm{Cl} 0.44$ to 2.07 , one trial, 359 women, low-quality evidence, average RR $1.01 ; 95 \% \mathrm{Cl} 0.78$ to 1.30 , three trials, 397 women, no statistical heterogeneity, low-quality evidence), or hyperthyroidism in pregnancy (average RR $1.90 ; 95 \% \mathrm{Cl} 0.57$ to 6.38 , one trial, 365 women, low-quality evidence). All of the trials contributing data to these outcomes took place in settings with mild to moderate iodine deficiency.

\section{Infant/child primary outcomes}

Compared with those who did not receive iodine, those who received iodine supplements had a $34 \%$ lower likelihood of perinatal mortality, however this difference was not statistically significant (average RR $0.66 ; 95 \% \mathrm{Cl} 0.42$ to 1.03 , two trials, 457 assessments, low-quality evidence). All of the perinatal deaths occurred in one trial conducted in a severely iodine-deficient setting. There were no clear differences between groups for low birthweight (average RR 0.56; 95\% Cl 0.26 to 1.23, two trials, 377 infants, no statistical heterogeneity, low-quality evidence), neonatal hypothyroidism/elevated thyroid-stimulating hormone (TSH) (average RR 0.58; $95 \% \mathrm{Cl} 0.11$ to 3.12 , two trials, 260 infants, very low-quality evidence) or the adverse effect of elevated neonatal thyroid peroxidase antibodies (TPO-ab) (average RR 0.61; 95\% $\mathrm{Cl} 0.07$ to 5.70, one trial, 108 infants, very low-quality evidence). All of the trials contributing data to these outcomes took place in areas with mild to moderate iodine deficiency. No trials reported on hypothyroidism/elevated TSH or any adverse effect beyond the neonatal period.

\section{Authors' conclusions}

There were insufficient data to reach any meaningful conclusions on the benefits and harms of routine iodine supplementation in women before, during or after pregnancy. The available evidence suggested that iodine supplementation decreases the likelihood of postpartum hyperthyroidism and increases the likelihood of the adverse effect of digestive intolerance in pregnancy - both considered potential adverse effects. We considered evidence for these outcomes low or very low quality, however, because of study design limitations and wide confidence intervals. In addition, due to the small number of trials and included women in our meta-analyses, these findings must be interpreted with caution. There were no clear effects on other important maternal or child outcomes though these findings must also be interpreted cautiously due to limited data and low-quality trials. Additionally, almost all of the evidence came from settings with mild or moderate iodine deficiency and therefore may not be applicable to settings with severe deficiency.

More high-quality randomised controlled trials are needed on iodine supplementation before, during and after pregnancy on maternal and infant/child outcomes. However, it may be unethical to compare iodine to placebo or no treatment in severe deficiency settings. Trials may also be unfeasible in settings where pregnant and lactating women commonly take prenatal supplements with iodine. Information is needed on optimal timing of initiation as well as supplementation regimen and dose. Future trials should consider the outcomes in this review and follow children beyond the neonatal period. Future trials should employ adequate sample sizes, assess potential adverse effects (including the nature and extent of digestive intolerance), and be reported in a way that allows assessment of risk of bias, full data extraction and analysis by the subgroups specified in this review.

\section{PLAIN LANGUAGE SUMMARY}

\section{lodine supplementation for women before, during or after pregnancy}

\section{What is the issue?}

It is estimated that over 1.8 billion people worldwide do not get enough iodine in their diet, putting them at risk of iodine deficiency. lodine is an essential nutrient needed in small amounts for the body to make thyroid hormones. The World Health Organization (WHO) recommends that iodine is added to salt to prevent problems caused by lack of iodine. Women who are pregnant or breastfeeding need extra iodine, which puts them at greater risk of deficiency. The breast milk contains iodine for the infant. 


\section{Why is this important?}

Thyroid function is increased during pregnancy as thyroid hormones produced by the mother (and the baby as the pregnancy progresses) are essential for growth and development of the baby and to regulate the development of the brain and nervous system. Nervous tissue begins to develop as early as the second month of pregnancy. If women have too little iodine during pregnancy or infants have too little during early childhood, the damage may be irreversible. Research has shown that severe iodine deficiency can stunt children's normal physical growth as well as harm normal mental development, resulting in lower intelligence quotients. Less is known about the consequences of mild or moderate deficiency. Too much iodine can also cause harm and have negative effects on mothers and babies, for example by causing the thyroid to become overactive.

Although salt is the commonly the main source of iodine, expert medical groups recommend that women in many countries take iodine supplements during and following pregnancy to help ensure their iodine needs are met.

\section{What evidence did we find?}

We searched for evidence in November 2016 and identified 14 randomised controlled trials of iodine supplements in the form of tablets, capsules, drops or injections before, during or after pregnancy. Eleven trials with over 2700 women contributed findings to the review. Eight trials compared iodine with no treatment or a placebo and three trials compared iodine given with other vitamins and minerals against only the vitamins and minerals.

Women who received iodine supplements were less likely to develop the unwanted effect of hyperthyroidism (an overactive thyroid gland) after giving birth (three trials involving 543 women) but they were more likely to experience nausea or vomiting during pregnancy (one trial involving 76 women) when compared to those who did not receive iodine. One trial ( 365 women) did not find any difference in the number of women with an overactive thyroid gland during pregnancy. The number of women with an underactive thyroid gland (hypothyroidism) was not clearly different either during pregnancy (one trial involving 365 women) or after giving birth (three trials involving 540 women) when iodine supplements were given. A similar number of women had raised thyroid antibodies during pregnancy (one trial, 359 women) and after giving birth (three trials, 397 women). We found no clear differences between women given iodine supplements and those not when looking at preterm births (two trials, 376 women) or deaths around the time of giving birth (two trials, 457 women), babies born with a low birthweight (two trials, 377 babies), newborn babies with an underactive thyroid gland (two trials, 260 babies) or with raised thyroid antibodies (one trial, 108 babies).

The quality of the evidence was low to very low, mostly because few trials looked at each outcome or because of limitations in the study designs. Most of the findings were from one or two trials and small numbers of women were included. This means we are not confident in the results.

\section{What does this mean?}

The potential benefits and harms of any intervention must be weighed as part of deciding whether to use it. Our Cochrane Review provides a summary of the evidence but there were not enough data for any meaningful conclusions on the benefits and harms of routine iodine supplementation in women before, during or after pregnancy. The limited information we found suggests there are benefits and risks of iodine supplementation. More research will clarify the effects and safety of this intervention. Future research should use randomised controlled trial designs where practical and ethical, and include the outcomes from this review. 


\begin{tabular}{|c|c|c|c|c|c|c|c|}
\hline \multirow{15}{*}{ 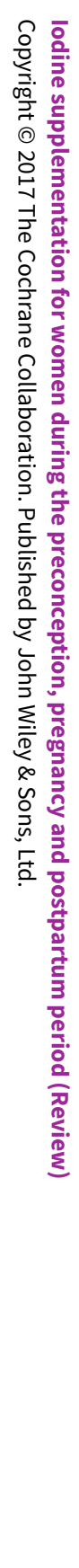 } & \multicolumn{7}{|c|}{$\begin{array}{l}\text { S U M M A R Y O F F I N D I NG S } \\
\text { Summary of findings for the main comparison. Any supplement containing iodine versus same st } \\
\text { (maternal outcomes) }\end{array}$} \\
\hline & \multicolumn{7}{|c|}{ Any supplement containing iodine versus same supplement without iodine or no treatment/placebo (maternal outcomes) } \\
\hline & \multicolumn{7}{|c|}{$\begin{array}{l}\text { Population: women during the preconception, pregnancy and postpartum period } \\
\text { Setting: Denmark, Germany, Morocco, New Zealand, Thailand, Zaire } \\
\text { Intervention: any supplement containing iodine } \\
\text { Comparison: same supplement without iodine or no treatment/placebo }\end{array}$} \\
\hline & \multirow[t]{2}{*}{ Outcomes } & \multicolumn{2}{|c|}{ Anticipated absolute effects ${ }^{\star}(95 \% \mathrm{Cl})$} & \multirow{2}{*}{$\begin{array}{l}\text { Relative effect } \\
(95 \% \mathrm{CI})\end{array}$} & \multirow{2}{*}{$\begin{array}{l}\text { № of partici- } \\
\text { pants } \\
\text { (studies) }\end{array}$} & \multirow{2}{*}{$\begin{array}{l}\text { Quality of the } \\
\text { evidence } \\
\text { (GRADE) }\end{array}$} & \multirow[t]{2}{*}{ Comments } \\
\hline & & $\begin{array}{l}\text { Risk with san } \\
\text { plement witl } \\
\text { iodine or no } \\
\text { ment/placeb }\end{array}$ & $\begin{array}{l}\text { Risk with any supplement contain- } \\
\text { ing iodine }\end{array}$ & & & & \\
\hline & \multirow{4}{*}{$\begin{array}{l}\text { Maternal hypothy- } \\
\text { roidism - pregnancy }\end{array}$} & Study popula & & \multirow{4}{*}{$\begin{array}{l}\text { Average RR } 1.90 \\
\text { (0.57 to 6.38) }\end{array}$} & \multirow{4}{*}{$\begin{array}{l}365 \\
(1 \mathrm{RCT})\end{array}$} & \multirow{4}{*}{$\begin{array}{l}\oplus \oplus \odot \odot \\
\operatorname{Low} 1,2\end{array}$} & \\
\hline & & 21 per 1000 & $\begin{array}{l}40 \text { per } 1000 \\
(12 \text { to } 134)\end{array}$ & & & & \\
\hline & & \multicolumn{2}{|l|}{ Moderate } & & & & \\
\hline & & 21 per 1000 & $\begin{array}{l}40 \text { per } 1000 \\
(12 \text { to } 135)\end{array}$ & & & & \\
\hline & \multirow{4}{*}{$\begin{array}{l}\text { Maternal hypothy- } \\
\text { roidism - postpartum }\end{array}$} & Study popula & & \multirow{4}{*}{$\begin{array}{l}\text { Average RR } 0.44 \\
(0.06 \text { to } 3.42)\end{array}$} & \multirow{4}{*}{$\begin{array}{l}540 \\
\text { (3 RCTs) }\end{array}$} & \multirow{4}{*}{$\begin{array}{l}\oplus \oplus \oplus \ominus \\
\text { Low } 2,3\end{array}$} & \\
\hline & & 7 per 1000 & $\begin{array}{l}4 \text { per } 1000 \\
(1 \text { to } 34)\end{array}$ & & & & \\
\hline & & \multicolumn{2}{|l|}{ Moderate } & & & & \\
\hline & & 11 per 1000 & $\begin{array}{l}5 \text { per } 1000 \\
(1 \text { to } 37)\end{array}$ & & & & \\
\hline & \multirow[t]{2}{*}{ Preterm birth } & Study popula & & \multirow{2}{*}{$\begin{array}{l}\text { Average RR } 0.71 \\
(0.30 \text { to } 1.66)\end{array}$} & \multirow{2}{*}{$\begin{array}{l}376 \\
(2 \mathrm{RCTs})\end{array}$} & \multirow{2}{*}{\multicolumn{2}{|c|}{$\begin{array}{l}\oplus \oplus \Theta \Theta \\
\text { Low } 1,2\end{array}$}} \\
\hline & & 111 per 1000 & $\begin{array}{l}78 \text { per } 1000 \\
\text { (33 to } 184 \text { ) }\end{array}$ & & & & \\
\hline
\end{tabular}




\begin{tabular}{|c|c|c|c|c|c|c|c|}
\hline \multirow{6}{*}{\multicolumn{2}{|c|}{ 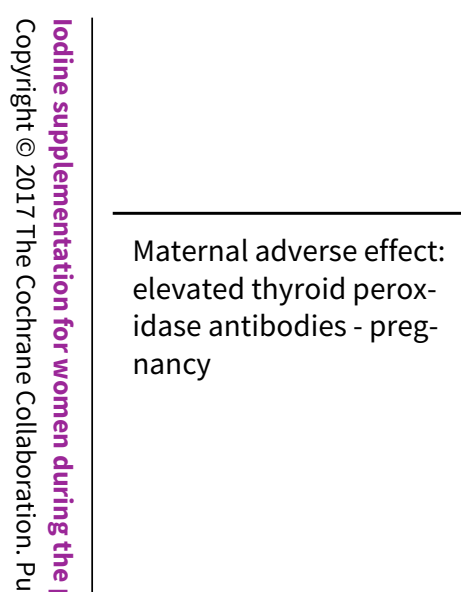 }} & \multicolumn{2}{|l|}{ Moderate } & & & & \multirow{6}{*}{ 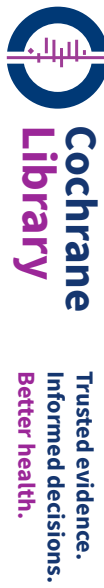 } \\
\hline & & 122 per 1000 & $\begin{array}{l}87 \text { per } 1000 \\
\text { (37 to } 202)\end{array}$ & & & & \\
\hline & & \multicolumn{2}{|c|}{ Study population } & \multirow{4}{*}{$\begin{array}{l}\text { Average RR } 0.95 \\
\text { (0.44 to } 2.07 \text { ) }\end{array}$} & \multirow{4}{*}{$\begin{array}{l}359 \\
(1 \mathrm{RCT})\end{array}$} & \multirow{4}{*}{$\begin{array}{l}\oplus \oplus \Theta \odot \\
\text { Low } 1,2\end{array}$} & \\
\hline & & 68 per 1000 & $\begin{array}{l}65 \text { per } 1000 \\
(30 \text { to } 142)\end{array}$ & & & & \\
\hline & & \multicolumn{2}{|l|}{ Moderate } & & & & \\
\hline & & 68 per 1000 & $\begin{array}{l}65 \text { per } 1000 \\
(30 \text { to } 142)\end{array}$ & & & & \\
\hline 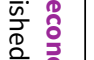 & \multirow{4}{*}{$\begin{array}{l}\text { Maternal adverse effect: } \\
\text { elevated TPO-ab - post- } \\
\text { partum }\end{array}$} & \multicolumn{2}{|c|}{ Study population } & \multirow{4}{*}{$\begin{array}{l}\text { Average RR } 1.01 \\
(0.78 \text { to } 1.30)\end{array}$} & \multirow{4}{*}{$\begin{array}{l}397 \\
\text { (3 RCTs) }\end{array}$} & \multirow{4}{*}{$\begin{array}{l}\oplus \oplus \ominus \ominus \\
\text { Low } 1,4\end{array}$} & \\
\hline 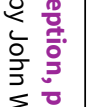 & & 301 per 1000 & $\begin{array}{l}304 \text { per } 1000 \\
\text { ( } 235 \text { to } 391)\end{array}$ & & & & \\
\hline 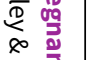 & & \multicolumn{2}{|l|}{ Moderate } & & & & \\
\hline 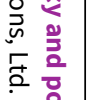 & & 77 per 1000 & $\begin{array}{l}78 \text { per } 1000 \\
(60 \text { to } 100)\end{array}$ & & & & \\
\hline 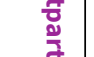 & \multirow{4}{*}{$\begin{array}{l}\text { Maternal adverse effect: } \\
\text { hyperthyroidism - preg- } \\
\text { nancy }\end{array}$} & \multicolumn{2}{|c|}{ Study population } & \multirow{4}{*}{$\begin{array}{l}\text { Average RR } 1.90 \\
\text { (0.57 to } 6.38)\end{array}$} & \multirow{4}{*}{$\begin{array}{l}365 \\
(1 \mathrm{RCT})\end{array}$} & \multirow{4}{*}{$\begin{array}{l}\oplus \oplus \ominus \ominus \\
\text { Low } 1,2\end{array}$} & \\
\hline $\begin{array}{l}\overline{3} \\
\frac{\overline{0}}{0} \\
\frac{\mathrm{D}}{\mathrm{y}} \\
0\end{array}$ & & 21 per 1000 & $\begin{array}{l}40 \text { per } 1000 \\
(12 \text { to } 134)\end{array}$ & & & & \\
\hline 甬. & & \multicolumn{2}{|l|}{ Moderate } & & & & \\
\hline & & 21 per 1000 & $\begin{array}{l}40 \text { per } 1000 \\
(12 \text { to } 135)\end{array}$ & & & & ळ. \\
\hline & \multirow{4}{*}{$\begin{array}{l}\text { Maternal adverse effect: } \\
\text { hyperthyroidism - post- } \\
\text { partum }\end{array}$} & \multicolumn{2}{|c|}{ Study population } & \multirow{4}{*}{$\begin{array}{l}\text { Average RR } 0.32 \\
(0.11 \text { to } 1.91)\end{array}$} & \multirow{4}{*}{$\begin{array}{l}543 \\
\text { (3 RCTs) }\end{array}$} & \multirow{4}{*}{$\begin{array}{l}\oplus \oplus \odot \odot \\
\text { Low 2, } 4\end{array}$} & $\stackrel{\mathscr{\Perp}}{\mathscr{U}}$ \\
\hline & & 49 per 1000 & $\begin{array}{l}16 \text { per } 1000 \\
(5 \text { to } 45)\end{array}$ & & & & 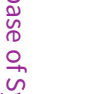 \\
\hline & & \multicolumn{2}{|l|}{ Moderate } & & & & 3 \\
\hline & & 6 per 1000 & 3 per 1000 & & & & 㫣 \\
\hline
\end{tabular}




\begin{tabular}{|c|c|c|c|c|c|}
\hline 훙 & & (1 to 7 ) & & & \\
\hline Maternal adverse effect: & Study popul & & Average & 76 & $\oplus \Theta \Theta \Theta$ \\
\hline pregnancy & 22 per 1000 & $\begin{array}{l}333 \text { per } 1,000 \\
(45 \text { to } 1,000)\end{array}$ & $\begin{array}{l}\text { RR } 15.33 \\
\text { (2.07 to } 113.70 \text { ) }\end{array}$ & & \\
\hline $\begin{array}{l}\stackrel{0}{3} \\
\stackrel{0}{0}\end{array}$ & Moderate & & & & \\
\hline 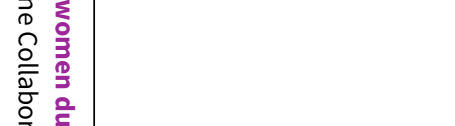 & 25 per 1000 & $\begin{array}{l}383 \text { per } 1000 \\
(52 \text { to } 1,000)\end{array}$ & & & \\
\hline
\end{tabular}

*The risk in the intervention group (and its 95\% confidence interval) is based on the assumed risk in the comparison group and the relative effect of the intervention (and its $95 \% \mathrm{Cl}$ ).

Cl: Confidence interval; RR: Risk ratio; TPO-ab: thyroid peroxidase antibodies

\section{GRADE Working Group grades of evidence}

High quality: We are very confident that the true effect lies close to that of the estimate of the effect

Moderate quality: We are moderately confident in the effect estimate: The true effect is likely to be close to the estimate of the effect, but there is a possibility that it is substantially different

Low quality: Our confidence in the effect estimate is limited: The true effect may be substantially different from the estimate of the effect

Very low quality: We have very little confidence in the effect estimate: The true effect is likely to be substantially different from the estimate of effect

1One study with design limitations (high risk for attrition bias).

2 Wide confidence interval.

3 Most studies contributing data had design limitations (high risk for attrition bias and unclear for selection bias).

${ }^{4}$ Most studies contributing data had design limitations (high risk for attrition bias and selection bias).

50 e study with high risk of blinding and attrition bias.

\section{Summary of findings 2 . Any supplement containing iodine versus same supplement without iodine or no treatment/placebo (child outcomes)}

Any supplement containing iodine versus same supplement without iodine or no treatment/placebo (child outcomes)

Population: women during the preconception, pregnancy and postpartum period

Setting: Germany, New Zealand, Thailand, Zaire

Intervention: any supplement containing iodine

Comparison: same supplement without iodine or no treatment/placebo

\begin{tabular}{l|lll} 
Outcomes & Anticipated absolute effects ${ }^{*}(95 \% \mathrm{Cl})$ & $\begin{array}{l}\text { Relative effect } \\
(95 \% \mathrm{Cl})\end{array}$ & $\begin{array}{l}\text { No of partici- } \\
\text { pants }\end{array}$ \\
& & $\begin{array}{l}\text { Quality of the } \\
\text { evidence }\end{array}$ & $\begin{array}{l}\text { Comments } \\
\text { (studies) }\end{array}$
\end{tabular}




\begin{tabular}{|c|c|c|c|c|c|}
\hline & $\begin{array}{l}\text { Risk with same supple- } \\
\text { ment without iodine or } \\
\text { no treatment/placebo }\end{array}$ & $\begin{array}{l}\text { Risk with any supplement contain- } \\
\text { ing iodine }\end{array}$ & & & \\
\hline \multirow[t]{4}{*}{ Perinatal mortality } & \multicolumn{2}{|l|}{ Study population } & \multirow{4}{*}{$\begin{array}{l}\text { Average RR } 0.66 \\
(0.42 \text { to } 1.03)\end{array}$} & \multirow{4}{*}{$\begin{array}{l}399 \\
(1 \mathrm{RCT})\end{array}$} & \multirow{4}{*}{$\begin{array}{l}\oplus \oplus \ominus \ominus \\
\text { Low } 1,2\end{array}$} \\
\hline & 208 per 1000 & $\begin{array}{l}137 \text { per } 1000 \\
(87 \text { to } 214)\end{array}$ & & & \\
\hline & \multicolumn{2}{|l|}{ Moderate } & & & \\
\hline & 208 per 1000 & $\begin{array}{l}137 \text { per } 1000 \\
(87 \text { to } 214)\end{array}$ & & & \\
\hline \multirow[t]{4}{*}{ Low birthweight } & \multicolumn{2}{|l|}{ Study population } & \multirow{4}{*}{$\begin{array}{l}\text { Average RR } 0.56 \\
(0.26 \text { to } 1.23)\end{array}$} & \multirow{4}{*}{$\begin{array}{l}377 \\
\text { (2 RCTs) }\end{array}$} & \multirow{4}{*}{$\begin{array}{l}\oplus \oplus \Theta \Theta \\
\text { Low } 2,3\end{array}$} \\
\hline & 90 per 1000 & $\begin{array}{l}51 \text { per } 1000 \\
\text { (24 to } 111)\end{array}$ & & & \\
\hline & \multicolumn{2}{|l|}{ Moderate } & & & \\
\hline & 96 per 1000 & $\begin{array}{l}54 \text { per } 1000 \\
\text { (25 to } 118)\end{array}$ & & & \\
\hline \multirow{4}{*}{$\begin{array}{l}\text { Neonatal hypothy- } \\
\text { roidism or elevated } \\
\text { TSH }\end{array}$} & \multicolumn{2}{|l|}{ Study population } & \multirow{4}{*}{$\begin{array}{l}\text { Average RR } 0.58 \\
(0.11 \text { to } 3.12)\end{array}$} & \multirow{4}{*}{$\begin{array}{l}219 \\
(1 \mathrm{RCT})\end{array}$} & \multirow{4}{*}{$\begin{array}{l}\oplus \Theta \Theta \odot \\
\text { Very low 2, 3, } 5\end{array}$} \\
\hline & 34 per 1000 & $\begin{array}{l}20 \text { per } 1000 \\
(4 \text { to } 106)\end{array}$ & & & \\
\hline & \multicolumn{2}{|l|}{ Moderate } & & & \\
\hline & 34 per 1000 & $\begin{array}{l}20 \text { per } 1000 \\
(4 \text { to } 106)\end{array}$ & & & \\
\hline \multirow{4}{*}{$\begin{array}{l}\text { Neonatal adverse } \\
\text { effect: elevated } \\
\text { TPO-ab }\end{array}$} & Study population & & \multirow{4}{*}{$\begin{array}{l}\text { Average RR } 0.61 \\
(0.07 \text { to } 5.70)\end{array}$} & \multirow{4}{*}{$\begin{array}{l}108 \\
(1 \mathrm{RCT})\end{array}$} & \multirow{4}{*}{$\begin{array}{l}\oplus \odot \odot \ominus \\
\text { Very low 2, 4, } 5\end{array}$} \\
\hline & 43 per 1000 & $\begin{array}{l}26 \text { per } 1000 \\
\text { ( } 3 \text { to } 244)\end{array}$ & & & \\
\hline & \multicolumn{2}{|l|}{ Moderate } & & & \\
\hline & 43 per 1000 & $\begin{array}{l}26 \text { per } 1000 \\
\text { ( } 3 \text { to } 245 \text { ) }\end{array}$ & & & \\
\hline
\end{tabular}


*The risk in the intervention group (and its $95 \%$ confidence interval) is based on the assumed risk in the comparison group and the relative effect of the intervention (and its $95 \% \mathrm{Cl})$.

CI: Confidence interval; RR: Risk ratio; TPO-ab: thyroid peroxidase antibodies; TSH: thyroid-stimulating hormone

\section{GRADE Working Group grades of evidence}

High quality: We are very confident that the true effect lies close to that of the estimate of the effect

Moderate quality: We are moderately confident in the effect estimate: The true effect is likely to be close to the estimate of the effect, but there is a possibility that it is substantially different

Low quality: Our confidence in the effect estimate is limited: The true effect may be substantially different from the estimate of the effect

Very low quality: We have very little confidence in the effect estimate: The true effect is likely to be substantially different from the estimate of effect

1Design limitations (high risk of attrition bias and unclear for selection bias).

2Wide confidence interval.

30ne study had design limitations (high risk for attrition bias).

${ }^{4}$ One study with design limitations (high risk for selection bias).

${ }^{5}$ Small number of events. 


\section{B A C K G R O U N D}

\section{Description of the condition}

lodine is an essential nutrient required for the biosynthesis of thyroid hormones thyroxine (T4) and triiodothyronine (T3), which are responsible for regulating growth, development and metabolism. Very little iodine is required to meet the body's needs, ranging from $90 \mu \mathrm{g}$ to $290 \mu \mathrm{g}$ per day depending on age and physiological status (IOM 2001). However it can be challenging to meet these needs given that naturally-occurring iodine is low in most foods and beverages, with the exception of seafood, including fish, shellfish and plants from the ocean (Rohner 2014). For many people, the major source of dietary iodine is added, from salt fortified with iodine or from dairy products in settings where iodine is added to animal feed or where iodine-containing antiseptics are used.

\section{lodine in preconception, pregnancy and breastfeeding}

Throughout pregnancy there are major alterations in thyroid function as a result of metabolic demands and hormonal changes (Glinoer 1997). The concentrations of T4 and T3 rise significantly until approximately mid-gestation and then remain relatively stable until the end of gestation at term. lodine requirements increase substantially during pregnancy; initially as a result of a $50 \%$ increase in thyroid hormone production and a 30\% to 50\% increase in the renal excretion of iodine (Glinoer 2007), and later in gestation when iodine passes through the placenta for fetal production of thyroid hormones (Glinoer 1997). Maternal and fetal thyroid hormones are essential in regulating the development of the fetal brain and nervous system including the creation and growth of nerve cells, the formation of synapses, which are required for communication between nerve cells, and myelination, which is the formation of a fat-based layer that allows for fast communication between nerve cells (Prado 2014). Some of these events begin in the second month of gestation (Prado 2014), so may be influenced by iodine status and thyroid hormone production prior to conception (or prior to knowledge of pregnancy).

During breastfeeding, thyroid hormone production and urinary iodine excretion return to non-pregnancy levels, but iodine requirements remain elevated because iodine is concentrated in the mammary gland for excretion in breast milk (Leung 2011). Breastmilk iodine content varies with maternal dietary iodine intake and is lowest in iodine-deficient areas and highest where additional iodine is routinely provided through supplements or universal salt iodization (Azizi 2009). As long as maternal iodine intake is adequate, breast milk can meet infant iodine needs.

\section{Recommended iodine intakes}

Minute amounts of iodine are required to meet iodine needs and prevent deficiency. Different agencies have recommended different intakes to meet iodine needs of non-pregnant, pregnant and breastfeeding women, ranging from $150 \mu \mathrm{g}$ to $290 \mu \mathrm{g}$ a day. The International Council for Control of lodine Deficiency Disorders (ICCIDD), World Health Organization (WHO), and United Nations Children's Fund (UNICEF) recommended a daily iodine intake of 250 $\mu \mathrm{g}$ for pregnant women and those breastfeeding their babies (WHO/ UNICEF/ICCIDD 2007). The US Institute of Medicine established a recommended dietary allowance of $220 \mu \mathrm{g}$ a day for women during pregnancy and $290 \mu \mathrm{g}$ a day whilst breastfeeding (IOM 2001). The European Food Safety Authority set the adequate intake among pregnant women and women who are breastfeeding their infants at $200 \mu \mathrm{g} /$ day (EFSA 2014). All three recommendations suggest $150 \mu \mathrm{g}$ a day for non-pregnant adult women though recommended intakes for the adolescent period differ.

Both the US Institute of Medicine and the European Commission Scientific Committee on Food have set tolerable upper intake levels for iodine, which are the highest levels of daily intake not likely to pose a risk of adverse health effects in the general population (IOM 2001; SCF 2006). These two organizations' recommendations vary greatly for non-pregnant, pregnant and breastfeeding women though, with the US Institute of Medicine level at $1100 \mu \mathrm{g}$ a day and the European Commission level set at $600 \mu \mathrm{g}$ a day. These recommended intakes are not intended for iodine-deficient populations however, as metabolic adaptations to deficiency could result in adverse health effects at lower intakes (Rohner 2014).

\section{Burden of iodine deficiency}

It is estimated that over 1.8 billion people worldwide have an insufficient iodine intake, putting them at risk of iodine deficiency (Andersson 2012). Europe is the region with the highest proportion of individuals with insufficient intake (44\%), whereas Southeast Asia has the highest number (540 million). Given the elevated iodine requirements during pregnancy and breastfeeding and the importance of thyroid hormones for growth and development of the nervous system, ensuring adequate status in women and young children is critical. However, as only a limited number of countries have completed surveys in pregnant women and women of reproductive age on national or large sub-national levels, there are insufficient data to directly estimate the regional or global prevalence of low iodine intake in these important target groups (Wong 2011).

\section{Consequences of iodine deficiency}

The consequences of iodine deficiency, which result from inadequate thyroid hormone production and can affect individuals of any age, sex, and physiological status, are collectively known as iodine deficiency disorders (Hetzel 1983; WHO/UNICEF/ICCIDD 2007). They are most serious and may be irreversible if they occur during pregnancy or early childhood, though the effects depend on the timing and severity of iodine deficiency (Zimmermann 2012a). If the increased iodine requirements during pregnancy are not met, the concentration of T4 diminishes (hypothyroxinaemia) in both mother and fetus, which can lead to irreversible brain damage with intellectual disability and neurologic abnormalities (Glinoer 2007; Williams 2008). Iodine deficiency in pregnancy has been associated with maternal and fetal goitre and hypothyroidism, increased pregnancy loss and infant mortality, and impairments in child development (Dunn 1993; Dunn 2001). Symptoms of hypothyroidism, or an underactive thyroid, include tiredness, weakness, poor memory and difficulty concentrating, weight gain, feeling cold, dry skin and hair loss (Jameson 2005). Globally, iodine deficiency is the most common cause of hypothyroidism (Jameson 2005) and the most common preventable cause of impaired brain development and mental function (WHO/UNICEF 2007).

The effect of iodine deficiency on child development can manifest itself as anything from mild intellectual blunting to cretinism, with a large proportion of the population experiencing intellectual impairment somewhere in between these extremes (Glinoer 2000). Endemic cretinism, the most serious iodine deficiency disorder, is a permanent condition of severely stunted physical and mental 
development that results from an untreated congenital deficiency of thyroid hormones caused by severe maternal iodine deficiency (Hetzel 1983). It is still unclear whether mild-to-moderate maternal iodine deficiency in humans produces changes in cognitive function. Some evidence suggests that children with chronic severe iodine deficiency have significantly lower intelligence quotient (IQ) scores than those with adequate iodine status (Zimmermann 2009). Some randomised clinical studies conducted in school-age children indicate that cognitive performance may improve with iodine supplementation, even in mildly deficient areas (Gordon 2009; Melse-Boonstra 2010). In the absence of iodine these effects are largely preventable by immediate thyroid hormone replacement, although deficits in memory and IQ may persist over time (Williams 2008). It is also thought that iodine deficiency could be associated with autism (Sullivan 2008) and with children's attention deficit and hyperactivity disorder (Vermiglio 2004).

A variety of factors affect iodine metabolism and thyroid function and can exacerbate iodine deficiency. Other nutritional deficiencies, including of selenium and iron, can lead to decreased thyroid hormone production and cause damage to the thyroid because key enzymes required for thyroid hormone synthesis and metabolism depend on these nutrients (Zimmermann 2002). Iron supplementation has been shown to improve the efficacy of iodine supplementation or salt iodization in iodine- and iron-deficient children (Hess 2002; Zimmermann 2000).

Compounds found naturally in some foods such as cassava, sorghum, soy and millet, and pollutants in food and water such as perchlorate and nitrate can also negatively affect iodine metabolism and thyroid function (Rohner 2014). Collectively known as goitrogens, these substances can compete with iodine for uptake by the thyroid and impair the activity of key enzymes required to produce thyroid hormones. Infants and young children appear particularly vulnerable to the effects of goitrogens, and effects are generally only seen where there is pre-existing iodine deficiency.

\section{Consequences of excess iodine}

Excess iodine exposure can also cause serious negative health effects, and can occur through ingestion of supplements, water or foods with high iodine content or via medical treatments or procedures. Acute iodine poisoning may cause gastrointestinal or cardiovascular symptoms, or even coma, after ingestion of many grams of iodine (Zimmermann 2008). Excess iodine can also cause the thyroid to become over or underactive (hyper or hypothyroidism). Hypothyroidism symptoms are described above. Symptoms of excess thyroid hormone production as a result of hyperthyroidism include hyperactivity, irritability, heat intolerance, palpitations, weakness, fatigue and weight loss (Jameson 2005).

In iodine sufficiency, the thyroid is able to adjust to a wide range of iodine intakes, so healthy individuals may tolerate up to $1 \mathrm{mg}$ daily (Zimmermann 2008). In areas of chronic iodine deficiency however, individuals are less tolerant to high iodine intake, especially older adults with longstanding goitre. lodineinduced hyperthyroidism has been reported in the initial phases of salt iodization programmes, though it is nearly always temporary (WHO/UNICEF/ICCIDD 2007). It was estimated that 11 countries have excessive iodine intakes (up from seven in 2007) as presented at the Sixty-sixth World Health Assembly in a progress report from the WHO in 2013.

\section{Indicators of iodine status}

\section{Urinary iodine concentration (UIC)}

In conditions of iodine sufficiency, over $90 \%$ of ingested iodine is excreted in the urine, whereas in chronic iodine deficiency the excretion may be less than $20 \%$, making urinary iodine concentration (UIC) a good indicator of recent iodine intake, or short-term iodine status (Rohner 2014). UIC has limited utility in assessing individual intake or status because of large variations within and between days (WHO 2013). These variations level out in large population samples though, making UIC a useful populationlevel indicator. UIC is not a direct indicator of thyroid function, but low values suggest a greater risk of developing thyroid disorders (Rohner 2014).

UIC is commonly collected from school age children and extrapolated to the general population or other population groups; however, neither this group nor non-pregnant women serve as an adequate proxy for pregnant women (Wong 2011). For pregnant women, a median UIC below $150 \mu \mathrm{g} / \mathrm{L}$ is indicative of insufficient iodine intake, $150 \mu \mathrm{g} / \mathrm{L}$ to $249 \mu \mathrm{g} / \mathrm{L}$ adequate iodine intake, $250 \mu \mathrm{g} /$ $\mathrm{L}$ to $499 \mu \mathrm{g} / \mathrm{L}$ above iodine requirements, and $500 \mu \mathrm{g} / \mathrm{L}$ or higher concentrations suggest an excessive intake (beyond that needed for prevention and control of iodine deficiency) (WHO 2013). For women who are breastfeeding their infants and children under two years of age, a median UIC of below $100 \mathrm{\mu g} / \mathrm{L}$ indicates insufficient iodine intake, and $100 \mu \mathrm{g} / \mathrm{L}$ or more indicates adequate iodine intake. For these population groups, the category of iodine intake is not extrapolated to category of iodine status.

\section{Goitre}

The development of goitre, or enlargement of the thyroid gland, begins as an adaptive response when iodine available to the thyroid is not sufficient for adequate thyroid hormone production (Rohner 2014). Goitre responds slowly to changes in iodine intake and is therefore an indicator of longer-term iodine status. In areas of chronic iodine deficiency it can take years for thyroid size to return to normal, and goitre may never completely disappear (Zimmermann 2012b).

The presence of goitre can be determined by neck inspection and palpation or by thyroid ultrasonography (Rohner 2014; WHO/ UNICEF/ICCIDD 2007). This method however has poor sensitivity and specificity in areas of mild-to-moderate iodine deficiency. In these settings, assessment of thyroid size by ultrasonography is preferred and technology is available for use in field settings. International reference values for thyroid volume using ultrasound are available only for school age children though (Zimmermann 2004).

\section{Thyroid-stimulating hormone (TSH)}

This hormone, also known as thyrotropin, is produced by the pituitary gland and stimulates thyroid hormone production and release by the thyroid gland (Rohner 2014). Serum TSH levels increase in response to low thyroid hormone concentration and decrease in response to high concentration; it is a very sensitive indicator of thyroid function and is the primary screening test for thyroid dysfunction (Jameson 2005). Though TSH levels may rise in response to iodine deficiency, they are often in the normal range, therefore TSH is not considered a sensitive indicator of iodine status (Rohner 2014; Zimmermann 2008). TSH is a useful 
indicator of iodine nutrition in neonates though because they have high thyroidal iodine turnover (Delange 1998). Moderately elevated levels (higher than $5 \mathrm{mlU} / \mathrm{L}$ in whole blood) indicate neonatal iodine deficiency, which is a direct reflection of iodine deficiency during pregnancy (WHO/UNICEF/ICCIDD 2007). A prevalence of less than $3 \%$ of infants with moderately elevated TSH is expected in iodine-sufficient regions (Rohner 2014; WHO/UNICEF/ICCIDD 2007). Neonatal TSH screening for congenital hypothyroidism is standard practice in many developed countries (WHO/UNICEF/ICCIDD 2007). This condition, which has genetic causes, is relatively rare (one in 4000 births) and indicated by highly elevated TSH levels (20 $\mathrm{mIU} / \mathrm{L}$ or higher), and requires immediate treatment to prevent permanent neurological damage.

Because of a physiological surge in newborns, neonatal TSH assessment must take place at least 48 hours following birth (WHO/ UNICEF/ICCIDD 2007). In some countries elevated neonatal TSH may be attributed to the use of beta-iodine-containing antiseptics so results need to be interpreted cautiously in these contexts.

\section{Thyroid hormones}

Triiodothyronine (T3) and its prohormone, thyroxine (T4), are hormones produced and secreted by the thyroid gland (Rohner 2014). T4 is converted to T3, the active hormone, in peripheral tissues. A very small amount (less than 1\%) of T4 and T3 in the blood is not bound to protein, and therefore biologically active. In the past, thyroid hormone assessments typically measured total amounts because the free levels were too low to detect. However, with the advent of newer techniques, free T4 and free T3, which better reflect the physiological effects of thyroid hormones than total hormone concentrations, are usually measured nowadays.

T3 and T4 levels are direct clinical indicators of thyroid function, but levels are protected in the early stages of thyroid dysfunction and changes occur only at later stages (Rohner 2014). Therefore these thyroid hormones are not good indicators of iodine status, except in cases of severe iodine deficiency. A diagnosis of subclinical hypothyroidism is based on elevated TSH with normal T4 and T3 levels. Overt hypothyroidism occurs when thyroid function further diminishes, as indicated by falling free T4 levels, and the diagnosis is based on high TSH and low T4. T3 levels are typically maintained even longer than $\mathrm{T} 4$ levels. Some research has shown that neonatal T4 levels are lower in iodine-deficient compared to iodine-sufficient areas; however, validated norms have not been established for comparison.

\section{Thyroglobulin $(\mathrm{Tg})$}

$\mathrm{Tg}$ is a protein matrix for thyroid hormone synthesis (Glinoer 1997). Tg levels rise early in pregnancy, and the increase is most pronounced towards the end of gestation. In newborns, Tg levels are normally increased in the first few days, possibly in response to the physiological TSH surge (Pezzino 1981).

$\mathrm{Tg}$ is an indirect indicator of thyroid function and $\mathrm{Tg}$ levels are positively correlated with thyroid volume (Rohner 2014). Tg is elevated in iodine-deficient populations and is also an indirect indicator of iodine status. Levels respond more quickly (weeks to months) to iodine repletion than TSH or goitre (Zimmermann 2008). Assays can be performed on samples collected on dried blood spots and international reference ranges are available for school-age children (Zimmermann 2004). The presence of anti-Tg antibodies, however, is reported to complicate interpretation of $\mathrm{Tg}$ values (Rohner 2014).

Complex changes in thyroid physiology can make interpretation of thyroid function and iodine status in pregnancy and early infancy difficult, therefore special considerations should to be taken into account to avoid misinterpreting results (Laurberg 2007). Though Stinca and colleagues recently reported that dried blood spot $\mathrm{Tg}$ is a sensitive indicator of iodine status in pregnant women and that $\mathrm{Tg}$ antibodies may not be necessary in this assessment (Stinca 2016).

\section{Description of the intervention}

\section{Guidance and recommendations}

Since 1993, universal salt iodization, or the addition of iodine to all salt for human and animal consumption including food industry salt, has been recommended for preventing and controlling iodine deficiency (UNICEF/WHO 1994; WHO 2014). As a result of this long-standing recommendation and the related support for its implementation, most countries have some form of salt iodization program in place to prevent and control iodine deficiency and its consequences (UNICEF 2008). Universal salt iodization is widely acknowledged as a cost-effective, feasible, and sustainable approach to control iodine deficiency, and research suggests that successful salt iodization programmes can meet the needs of population groups susceptible to iodine deficiency and its consequences, specifically pregnant and breastfeeding women and infants (Zimmermann 2007). However, it has been recognized that these groups may need to be targeted with other iodine interventions (Untoro 2007). WHO and UNICEF recommend considering iodine supplementation in pregnant women, women breastfeeding their infants and children from six to 23 months of age, alongside efforts to scale up salt iodization, in settings where large proportions of the population do not have access to iodized salt (WHO/UNICEF 2007). In addition, where pregnant women are difficult to reach, WHO and UNICEF recommend that supplementation be extended to all women of reproductive age. In some countries, for example the USA, Canadian and Australian medical bodies have issued specific recommendations for iodine supplementation in women who are pregnant or breastfeeding (and women considering becoming pregnant in Australia) (ATA 2006; NHMRC 2010).

\section{Supplement form, dose, and regimen}

\section{Oral supplements}

Several different types of oral iodine supplements are available for public health purposes. These can be broadly divided into frequent low dose (such as daily or weekly), or infrequent high dose (such as annually or only once). The low-dose formulations usually contain iodine as potassium iodide and come in the form of tablets or drops for oral consumption. Many commercially available multiplemicronutrient supplements including prenatal formulations also contain iodine, often $150 \mu \mathrm{g}$ for a daily dose (Leung 2009).

High-dose iodine supplements usually come in the form of oral iodized oil capsules; the iodine is stored mainly in the thyroid gland and can meet needs for up to a year. The above-mentioned WHO/ UNICEF guidance recommends a single annual dose of $400 \mathrm{mg}$ or a daily dose of $250 \mu \mathrm{g}$ for pregnant and breastfeeding women (or 150 $\mu \mathrm{g}$ a day for non-pregnant women) (WHO/UNICEF 2007), whereas 
the USA, Canadian and Australian recommendations suggest 150 $\mu \mathrm{g} /$ day (ATA 2006; NHMRC 2010).

\section{Injectable supplements}

Much of the early iodine supplementation research used high-dose intramuscular iodized oil injections (e.g. Pharoah 1971 and Pretell 1972) and this approach was used in public health programmes especially in the 1970 s and 1980s. This would currently be considered a medical intervention that should be provided under medical supervision. Other forms of medical iodine interventions are available including sodium iodide solution used in intravenous parenteral nutrition.

\section{How the intervention might work}

lodine requirements increase during pregnancy because of increased thyroid hormone production and iodine excretion, and during breastfeeding because iodine is concentrated in the mammary gland for excretion in breast milk. If maternal iodine requirements are not met during this period, the production of thyroid hormones may decrease and be inadequate for maternal, fetal and infant needs (Glinoer 2007). Consequences may include maternal or child hypothyroidism or goitre, pregnancy loss, low birthweight, infant mortality, and developmental delays ranging from mild intellectual impairment to cretinism.

Additional iodine intake through iodine supplementation may help meet the increased iodine needs for thyroid hormone production and transfer to the fetus/infant during pregnancy and the postpartum period and prevent or correct iodine deficiency and its consequences. lodine supplementation prior to conception could increase iodine stores and thyroid hormone production before the additional demands of pregnancy. This may be especially important in severely iodine-deficient areas to allow time for correction of long-standing deficiency. Even where iodine deficiency is less severe though, additional iodine intake prior to pregnancy may be warranted because thyroid hormones are important for brain and nervous system development events starting as early as the seventh week of gestation (Prado 2014), when women may not know or share with others that they are pregnant.

Previous evidence reviews reported that high-dose iodine supplementation through intramuscular injection prior to, or early in pregnancy reduced the incidence of cretinism and improved child cognitive development scores in severely iodine-deficient areas (Bougma 2013; Zimmermann 2012a). There is also evidence of improved birthweight, through oral iodine supplementation, and decreased child mortality, through injected iodized oil (Zimmermann 2012a).

From an implementation perspective, pregnant and postpartum women often have contact with the healthcare system, which generally provides or recommends prenatal and sometimes postnatal micronutrient supplementation - usually iron and folic acid. Similarly, where indicated, iodine supplementation could be integrated into routine antenatal and postnatal care. To reach women prior to pregnancy, existing contacts with the healthcare system or other platforms could be used to provide or recommend iodine supplementation for those planning on becoming pregnant or to all women of reproductive age, or both, because pregnancies are often unplanned (as is done with folic acid supplementation recommendations in many settings).

\section{Why it is important to do this review}

It is important to assess the effects and safety of iodine supplementation in women before or during pregnancy and in the postpartum period for optimal maternal and child outcomes and to inform policy making towards the achievement of the WHO global targets for maternal, infant and young child nutrition by 2025 (WHA 2012).

This review will complement the findings of other existing reviews assessing the provision of iodine through a variety of interventions. Mahomed and colleagues conducted one of the first Cochrane Reviews on the topic (now withdrawn), examining maternal iodine supplementation in areas of iodine deficiency (Mahomed 2006). More recently a non-Cochrane review examined the effect of prenatal or periconceptional iodine supplementation on child development, growth and other clinical outcomes (Zhou 2013). The effects of iodine supplementation for preventing iodine deficiency disorders in children (Angermayr 2004) and mortality and adverse neurodevelopmental outcomes in preterm infants (Ibrahim 2006) are addressed in other Cochrane Reviews. A review on salt iodization for prevention of iodine deficiency disorders is published elsewhere (Aburto 2014) and a Cochrane Review on fortification of foods and condiments (other than salt) with iodine for prevention of iodine deficiency disorders (Land 2013) is being conducted. Furthermore, a review on the effect of iodized salt or iodine supplements on prenatal and postnatal growth (Farebrother 2015) is also underway. Cochrane reviews have also been conducted on point-of-use fortification of foods with multiple-micronutrient powders (Suchdev 2015) and multiplemicronutrient supplementation (Haider 2015) for women during pregnancy.

\section{O B JECTIVES}

To assess the benefits and harms of supplementation with iodine, alone or in combination with other vitamins and minerals, for women in the preconceptional, pregnancy or postpartum period on their and their children's outcomes.

\section{METHODS}

\section{Criteria for considering studies for this review \\ Types of studies}

We included randomised and quasi-randomized controlled trials with randomisation at either the individual or cluster level. We intended to include eligible cross-over trials (and use only the results from the first period) however we did not identify any such studies.

\section{Types of participants}

Women who become pregnant, or pregnant or postpartum women of any chronological age and parity (number of births), regardless as to the iodine status of the study population or setting. We included studies that randomised women to receive treatment starting at any point prior to conception, during pregnancy or within the first six weeks postpartum. We planned to exclude studies specifically targeting women screened for and diagnosed with thyroid disorders (as defined by trial authors) or other health problems (e.g. thyroid disease, HIV, tuberculosis) however we did not identify any such studies. 


\section{Types of interventions}

Injected or oral iodine supplementation (such as tablets, capsules, drops) during preconception, pregnancy or the postpartum period irrespective of compound, dose, frequency or duration.

Specifically, where data were available we planned to assess the following comparisons:

1. any supplement containing iodine versus same supplement without iodine or no intervention/placebo;

2. any oral iodine supplement versus same supplement without iodine or no intervention/placebo;

3. oral iodine-only supplement versus no intervention or placebo;

4. oral iodine supplement with other vitamins and/or minerals versus only other vitamins and/or minerals (exact same formulation of other vitamins/minerals, but no iodine);

5. any injected iodine supplement versus same supplement without iodine or no intervention/placebo;

6. injected iodine-only supplement versus no intervention or placebo;

7. injected iodine supplement with other vitamins and/or minerals versus only other vitamins and/or minerals (exact same formulation of other vitamins/minerals, but no iodine).

We only identified data for comparisons 1 through 6 . Because we did not identify any studies for comparison 7 , comparisons 5 and 6 include the exact same data and we have only reported comparison 5. We have summarized comparisons 2, 3, 4 and 5 in comparison 1 , and we have summarized comparisons 3 and 4 in comparison 2 . We have summarized comparison 1 , the main comparison, in the 'Summary of findings' tables (Summary of findings for the main comparison and Summary of findings 2).

We included interventions that combined iodine supplementation with co-interventions (e.g. education), only if the co-interventions were the same across study arms. We excluded studies that examined tube feeding, parenteral nutrition, or food-based interventions (e.g. fortified or bio fortified foods, point-of-use fortification with micronutrient powders or lipid-based nutrient supplements).

\section{Types of outcome measures}

We included studies which met the above-mentioned criteria regardless of outcomes reported, though we only extracted the outcomes described below.

\section{Primary outcomes}

\section{Maternal}

1. Hypothyroidism (as defined by trial authors)

2. Preterm birth (as defined by trial authors)

3. Adverse effects

a. Elevated thyroid peroxidase antibodies (TPO-ab) (as defined by trial authors)

b. Hyperthyroidism (as defined by trial authors)

c. Digestive intolerance (as defined by trial authors)

\section{Infants and children - to $\mathbf{2 3}$ months of age}

1. Perinatal mortality (including stillbirth/fetal death and neonatal death, as defined by trial authors)
2. Low birthweight (less than $2500 \mathrm{~g}$ )

3. Hypothyroidism or elevated TSH (as defined by trial authors)

4. Adverse effects
a. Elevated TPO-ab (as defined by trial authors)
b. Hyperthyroidism (as defined by trial authors)

\section{Secondary outcomes}

Maternal

1. Spontaneous miscarriage (as defined by trial authors)

2. Thyroid size (assessed by any method)

3. Thyroglobulin $(\mathrm{Tg})(\mu \mathrm{g} / \mathrm{L})$

4. Insufficient iodine intake (pregnancy: median urinary iodine concentration (UIC) less than $150 \mu \mathrm{g} / \mathrm{L}$, breastfeeding: median UIC less than $100 \mu \mathrm{g} / \mathrm{L}$ )

5. Excessive iodine intake (pregnancy only: median UIC greater than or equal to $500 \mu \mathrm{g} / \mathrm{L}$ )

\section{Infants and children - to 23 months of age}

1. Small-for-gestational age (as defined by trial authors)

2. Congenital anomalies (including cretinism, as defined by trial authors)

3. Growth (anthropometric Z scores)

4. Thyroid size (assessed by any method)

5. Insufficient iodine intake (median UIC less than $100 \mu \mathrm{g} / \mathrm{L}$ )

6. Mental or motor development (as defined by trial authors)

7. Infant death (death in the first year of life)

For relevant maternal outcomes, we included both the pregnancy and postpartum period. If maternal outcomes were assessed at multiple time points, unless otherwise specified, we used the last assessment during pregnancy and the last assessment in the postpartum period. We planned to include the last assessment during the intervention period and the last assessment during the follow-up period though did not because many of the trials were single dose and therefore this distinction was not relevant, and also because of the way data were presented in most of the trials. We did not include any outcomes during the preconception period. For infant and child outcomes assessed at multiple time points, where relevant we planned to include the neonatal period (to 28 days), infancy (under one year), and childhood (beyond one year). We summarized primary outcomes in 'Summary of findings' tables (Summary of findings for the main comparison, Summary of findings 2).

We planned to include any adverse event, such as iodine-induced hyperthyroidism, in the mother and child as primary outcomes. None of the trials which reported on hyperthyroidism indicated whether it was or suspected to be iodine-induced (none of these trials took place in severely-deficient women so it is unlikely that the hyperthyroidism would have been caused by the supplemental iodine). The only other reported outcomes considered by the trial or review authors to be potentially adverse were elevated TPO$a b$ and digestive intolerance. Therefore we replaced any adverse effects with hyperthyroidism and elevated TPO-ab (and digestive intolerance for women), and extracted these outcomes separately to avoid losing potentially important information.

Urinary and breast milk iodine concentrations are probably the most common indicators of iodine status; they provide important 
information on the adherence and biological response to the intervention or potential contamination in the control group. However these indicators are generally highly skewed and are typically reported as median with some description of the range. As we did not have access to primary data, we have presented these outcomes in Table 1 but they were not included in a meta-analysis and did not directly inform the conclusions of the review.

\section{Search methods for identification of studies}

The following methods section is based on a standard template used by Cochrane Pregnancy and Childbirth.

\section{Electronic searches}

We searched Cochrane Pregnancy and Childbirth's Trials Register by contacting their Information Specialist (14 November 2016).

The Register is a database containing over 22,000 reports of controlled trials in the field of pregnancy and childbirth. For full search methods used to populate Pregnancy and Childbirth's Trials Register including the detailed search strategies for CENTRAL, MEDLINE, Embase and CINAHL; the list of handsearched journals and conference proceedings, and the list of journals reviewed via the current awareness service, please follow this link to the editorial information about the Cochrane Pregnancy and Childbirth in the Cochrane Library and select the 'Specialized Register' section from the options on the left side of the screen.

Briefly, Cochrane Pregnancy and Childbirth's Trials Register is maintained by their Information Specialist and contains trials identified from:

1. monthly searches of the Cochrane Central Register of Controlled Trials (CENTRAL);

2. weekly searches of MEDLINE (Ovid);

3. weekly searches of Embase (Ovid);

4. monthly searches of CINAHL (EBSCO);

5. handsearches of 30 journals and the proceedings of major conferences;

6. weekly current awareness alerts for a further 44 journals plus monthly BioMed Central email alerts.

Search results are screened by two people and the full text of all relevant trial reports identified through the searching activities described above is reviewed. Based on the intervention described, each trial report is assigned a number that corresponds to a specific Pregnancy and Childbirth review topic (or topics), and is then added to the Register. The Information Specialist searches the Register for each review using this topic number rather than keywords. This results in a more specific search set which has been fully accounted for in the relevant review sections (Included studies; Excluded studies; Studies awaiting classification; Ongoing studies).

In addition, we searched the WHO International Clinical Trials Registry Platform (ICTRP) (17 November 2016) for unpublished, planned and ongoing trials using search terms as described in Appendix 1.

\section{Searching other resources}

We searched through the bibliographies of existing reviews on similar topics and of retrieved studies. We contacted experts in the field as well as authors of retrieved studies for lists of other studies that should be considered for inclusion.

For assistance in identifying ongoing or unpublished studies, we also contacted the WHO Departments of Reproductive Health and Research and Nutrition for Health and Development, the lodine Global Network, the nutrition section of the United Nations Children's Fund (UNICEF), the World Food Programme (WFP), the US Centers for Disease Control and Prevention (CDC), the Micronutrient Initiative (MI), the Global Alliance for Improved Nutrition (GAIN), Hellen Keller International (HKI), and Sight and Life (28 November 2016).

We did not apply any date or language restrictions.

\section{Data collection and analysis}

The following methods section is based on a standard template used by Cochrane Pregnancy and Childbirth.

\section{Selection of studies}

Two review authors (KBH and LDR) independently assessed for inclusion all the potential studies we identified as a result of the search strategy. We resolved any disagreement through discussion and, if required, consulted with a third review author (ACW). For one study (Mohammed 2015), funded by the organization of the two authors doing the eligibility, another author (JPP) assessed and determined it was excluded. We included studies published as abstracts but if we could not assess quality and extract information (after attempting to contact study authors), these studies were marked as "awaiting classification".

\section{Data extraction and management}

We designed a form to extract data and record information requested from study authors. For eligible studies, data were extracted once using the agreed form by three review authors $(\mathrm{KBH}$, BAP and CMYY). Two review authors ( $\mathrm{KBH}$ and BAP) entered the data into Review Manager 5 (RevMan 5) software (RevMan 2014). We resolved discrepancies through discussion or, if required, consulted a third person.

When information regarding any of the above was unclear, we attempted to contact authors of the original reports to provide further details.

\section{Assessment of risk of bias in included studies}

Two review authors independently assessed risk of bias for each study using the criteria outlined in the Cochrane Handbook for Systematic Reviews of Interventions (Higgins 2011a). We resolved any disagreement by discussion or by involving a third assessor.

\section{(1) Random sequence generation (checking for possible selection bias)}

We described for each included study the method used to generate the allocation sequence in sufficient detail to allow an assessment of whether it should produce comparable groups.

We assessed the method as:

- low risk of bias (any truly random process, e.g. random number table; computer random number generator); 
- high risk of bias (any non-random process, e.g. odd or even date of birth; hospital or clinic record number);

- unclear risk of bias.

\section{(2) Allocation concealment (checking for possible selection bias)}

We described for each included study the method used to conceal allocation to interventions prior to assignment and assess whether intervention allocation could have been foreseen in advance of, or during recruitment, or changed after assignment.

We assessed the methods as:

- low risk of bias (e.g. telephone or central randomisation; consecutively-numbered sealed opaque envelopes);

- high risk of bias (open random allocation; unsealed or nonopaque envelopes, alternation; date of birth);

- unclear risk of bias.

\section{(3.1) Blinding of participants and personnel (checking for} possible performance bias)

We described for each included study the methods used, if any, to blind study participants and personnel from knowledge of which intervention a participant received. We considered that studies were at low risk of bias if they were blinded, or if we judged that the lack of blinding would be unlikely to affect results. Where relevant, we planned to assess blinding separately for different outcomes or classes of outcomes.

We assessed the methods as:

- low, high or unclear risk of bias for participants;

- low, high or unclear risk of bias for personnel.

\section{(3.2) Blinding of outcome assessment (checking for possible detection bias)}

We described for each included study the methods used, if any, to blind outcome assessors from knowledge of which intervention a participant received. Where relevant, we planned to assess blinding separately for different outcomes or classes of outcomes.

We assessed methods used to blind outcome assessment as:

- low, high or unclear risk of bias.

\section{(4) Incomplete outcome data (checking for possible attrition bias due to the amount, nature and handling of incomplete outcome data)}

We described for each included study, and for each outcome or class of outcomes, the completeness of data including attrition and exclusions from the analysis. We stated whether attrition and exclusions were reported and the numbers included in the analysis at each stage (compared with the total randomised participants), reasons for attrition or exclusion where reported, and whether missing data were balanced across groups or were related to outcomes. Where sufficient information was reported, or could be supplied by the trial authors, we planned to re-include missing data in the analyses which we undertook.

We assessed methods as:
- low risk of bias (e.g. no missing outcome data; missing outcome data were less than $20 \%$ and were balanced across groups);

- high risk of bias (e.g. numbers or reasons for missing data imbalanced across groups; 'as-treated' analysis done with substantial departure of intervention received from that assigned at randomisation);

- unclear risk of bias (e.g. level of missing data was unclear).

\section{(5) Selective reporting (checking for reporting bias)}

We described for each included study how we investigated the possibility of selective outcome reporting bias and what we found.

We assessed the methods as:

- low risk of bias (where it was clear that all of the study's prespecified outcomes and all expected outcomes of interest to the review were reported);

- high risk of bias (where not all the study's pre-specified outcomes were reported; one or more reported primary outcomes were not pre-specified; outcomes of interest were reported incompletely and so could not be used; study failed to include results of a key outcome that would have been expected to have been reported);

- unclear risk of bias.

(6) Other bias (checking for bias due to problems not covered by (1) to (5) above)

We described for each included study any important concerns we had about other possible sources of bias.

We assessed whether each study was free of other problems that could put it at risk of bias:

- low risk of other bias;

- high risk of other bias;

- unclear whether there was risk of other bias.

\section{(7) Overall risk of bias}

We made explicit judgements about whether studies were at high risk of bias, according to the criteria given in the Cochrane Handbook for Systematic Reviews of Interventions (Higgins 2011a). With reference to (1) to (6) above, we assessed the likely magnitude and direction of the bias and whether we considered it was likely to impact on the findings. We planned to explore the impact of the level of bias through undertaking sensitivity analyses however we considered only one trial at low overall risk of bias therefore this analysis would not have been meaningful.

\section{Assessing the quality of the evidence using GRADE}

We assessed the overall quality of the evidence for primary outcomes using the GRADE approach as outlined in the GRADE handbook in order to assess the quality of the body of evidence relating to the primary outcomes for any supplement containing iodine versus same supplement without iodine or no intervention/ placebo. Two review authors independently assessed the quality of the evidence for each of the maternal and child primary outcomes.

Maternal outcomes

1. Hypothyroidism (as defined by trial authors) 
2. Preterm birth (as defined by trial authors)

3. Adverse effects

a. Elevated thyroid peroxidase antibodies (TPO-ab) (as defined by trial authors)

b. Hyperthyroidism (as defined by trial authors)

c. Digestive intolerance (as defined by trial authors)

\section{Infant/child outcomes}

1. Perinatal mortality (including stillbirth/fetal death and neonatal death, as defined by trial authors)

2. Low birthweight (less than $2500 \mathrm{~g}$ )

3. Hypothyroidism or elevated TSH (as defined by trial authors)

4. Adverse effects

a. Elevated TPO-ab (as defined by trial authors)

b. Hyperthyroidism (as defined by trial authors)

We used the GRADEpro Guideline Development Tool to import data from RevMan 5 (RevMan 2014) in order to create 'Summary of findings' tables (Summary of findings for the main comparison; Summary of findings 2). We produced a summary of the intervention effect and a measure of quality for each of the above outcomes using the GRADE approach. The GRADE approach uses five considerations (study limitations, consistency of effect, imprecision, indirectness and publication bias) to assess the quality of the body of evidence for each outcome. The evidence can be downgraded from 'high quality' by one level for serious (or by two levels for very serious) limitations, depending on assessments for risk of bias, indirectness of evidence, serious inconsistency, imprecision of effect estimates or potential publication bias.

\section{Measures of treatment effect}

\section{Dichotomous data}

For dichotomous data, we have presented results as summary risk ratio (RR) with $95 \%$ confidence intervals $(\mathrm{Cl})$.

\section{Continuous data}

For continuous data, we used the mean difference (MD) if outcomes were measured in the same way between trials. We planned to use the standardized mean difference to combine trials that measured the same outcome, but used different methods.

Where trials reported median, we included this information in additional tables and a narrative summary of the findings.

\section{Unit of analysis issues}

\section{Cluster-randomized trials}

We included cluster-randomized trials in the analyses along with individually-randomized trials. Cluster-randomized trials are labelled with a (C). We had planned to adjust their standard errors and determine effective sample size using the methods described in the Cochrane Handbook for Systematic Reviews of Interventions using an estimate of the intra cluster correlation co-efficient (ICC) derived from the trial (if possible), from a similar trial or from a study of a similar population to take into account the design effect (Higgins 2011b). If we used ICCs from other sources, we planned to report this and conduct sensitivity analyses to investigate the effect of variation in the ICC. However we identified only two cluster-randomized trials. In one, family was the unit of allocation, and it was not possible to know if there was more than one pregnant women per family and therefore any clustering effect (Pharoah 1971 (C)). Therefore we did not adjust data from this trial for clustering. In the other cluster-randomized study, the reported analysis accounted for clustering therefore no additional adjustments were necessary (Bouhouch 2014 (C)).

We synthesized the relevant information from the clusterrandomized and individually-randomized trials.

We considered it reasonable to combine the results from both if there was little heterogeneity between the study designs and the interaction between the effect of intervention and the choice of randomisation unit was considered to be unlikely. We also acknowledged heterogeneity in the randomisation unit.

\section{Cross-over trials}

We planned to include cross-over trials which would be otherwise eligible for inclusion and use only data from the first period (if the data were presented in this way) and anticipated that additional methods for 'Risk of bias' assessment and analysis would not be needed. We did not identify any eligible cross-over trials though.

\section{Other unit of analysis issues}

For studies with more than two intervention groups (multi-arm studies, e.g. using different doses), we included only directly relevant arms. For studies with more than one relevant arm we combined the arms into a single pair-wise comparison (Higgins 2011) and included the disaggregated data in the corresponding subgroup category. To avoid double counting participants, if the control group was shared by different study arms, we divided the control group (events and total population) over the number of relevant subgroup categories.

For studies that included non-pregnant women, we only included those who became pregnant.

If a study examined supplementing both the mother and infant, and was otherwise eligible, we included that study arm and the maternal data but excluded the infant data, as it would have been affected by the infant intervention.

We included all relevant details in the Characteristics of included studies tables.

\section{Dealing with missing data}

For included studies, we noted levels of attrition in the Characteristics of included studies tables.

For all outcomes, we carried out analyses, as far as possible, on an intention-to-treat basis, that is, we attempted to include all participants randomised to each group in the analyses, and all participants were analysed in the group to which they were allocated, regardless of whether or not they received the allocated intervention. The denominator for each outcome in each trial was the number randomised minus any participants whose outcomes were known to be missing.

\section{Assessment of heterogeneity}

We assessed statistical heterogeneity in each meta-analysis using the $\mathrm{Tau}^{2}, \mathrm{I}^{2}$ (Higgins 2003) and $\mathrm{Chi}^{2}$ statistics (Deeks 2011). We considered heterogeneity as substantial if an $\mathrm{I}^{2}$ statistic was greater 
than $30 \%$ and either the $\mathrm{Tau}^{2}$ was greater than zero, or there was a low $P$ value (less than 0.10 ) in the $\mathrm{Chi}^{2}$ test for heterogeneity. We planned to explore any identified substantial heterogeneity (above $30 \%$ ) by pre-specified subgroup analysis.

\section{Assessment of reporting biases}

We planned to investigate reporting biases (such as publication bias) using funnel plots if there were 10 or more studies in the metaanalysis. We planned to assess funnel plot asymmetry visually and if asymmetry was suggested by a visual assessment, we planned to perform exploratory analyses to investigate it. However there were no meta-analyses with 10 or more studies so we were unable to assess reporting bias.

\section{Data synthesis}

We carried out statistical analysis using the RevMan 5 software (RevMan 2014). We intended to use fixed-effect meta-analysis for combining data where it would be reasonable to assume that studies were estimating the same underlying treatment effect: that is, where trials were examining the same intervention, and we judged the trials' populations and methods sufficiently similar. Since we identified both clinical heterogeneity (sufficient to expect that the underlying treatment effects differed between trials) or substantial statistical heterogeneity, or both, we used random-effects meta-analysis to produce overall summaries if we considered an average treatment effect across trials to be clinically meaningful. We treated the random-effects summary as the average of the range of possible treatment effects and we have discussed the clinical implications of treatment effects differing between trials. If the average treatment effect was not clinically meaningful, we did not combine trials.

As we used random-effects analyses, we have presented the results as the average treatment effect with $95 \% \mathrm{Cls}$, and the estimates of $\mathrm{Tau}^{2}$ and $\mathrm{I}^{2}$.

\section{Subgroup analysis and investigation of heterogeneity}

If we identified substantial heterogeneity, we planned to attempt to investigate it using subgroup analyses and sensitivity analyses. We considered whether an overall summary was meaningful and, if it was, used random-effects analysis to produce it.

We planned to carry out the following subgroup analyses, when information was available, and using only information reported by the trial.

1. By period of supplementation: only before pregnancy versus only during pregnancy versus only during the postpartum period versus mixed.

2. By supplementation regimen: daily versus weekly versus annual or single dose.

3. By access to iodized salt: less than $50 \%$ versus $50 \%$ to $69 \%$ versus greater than or equal to $70 \%$ versus not reported.
4. By iodine status of the participants at the start of the intervention: adequate versus mild or moderate deficiency versus severe deficiency versus unknown (as defined by trial authors, or following WHO-recommended criteria).

5. By breastfeeding status: yes at any time versus never versus mixed/not reported. Note: this factor is not related to pregnancy outcomes therefore this analysis was performed only on maternal postpartum and child outcomes.

We planned to include only the primary outcomes in subgroup analyses.

If we found substantial heterogeneity for any primary outcome, we planned to assess subgroup differences by interaction tests available within RevMan 5 (RevMan 2014). We planned to report the results of subgroup analyses quoting the $\mathrm{Chi}^{2}$ statistic and $\mathrm{P}$ value, and the interaction test $\mathrm{I}^{2}$ value.

We decided to add subgroups for a given outcome only where there were at least four studies as we considered anything less to be insufficient to conduct meaningful analysis by the covariate. However no outcome with statistical heterogeneity included data from four or more trials, so we did not perform any subgroup analyses.

\section{Sensitivity analysis}

We planned to conduct sensitivity analysis based on the risk of bias of the studies. We considered a study to be of high quality if it was graded as 'low risk of bias' in both randomisation and allocation concealment and in either blinding or loss to follow-up. However we only considered one trial at low risk of bias therefore did not conduct this sensitivity analysis. We planned to conduct other sensitivity analyses based on the studies included, for example, if we identified and included any cluster-randomized trials we would carry out sensitivity analysis using a range of ICC values.

We planned to carried out sensitivity analysis for primary outcomes only.

\section{RE S U L T S}

\section{Description of studies}

See: Characteristics of included studies; Characteristics of excluded studies; Characteristics of ongoing studies tables.

\section{Results of the search}

The search of Cochrane Pregnancy and Childbirth's Trials Register retrieved 43 reports and the additional search strategy identified another 53 reports. See: Figure 1 which shows the process for assessing and selecting the studies (Moher 2009). We have included 14 and excluded 48 trials; five are ongoing or have not yet been published and two are awaiting classification. Eleven trials involving over 2000 women contributed data for the comparisons in this review (three trials did not report any primary or secondary outcomes (Kämpe 1990; Mulrine 2010; Silva 1981). 
Figure 1. Study flow diagram

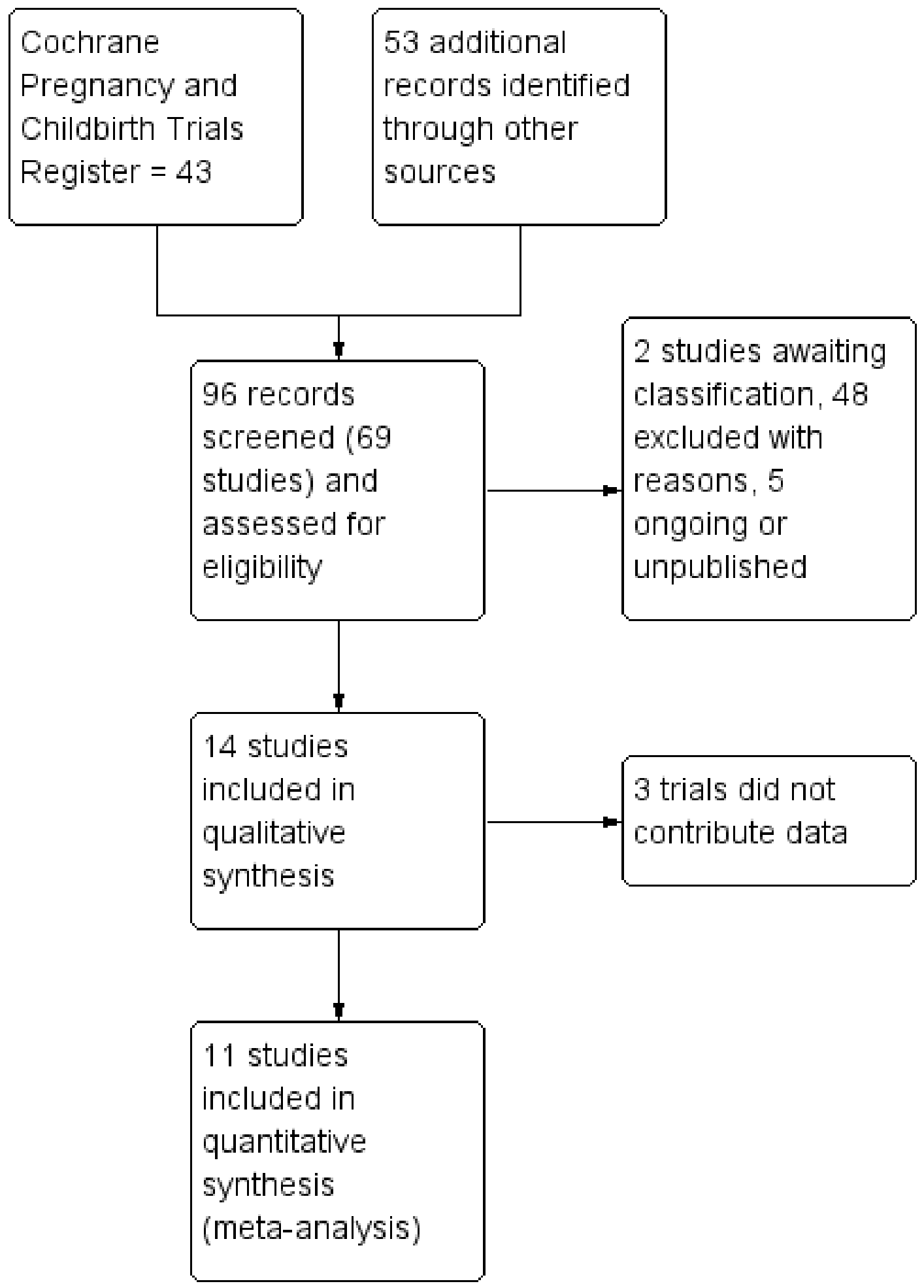

\section{Included studies}

\section{Design}

Most of the included studies were randomised controlled trials, except for four which were quasi-randomized (Kevany 1969; Liesenkotter 1996; Pharoah 1971 (C); Silva 1981). Individuals were the unit of allocation for all except for two cluster-randomized trials which allocated clinic days (Bouhouch 2014 (C)) and families (Pharoah 1971 (C)). The Bouhouch 2014 (C) analysis adjusted for clustering. Seven of the trials were reportedly double-blinded (Bouhouch 2014 (C); Glinoer 1993; Mulrine 2010; Nohr 2000; Pharoah 1971 (C); Zhou 2015; Gowachirapant 2014). Samples sizes were generally small (eight trials were 120 or less) and ranged from 54 to 671 . Two trials which recruited families or communities did 
not specify how many pregnant women, or women who became pregnant, were initially included (Kevany 1969; Pharoah 1971 (C)). One trial stopped at a sample size of 59 women (planned $n=$ 1098) and was unblinded (Zhou 2015). Three trials were assessed as eligible for inclusion but did not contribute data because they did not report on any prespecified primary or secondary outcomes (Kämpe 1990; Mulrine 2010; Silva 1981).

\section{Settings}

Six trials were conducted in Europe, in Belgium (Glinoer 1993), Denmark (Nohr 2000; Pedersen 1993), France (Brucker-Davis 2013), Germany (Liesenkotter 1996) and Sweden (Kämpe 1990). The other trials took place in Australia (Zhou 2015), Chile (Silva 1981), Morocco (Bouhouch 2014 (C)), New Zealand (Mulrine 2010), Papua New Guinea (Pharoah 1971 (C)), Peru (Kevany 1969), Thailand (Gowachirapant 2014), and Zaire (Thilly 1978). The trials which reported when the research took place did so from 1966 through 2011.

\section{Participants}

Most of the trials recruited women during pregnancy through antenatal care contacts at clinics or hospitals (Brucker-Davis 2013; Glinoer 1993; Kämpe 1990; Liesenkotter 1996; Nohr 2000; Pedersen 1993; Silva 1981; Thilly 1978; Zhou 2015; Gowachirapant 2014). Two trials recruited postpartum women at the infant's first vaccination visit (Bouhouch 2014 (C)) or via advertisements (Mulrine 2010). Two included entire families or communities and as a result, pregnant or non-pregnant women who later became pregnant were included (Kevany 1969; Pharoah 1971 (C)).

Average age of participants, where reported, ranged from 23 to 32 years. Information on socioeconomic status was generally not reported. Five trials reported on anthropometric nutritional status at baseline, though different indicators were used. Women in the Danish trials were pregnant and average weight ranged from $62 \mathrm{~kg}$ to $68 \mathrm{~kg}$ (Nohr 2000; Pedersen 1993), body mass index $(\mathrm{kg} / \mathrm{m} 2)$ of postpartum women in the Moroccan trial was 25.6 (Bouhouch 2014 (C)) and of pregnant women in the French trial was 22 (BruckerDavis 2013). In the Thai trial, $14 \%$ to $17 \%$ of pregnant women were overweight or obese (Gowachirapant 2014).

Information on baseline iodine status of the participants or the study area was provided in all but one trial (Kämpe 1990). Where mean UIC was reported, it ranged from $30 \mu \mathrm{g} / \mathrm{L}$ to approximately $130 \mathrm{\mu g} / \mathrm{L}$ and women had insufficient iodine intake, as indicated by median UIC below $150 \mu \mathrm{g} / \mathrm{L}$ for pregnant women or below $100 \mu \mathrm{g} / \mathrm{L}$ for breastfeeding women (Bouhouch 2014 (C); Brucker-Davis 2013; Glinoer 1993; Liesenkotter 1996; Mulrine 2010; Nohr 2000; Pedersen 1993; Silva 1981; Gowachirapant 2014; Zhou 2015). Three trials only reported goitre prevalence which ranged from 20\% to $70 \%$ (Kevany 1969; Pharoah 1971 (C); Thilly 1978). One study area was reported as high in endemic cretinism (Pharoah 1971 (C)).

Only four trials reported information on household coverage of iodized salt. Coverage was above $80 \%$ in the three trials that used participant-reported information (Brucker-Davis 2013; Mulrine 2010; Gowachirapant 2014). Bouhouch 2014 (C) collected and analysed household salt samples in a sub-sample and found that $57 \%$ contained some iodine (6\% with "adequate" or at least 15 ppm iodine and $51 \%$ with iodine less than $15 \mathrm{ppm}$ ).
Two trials screened women for thyroid peroxidase antibodies (TPOab) and recruited only women with elevated levels (Kämpe 1990; Nohr 2000).

\section{Interventions}

Seven trials included iodine supplementation during pregnancy only (Glinoer 1993; Nohr 2000; Pharoah 1971 (C); Silva 1981; Thilly 1978; Zhou 2015; Gowachirapant 2014), three included iodine supplementation only during the postpartum period (Bouhouch 2014 (C); Kämpe 1990; Mulrine 2010) and four gave iodine to the same women in both pregnancy and the postpartum period (Brucker-Davis 2013; Liesenkotter 1996; Nohr 2000; Pedersen 1993). Two trials provided iodine supplementation to women who later became pregnant (Kevany 1969; Pharoah 1971 (C)).

Most of the included trials used daily oral iodine supplementation, mainly in the form of tablets (Brucker-Davis 2013; Liesenkotter 1996; Mulrine 2010; Nohr 2000; Zhou 2015; Gowachirapant 2014) though one used capsules (Kämpe 1990), two used drops (Pedersen 1993; Silva 1981) and one trial reported using a daily supplement but did not specify the form (Glinoer 1993). The daily iodine dose ranged from $75 \mu \mathrm{g}$ to $300 \mu \mathrm{g}$ and the duration ranged from approximately one to 17 months. Where the iodine compound was reported, it was mostly potassium iodide (Glinoer 1993; Kämpe 1990; Liesenkotter 1996; Pedersen 1993; Silva 1981; Gowachirapant 2014) though one trial used potassium iodate (Mulrine 2010). One trial used a single high dose oral iodine supplement, in the form of two soft gel capsules containing iodized poppyseed oil with $400 \mathrm{mg}$ iodine (Bouhouch 2014 (C)).

The three earliest trials, which took place in the 1960s and 1970s, used single high-dose intramuscular injections of iodized oil (Kevany 1969; Pharoah 1971 (C); Thilly 1978). One trial repeated this intervention in the same communities three years later (Kevany 1969). The iodine dose in these trials ranged from $475 \mathrm{mg}$ to 1600 $\mathrm{mg}$, though in one study adult women with nodular goitre were given a lower dose of $95 \mathrm{mg}$ (Kevany 1969). Thilly 1978 specified that the iodine was slowly resorbable.

Most of the included trials used iodine-only supplementation, except for three which provided the same additional vitamins and minerals to the intervention and control groups, either as part of the supplement containing iodine (Brucker-Davis 2013; Nohr 2000) or as a separate supplement (Gowachirapant 2014).

\section{Comparisons}

Most studies had two trial arms comparing an iodine intervention with a no-iodine comparison in the same population group though two trials also included an additional intervention arm (one included two different iodine doses (Mulrine 2010) and one included iodine in pregnancy only and in pregnancy and postpartum (Nohr 2000)). Two trials also had a third arm with thyroxine (or thyroxine and iodine) supplementation (Glinoer 1993; Kämpe 1990) however these arms were not eligible and therefore were not included in this review.

Seven trials reported use of a placebo comparison group (Bouhouch 2014 (C); Glinoer 1993; Kevany 1969; Mulrine 2010; Pharoah 1971 (C); Zhou 2015; Gowachirapant 2014), four used no intervention (Kämpe 1990; Liesenkotter 1996; Pedersen 1993; Silva 1981), and two used other micronutrients (Brucker-Davis 2013; Nohr 2000). For one study, we found conflicting information about 
the control supplement composition as some reports stated it was a placebo and some stated it included vitamins (Thilly 1978). For the purposes of this review, we have considered the control for this trial as placebo.

\section{Comparison 1}

Eleven studies compared the effects of any supplement containing iodine versus same supplement without iodine or no treatment/ placebo (Bouhouch 2014 (C); Brucker-Davis 2013; Glinoer 1993; Kevany 1969; Liesenkotter 1996; Nohr 2000; Pedersen 1993; Pharoah 1971 (C); Thilly 1978; Zhou 2015; Gowachirapant 2014). Three trials were otherwise eligible but did not contribute any data for this comparison (Kämpe 1990; Mulrine 2010; Silva 1981).

\section{Comparison 2}

Eight trials compared the effects of any oral iodine supplement versus the same supplement without iodine or no treatment/ placebo (Bouhouch 2014 (C); Brucker-Davis 2013; Glinoer 1993; Liesenkotter 1996; Nohr 2000; Pedersen 1993; Zhou 2015; Gowachirapant 2014). Three trials were otherwise eligible but did not contribute any data for this comparison (Kämpe 1990; Mulrine 2010; Silva 1981).

\section{Comparison 3}

Five trials compared an oral iodine-only supplement versus no intervention or placebo (Bouhouch 2014 (C); Glinoer 1993; Liesenkotter 1996; Pedersen 1993; Zhou 2015). Three trials were otherwise eligible but did not contribute any data for this comparison (Kämpe 1990; Mulrine 2010; Silva 1981).

\section{Comparison 4}

Three trials compared the effects of oral iodine supplements with other vitamins and/or minerals versus only other vitamins and/or minerals (exact same formulation of other vitamins/minerals, but no iodine) (Brucker-Davis 2013; Nohr 2000; Gowachirapant 2014).

\section{Comparison 5}

Three trials compared the effects of any injected iodine supplement versus same supplement without iodine or no treatment/placebo (Kevany 1969; Pharoah 1971 (C); Thilly 1978).

\section{Comparison 6}

Three trials compared the effects of any injected iodine-only supplement versus no intervention or placebo (Kevany 1969; Pharoah 1971 (C); Thilly 1978).

\section{Comparison 7}

No studies compared an injected iodine supplement with other vitamins and/or minerals versus only other vitamins and/or minerals (exact same formulation of other vitamins/minerals, but no iodine). Because of this, the trials (and data) are the same for comparisons 5 and 6 , therefore we have only reported comparison 5.

See Characteristics of included studies for a detailed description of the trials.

\section{Excluded studies}

We excluded 48 trials. The main reason for excluding studies was that they were not randomised or quasi-randomized trials.
Some randomised trials, or trials where it was unclear whether randomisation was used, were excluded because they compared different iodine doses (without a placebo or a no treatment control) or assessed iodized salt (Antonangeli 2002; Mohammed 2015; Romano 1991; Santiago 2013; Troshina 2010).

See the Characteristics of excluded studies tables for detailed descriptions of the excluded studies and the reasons for exclusion.

\section{Risk of bias in included studies}

\section{Allocation \\ Random sequence generation}

We considered five trials at low risk of selection bias for random sequence generation (Bouhouch 2014 (C); Brucker-Davis 2013; Thilly 1978; Zhou 2015; Gowachirapant 2014). Four we deemed high risk because they used quasi-randomization (Kevany 1969; Liesenkotter 1996; Pharoah 1971 (C); Silva 1981). The remaining trials were reportedly randomised but did not provide adequate information on how random sequences were generated, therefore we considered risk of bias in this domain unclear.

\section{Allocation concealment}

We considered three trials at low risk of selection bias for allocation concealment because clinic days were the unit of randomisation or were used to assign individuals (and study staff could not have reasonably influenced the day women showed up for clinic) (Bouhouch 2014 (C); Liesenkotter 1996) or because randomisation was performed centrally (Zhou 2015). We considered three trials at high risk because they used alternation to assign individuals, or families, to groups (Kevany 1969; Pharoah 1971 (C); Silva 1981). The remaining trials did not adequately report the methods used to conceal allocation so we considered the risk to be unclear.

\section{Blinding}

\section{Blinding of participants and staff}

We considered four trials at low risk of performance bias because a placebo was used for the control group and staff and participants were reportedly blinded to group assignment (Bouhouch 2014 (C); Mulrine 2010; Thilly 1978; Gowachirapant 2014). We determined six trials high risk because no blinding was reported and the control group did not receive any intervention (Kämpe 1990; Liesenkotter 1996; Pedersen 1993; Silva 1981) or because it was described as an "open study" (Brucker-Davis 2013) or unblinded during the study due to ethical consideration to placebo group (Zhou 2015). It was not possible to assess risk of bias in this domain for the other four trials due to lack of information reported (Glinoer 1993; Kevany 1969; Nohr 2000; Pharoah 1971 (C)).

\section{Blinding of outcome assessors}

Risk of detection bias was mostly unclear because study authors did not adequately report this information, with the exception of two trials which we considered low risk because they specified that outcome assessors were blinded to group assignment (Pharoah 1971 (C); Gowachirapant 2014) and two trials which were considered high risk because they were described as an "open study" (Brucker-Davis 2013) or because the trial was unblinded mid-way through (Zhou 2015). 


\section{Incomplete outcome data}

Two trials were at low risk of attrition bias because of low (less than $20 \%$ ) and balanced incomplete outcome data (Nohr 2000, Zhou 2015). We determined seven trials to be a high risk because of high or imbalanced incomplete outcome data, or both (Bouhouch 2014 (C); Brucker-Davis 2013; Mulrine 2010; Pharoah 1971 (C); Silva 1981; Thilly 1978; Gowachirapant 2014). For the remaining studies, lack of detailed information on attrition precluded judgement (Glinoer 1993; Kämpe 1990; Kevany 1969; Liesenkotter 1996; Pedersen 1993).

\section{Selective reporting}

For most of the included trials, we did not have access to the study protocol or clinical trial registration which stated the pre-specified outcomes, therefore the risk of reporting bias due to selective reporting was unclear. In two cases we did have access to the trial registry and were able to determine the trial to be low (Zhou 2015) or high (Bouhouch 2014 (C)) risk of reporting bias, based on

Figure 2. Risk of bias graph: review authors' judgements about each risk of bias item presented as percentages across all included studies

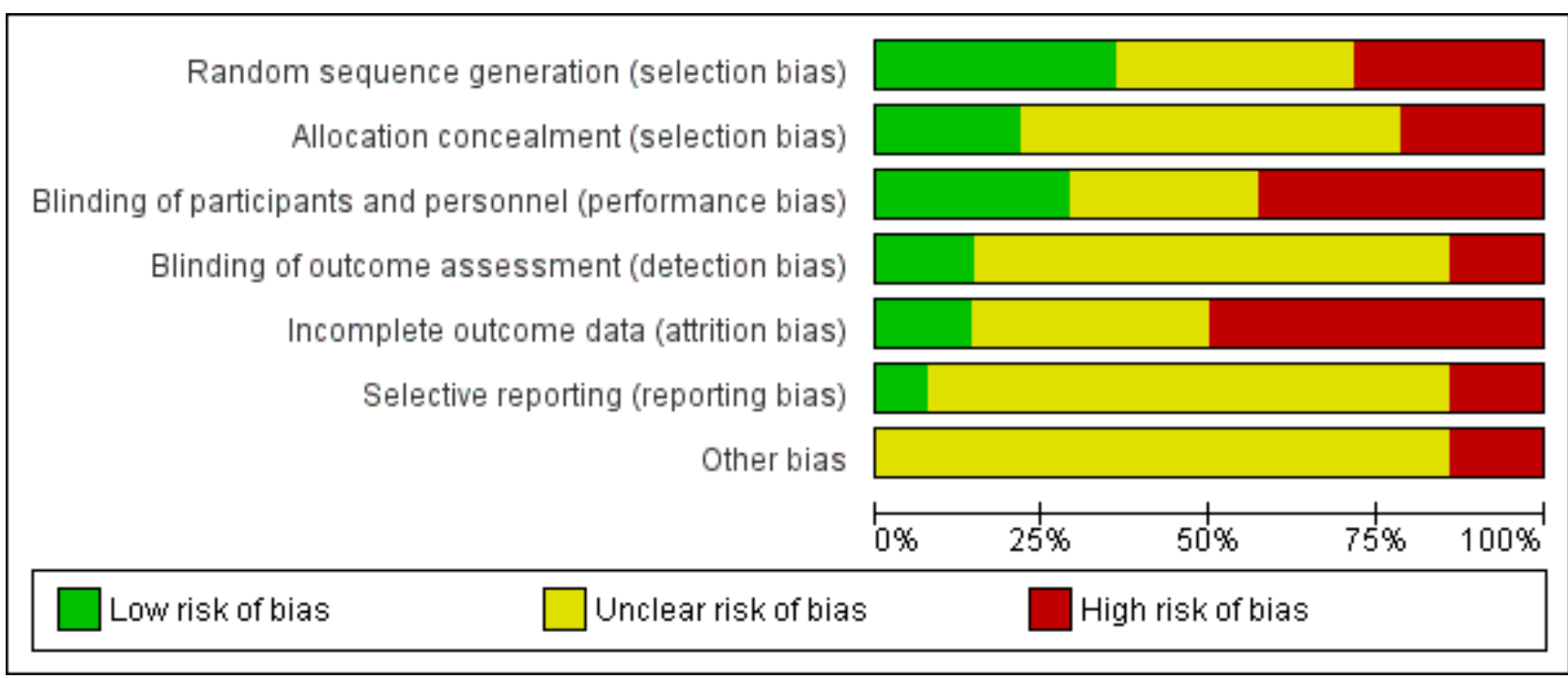


Figure 3. Risk of bias summary: review authors' judgements about each risk of bias item for each included study

\begin{tabular}{|c|c|c|c|c|c|c|c|}
\hline & 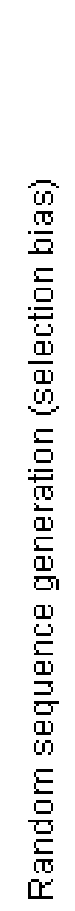 & 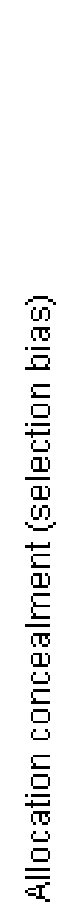 & 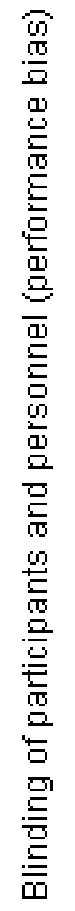 & 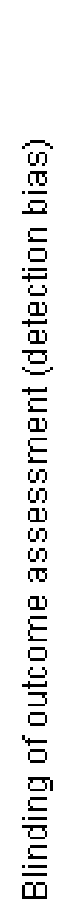 & 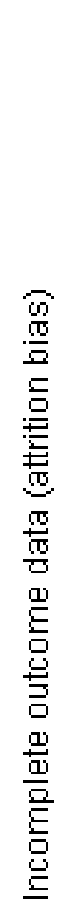 & 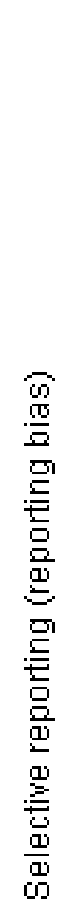 & 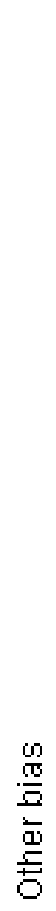 \\
\hline Bouhouch 2014 (C) & + & + & + & $?$ & - & - & $?$ \\
\hline Brucker-Davis 2013 & + & $?$ & $\theta$ & - & - & - & $?$ \\
\hline Glinoer 1993 & $?$ & $?$ & $?$ & $?$ & $?$ & $?$ & $?$ \\
\hline Gowachirapant 2014 & + & $?$ & + & + & - & $?$ & $?$ \\
\hline Kämpe 1990 & $?$ & $?$ & 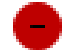 & $?$ & $?$ & $?$ & $?$ \\
\hline Kevany 1969 & - & - & $?$ & $?$ & $?$ & $?$ & \\
\hline Liesenkotter 1996 & 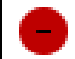 & + & 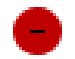 & $?$ & $?$ & $?$ & $?$ \\
\hline Mulrine 2010 & $?$ & $?$ & + & $?$ & & ? & ? \\
\hline Nohr 2000 & $?$ & $?$ & $?$ & $?$ & + & $?$ & $?$ \\
\hline Pedersen 1993 & $?$ & $?$ & A & $?$ & $?$ & $?$ & $?$ \\
\hline Pharoah 1971 (C) & & - & $?$ & + & & $?$ & \\
\hline Silva 1981 & & - & - & $?$ & & $?$ & $?$ \\
\hline Thilly 1978 & + & $?$ & + & $?$ & & $?$ & $?$ \\
\hline Zhou 2015 & + & + & 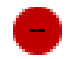 & & + & + & $?$ \\
\hline
\end{tabular}




\section{Effects of interventions}

See: Summary of findings for the main comparison Any supplement containing iodine versus same supplement without iodine or no treatment/placebo (maternal outcomes); Summary of findings 2 Any supplement containing iodine versus same supplement without iodine or no treatment/placebo (child outcomes)

In this review we included 14 trials involving 3154 women, though one trial did not report the number of women randomised (Pharoah 1971 (C)). Three trials involving 417 women (Kämpe 1990; Mulrine 2010; Silva 1981) did not contribute data because they did not report any primary or secondary outcomes. We have organized the summary results by comparison, by primary and secondary outcomes and by maternal and child outcomes.

See Data and analyses for detailed results on primary and secondary outcomes. We have set out below five out of the seven prespecified comparisons. None of the included trials included an assessment of comparison 7, which meant that the originallyplanned comparisons 5 and 6 were the exact same and therefore we have not reported the results from comparison 6 separately.

For each of the comparisons and outcomes with data, we have indicated the number of studies, the number of studies contributing data and the total number of women or children included in that analysis (instead of the number randomised in case of attrition).

(1) Any supplement containing iodine versus same supplement without iodine or no treatment/placebo (11 trials, 2737 participants)

Eleven trials contributed data involving 2737 women (Bouhouch 2014 (C); Brucker-Davis 2013; Glinoer 1993; Kevany 1969; Liesenkotter 1996; Nohr 2000; Pedersen 1993; Pharoah 1971 (C); Thilly 1978; Zhou 2015; Gowachirapant 2014). None were considered high quality. Three other trials did not contribute any data to our analyses (Kämpe 1990; Mulrine 2010; Silva 1981).

\section{Maternal primary outcomes}

\section{Hypothyroidism - pregnancy (as defined by trial authors)}

Data from one trial (Gowachirapant 2014) involving 365 women showed no difference in risk of hypothyroidism in pregnancy between women who received and did not receive iodine supplementation (risk ratio (average RR) 1.90; 95\% confidence interval (Cl) 0.57 to 6.38 , low-quality evidence) (Analysis 1.1).

\section{Hypothyroidism - postpartum (as defined by trial authors)}

Among 540 women in three trials (Bouhouch 2014 (C); Liesenkotter 1996; Gowachirapant 2014), those who received iodine supplementation were as likely to be diagnosed with hypothyroidism in the postpartum period as those who did not receive any iodine (average RR $0.44 ; 95 \% \mathrm{Cl} 0.06$ to 3.42 , low-quality evidence) (Analysis 1.2). We did not find evidence of statistical heterogeneity $\left(\mathrm{I}^{2}=0 \%, \mathrm{Tau}^{2}=0.00\right.$ and $\mathrm{Chi}^{2}$ test for heterogeneity $P=0.41)$.

\section{Preterm birth (as defined by trial authors)}

Two trials (Zhou 2015; Gowachirapant 2014) involving 376 pregnant women reported on preterm birth, and showed no difference between groups (average RR $0.71 ; 95 \% \mathrm{Cl} 0.30$ to 1.66 , low-quality evidence) (Analysis 1.3). We identified substantial heterogeneity for this outcome though $\left(\mathrm{I}^{2}=32 \%, \mathrm{Tau}^{2}=0.13\right.$ and $\mathrm{Chi}^{2}$ test for heterogeneity $\mathrm{P}=0.23$ ).

Maternal adverse effect: elevated thyroid peroxidase antibodies (TPOab) - pregnancy (as defined by trial authors)

One trial with 359 women reported on elevated TPO-ab in pregnancy (Gowachirapant 2014) and found no difference in risk between the iodine and control groups (average RR 0.95; $95 \% \mathrm{Cl}$ 0.44 to 2.07 , low-quality evidence) (Analysis 1.4).

Maternal adverse effect: elevated TPO-ab - postpartum (as defined by trial authors)

This outcome was reported in three trials with 397 women (Liesenkotter 1996; Pedersen 1993; Gowachirapant 2014). Findings show no difference in the likelihood between the group that received iodine and the group that did not (average RR 1.01; 95\% $\mathrm{Cl} 0.78$ to 1.30 , low-quality evidence) (Analysis 1.5). We did not find any evidence of statistical heterogeneity for this analysis $\left(I^{2}=0 \%\right.$, $\mathrm{Tau}^{2}=0.00$ and $\mathrm{Chi}^{2}$ test for heterogeneity $\mathrm{P}=0.63$ ).

Maternal adverse effect: hyperthyroidism - pregnancy (as defined by trial authors)

One trial with 365 women reported on this outcome (Gowachirapant 2014) and found no difference between groups (average RR $1.90 ; 95 \% \mathrm{Cl} 0.57$ to 6.38 , low-quality evidence) (Analysis 1.6).

Maternal adverse effect: hyperthyroidism - postpartum (as defined by trial authors)

Data from three studies involving 543 women (Bouhouch 2014 (C); Liesenkotter 1996; Gowachirapant 2014) showed that $1.6 \%$ of those who received iodine supplementation and $4.9 \%$ of those who did not had hyperthyroidism in the postpartum period (average RR $0.32 ; 95 \% \mathrm{Cl} 0.11$ to 0.91 , low-quality evidence) (Analysis 1.7). There was no statistical heterogeneity $\left(I^{2}=0 \%\right.$, Tau ${ }^{2}=0.00$ and $\mathrm{Chi}^{2}$ test for heterogeneity $\mathrm{P}=0.67$ ).

Maternal adverse effect: digestive intolerance - pregnancy (as defined by trial authors)

One trial with 76 women reported on this outcome (Brucker-Davis 2013) and found a higher likelihood of digestive intolerance in the iodine group whereby $33.3 \%$ of women who received iodine and $2.2 \%$ of those who did not dropped out of the study due to nausea or vomiting (average RR 15.33; 95\% $\mathrm{Cl} 2.70$ to 113.7 , very low-quality evidence) (Analysis 1.8).

\section{Infant/child primary outcomes}

Perinatal mortality (including stillbirth/fetal death and neonatal death, as defined by trial authors)

Two trials with 457 assessments (Thilly 1978; Zhou 2015) reported on this outcome, though all of the deaths occurred in one trial (Thilly 1978). In this trial there was lower perinatal mortality in the group that received iodine supplementation compared to the control group, however the difference did not reach statistical significance (average RR $0.66 ; 95 \% \mathrm{Cl} 0.42$ to 1.03 , low-quality evidence) (Analysis 1.9). 


\section{Low birthweight (less than $\mathbf{2 5 0 0} \mathrm{g}$ )}

Two trials with 377 infants reported on this outcome (Zhou 2015; Gowachirapant 2014) and showed no difference between groups (average RR $0.56 ; 95 \% \mathrm{Cl} 0.26$ to 1.23 , low-quality evidence) (Analysis 1.10). There was no evidence of statistical heterogeneity $\left(\mathrm{I}^{2}=0 \%, \mathrm{Tau}^{2}=0.00\right.$ and $\mathrm{Chi}^{2}$ test for heterogeneity $\left.\mathrm{P}=0.62\right)$.

Neonatal hypothyroidism or elevated thyroid-stimulating hormone (TSH) (as defined by trial authors)

This outcome was reported in two trials (Zhou 2015; Gowachirapant 2014) with 260 infant assessments, although all of the cases occurred in one trial (Gowachirapant 2014). The average RR for neonatal elevated TSH in this trial was $0.58(95 \% \mathrm{Cl} 0.11$ to 3.12, very low-quality evidence) (Analysis 1.11).

\section{Neonatal adverse effect - elevated TPO-ab (as defined by trial authors)}

One study with 108 assessments (Liesenkotter 1996) reported on this outcome and showed no difference between infants whose mothers received iodine and those who did not (average RR 0.61; $95 \% \mathrm{Cl} 0.07$ to 5.70 , very low-quality evidence) (Analysis 1.12). In this trial, all of the neonates with elevated TPO-ab were born to women with elevated TPO-ab at baseline.

Neonatal adverse effect - hyperthyroidism (as defined by trial authors)

No trials reported this outcome.

\section{Maternal secondary outcomes}

Spontaneous miscarriage (as defined by trial authors)

Three trials (Brucker-Davis 2013; Zhou 2015; Gowachirapant 2014) with information on 645 pregnancies showed a similar likelihood of spontaneous miscarriage (average RR $1.31 ; 95 \% \mathrm{Cl} 0.64$ to 2.69 ) and no evidence of statistical heterogeneity $\left(\mathrm{I}^{2}=0 \%, \mathrm{Tau}^{2}=0.00\right.$ and $\mathrm{Chi}^{2}$ test for heterogeneity $\mathrm{P}=0.64$ ) (Analysis 1.13).

\section{Maternal goitre - pregnancy (assessed by any method)}

Two studies (Glinoer 1993; Gowachirapant 2014) with 486 women showed no difference in likelihood of goitre in pregnancy (average RR $1.00 ; 95 \% \mathrm{Cl} 0.33$ to 3.06 ) however we found significant heterogeneity for this outcome $\left(\mathrm{I}^{2}=53 \%, \mathrm{Tau}^{2}=0.35\right.$ and $\mathrm{Chi}^{2}$ test for heterogeneity $\mathrm{P}=0.14$ ) (Analysis 1.14).

\section{Maternal goitre - postpartum (assessed by any method)}

Postpartum goitre was reported in two trials (Liesenkotter 1996; Gowachirapant 2014). Data from 370 women showed no evidence of difference (average RR 1.17; 95\% $\mathrm{Cl} 0.64$ to 2.16 ) though we did identify substantial heterogeneity $\left(\mathrm{I}^{2}=33 \%\right.$, $\mathrm{Tau}^{2}=0.10$ and $\mathrm{Chi}^{2}$ test for heterogeneity $P=0.22$ ) (Analysis 1.15).

\section{Maternal thyroid volume - pregnancy (in $\mathrm{mL}$ ) (assessed by any method)}

This outcome was reported in three trials with 496 participants, all of which reported median thyroid volume so no meta-analysis was performed (Brucker-Davis 2013; Pedersen 1993; Gowachirapant 2014). In two trials, findings showed lower median thyroid volume in the iodine compared to the no-iodine groups (Brucker-Davis 2013; Pedersen 1993) (Table 2). Gowachirapant 2014, however, found similar thyroid volumes in both groups.
Maternal thyroid volume - postpartum (in $\mathrm{mL}$ ) (assessed by any method)

Four trials with 457 women reported on this outcome (BruckerDavis 2013; Liesenkotter 1996; Pedersen 1993; Gowachirapant 2014) and most used median thyroid volume, so we did not perform a meta-analysis. Three of the studies showed similar postpartum thyroid volumes between the iodine and no iodine groups (Liesenkotter 1996; Pedersen 1993; Gowachirapant 2014). (Table 3). One trial, however, reported a lower median thyroid volume (by $1.2 \mathrm{~mL}$ ) in the iodine group (Brucker-Davis 2013).

\section{Maternal thyroglobulin ( $\mathrm{Tg}$ ) - pregnancy (in $\mu \mathrm{g} / \mathrm{L}$ )}

This outcome was reported in four studies with 562 women (Brucker-Davis 2013; Nohr 2000; Pedersen 1993; Gowachirapant 2014) all of which reported median Tg, so we did not perform a meta-analysis. In all four trials, median Tg in pregnancy was lower in the group which received iodine compared to the no-iodine group; the difference ranged from $2.1 \mu \mathrm{g} / \mathrm{L}$ to $7.5 \mu \mathrm{g} / \mathrm{L}$ (Table 4).

\section{Maternal Tg - postpartum (in $\mu \mathrm{g} / \mathrm{L}$ )}

Four trials involving 457 women (Brucker-Davis 2013; Liesenkotter 1996; Pedersen 1993; Gowachirapant 2014) reported this outcome, mostly as median $\mathrm{Tg}$, therefore we did not perform a meta-analysis. All four trials showed that women who received iodine had lower postpartum Tg levels compared to those who did not (Table 5). The difference between groups ranged from $1.57 \mu \mathrm{g} / \mathrm{L}$ to $11.6 \mu \mathrm{g} / \mathrm{L}$.

Insufficient iodine intake - pregnancy (median urinary iodine concentration (UIC) less than $150 \mu \mathrm{g} / \mathrm{L}$ )

Two studies with 432 participants reported on this outcome (Brucker-Davis 2013; Gowachirapant 2014). Results show that women who received iodine supplements had a lower likelihood of insufficient iodine intake in pregnancy compared to those who did not receive any iodine. In the iodine group, 33.3\% of women had inadequate iodine intake in pregnancy compared to $53.2 \%$ in the control group (average RR $0.64 ; 95 \% \mathrm{Cl} 0.51$ to 0.80 ) (Analysis 1.16). There was no evidence of statistical heterogeneity for this outcome $\left(\mathrm{I}^{2}=0 \%, \mathrm{Tau}^{2}=0.00\right.$ and $\mathrm{Chi}^{2}$ test for heterogeneity $\left.\mathrm{P}=0.56\right)$.

Insufficient iodine intake - postpartum (breastfeeding: median UIC less than $100 \mu \mathrm{g} / \mathrm{L}$ )

Results from two trials (Bouhouch 2014 (C); Gowachirapant 2014) involving 425 women showed that iodine supplementation reduced the likelihood of having insufficient iodine intake in the postpartum period (average RR $0.81 ; 95 \% \mathrm{Cl} 0.70$ to 0.93 ), with no evidence of statistical heterogeneity $\left(\mathrm{I}^{2}=0 \%, \mathrm{Tau}^{2}=0.00\right.$ and $\mathrm{Chi}^{2}$ test for heterogeneity $\mathrm{P}=0.90$ ) (Analysis 1.17).

Excessive iodine intake (pregnancy only: median UIC greater than or equal to $500 \mu \mathrm{g} / \mathrm{L}$ )

One trial (Gowachirapant 2014) with 356 women reported that $7.0 \%$ of women who received iodine supplements and $1.6 \%$ of women who did not had excessive iodine intake during pregnancy (average RR 4.33; $95 \% \mathrm{Cl} 1.24$ to 15.07 ) (Analysis 1.18).

\section{Infant/child secondary outcomes}

\section{Small-for-gestational age (as defined by trial authors)}

This outcome was reported in two trials (Zhou 2015; Gowachirapant 2014) with 377 infants that showed no evidence of difference between groups (average RR 1.26; 95\% Cl 0.77 to 2.05) (Analysis 
1.19). There was no substantial heterogeneity $\left(\mathrm{I}^{2}=0 \%\right.$, $\mathrm{Tau}^{2}=0.00$ and $\mathrm{Chi}^{2}$ test for heterogeneity $\mathrm{P}=0.83$ ).

Congenital anomalies (including cretinism, as defined by trial authors)

Two trials (Pharoah 1971 (C); Zhou 2015), which assessed 875 children, showed a lower frequency of congenital anomalies in the iodine group compared to the control group, $1.7 \%$ versus $6.4 \%$, respectively, though all of the cases came from one trial (Pharoah 1971 (C)) (average RR 0.27; 95\% Cl 0.12 to 0.60) (Analysis 1.20). In six out of seven cases in the iodine group and five out of 26 cases in the control group, the mothers received the treatment during pregnancy. The other mothers received treatment before pregnancy.

\section{Growth (anthropometric Z scores)}

No trials reported on this outcome.

\section{Neonatal goitre (assessed by any method)}

This outcome was reported in three trials (Glinoer 1993; Kevany 1969; Liesenkotter 1996) that assessed 684 neonates. Findings showed a lower likelihood of enlarged thyroid gland in the neonates in the iodine group compared to the control group (average RR $0.11 ; 95 \% \mathrm{Cl} 0.02$ to 0.56 ) (Analysis 1.21) with no evidence of statistical heterogeneity $\left(\mathrm{I}^{2}=0 \%, \mathrm{Tau}^{2}=0.00\right.$ and $\mathrm{Chi}^{2}$ test for heterogeneity $\mathrm{P}=0.76$ )

\section{Neonatal thyroid volume (in $\mathrm{mL}$ ) (assessed by any method)}

Three trials with assessments of 359 neonates (Glinoer 1993; Liesenkotter 1996; Gowachirapant 2014) showed lower thyroid volume in the iodine compared to the control group. The MD was $-0.34 \mathrm{~mL}(95 \% \mathrm{Cl}-0.58$ to -0.11$)$ though there was evidence of statistical heterogeneity $\left(\mathrm{I}^{2}=93 \%\right.$, $\mathrm{Tau}^{2}=0.04$ and $\mathrm{Chi}^{2}$ test for heterogeneity $\mathrm{P}<0.00001$ ) (Analysis 1.22).

\section{Insufficient neonatal iodine intake (median UIC less than $100 \mu \mathrm{g} / \mathrm{L}$ )}

One trial (Gowachirapant 2014), which assessed 159 neonates, found a higher likelihood of insufficient iodine intake in the iodine compared to the control group (average RR 2.14; $95 \% \mathrm{Cl} 1.04$ to 4.37) (Analysis 1.23).

\section{Neonatal mental or motor development (as defined by trial authors)}

One study (Gowachirapant 2014) reported scores from the Neonatal Behavioral Assessment Scales in median and IQR for 149 neonates (Table 6). Out of the eight sub-scales, three showed higher median scores in the iodine group compared to the control group, one showed a higher score in the control group, and three showed equal scores in both groups.

\section{Child mental or motor development (as defined by trial authors)}

Data from two trials (Kevany 1969; Thilly 1978), which measured 174 children, showed a higher IQ score in the group whose mothers received iodine compared to those who did not. The MD was 11.21 points (95\% Cl 7.96 to 14.46$)$ (Analysis 1.24) with no statistical heterogeneity $\left(\mathrm{I}^{2}=0 \%, \mathrm{Tau}^{2}=0.00 ; \mathrm{Chi}^{2}\right.$ test for heterogeneity $\mathrm{P}=$ 0.70). These findings were combined using MD because the same instrument, the Brunet-Lézine scale, was used in both trials.

One trial (Zhou 2015) reported on child cognitive, language development, motor, social-emotional and adaptive behaviour scores for 53 children at 18 months of age assessed by the Bayley scales of infant and toddler development (Bayley-III). Scores were similar in both groups (Analysis 1.25; Analysis 1.26; Analysis 1.27; Analysis 1.28; Analysis 1.29). The same trial also reported moderate and severe developmental delays based on the cognitive, language and motor scores and found no significant differences between groups (Analysis 1.30; Analysis 1.31; Analysis 1.32; Analysis 1.33; Analysis 1.34; Analysis 1.35).

\section{Infant death (death in the first year of life)}

No trials reported on this outcome.

\section{Other outcomes}

We also extracted data on urinary and breast milk iodine concentration following supplementation (Table 1). Average UIC was generally higher in the intervention than the control groups, however this was not the case for all studies and in some cases depended on the timing of assessment (e.g. higher in the iodine group during pregnancy but not postpartum Brucker-Davis 2013 and Pedersen 1993) and the group assessed (e.g. higher among intervention women but lower among intervention neonates, compared to controls (Gowachirapant 2014)). With the exception of one trial (Zhou 2015), in each study where breast milk iodine concentration was assessed, levels were higher in the iodine compared to the control groups (Bouhouch 2014 (C); Glinoer 1993; Pedersen 1993).

\section{(2) Any oral iodine supplement versus same supplement without iodine or no treatment/placebo (eight trials, 1274 participants)}

Eight trials involving 1274 women were included in this comparison (Bouhouch 2014 (C); Brucker-Davis 2013; Glinoer 1993; Liesenkotter 1996; Nohr 2000; Pedersen 1993; Zhou 2015; Gowachirapant 2014). None were considered high quality. Three other trials did not contribute any data to our analyses (Kämpe 1990; Mulrine 2010; Silva 1981).

\section{Maternal primary outcomes}

\section{Hypothyroidism - pregnancy (as defined by trial authors)}

Data from one trial (Gowachirapant 2014) involving 365 women showed no difference in risk of hypothyroidism in pregnancy between women who received and did not receive iodine supplementation (average RR 1.90; $95 \% \mathrm{Cl} 0.57$ to 6.38) (Analysis 2.1).

\section{Hypothyroidism - postpartum (as defined by trial authors)}

Among 540 women in three trials (Bouhouch 2014 (C); Liesenkotter 1996; Gowachirapant 2014), those who received oral iodine supplementation were as likely to be diagnosed with hypothyroidism in the postpartum period compared to those who did not receive any iodine (average RR $0.44 ; 95 \% \mathrm{Cl} 0.06$ to 3.42) (Analysis 2.2). We did not find evidence of statistical heterogeneity $\left(\mathrm{I}^{2}=0 \%, \mathrm{Tau}^{2}=0.00\right.$ and $\mathrm{Chi}^{2}$ test for heterogeneity $\left.\mathrm{P}=0.41\right)$.

\section{Preterm birth (as defined by trial authors)}

Two trials (Zhou 2015; Gowachirapant 2014) involving 376 women reported on preterm birth, and showed no difference between groups (average RR $0.71 ; 95 \% \mathrm{Cl} 0.30$ to 1.66 ) though there was statistical heterogeneity $\left(\left(\mathrm{I}^{2}=32 \%, \mathrm{Tau}^{2}=0.13\right.\right.$ and $\mathrm{Chi}^{2}$ test for heterogeneity $\mathrm{P}=0.23$ ) (Analysis 2.3 ). 
Maternal adverse effect: elevated TPO-ab - pregnancy (as defined by trial authors)

One trial with 359 women reported on elevated thyroid peroxidase antibodies in pregnancy (Gowachirapant 2014) and found no difference in risk between the oral iodine and control groups (average RR 0.95; 95\% Cl 0.44 to 2.07) (Analysis 2.4).

\section{Maternal adverse effect: elevated TPO-ab - postpartum (as defined by} trial authors)

This outcome was reported in three trials with 397 women (Liesenkotter 1996; Pedersen 1993; Gowachirapant 2014). Findings show no difference in the likelihood between the group which received oral iodine and the group which did not receive any iodine (average RR $1.01 ; 95 \% \mathrm{Cl} 0.78$ to 1.30 ) (Analysis 2.5). We did not find any evidence of statistical heterogeneity for this analysis $\left(\mathrm{I}^{2}=0 \%\right.$, $\mathrm{Tau}^{2}=0.00$ and $\mathrm{Chi}^{2}$ test for heterogeneity $\left.\mathrm{P}=0.63\right)$.

Maternal adverse effect: hyperthyroidism - pregnancy (as defined by trial authors)

One trial with 365 women reported on this outcome (Gowachirapant 2014) and found no difference between groups (average RR 1.90; 95\% Cl 0.57 to 6.38) (Analysis 2.6).

Maternal adverse effect: hyperthyroidism - postpartum (as defined by trial authors)

Data from three studies involving 543 women (Bouhouch 2014 (C); Liesenkotter 1996; Gowachirapant 2014) showed that $1.6 \%$ of those who received oral iodine supplementation and $4.9 \%$ of those who did not had hyperthyroidism in the postpartum period (average RR $0.32,95 \% \mathrm{Cl} 0.11$ to 0.91 ) (Analysis 2.7 ). There was no statistical heterogeneity $\left(\mathrm{I}^{2}=0 \%, \mathrm{Tau}^{2}=0.00\right.$ and $\mathrm{Chi}^{2}$ test for heterogeneity $\mathrm{P}=0.67)$.

Maternal adverse effect: digestive intolerance - pregnancy (as defined by trial authors)

One trial with 76 women reported on this outcome (Brucker-Davis 2013) and found a higher likelihood of digestive intolerance in the group which received oral iodine supplementation compared to those who did not. One-third of women (33.3\%) in the iodine group and $2.2 \%$ of women in the control group dropped out of the study due to nausea or vomiting (average RR 15.33; 95\% Cl 2.70 to 113.70 ) (Analysis 2.8).

\section{Infant/child primary outcomes}

Perinatal mortality (including stillbirth/fetal death and neonatal death, as defined by trial authors)

One trial with 58 assessments (Zhou 2015) reported no events in either group (Analysis 2.9).

\section{Low birthweight (less than $2500 \mathrm{~g}$ )}

Two trials with 377 infants reported on this outcome (Gowachirapant 2014) and showed no difference between groups (average RR 0.56; 95\% Cl 0.26 to 1.23 ) (Analysis 2.10).

Neonatal hypothyroidism or elevated TSH (as defined by trial authors)

This outcome was reported in two trials (Zhou 2015; Gowachirapant 2014) with 260 infant assessments. All of the cases though occurred in one trial (Gowachirapant 2014); the average RR for neonatal elevated TSH in this trial was $0.58(95 \% \mathrm{Cl} 0.11$ to 3.12$)$ (Analysis 2.11).

\section{Neonatal adverse effect - elevated TPO-ab (as defined by trial authors)}

One study with 108 assessments (Liesenkotter 1996) reported on this outcome and showed no difference between infants whose mothers received oral iodine and those who did not (average RR $0.61 ; 95 \% \mathrm{Cl} 0.07$ to 5.70 ) (Analysis 2.12). In this trial, all of the neonates with elevated TPO-ab were born to women with elevated TPO-ab at baseline.

Neonatal adverse effect - hyperthyroidism (as defined by trial authors)

No trials reported this outcome.

\section{Maternal secondary outcomes}

Spontaneous miscarriage (as defined by trial authors)

Three trials (Brucker-Davis 2013; Zhou 2015; Gowachirapant 2014) with information on 645 pregnancies showed a similar likelihood of spontaneous miscarriage (average RR 1.31 ; $95 \% \mathrm{Cl} 0.64$ to 2.69 ) and no evidence of statistical heterogeneity $\left(\mathrm{I}^{2}=0 \%, \mathrm{Tau}^{2}=0.00\right.$ and $\mathrm{Chi}^{2}$ test for heterogeneity $\left.\mathrm{P}=0.64\right)$ ) (Analysis 2.13 ).

\section{Maternal goitre - pregnancy (assessed by any method)}

Two studies (Glinoer 1993; Gowachirapant 2014) with 486 women showed no difference in likelihood of goitre in pregnancy (average RR 1.00; $95 \% \mathrm{Cl} 0.33$ to 3.06 ) however we found significant heterogeneity for this outcome $\left(\mathrm{I}^{2}=53 \%\right.$, $\mathrm{Tau}^{2}=0.35$ and $\mathrm{Chi}^{2}$ test for heterogeneity $\mathrm{P}=0.14$ ) (Analysis 2.14).

\section{Maternal goitre - postpartum (assessed by any method)}

Postpartum enlarged thyroid gland or goitre was reported in two trials (Liesenkotter 1996; Gowachirapant 2014). Data from 370 women showed no evidence of difference (average RR $1.17 ; 95 \% \mathrm{Cl}$ 0.64 to 2.16$)$ though we did identify substantial heterogeneity $\left(I^{2}=\right.$ $33 \%, \mathrm{Tau}^{2}=0.10$ and $\mathrm{Chi}^{2}$ test for heterogeneity $\mathrm{P}=0.22$ ) (Analysis 2.15).

\section{Maternal thyroid volume - pregnancy (in $\mathrm{mL}$ ) (assessed by any method)}

This outcome was reported in three trials with 496 participants, all of which reported median thyroid volume so no meta-analyses was performed (Brucker-Davis 2013; Pedersen 1993; Gowachirapant 2014). In two trials, findings showed lower median thyroid volume in the oral iodine compared to the no iodine groups (Brucker-Davis 2013; Pedersen 1993) (Table 2). Zimmermann and colleagues however found similar thyroid volumes in both groups (Gowachirapant 2014).

\section{Maternal thyroid volume - postpartum (in $\mathrm{mL}$ ) (assessed by any method)}

Four trials with 457 women reported on this outcome (BruckerDavis 2013; Liesenkotter 1996; Pedersen 1993; Gowachirapant 2014) and most used median thyroid volume so we did not perform a meta-analysis. Three of the studies showed similar postpartum thyroid volumes between the oral iodine and no iodine groups (Liesenkotter 1996; Pedersen 1993; Gowachirapant 2014). (Table 3). One trial however reported a lower median thyroid volume (by 1.2 $\mathrm{mL}$ ) in the iodine group (Brucker-Davis 2013).

\section{Maternal Tg - pregnancy (in $\mu \mathrm{g} / \mathrm{L}$ )}

This outcome was reported in four studies with 562 women (Brucker-Davis 2013; Nohr 2000; Pedersen 1993; Gowachirapant 2014) all of which reported median $\mathrm{Tg}$ so we did not perform a meta- 
analysis. In all four trials, median Tg in pregnancy was lower in the group which received oral iodine compared to the no iodine group; the difference ranged from 2.1 to $7.5 \mu \mathrm{g} / \mathrm{L}$ (Table 4).

\section{Maternal Tg - postpartum (in $\mu \mathrm{g} / \mathrm{L}$ )}

Four trials involving 457 women (Brucker-Davis 2013; Liesenkotter 1996; Pedersen 1993; Gowachirapant 2014 reported this outcome, mostly as median Tg therefore we did not perform a metaanalysis. All four trials showed that women who received oral iodine supplements had lower postpartum Tg levels compared to those who did not (Table 5). The difference between groups ranged from 1.57 to $11.6 \mu \mathrm{g} / \mathrm{L}$.

\section{Insufficient iodine intake - pregnancy (median UIC less than $150 \mu \mathrm{g} / \mathrm{L}$ )}

Two studies with 432 participants reported on this outcome (Brucker-Davis 2013; Gowachirapant 2014). Results show that women who received oral iodine supplements had a lower likelihood of insufficient iodine intake in pregnancy compared to the comparison group; $33.3 \%$ of women in the iodine group had inadequate iodine intake compared to $53.2 \%$ in the control group (average RR $0.64 ; 95 \% \mathrm{Cl} 0.51$ to 0.80 ) (Analysis 2.16). There was no evidence of statistical heterogeneity for this outcome $\left(\mathrm{I}^{2}=0 \%\right.$, $\mathrm{Tau}^{2}$ $=0.00$ and $\mathrm{Chi}^{2}$ test for heterogeneity $\mathrm{P}=0.56$ ).

\section{Insufficient iodine intake - postpartum (breastfeeding: median UIC less than $100 \mu \mathrm{g} / \mathrm{L}$ )}

Results from two trials (Bouhouch 2014 (C); Gowachirapant 2014) involving 425 women show that iodine supplementation reduced the likelihood of having insufficient iodine intake in the postpartum period (average RR $0.81 ; 95 \% \mathrm{Cl} 0.70$ to 0.93 ) with no evidence of statistical heterogeneity $\left(\mathrm{I}^{2}=0 \%, \mathrm{Tau}^{2}=0.00\right.$ and $\mathrm{Chi}^{2}$ test for heterogeneity $\mathrm{P}=0.90$ ) (Analysis 2.17).

\section{Excessive iodine intake (pregnancy only: median UIC greater than or equal to $500 \mu \mathrm{g} / \mathrm{L}$ )}

One trial (Gowachirapant 2014) with 356 women showed that $7.0 \%$ of women who oral received iodine supplements and $1.6 \%$ of women who did not had excessive iodine intake during pregnancy (average RR 4.33; 95\% Cl 1.24 to 15.07) (Analysis 2.18).

\section{Infant/child secondary outcomes}

\section{Small-for-gestational age (as defined by trial authors)}

This outcome was reported in two trials (Zhou 2015; Gowachirapant 2014) with 377 infants which showed no evidence of difference between groups (average RR 1.26, 95\% $\mathrm{Cl} 0.77$ to 2.05). There was no evidence of statistical heterogeneity $\left(\mathrm{I}^{2}=0 \%, \mathrm{Tau}^{2}=0.00\right.$ and $\mathrm{Chi}^{2}$ test for heterogeneity $\mathrm{P}=0.83$ ) (Analysis 2.19).

Congenital anomalies (including cretinism, as defined by trial authors)

One trial with 57 infants (Zhou 2015) reported this outcome, with no cases of congenital anomalies in either group (Analysis 2.20).

\section{Growth (anthropometric Z scores)}

No trials reported on this outcome.

\section{Neonatal goitre (assessed by any method)}

This outcome was reported in two trials (Glinoer 1993; Liesenkotter 1996) which assessed 228 neonates. Findings showed a lower likelihood of enlarged thyroid gland in the neonate following oral iodine supplementation in the mother (average RR $0.11 ; 95 \% \mathrm{Cl} 0.02$ to 0.56$)$, with no evidence of statistical heterogeneity $\left(I^{2}=0 \%\right.$, $\mathrm{Tau}^{2}$ $=0.00$ and $\mathrm{Chi}^{2}$ test for heterogeneity $\mathrm{P}=0.76$ ) (Analysis 2.21).

Neonatal thyroid volume (in $\mathrm{mL}$ ) (assessed by any method)

Three trials with assessments of 359 neonates (Glinoer 1993; Liesenkotter 1996; Gowachirapant 2014) showed lower thyroid volume in the oral iodine compared to the control group. The MD was $-0.34 \mathrm{~mL}(95 \% \mathrm{Cl}-0.58$ to -0.11$)$ though there was evidence of statistical heterogeneity $\left(\mathrm{I}^{2}=93 \%, \mathrm{Tau}^{2}=0.04\right.$ and $\mathrm{Chi}^{2}$ test for heterogeneity $\mathrm{P}=0.00001$ ) (Analysis 2.22).

Insufficient neonatal iodine intake (median UIC less than $100 \mu \mathrm{g} / \mathrm{L}$ )

One trial (Gowachirapant 2014) which assessed 159 neonates found a higher likelihood of insufficient iodine intake in the oral iodine compared to the control group (average RR 2.14; $95 \% \mathrm{Cl} 1.04$ to 4.37) (Analysis 2.23).

\section{Neonatal mental or motor development (as defined by trial authors)}

One study (Gowachirapant 2014) reported scores from the Neonatal Behavioral Assessment Scales in median and IQR for 149 neonates (Table 6). Out of the eight sub-scales, three showed higher median scores in the oral iodine group compared to the control group, one showed a higher score in the control group, and three showed equal scores in both groups.

\section{Child mental or motor development (as defined by trial authors)}

One trial (Zhou 2015) reported on child cognitive, language development, motor, social-emotional and adoptive behaviour scores for 53 children at 18 months of age assessed by the Bayley scales of infant and toddler development (Bayley-III). Scores were similar in both groups (Analysis 2.24; Analysis 2.25; Analysis 2.26; Analysis 2.27; Analysis 2.28). This trial also reported moderate and severe developmental delays based on the cognitive, language and motor scores and found no significant differences between groups (Analysis 2.29; Analysis 2.30; Analysis 2.31; Analysis 2.32; Analysis 2.33; Analysis 2.34).

\section{Infant death (death in the first year of life)}

No trials reported on this outcome.

\section{(3) Oral iodine-only supplement versus no intervention or placebo (five trials, 580 participants)}

Five studies involving 580 women were included in this comparison (Bouhouch 2014 (C); Glinoer 1993; Liesenkotter 1996; Pedersen 1993; Zhou 2015), all of which contributed data. None were assessed as high quality.

\section{Maternal primary outcomes}

Hypothyroidism - pregnancy (as defined by trial authors)

No trials reported on this outcome.

\section{Hypothyroidism - postpartum (as defined by trial authors)}

Among 340 women in three trials (Bouhouch 2014 (C); Liesenkotter 1996; Pedersen 1993), those who received oral iodine-only supplementation were as likely to be diagnosed with hypothyroidism in the postpartum period as those who did not receive any iodine (average RR $0.91 ; 95 \% \mathrm{Cl} 0.10$ to 8.60) (Analysis 3.1). We did not find evidence of statistical heterogeneity $\left(I^{2}=0 \%\right.$, $\mathrm{Tau}^{2}=0.00$ and $\mathrm{Chi}^{2}$ test for heterogeneity $\mathrm{P}=0.32$ ). 


\section{Preterm birth (as defined by trial authors)}

One trial with 58 assessments (Zhou 2015) showed no difference in the likelihood of preterm birth for women who received oral supplements with iodine only compared to those who received no iodine (average RR $1.25 ; 95 \% \mathrm{Cl} 0.37$ to 4.19 ) (Analysis 3.2).

Maternal adverse effect: elevated TPO-ab - pregnancy (as defined by trial authors)

No trial reported on this outcome.

Maternal adverse effect: elevated TPO-ab - postpartum (as defined by trial authors)

This outcome was reported in two trials with 162 women (Liesenkotter 1996; Pedersen 1993). Findings showed no difference between the group which received oral iodine-only and the group which did not receive any iodine (average RR $0.62 ; 95 \% \mathrm{Cl} 0.15$ to 2.51) (Analysis 3.3). We did not find any evidence of statistical

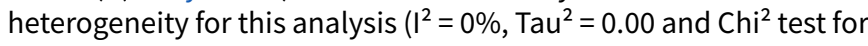
heterogeneity $\mathrm{P}=0.52$ ).

Maternal adverse effect: hyperthyroidism - pregnancy (as defined by trial authors)

No trial reported on this outcome.

Maternal adverse effect: hyperthyroidism - postpartum (as defined by trial authors)

Two trials involving 286 women (Bouhouch 2014 (C); Liesenkotter 1996) reported postpartum hyperthyroidism. This event occurred only in one trial though (Bouhouch 2014 (C)) and there was no difference in the likelihood of postpartum hyperthyroidism between groups (average RR 0.29; 95\% Cl 0.01 to 7.06) (Analysis 3.4).

Maternal adverse effect: digestive intolerance - pregnancy (as defined by trial authors)

No trial reported on this outcome.

\section{Infant/child primary outcomes}

Perinatal mortality (including stillbirth/fetal death and neonatal death, as defined by trial authors)

One trial with 58 assessments (Zhou 2015) reported no events in either group (Analysis 3.5).

\section{Low birthweight (less than $2500 \mathrm{~g}$ )}

One trial (Zhou 2015) reported this outcome with 58 neonates, showing no difference between groups (average RR $0.33 ; 95 \% \mathrm{Cl}$ 0.04 to 3.02) (Analysis 3.6).

Neonatal hypothyroidism or elevated TSH (as defined by trial authors)

One trial with 41 assessments (Zhou 2015) reported on this outcome and showed no events in either group (Analysis 3.7),

\section{Neonatal adverse effect - elevated TPO-ab (as defined by trial authors)}

One study with 108 assessments (Liesenkotter 1996) reported on this outcome and showed no difference between groups (average RR 0.61; 95\% Cl 0.07 to 5.70) (Analysis 3.8).

Neonatal adverse effect - hyperthyroidism (as defined by trial authors) No trials reported this outcome.

\section{Maternal secondary outcomes}

Spontaneous miscarriage (as defined by trial authors)

This outcome was reported in one trial with 58 pregnant women (Zhou 2015), which showed no difference in likelihood of spontaneous miscarriage between the oral iodine-only and no iodine groups (average RR 3.00; 95\% $\mathrm{Cl} 0.13$ to 70.74) (Analysis 3.9).

\section{Maternal goitre - pregnancy (assessed by any method)}

One study involving 120 women (Glinoer 1993) reported on goitre in pregnancy and found no difference between groups (average RR $0.60 ; 95 \% \mathrm{Cl} 0.23$ to 1.55 ) (Analysis 3.10 ).

\section{Maternal thyroid size - goitre postpartum (assessed by any method)}

Postpartum goitre was reported in one trial (Liesenkotter 1996). Data from 108 women showed no evidence of difference between groups (average RR 1.01; 95\% Cl 0.73 to 1.39) (Analysis 3.11).

Maternal thyroid volume - pregnancy (in $\mathrm{mL}$ ) (assessed by any method)

One trial with 54 women (Pedersen 1993) reported on this outcome. Median thyroid volume in the oral iodine-only group was lower, by $1.3 \mathrm{~mL}$, than in the no-iodine group (Table 2).

\section{Maternal thyroid volume - postpartum (in $\mathrm{mL}$ ) (assessed by any method)}

Two trials including 157 women reported on this outcome (Liesenkotter 1996; Pedersen 1993). Findings show similar median thyroid volume in the iodine-only supplementation group and the no-iodine group (Table 3).

\section{Maternal Tg - pregnancy ( $\mu \mathrm{g} / \mathrm{L})$}

This outcome was reported in one trial with 54 women (Pedersen 1993) which showed $45 \%$ lower postpartum Tg levels in the iodineonly group compared to the group that received no iodine (Table 4).

\section{Maternal Tg - postpartum ( $\mu \mathrm{g} / \mathrm{L})$}

Two trials involving 157 women (Liesenkotter 1996; Pedersen 1993) reported on this outcome. We did not perform a metaanalysis because one trial reported median Tg. Results from these studies show lower postpartum $\mathrm{Tg}$ levels in the iodine-only supplementation group compared to the no-iodine group (Table 5). In one trial mean Tg was $5.2 \mu \mathrm{g} / \mathrm{L}$ lower (Liesenkotter 1996) and in the other median $\mathrm{Tg}$ was $5.6 \mu \mathrm{g} / \mathrm{L}$ lower (Pedersen 1993).

Insufficient iodine intake - pregnancy (median UIC less than $150 \mu \mathrm{g} / \mathrm{L}$ ) No trial reported on this outcome.

Insufficient iodine intake - postpartum (breastfeeding: median UIC less than $100 \mu \mathrm{g} / \mathrm{L}$ )

Results from one trial (Bouhouch 2014 (C)) with 175 women show that those who received oral iodine-only supplements were less likely to have inadequate iodine intake in the postpartum period compared to those who received no iodine (average RR $0.81 ; 95 \%$ $\mathrm{Cl} 0.69$ to 0.96 ) (Analysis 3.12).

Excessive iodine intake (pregnancy only: median UIC greater than or equal to $500 \mu \mathrm{g} / \mathrm{L}$ )

No trial reported on this outcome. 


\section{Infant/child secondary outcomes}

\section{Small-for-gestational age (as defined by trial authors)}

One trial with 58 neonates (Zhou 2015) reported this outcome (average RR 1.50; 95\% Cl 0.27 to 8.32) (Analysis 3.13).

Congenital anomalies (including cretinism, as defined by trial authors)

One trial with 57 infants (Zhou 2015) reported on congenital anomalies and showed no cases in either group (Analysis 3.14).

\section{Growth (anthropometric Z scores)}

No trial reported on this outcome.

\section{Neonatal goitre (assessed by any method)}

Two trials with 228 neonates (Glinoer 1993; Liesenkotter 1996) reported on this outcome and showed a lower likelihood of neonatal goitre in the oral iodine-only supplementation group compared to the control group (average RR $0.11 ; 95 \% \mathrm{Cl} 0.02$ to 0.56 ) (Analysis 3.15). We found no evidence of statistical heterogeneity $\left(\mathrm{I}^{2}=0 \%, \mathrm{Tau}^{2}=0.00\right.$ and $\mathrm{Chi}^{2}$ test for heterogeneity $P=0.76)$.

\section{Neonatal thyroid volume (in $\mathrm{mL}$ ) (assessed by any method)}

This outcome was reported in two studies with 228 assessments (Glinoer 1993; Liesenkotter 1996) which showed a lower neonatal thyroid volume, by $0.53 \mathrm{~mL}$, in the oral iodine-only group in comparison to the control group $(95 \% \mathrm{Cl}-1.02$ to -0.03$)$ (Analysis 3.16). However there was significant statistical heterogeneity $\left(\mathrm{I}^{2}=\right.$ $91 \%, \mathrm{Tau}^{2}=0.12$ and $\mathrm{Chi}^{2}$ test for heterogeneity $\left.\mathrm{P}=0.0007\right)$.

\section{Insufficient neonatal iodine intake (median UIC less than $100 \mu \mathrm{g} / \mathrm{L}$ )}

No trial reported on this outcome.

\section{Child mental or motor development (as defined by trial authors)}

One trial (Zhou 2015) reported on child cognitive, language development, motor, social-emotional and adaptive behaviour scores at 18 months of age for 53 children assessed by the Bayley scales of infant and toddler development (Bayley-II). Scores were similar in both groups (Analysis 3.17; Analysis 3.18; Analysis 3.19; Analysis 3.20; Analysis 3.21). The same trial also reported moderate and severe developmental delays based on the cognitive, language and motor scores and found no significant differences between groups (Analysis 3.22; Analysis 3.23; Analysis 3.24; Analysis 3.25; Analysis 3.26; Analysis 3.27).

\section{Infant death (death in the first year of life)}

No trial reported on this outcome.

(4) Oral iodine supplement with other vitamins and/or minerals versus only other vitamins and/or minerals (exact same formulation of other vitamins/minerals, but no iodine) (three trials, 694 participants)

Three studies involving 694 women were included in this comparison (Brucker-Davis 2013; Nohr 2000; Gowachirapant 2014); all three contributed data. None were assessed as high quality.

\section{Maternal primary outcomes \\ Hypothyroidism - pregnancy (as defined by trial authors)}

Data from one trial (Gowachirapant 2014) involving 365 women showed no difference in risk of hypothyroidism in pregnancy between women who received supplements containing iodine and other vitamins/minerals and those who received only the other vitamins/minerals (average RR 1.90; $95 \% \mathrm{Cl} 0.57$ to 6.38) (Analysis 4.1).

\section{Hypothyroidism - postpartum (as defined by trial authors)}

One study (Gowachirapant 2014) with 254 women reported on this outcome and found no evidence of difference in the likelihood of postpartum hypothyroidism between groups (average RR 0.97; 95\% $\mathrm{Cl} 0.06$ to 15.32 ) (Analysis 4.2).

\section{Preterm birth (as defined by trial authors)}

Only one trial (Gowachirapant 2014) involving 318 women reported on preterm birth, and showed no difference between groups (average RR $0.51 ; 95 \% \mathrm{Cl} 0.23$ to 1.14) (Analysis 4.3).

Maternal adverse effect: elevated TPO-ab - pregnancy (as defined by trial authors)

One trial (Gowachirapant 2014) involving 359 women showed no difference between groups (average RR 0.95; 95\% Cl 0.44 to 2.07) (Analysis 4.4).

Maternal adverse effect: elevated TPO-ab - postpartum (as defined by trial authors)

This outcome was reported in one trial (Gowachirapant 2014) with 235 women, which showed no difference between groups (average RR 1.03; 95\% Cl 0.79 to 1.33 ) (Analysis 4.5).

Maternal adverse effect: hyperthyroidism - pregnancy (as defined by trial authors)

One trial with 365 women reported on this outcome (Gowachirapant 2014) and found no difference between groups (average RR 1.90; 95\% Cl 0.57 to 6.38) (Analysis 4.6).

Maternal adverse effect: hyperthyroidism - postpartum (as defined by trial authors)

This outcome was reported in one trial involving 257 women (Gowachirapant 2014) (average RR 0.35; 95\% Cl 0.12 to 1.06 ) (Analysis 4.7).

Maternal adverse effect: digestive intolerance - pregnancy (as defined by trial authors)

One trial with 76 women reported on this outcome (BruckerDavis 2013) and found a higher likelihood of digestive intolerance in the group that received oral iodine supplementation with other micronutrients compared to those who received only other micronutrients. One third of women (33.3\%) in the iodine group and $2.2 \%$ of women in the control group dropped out of the study due to nausea or vomiting (average RR 15.33, 95\% CI 2.07 to 113.70 ; participants $=76$ ) (Analysis 4.8).

\section{Infant/child primary outcomes}

Perinatal mortality (including stillbirth/fetal death and neonatal death, as defined by trial authors)

No trial reported on this outcome. 


\section{Low birthweight (less than $\mathbf{2 5 0 0} \mathrm{g}$ )}

One study with 319 infants reported on this outcome (Gowachirapant 2014) and showed no difference between groups (average RR $0.61 ; 95 \% \mathrm{Cl} 0.27$ to 1.39 ) (Analysis 4.9).

Neonatal hypothyroidism or elevated TSH (as defined by trial authors)

This outcome was reported in one trial (Gowachirapant 2014) with 219 infant assessments; the average RR for neonatal elevated TSH was 0.58 ( $95 \% \mathrm{Cl} 0.11$ to 3.12) (Analysis 4.10).

Neonatal adverse effect - elevated TPO-ab (as defined by trial authors) No trials reported this outcome.

Neonatal adverse effect - hyperthyroidism (as defined by trial authors)

No trials reported this outcome.

\section{Maternal secondary outcomes}

Spontaneous miscarriage (as defined by trial authors)

Two trials (Brucker-Davis 2013; Gowachirapant 2014) with information on 587 pregnancies showed a similar likelihood of spontaneous miscarriage (average RR $1.26 ; 95 \% \mathrm{Cl} 0.60$ to 2.62) and no evidence of statistical heterogeneity $\left(\mathrm{I}^{2}=0 \%, \mathrm{Tau}^{2}=0.00 \mathrm{and} \mathrm{Chi}^{2}\right.$ test for heterogeneity $\mathrm{P}=0.43$ ) (Analysis 4.11).

\section{Maternal goitre - pregnancy (assessed by any method)}

One trial with 366 women (Gowachirapant 2014) showed no difference between groups (average RR 1.89; $95 \% \mathrm{Cl} 0.56$ to 6.34) (Analysis 4.12).

\section{Maternal goitre - postpartum (assessed by any method)}

This outcome was reported in one study (Gowachirapant 2014) involving 262 women. Results showed no difference between women who received oral iodine with other micronutrients and those who received only other micronutrients (average RR 2.06; $95 \% \mathrm{Cl} 0.64$ to 6.68 ) (Analysis 4.13).

\section{Maternal thyroid volume - pregnancy (in $\mathrm{mL}$ ) (assessed by any} method)

Two trials (Brucker-Davis 2013; Gowachirapant 2014) with 442 participants reported median prenatal thyroid volume so we did not perform a meta-analysis. Values were similar in both groups in one trial (Gowachirapant 2014) and $0.4 \mathrm{~mL}$ lower in the group receiving iodine with other micronutrients compared to the noiodine group in the other trial (Brucker-Davis 2013) (Table 2).

\section{Maternal thyroid volume - postpartum (in $\mathrm{mL}$ ) (assessed by any method)}

Two trials (Brucker-Davis 2013; Gowachirapant 2014) with 300 women reported median postpartum thyroid volume, so we did not perform a meta-analysis for this outcome. Findings showed similar values in both groups in one trial (Gowachirapant 2014) and $1.2 \mathrm{~mL}$ lower thyroid volume in the group that received iodine with other micronutrients compared to the no-iodine group in the other trial (Brucker-Davis 2013)(Table 3).

\section{Maternal Tg - pregnancy $(\mu \mathrm{g} / \mathrm{L})$}

This outcome was reported in three studies (Brucker-Davis 2013; Nohr 2000; Gowachirapant 2014) with 508 women. All three trials reported median $\mathrm{Tg}$ therefore we did not perform a meta- analysis. In each of these trials, prenatal Tg concentrations were lower in women who received iodine supplements with other micronutrients compared to those who received no iodine (Table 4). Differences ranged from $2.1 \mu \mathrm{g} / \mathrm{L}$ to $5.3 \mu \mathrm{g} / \mathrm{L}$.

\section{Maternal Tg - postpartum $(\mu \mathrm{g} / \mathrm{L})$}

Two trials involving 300 women (Brucker-Davis 2013; Gowachirapant 2014) reported median postpartum Tg. In both of these studies, $\mathrm{Tg}$ concentrations were lower in the group receiving iodine plus other micronutrients than in the no-iodine group (Table 5), in one study by $1.57 \mu \mathrm{g} / \mathrm{L}$ (Gowachirapant 2014) and in another by $11.6 \mu \mathrm{g} / \mathrm{L}$ (Brucker-Davis 2013).

Insufficient iodine intake - pregnancy (median UIC less than $150 \mu \mathrm{g} / \mathrm{L}$ )

Two studies with 432 participants reported on this outcome (Brucker-Davis 2013; Gowachirapant 2014). Results show that women who received iodine supplements with other micronutrients had a lower likelihood of insufficient iodine intake in pregnancy compared to those who received only other micronutrients (average RR $0.64 ; 95 \% \mathrm{Cl} 0.51$ to 0.80 ) (Analysis 4.14). There was no evidence of statistical heterogeneity for this outcome $\left(\mathrm{I}^{2}=0 \%, \mathrm{Tau}^{2}=0.00\right.$ and $\mathrm{Chi}^{2}$ test for heterogeneity $\left.\mathrm{P}=0.56\right)$.

Insufficient iodine intake - postpartum (breastfeeding: median UIC less than $100 \mu \mathrm{g} / \mathrm{L}$ )

Findings from one trial (Gowachirapant 2014) with 250 women showed no clear difference of having insufficient iodine intake postpartum (average RR $0.80 ; 95 \% \mathrm{Cl} 0.61$ to 1.04 ) (Analysis 4.15).

Excessive iodine intake (pregnancy only: median UIC greater than or equal to $500 \mu \mathrm{g} / \mathrm{L}$ )

One study with 356 women reported on this outcome (Gowachirapant 2014) and found a greater likelihood of excessive iodine intake in pregnancy in women who received iodine and other vitamins/minerals compared to those who received only other vitamins/minerals (average RR 4.33; 95\% Cl 1.24 to 15.07) (Analysis 4.16).

\section{Infant/child secondary outcomes}

Small-for-gestational age (as defined by trial authors)

This outcome was reported in one trial (Gowachirapant 2014) with 319 assessments which showed no evidence of difference between groups (average RR 1.24; $95 \% \mathrm{Cl} 0.74$ to 2.06 ) (Analysis 4.17).

Congenital anomalies (including cretinism, as defined by trial authors) No trials reported on this outcome.

Growth (anthropometric $Z$ scores)

No trials reported on this outcome.

Neonatal goitre (assessed by any method)

No trials reported on this outcome.

Neonatal thyroid volume (in $\mathrm{mL}$ ) (assessed by any method)

This outcome was reported in one trial (Gowachirapant 2014) which assessed 131 neonates and found a trend towards lower thyroid volume in the group whose mothers received iodine with other micronutrients compared to those who received only other micronutrients (MD $-0.09 ; 95 \% \mathrm{Cl}-0.18$ to -0.00 ) (Analysis 4.18). 
Insufficient neonatal iodine intake (median UIC less than $100 \mu \mathrm{g} / \mathrm{L}$ )

One trial (Gowachirapant 2014), which assessed 159 neonates, found a higher likelihood of insufficient iodine intake in the iodine compared to the control group (average RR 2.14; 95\% Cl 1.04 to 4.37) (Analysis 4.19).

\section{Neonatal mental or motor development (as defined by trial authors)}

One study (Gowachirapant 2014) reported scores from the Neonatal Behavioral Assessment Scales for 149 neonates in median and IQR (Table 6). Out of the eight sub-scales, three showed higher median scores in the oral iodine group compared to the control group, one showed a higher score in the control group, and three showed equal scores in both groups.

\section{Infant death (death in the first year of life)}

No trials reported on this outcome.

\section{(5) Any injected iodine supplement versus same supplement without iodine or no treatment/placebo (three trials,1463 participants)}

Three trials were included in this comparison (Kevany 1969; Pharoah 1971 (C); Thilly 1978), all of which contributed data. One trial did not report the number of women randomised (Pharoah 1971 (C)). None of the studies were assessed as high quality.

\section{Maternal primary outcomes}

None of the trials reported on this review's maternal primary outcomes (hypothyroidism during pregnancy or postpartum; preterm birth or any adverse effect in pregnancy or postpartum).

\section{Infant/child primary outcomes}

Perinatal mortality (including stillbirth/fetal death and neonatal death, as defined by trial authors)

One trial with 399 assessments (Thilly 1978) reported on this outcome and found a trend towards lower perinatal mortality in the injected-iodine compared to the control group (average RR 0.66; $95 \% \mathrm{Cl} 0.42$ to 1.03 ) (Analysis 5.1).

No trials reported on this review's other infant primary outcomes (low birthweight, hypothyroidism or elevated TSH or any adverse effect).

\section{Maternal secondary outcomes}

No trials reported on the prespecified maternal secondary outcomes (spontaneous miscarriage, maternal goitre during pregnancy or postpartum, thyroid volume - pregnancy or postpartum, Tg - pregnancy or postpartum, insufficient or excessive iodine intake during pregnancy or postpartum).

\section{Infant/child secondary outcomes}

Congenital anomalies (including cretinism, as defined by trial authors)

One study (Pharoah 1971 (C)), which assessed 818 children, showed a lower frequency of congenital anomalies in the injected iodine group compared to the control group (average RR $0.27 ; 95 \% \mathrm{Cl} 0.12$ to 0.60) (Analysis 5.2).

\section{Neonatal goitre (assessed by any method)}

One trial with 465 neonates (Kevany 1969) reported on this outcome; no events were found in either group (Analysis 5.3).

\section{Mental or motor development (as defined by trial authors)}

Data from two trials (Kevany 1969; Thilly 1978), which measured 174 children, showed a higher IQ score, by 11.21 points on average, in the injected iodine compared to the control group $(95 \% \mathrm{Cl} 7.96$ to 14.46$)$, with no statistical heterogeneity $\left(\mathrm{I}^{2}=0 \%, \mathrm{Tau}^{2}=0.00 ; \mathrm{Chi}^{2}\right.$ test for heterogeneity $\mathrm{P}=0.70$ ) (Analysis 5.4).

No trials reported on any of the other infant/child prespecified secondary outcomes (growth, small-for-gestational age, thyroid volume, insufficient neonatal iodine intake or infant death).

(6) Injected iodine-only supplement versus no intervention or placebo (three trials)

All of the trials included in comparison 5 reported using injected iodine-only supplements (Kevany 1969; Pharoah 1971 (C); Thilly 1978). Therefore the findings for comparison 6 are the same as for comparison 5 and are not repeated here.

(7) Injected iodine supplement with other vitamins and/or minerals versus only other vitamins and/or minerals (exact same formulation of other vitamins/minerals, but no iodine) (no trials)

No studies were included in this comparison.

\section{DISCUSSION}

\section{Summary of main results}

This review evaluates the effects of oral or injected iodine supplementation alone or in combination with other micronutrients prior to, during, or following pregnancy. It includes 14 trials, though only 11 (with over 2700 women) contributed data. Eight of these 11 trials compared iodine alone versus no treatment or placebo (five oral and three injected) and three compared iodine with other vitamins/minerals compared to only other vitamins/ minerals (all oral). We did not identify any studies that used injected iodine with other vitamins/minerals compared to only other vitamins/minerals.

We have summarized the primary outcome findings along with an overall assessment of quality of evidence in 'Summary of findings' tables (Summary of findings for the main comparison; Summary of findings 2).

In comparison to the group that received no iodine, those who received iodine had a lower likelihood of postpartum hyperthyroidism (1.6\% versus $4.9 \%$ in three trials, low-quality evidence) and a higher likelihood of digestive intolerance in pregnancy $(33.3 \%$ versus $2.2 \%$ in one trial, very low-quality evidence). Both hyperthyroidism and digestive intolerance were considered potential adverse effects. Those who received iodine supplementation also had a lower likelihood of perinatal mortality (11.9\% versus $18.2 \%$ in two trials, low-quality evidence), though this finding was not statistically significant. For the remaining primary outcomes, there were no clear differences between groups.

For secondary outcomes, in comparison to the group which received no iodine, those who received iodine supplementation had lower likelihood of insufficient iodine intake in pregnancy (two trials) and the postpartum period (two trials), greater likelihood of excessive iodine intake in pregnancy (one trial), lower likelihood of congenital anomalies (two trials), lower likelihood of neonatal 
goitre (three trials), lower neonatal thyroid volume (three trials), higher likelihood of neonatal insufficient iodine intake (one trial) and higher child mental development score (two trials).

No trials reported on infant/child growth or infant death and we found evidence of no effect for the remaining secondary outcomes.

Our findings, both those showing an effect and those showing no effect, must be interpreted with caution due to the low number of studies contributing data and small sample sizes.

\section{Overall completeness and applicability of evidence}

This review included data from 11 randomised or quasirandomized controlled trials that have taken place in 13 countries since the 1960s. We consider this evidence base to be limited, both in the number of trials and included women and in the outcomes of interest reported. The majority of primary outcomes were reported in only one or two trials. Where we identified substantial statistical heterogeneity, we were unable to perform any of the planned subgroup analyses because of insufficient data. None of the included trials were assessed as high quality and the quality of evidence for all of the primary outcomes was considered low or very low.

lodine supplementation in women who may become pregnant, and pregnant or breastfeeding women generally aims to prevent and/ or treat iodine deficiency and its consequences, both in the woman and her child. Our review has shown that iodine supplementation may decrease the risk of postpartum hyperthyroidism and increase the likelihood of experiencing nausea or vomiting in pregnancy. Evidence for these outcomes came from trials which took place in areas with mild to moderate iodine deficiency. These findings must be interpreted cautiously; the postpartum findings were driven by findings from one study and the digestive intolerance results came from one trial. There was an indication of decreased risk of perinatal mortality, though the difference between groups was not statistically significant and all of the events occurred in one trial which took place in a setting with severe iodine deficiency.

We have also demonstrated that iodine supplementation may affect indicators of iodine intake and iodine or thyroid status in women and their children - mostly positively with the exception of an increased risk of excessive intake in pregnancy and higher likelihood of insufficient neonatal intake. We also identified evidence for prevention of cretinism in a severely iodine-deficient area and mixed findings on mental development indicators, with positive effects in studies that took place in settings with severe deficiency. We had planned on performing subgroup analyses, including by baseline iodine status, however we did not identify enough trials to perform these additional analyses for any of the included outcomes.

The importance of routine iodine supplementation for important outcomes in pregnancy and postpartum and in children under two still needs to be demonstrated. To our knowledge there are five planned, ongoing or unpublished trials which may be eligible for inclusion in this review, in addition to data not yet published for the Indian component of the Gowachirapant 2014 trial (see Characteristics of ongoing studies). We expect that when reported, these trials will help fill some of the evidence gaps identified in this review. This review should be updated to incorporate the new findings once they are published.

\section{Quality of the evidence}

The overall risk of bias was unclear in most of the trials. Methods for sequence generation and allocation concealment were either not specified or considered at high risk of selection bias for most trials. Similarly, most trials did not describe blinding of personnel, participants and outcome assessors or the methods were considered at high risk of performance or detection bias. For most of the outcomes however, lack of blinding would be unlikely to influence results, though we cannot rule out this possibility. All but two studies were considered at either high risk of attrition bias due to incomplete outcome data or unclear risk because this information was not provided. For reporting and other bias, we generally did not have enough information to classify trials as high or low risk.

We assessed the quality of the evidence using GRADE and judged the evidence for comparison 1 , any supplement containing iodine compared with same supplement without iodine or no treatment/ placebo, for maternal primary outcomes (Summary of findings for the main comparison), and child primary outcomes (Summary of findings 2) (no outcomes beyond the neonatal period were reported in the included trials). For maternal outcomes, the quality of evidence was judged as low for maternal hypothyroidism during pregnancy, postpartum, preterm, elevated TPO-ab during pregnancy and postpartum, hyperthyroidism during pregnancy and postpartum. Digestive intolerance was judged as very lowquality evidence. For child outcomes, the quality of evidence was judged as low to very low for perinatal mortality, low birthweight, neonatal hypothyroidism or elevated TSH, and neonatal elevated TPO-ab. The main reasons for downgrading were design limitations, wide confidence intervals and small event size.

\section{Potential biases in the review process}

We aimed to minimize bias at each stage of the review process. Two review authors independently assessed eligibility for inclusion, carried out data extraction and assessed risk of bias. However we recognize that this type of review requires many subjective judgements and others undertaking the same review may have made different decisions, particularly regarding eligibility and risk of bias.

We attempted to use a systematic and transparent process to assess the quality of the evidence relating to specific outcomes and produce 'Summary of findings' tables. Two review authors independently assessed the evidence for each quality domain for each outcome. Any disagreements were discussed and we involved a third review author where necessary. We planned to use funnel plots to assess publication bias but we were not able to do this for any of the outcomes due to the limited number of studies contributing data. We also relied mostly on published literature and did not systematically search for grey literature.

\section{Agreements and disagreements with other studies or reviews}

Zhou and colleagues conducted a systematic review on the effects of iodine supplementation during pregnancy or the periconceptional period on child growth and development as well as pregnancy outcomes and thyroid function, and included randomised or quasi-randomized controlled trials (Zhou 2013). Our findings are consistent with the authors' conclusions that there was 
a lack of high-quality evidence on the effect of supplementation on child growth and cognition.

Taylor and colleagues undertook a systematic review on the impact of iodine supplementation in settings with mild-to-moderate iodine deficiency (Taylor 2013). They included observational studies and randomised controlled trials of maternal iodine supplementation in pregnancy. Of the trials, they found that most showed a positive impact on maternal $\mathrm{Tg}$ levels and maternal thyroid volume, no evidence of negative effect on maternal TPO$\mathrm{ab}$, and lower thyroid volume in neonates of women who received iodine. We found similar results, with the exception of maternal thyroid volume, where our findings were mixed.

Zimmermann and colleagues conducted a narrative systematic review/systematic literature search on the effects of iodine deficiency in pregnancy and infancy, and included trials on supplementation before and during pregnancy (Zimmermann 2012a). The authors concluded that in moderate to severely iodinedeficient areas, iodine supplementation prevented cretinism, increased birthweight, reduced perinatal and infant death and improved child cognition. They also concluded that mild deficiency could impair thyroid function but that effects on child cognitive or neurologic function were uncertain. This review reached different conclusions to ours, however this may be explained by its design; it did not specify criteria for study inclusion and included nonrandomized trials as well as studies with different comparisons.

An additional review and meta-analysis looked at iodine and mental development of young children and included randomised and non-randomized supplementation trials (in mothers or infants, or both) and prospective cohort studies stratified by mother or infant iodine status (Bougma 2013). Findings showed a positive impact of iodine, regardless as to the study design, ranging from 6.9 to 10.2 IQ points, whereas our findings on child development were mixed.

Angermayr and Clar conducted a Cochrane Review on the effects of iodine supplementation for preventing iodine deficiency disorders in children and found that most trials resulted in increased urinary iodine excretion, an overall tendency towards reduction of goitre and mixed results for cognitive, psychomotor and physical development (Angermayr 2004). Less than $2 \%$ of children studied showed adverse effects and these effects were largely minor and transient. Most trials included in this review used iodized oil and most were considered low quality.

In the Cochrane Review on iodine supplementation for preventing mortality and adverse neurodevelopmental outcomes in preterm infants, Ibrahim and colleagues found only one eligible trial to include (Ibrahim 2006). This trial was underpowered for mortality and did not assess neurodevelopment. It showed no effect of iodine on T3, T4 or thyrotropin or the incidence of chronic lung disease. Our review did not include any of these outcomes.

Aburto and colleagues performed a review on the effect and safety of salt iodization for prevention of iodine deficiency disorders, which included over 80 studies of various designs (Aburto 2014). Findings showed that iodized salt increased intelligence quotient and urinary iodine excretion and reduced the risk of goitre, cretinism, low intelligence and low urinary iodine excretion. There was no effect found on hypothyroidism, considered by authors as a potential adverse effect, and inconsistent results for hyperthyroidism.

A Cochrane Review on point-of-use fortification of foods with multiple-micronutrient powders for women during pregnancy identified one eligible trial that included iodine in the formulation, along with six other nutrients (Suchdev 2015). The comparison was tablets with the same formulation, therefore the findings are not relevant for discussion here. Similarly, the Haider and Bhutta Cochrane Review on multiple-micronutrient supplementation for women during pregnancy included trials that compared multiplemicronutrient supplements with supplements containing iron and folic acid, iron only, or placebo (Haider 2015).

Some of our findings were unexpected. The evidence that iodine supplementation reduced the likelihood of hyperthyroidism in the postpartum period came mainly from one trial, which took place in women with mild iodine deficiency in Thailand (Gowachirapant 2014). We are not certain of a mechanism to explain this relationship. It is possible that iodine supplementation helped to prevent postpartum thyroiditis, a feature of which is often hyperthyroidism (Stagnaro-Green 2012). Other available evidence however suggests that iodine has no effect on or aggravates postpartum thyroiditis. We also found, with data from the same trial, that iodine supplementation increased the likelihood of insufficient iodine intake in neonates (as indicated by UIC) (Gowachirapant 2014). This finding is also unexpected and we are not aware of a plausible explanation.

\section{AUTHORS' CONCLUSIONS}

\section{Implications for practice}

Overall, there were insufficient data for any meaningful conclusions on the benefits and harms of routine iodine supplementation in women before, during or after pregnancy. Based on the information available for our primary outcomes, we found evidence of benefit (reduced likelihood of postpartum hyperthyroidism) and harm (increased likelihood of digestive intolerance) in settings with mild to moderate iodine deficiency. We also found effects, mostly positive, on some indicators of iodine intake and iodine or thyroid status. All of our findings must be interpreted with caution due to the small number of trials and included women and low (or very low) quality of the evidence. We did not identify any trials that reported on growth (using anthropometric Z scores) or infant death, and no trials reported on elevated thyroid-stimulating hormone/hypothyroidism or adverse effects in children beyond the neonatal period.

Medical bodies in several countries have concluded that the potential benefits of iodine supplementation in pregnancy and breastfeeding (and in some countries in women before pregnancy) outweigh the potential harms. In many countries, especially in high-resource settings, it is common practice for women to take multiple-micronutrient supplements during and after pregnancy and these supplements often contain iodine.

Decisions on recommending or taking iodine supplements should be informed by the likelihood and severity of potential benefits as well as harms, and are influenced by values and preferences. For some, knowledge that iodine supplements during these periods can help ensure adequate intake may be sufficient, given the scientific basis behind the recommended intakes. Others may want 
more direct evidence on functional outcomes. Though we were unable to explore the role of the women's initial iodine status in our review, it is an important factor to consider. This information would generally not be available for individuals but may be known for the population.

\section{Implications for research}

This review highlights the need for additional high-quality randomised controlled trials of iodine supplementation before, during and after pregnancy on maternal and infant/child outcomes. However given the body of evidence including and beyond this review, it may be unethical to compare iodine to placebo or no treatment in severe deficiency settings. Such trials may also be unfeasible in any setting where pregnant and lactating women commonly take prenatal supplements with iodine. Information is also needed on optimal timing of initiation as well as supplementation regimen and dose. We recommend future trials include the outcomes from this review, especially the primary outcomes, and follow children beyond the neonatal period. All trials should assess potential adverse effects, including the nature and extent of digestive intolerance. Future research should be reported in a way that allows assessment of risk of bias, full data extraction and analysis by the subgroups specified in this review.

\section{ACK N OWLEDGEMENTS}

We would like to thank the Cochrane Pregnancy and Childbirth Group for their support during the development of this review. We also would like to acknowledge Constance MY Yap, Bennan Tong and Antonina N Mutoro for their contributions to the protocol.

The review protocol was partially developed during the WHO/ Cochrane Collaboration/Micronutrient Initiative/Cornell University Summer Institute for Systematic Reviews in Nutrition for Global Policy Making hosted at the Division of Nutritional Sciences, Cornell University, Ithaca, USA in 7-18 July, 2014 (Kimberly Harding) and in 27 July - 7 August 2015 (Brian Payne). The World Health Organization partially supports this programme.

As part of the pre-publication editorial process, this review has been commented on by three peers (an editor and two referees who are external to the editorial team), a member of Cochrane Pregnancy and Childbirth's international panel of consumers and the Group's Statistical Adviser.

This project was supported by the National Institute for Health Research, via Cochrane Infrastructure funding to Cochrane Pregnancy and Childbirth. The views and opinions expressed therein are those of the authors and do not necessarily reflect those of the Systematic Reviews Programme, NIHR, NHS or the Department of Health.

The World Health Organization and Kimberly Harding and Angela C Webster and Constance Yap and Brian Payne and Erika Ota and Luz Maria De-Regil retain copyright and all other rights in their respective contributions to the manuscript of this Review as submitted for publication. 


\section{REFERE N CE S}

\section{References to studies included in this review}

Bouhouch 2014 (C) \{published data only\}

* Bouhouch RR, Bouhouch S, Cherkaoui M, Aboussad A, Stinca S, Haldimann M, et al. Direct iodine supplementation of infants versus supplementation of their breastfeeding mothers: a double-blind, randomised, placebo-controlled trial. Lancet. Diabetes \& Endocrinology 2014;2(3):197-209.

Bouhouch RR, Bouhouch S, Stinca S, Cherkaoui M, Aboussad A, Andersson $\mathrm{M}$, et al. Infant iodine supplementation and motor and cognitive development: a randomized controlled trial. FASEB Journal 2013;27:346.1.

\section{Brucker-Davis 2013 \{published data only\}}

Brucker-Davis F. Assessment of thyroid function throughout pregnancy with and without iodine supplementation. ClinicalTrials.gov (clinicaltrials.gov/) [accessed 22 May 2015] 2009.

Brucker-Davis F. Effect of iodine supplementation and during pregnancy on neuropsychological development of children assessed at 2 years old. ClinicalTrials.gov (clinicaltrials.gov/) [accessed 22 May 2015] 2010.

Brucker-Davis F, Ganier-Chauliac F, Gal J, Panaia-Ferrari P, Pacini $P$, Fenichel $P$, et al. Neurotoxicant exposure during pregnancy is a confounder for assessment of iodine supplementation on neurodevelopment outcome. Neurotoxicology and Teratology 2015;51:45-51.

* Brucker-Davis F, Panaia-Ferrari P, Gal J, Fenichel P, Hieronimus S. Iodine supplementation throughout pregnancy does not prevent the drop in FT4 in the second and third trimesters in women with normal initial thyroid function. European Thyroid Journal 2013;2(3):187-94.

Hiéronimus S, Ferrari P, Gal J, Berthier F, Azoulay S, Bongain A, et al. Relative impact of iodine supplementation and maternal smoking on cord blood thyroglobulin in pregnant women with normal thyroid function. European Thyroid Journal 2013;1(4):264-73.

\section{Glinoer 1993 \{published data only\}}

* Glinoer D. Maternal thyroid function in pregnancy. Journal of Endocrinological Investigation 1993;16:374-8.

Glinoer D, De Nayer P, Delange F, Lemone M, Toppet V, Sephl M, et al. A randomized trial for the treatment of mild iodine deficiency during pregnancy: maternal and neonatal effects. Journal of Clinical Endocrinology and Metabolism 1995;80:258-69.

\section{Gowachirapant 2014 \{published data only\}}

* Gowachirapant S. Effects of iodine supplementation in mildto-moderately iodine-deficient pregnant women on thyroid function, pregnancy outcomes and newborn development in Thailand [Doctoral dissertation]. Wageningen: Wageningen University, 2014
Melse-Boonstra A, Gowachirapant S, Jaiswal N, Winichagoon P, Srinivasan K, Zimmermann MB. lodine supplementation in pregnancy and its effect on child cognition. Journal of Trace Elements in Medicine and Biology 2012;26:134-6.

\section{Kämpe 1990 \{published data only\}}

Kampe O, Jansson R, Karlsson FA. Effects of L-thyroxine and iodide on the development of autoimmune postpartum thyroiditis. Journal of Clinical Endocrinology \& Metabolism 1990;70(4):1014-8.

\section{Kevany 1969 \{published data only\}}

* Kevany J, Fierro-Benitez R, Pretell EA, Stanbury JB. Prophylaxis and treatment of endemic goiter with iodized oil in rural Ecuador and Peru. American Journal of Clinical Nutrition 1969;22(12):1597-607.

Pretell E, Palacios P, Tello L, Wan M, Utiger R, Stanbury JB. lodine deficiency and the maternal/fetal relationship. In: Dunn JT, Medeiros-Neto GA editor(s). Endemic Goiter and Cretinism: Continuing Threats to World Health. Washington, DC: PAHO, 1974:143-55.

Pretell EA, Caceres A. Impairment of mental development by iodine deficiency and its correction. In: Stanbury JB editor(s). The Damaged Brain of lodine Deficiency: Cognitive, Behavioral, Neuromotor and Educative Aspects. New York: Cognizant Communication, 1994:187-91.

Pretell EA, Moncloa F, Salinas R, Guerra-Garcia R, Kawano A, Gutierrez L, et al. Endemic goiter in rural Peru: effect of iodized oil on prevalence and size of goiter and on thyroid iodine metabolism in known endemic goitrous populations. Chapter 34. Endemic Goiter, Report of the Meeting of the PAHO Scientific Group on Research in Endemic Goiter; 1968 June 27-29, Puebla, Mexico. Washington DC: PAHO, 1969:419-437.

Pretell EA, Torres T, Zenteno V, Cornejo M. Prophylaxis of endemic goiter with iodized oil in rural Peru. Advances in Experimental Medicine and Biology 1972;30:249-65.

\section{Liesenkotter 1996 \{published data only\}}

Liesenkotter KP, Gopel W, Bogner U, Stach B, Gruters A. Earliest prevention of endemic goiter by iodine supplementation during pregnancy. European Journal of Endocrinology 1996;134(4):443-8.

\section{Mulrine 2010 \{published data only\}}

* Mulrine HM, Skeaff SA, Ferguson EL, Gray AR, Valeix P. Breast-milk iodine concentration declines over the first 6 mo postpartum in iodine-deficient women. American Journal of Clinical Nutrition 2010;92(4):849-56.

Skeaff S. A randomised double-blind, placebo-controlled intervention trial to study the effect of iodine supplementation on breast milk iodine concentration and iodine status in lactating women and their breast-fed infants. Australian Clinical Trials Register (www.actr.org.au) (accessed 6 December 2005). 
Nohr 2000 \{published data only\}

Nohr SB, Jorgensen A, Pedersen KM, Laurberg P. Postpartum thyroid dysfunction in pregnant thyroid peroxidase antibodypositive women living in an area with mild to moderate deficiency: is iodine supplementation safe?. Journal of Clinical Endocrinology and Metabolism 2000;85(9):3191-8.

\section{Pedersen 1993 \{published data only\}}

Pedersen KM, Laurberg P, Iversen E, Knudsen PR, Gregersen HE, Rasmussen OS, et al. Amelioration of some pregnancyassociated variations in thyroid function by iodine supplementation. Journal of Clinical Endocrinology and Metabolism 1993;77:1078-83.

\section{Pharoah 1971 (C) \{published data only\}}

Connolly KJ, Pharoah PO, Hetzel BS. Fetal iodine deficiency and motor performance during childhood. Lancet 1979;2(8153):1149-51.

Pharoah P, Buttfield IH, Hetzel BS. Neurological damage to the fetus resulting from severe iodine deficiency during pregnancy. International Journal of Epidemiology 2012;41(3):589-92.

Pharoah PO, Buttfield IH, Hetzel BS. The effect of iodine prophylaxis on the incidence of endemic cretinism. Advances in Experimental Medicine and Biology 1972;30:201-21.

Pharoah PO, Connolly KJ, Ekins RP, Harding AG. Maternal thyroid hormone levels in pregnancy and the subsequent cognitive and motor performance of the children. Clinical Endocrinology 1984;21(3):265-70.

Pharoah PO, Ellis SM, Ekins RP, Williams ES. Maternal thyroid function, iodine deficiency and fetal development. Clinical Endocrinology 1976;5(2):159-66.

* Pharoah POD, Buttfield IH, Hetzel BS. Neurological damage to the fetus resulting from severe iodine deficiency during pregnancy. Lancet 1971;1:308-10.

Pharoah POD, Connolly KJ. A controlled trial of iodinated oil for the prevention of endemic cretinism: a long-term follow-up. International Journal of Epidemiology 1987;16:68-73.

Pharoah POD, Connolly KJ. Effects of maternal iodine supplementation during pregnancy. Archives of Disease in Childhood 1991;66:145-7.

\section{Silva 1981 \{published data only\}}

Silva JE, Silva S. Interrelationships among serum thyroxine, triiodothyronine, reverse triiodothyronine, and thyroidstimulating hormone in iodine-deficient pregnant women and their offspring: effects of iodine supplementation. Journal of Clinical Endocrinology and Metabolism 1981; Vol. 52, issue 4:671-7.

\section{Thilly 1978 \{published data only\}}

Moreno-Reyes R, Swennen B, Gillies J, Thilly CH. Oral iodized oil in the prevention of neonatal hypothyroidism. Annales d'Endocrinologie 1991;52:58.

* Thilly CH, Delange F, Lagasse R, Bourdoux P, Ramioul L, Berquist $\mathrm{H}$, et al. Fetal hypothyroidism and maternal thyroid status in severe endemic goiter. Journal of Clinical Endocrinology and Metabolism 1978;47:354-60.

Thilly CH, Lagasse R, Roger G, Bourdoux P, Ermans AM. Impaired fetal and postnatal development and high perinatal deathrate in a severe iodine deficient area. In: Thyroid research VIII. Proceedings of the Eighth International Thyroid Congress. Sydney, Australia: Oxford, UK: Pergamon, February 3-8, 1980:20-3.

Thilly CH, Roger G, Lagasse R, Tshibangu D, Vanderpas JB, Berquist $\mathrm{H}$, et al. Fetomaternal relationship, fetal hypothyroidism, and psychomotor retardation. In Role of Cassava in the etiology of endemic goitre and cretinism. International Development Research Centre. Ottawa, Canada, 1980:111-82.

Thilly CH, Swennen B, Moreno-Reyes R, Hindlet JY, Bourdoux P, Vanderpas JB. Maternal, fetal, and juvenile hypothyroidism, birth weight and infant mortality in the etiopathogenesis of the IDD spectra in Zaire and Malawi. In: Stanbury JB editor(s). The Damaged Brain of lodine Deficiency: Cognitive, Behavioral, Neuromotor and Educative Aspects. New York: Cognizant Communication Corporation, 1994:241-50.

Vanderpas J, Thilly $\mathrm{CH}$. Endemic neonatal, infantile and juvenile hypothyroidism in Ubangi, Northern Zaire: clinical consequences and prevention. In: Stanbury JB editor(s). The Damaged Brain of lodine Deficiency. New York: Cognizant Communication, 1994:209-24.

\section{Zhou 2015 \{published data only\}}

Zhou J. Pregnancy iodine and neurodevelopment in kids (PINK). Australian New Zealand Clinical Trials Register (www.anzctr.org.au) (accessed 21 May 2010).

Zhou SJ, Skeaff S, Ryan P, Doyle LW, Anderson PJ, Kornman L, et al. Effect of iodine supplementation in pregnancy on childhood development: results from a randomised controlled trial (RCT). Journal of Paediatrics and Child Health 2015; Vol. 51, issue Suppl 1:34.

* Zhou SJ, Skeaff SA, Ryan P, Doyle LW, Anderson PJ, Kornman $L$, et al. The effect of iodine supplementation in pregnancy on early childhood neurodevelopment and clinical outcomes: results of an aborted randomised placebo-controlled trial. Trials 2015;16:563. [PUBMED: 26654905]

\section{References to studies excluded from this review}

\section{Amiri 2016 \{published data only\}}

Amiri P, Hamzavi-Zarghani N, Nazeri P, Ghofranipour F, Karimi M, Amouzegar A, et al. Can an educational intervention improve iodine nutrition status in pregnant women? A randomized controlled trial. Thyroid: Official Journal of the American Thyroid Association 2016 Nov 3 [Epub ahead of print].

\section{Anees 2015 \{published data only\}}

Anees M, Anis RA, Yousaf S, Murtaza I, Sultan A, Arslan M, et al. Effect of maternal iodine supplementation on thyroid function and birth outcome in goiter endemic areas. Current Medical Research and Opinion 2015;1(4):667-74. 
Antonangeli 2002 \{published data only\}

Antonangeli L, Maccherini D, Cavaliere R, Di Giulio C, Reinhardt B, Pinchera A, et al. Comparison of two different doses of iodide in the prevention of gestational goiter in marginal iodine deficiency: a longitudinal study. European Journal of Endocrinology 2002;147(1):29-34.

\section{Azizi 2003 \{published data only\}}

Azizi F, Aminorroya A, Hedayati M, Rezvanian H, Amini M, Mirmiran P. Urinary iodine excretion in pregnant women residing in areas with adequate iodine intake. Public Health Nutrition 2003;6(1):95-8.

\section{Berbel 2009 \{published data only\}}

Berbel P, Mestre JL, Santamaria A, Palazon I, Franco A, Graells M, et al. Delayed neurobehavioral development in children born to pregnant women with mild hypothyroxinemia during the first month of gestation: the importance of early iodine supplementation. Thyroid 2009;19:511-9.

\section{Cao 1994 \{published data only\}}

Cao XY, Jiang XM, Kareem A, Dou ZH, Abdul Rakeman M, Zhang $\mathrm{ML}$, et al. lodination of irrigation water as a method of supplying iodine to a severely iodine-deficient population in Xinjiang, China. Lancet 1994;344(8915):107-10.

\section{Chaouki 1994 \{published data only\}}

Chaouki ML, Benmiloud M. Prevention of iodine deficiency disorders by oral administration of lipiodol during pregnancy. European Journal of Endocrinology 1994;130:547-51.

\section{Chiovato 1994 \{published data only\}}

Chiovato L, Aghini-Lombardi F, Vitti P, Ferretti G, Marcheschi M, Pinchera A. The impact of iodine deficiency on the neurological and cognitive development: the European experience. Stambury JB, editor(s). The Damaged Brain of lodine Deficiency: Neuromotor, Cognitive, Behavioral and Educative Aspects. New York: Cognizant Communication Company, 1994:293-8

\section{Connelly 2012 \{published data only\}}

Connelly KJ, Boston BA, Pearce EN, Sesser D, Snyder D, Braverman LE, et al. Congenital hypothyroidism caused by excess prenatal maternal iodine ingestion. Journal of Pediatrics 2012;161:760-2.

\section{Dean 1950 \{published data only\}}

Dean RFA. lodine as an aid to lactation. Lancet 1950;1:762-3.

\section{Delange 1996 \{published data only\}}

Delange F. Administration of iodized oil during pregnancy: a summary of the published evidence. Bulletin of the World Health Organization 1996;74(1):101-8.

\section{Delange 2004 \{published data only\}}

Delange F. Optimal iodine nutrition during pregnancy, lactation and the neonatal period. International Journal of Endocrinology and Metabolism 2004;2:1-12.

\section{Fierro-Benitez 1988 \{published data only\}}

Fierro-Benitez R, Cazar R, Stanbury JB, Rodriguez P, Garces F, Fierro-Renoy $F$, et al. Effects on school children of prophylaxis of mothers with iodized oil in an area of iodine deficiency. Journal of Endocrinological Investigation 1988;11(5):327-35.

Gruñeiro-Papendieck 2004 \{published data only\} Gruñeiro-Papendieck L, Chiesa A, Mendez V, Bengolea S, Prieto L. Neonatal TSH levels as an index of iodine sufficiency: differences related to time of screening sampling and methodology. Hormone Research in Paediatrics 2004;62(6):272-6

Hetzel 2002 \{published data only\}

Hetzel BS. Eliminating iodine deficiency disorders - the role of the International Council in the global partnership. Bulletin of the World Health Organanization 2002;80(5):413-7; 410-3.

\section{Isa 2000 \{published data only\}}

Isa ZM, Alias IZ, Kadir KA, Ali O. Effect of iodized oil supplementation on thyroid hormone levels and mental performance among Orang Asli schoolchildren and pregnant mothers in an endemic goitre area in Peninsular Malaysia. Asia Pacific Journal of Clinical Nutrition 2000;9(4):274-81.

\section{Joshi 2011 \{published data only\}}

Joshi A, Pokhrel T, Bastola SP, Banjara R, Joshi AB. lodine supplementation in pregnancy and its effects on perinatal outcome. Nepal Medical College Journal 2011;13(2):128-30.

\section{Kamiński 2003 \{published data only\}}

Kamiński M, Drewniak W, Szymański W, Junik R, Kamińska A. Urinary iodine excretion and thyroid function in pregnant women of Bydgoszcz District prior to and after the introduction of iodized salt. Ginekologia Polska 2003;74(10):1126-9.

Klett 1999 \{published data only\}

Klett M, Ohlig M, Manz F, Tröger J, Heinrich U. Effect of iodine supply on neonatal thyroid volume and TSH. Acta Paediatrica. Supplement 1999;88(432):18-20.

\section{Kurtoglu 2004 \{published data only\}}

Kurtoglu S, Akcakus M, Kocaoglu C, Gunes T, Budak N, Atabek ME, et al. lodine status remains critical in mother and infant in Central Anatolia (Kayseri) of Turkey. European Journal of Nutrition 2004;43(5):297-303.

\section{McDonnell 2003 \{published data only\}}

McDonnell CM, Harris M, Zacharin MR. lodine deficiency and goitre in schoolchildren in Melbourne. Medical Journal of Australia 2003;178(4):159-62.

\section{Mohammed 2015 \{published data only\}}

Mohammed H, Marquis G, Aboud F, Bougma K, Samuel A. A cluster RCT evaluating the effect of iodized salt on infant development in amhara region of Ethiopia. FASEB Journal 2015;29(1 Suppl):LB264.

\section{Moleti 2008 \{published data only\}}

Moleti M, Lo Presti VP, Campolo MC, Mattina F, Galletti M, Mandolfino $\mathrm{M}$, et al. lodine prophylaxis using iodized salt and 
risk of maternal thyroid failure in conditions of mild iodine deficiency. Journal of Clinical Endocrinology and Metabolism 2008;93(7):2616-21.

\section{Morreale de Escobar 1993 \{published data only\}}

Morreale de Escobar G, Obregón MJ, Calvo R, Escobar del Rey F. Effects of iodine deficiency on thyroid hormone metabolism and the brain in fetal rats: the role of the maternal transfer of thyroxin. American Journal of Clinical Nutrition 1993;57(2 Suppl):280S-285S.

\section{Murcia 2011 \{published data only\}}

Murcia M, Rebagliato M, Iñiguez C, Lopez-Espinosa MJ, Estarlich M, Plaza B, et al. Effect of iodine supplementation during pregnancy on infant neurodevelopment at 1 year of age. American Journal of Epidemiology 2011;173(7):804-12.

\section{Nohr 1993 \{published data only\}}

Nøhr SB, Laurberg P, Børlum KG, Pedersen KM, Johannesen PL, Damm $P$, et al. lodine deficiency in pregnancy in Denmark. Regional variations and frequency of individual iodine supplementation. Acta Obstetricia et Gynecologica Scandinavica 1993;72(5):350-3.

\section{O'Donnell 2002 \{published data only\}}

O'Donnell KJ, Rakeman MA, Zhi-Hong D, Xue-Yi C, Mei ZY, DeLong N, et al. Effects of iodine supplementation during pregnancy on child growth and development at school age. Developmental Medicine \& Child Neurology 2002;44(2):76-81.

\section{Oltarzewski 2003 \{published data only\}}

Oltarzewski M, Szymborski J. Neonatal hypothyroid screening in monitoring of iodine deficiency and iodine supplementation in Poland. Journal of Endocrinological Investigation 2003;2:27-31.

\section{Qian 2005 \{published data only\}}

Qian M, Wang D, Watkins WE, Gebski V, Yan YQ, Li M, et al. The effects of iodine on intelligence in children: a meta-analysis of studies conducted in China. Asia Pacific Journal of Clinical Nutrition 2005;14(1):32-42.

\section{Rebagliato 2013 \{published data only\}}

Rebagliato M, Murcia M, Alvarez-Pedrerol M, Espada M, Fernandez-Somoano A, Lertxundi N, et al. lodine supplementation during pregnancy and infant neuropsychological development: INMA mother and child cohort study. American Journal of Epidemiology 2013;177(9):944-53.

\section{Reinhardt 1998 \{published data only\}}

Reinhardt W, Kohl S, Hollmann D, Klapp G, Benker G, Reinwein $D$, et al. Efficacy and safety of iodine in the postpartum period in an area of mild iodine deficiency. European Journal of Medical Research 1998;3(4):203-10.

\section{Romano 1991 \{published data only\}}

Romano R, Jannini EA, Pepe M, Grimaldi A, Olivieri M, Spennati $\mathrm{P}$, et al. The effects of iodoprophylaxis on thyroid size during pregnancy. American Journal of Obstetrics and Gynecology 1991;164:482-5.

\section{Saadat 2004 \{published data only\}}

Saadat N, Robabeh SOS, Fereidoun A. Impact of iodized oil injection during pregnancy on thyroid function test of offsprings. Medical Journal of the Islamic Republic of Iran 2004;17(4):1382.

\section{Sack 2003 \{published data only\}}

Sack J, Goldstein A, Charpak N, Rozin A, Ruiz-Pelaez JG, Figueroa de Calume $Z$, et al. Postpartum maternal hyperthyrotropinemia in an area in which iodine supplementation is required. Thyroid 2003;13(10):959-64.

\section{Salarkia 2004 \{published data only\}}

Salarkia N, Mirmiran P, Azizi F. Timing of the effect of iodine supplementation on intelligence quotients of schoolchildren. International Journal of Endocrinology and Metabolism 2004;2004(2):95-102.

\section{Santiago 2013 \{published data only\}}

Santiago P, Velasco I, Muela JA, Sánchez B, Martínez J, Rodriguez $A$, et al. Infant neurocognitive development is independent of the use of iodised salt or iodine supplements given during pregnancy. British Journal of Nutrition 2013;110(5):831-40.

\section{Smyth 1997 \{published data only\}}

Smyth PP, Hetherton AM, Smith DF, Radcliff M, O'Herlihy C. Maternal iodine status and thyroid volume during pregnancy: correlation with neonatal iodine intake. Journal of Clinical Endocrinology and Metabolism 1997;82(9):2840-3.

\section{Smyth 2005 \{published data only\}}

Smyth PP, Wijeyaratne CN, Kaluarachi WN, Smith DF, Premawardhana LD, Parkes AB, et al. Sequential studies on thyroid antibodies during pregnancy. Thyroid 2005;15(5):474-7.

Troshina 2010 \{published data only\}

Troshina EA, Abdulkhabirova FM, Sekinaeva AV, II'in AV, Arbuzova MI, Petrova VN, et al. Prevention of iodine deficiency diseases in pregnant and lactating women. Klinicheskaia Meditsina 2010;88(5):26-31.

Urban 2000 \{published data only\}

Urban G, Wnek M, Bazowska G. lodine supplementation during pregnancy and its influence on the newborn. Ginekologia Polska 2000;71(8):690-4.

\section{Velasco 2009 \{published data only\}}

Velasco I, Carreira M, Santiago P, Muela JA, Garcia-Fuentes E, Sanchez-Munoz B, et al. Effect of iodine prophylaxis during pregnancy on neurocognitive development of children during the first two years of life. Journal of Clinical Endocrinology and Metabolism 2009;94(3):234-41.

\section{Vermiglio 2004 \{published data only\}}

Vermiglio F, Lo Presti VP, Moleti M, Sidoti M, Tortorella G, Scaffidi G, et al. Attention deficit and hyperactivity disorders in the offspring of mothers exposed to mild-moderate iodine deficiency: a possible novel iodine deficiency disorder in developed countries. Journal of Clinical Endocrinology and Metabolism 2004;89(12):6054-60. 
Versloot 1997 \{published data only\}

Versloot PM, Schröder-van der Elst JP, Van der Heide D, Boogerd L. Effects of marginal iodine deficiency during pregnancy: iodide uptake by the maternal and fetal thyroid. American Journal of Physiology 1997;273(6 Pt 1):E1121-6.

Vitnerova 2000 \{published data only\}

Vitnerova N, Miskova I, Kotesovec F. Treatment of iodine deficiency in pregnant women in the Teplice District. Casopís Lékaru Ceských 2000;139(17):533-6.

\section{Vitti 1992 \{published data only\}}

Vitti P, Aghini-Lombardi F, Antonangeli L, Rago T, Chiovato L, Pinchera $\mathrm{A}$, et al. Mild iodine deficiency in fetal/neonatal life and neuropsychological performances. Acta Medica Austriaca 1992;19 Suppl 1:57-9.

Yan 2005 \{published data only\}

Yan YQ, Chen ZP, Yang XM, Liu H, Zhang JX, Zhong W, et al. Attention to the hiding iodine deficiency in pregnant and lactating women after universal salt iodization: a multicommunity study in China. Journal of Endocrinological Investigation 2005;28(6):547-53.

Zhu 1995 \{published data only\}

Zhu Q, Huang Z, Lei DWY, Liu L, Zhang H. The effect of iodine deficiency in pregnant women on the physical development of their infants. Acta Nutrimenta Sinica 1995;17(4):391-5.

\section{Zimmermann 2005 \{published data only\}}

Zimmermann MB, Aeberli I, Torresani T, Bürgi H. Increasing the iodine concentration in the Swiss iodized salt program markedly improved iodine status in pregnant women and children: a 5-y prospective national study. American Journal of Clinical Nutrition 2005;82(2):388-92.

\section{References to studies awaiting assessment}

\section{Belykh 2014 \{published data only\}}

Belykh N, Mamenko M, Kovalenko N, Minyaylo N, Plugatarenko N. Effectiveness of iodine prophylaxis in pregnant, lactating mothers and infants in mild iodine deficiency region. European Thyroid Journal 2014;3(Suppl 1):117-8, Abstract no: P29.

\section{Hronek 2001 \{published data only\}}

Hronek M, Miturova K, Kudlackova Z, Beranova E. Importance of iodine intake during pregnancy - iodine supplementation and its risks. Ceská Gynekologie 2001;66(3):199-202.

\section{References to ongoing studies}

\section{Caron 2006 \{published data only\}}

NCT00379535. Phase III : preventing lack of iodine during pregnancy. Effect of supplying woman with potassium iodine to the neuro-cognitive children development until two years. clinicaltrials.gov/show/NCT00379535 Date first received: 21 September 2006

\section{Nyström 2015a \{published data only\}}

NCT02378246. lodine status in Swedish pregnant women effect of iodine supplementation in the thyroid function of mother and infant. clinicaltrials.gov/show/NCT02378246 Date first received: 19 January 2015.

\section{Nyström 2015b \{published data only\}}

NCT02378233. lodine status in Swedish lactating women - effect of iodine supplementation in the thyroid function of mother and infant. clinicaltrials.gov/show/NCT02378233 Date first received: 19 January 2015.

Teng 2013 \{published data only\}

ChiCTR-TRC-13003805. Screening and intervention for iodine deficiency, iron deficiency and subclinical thyroid insufficiency in women planning pregnancy and in early pregnant women. chictr.org/en/ChiCTR-TRC-13003805 Date first received: 19 August 2013.

Torres 2010 \{published data only\}

* NCT01301768. Group education to improve the iodine nutrition in pregnancy: cluster randomized trial. clinicaltrials.gov/show/NCT01301768 Date first received: 31 May 2010.

Prieto G, Torres MT, Frances L, Falguera G, Vila L, Manresa JM, et al. Nutritional status of iodine in pregnant women in Catalonia (Spain): Study on hygiene-dietetic habits and iodine in urine. BMC Pregnancy and Childbirth 2011;11:17.

\section{Additional references}

\section{Aburto 2014}

Aburto N, Abudou M, Candeias V, Wu T. Effect and safety of salt iodization to prevent iodine deficiency disorders: a systematic review with meta-analyses. http://apps.who.int/iris/ bitstream/10665/148175/1/9789241508285_eng.pdf (accessed 23 February 2017). Geneva: World Health Organization, 2014:1-151.

\section{Andersson 2012}

Andersson M, Karumbunathan V, Zimmermann MB. Global iodine status in 2011 and trends over the past decade. Journal of Nutrition 2012;142(4):744-50.

\section{Angermayr 2004}

Angermayr L, Clar C. lodine supplementation for preventing iodine deficiency disorders in children. Cochrane Database of Systematic Reviews 2004, Issue 2. [DOI: 10.1002/14651858.CD003819.pub2]

\section{ATA 2006}

Public Health Committee of the American Thyroid Association (ATA). lodine supplementation for pregnancy and lactation United States and Canada: recommendations of the American Thyroid Association. Thyroid 2006;16(10):949-51.

\section{Azizi 2009}

Azizi F, Smyth P. Breastfeeding and maternal and infant iodine nutrition. Clinical Endocrinology 2009;70(5):803-9. 


\section{Bougma 2013}

Bougma K, Aboud FE, Harding KB, Marquis GS. lodine and mental development of children 5 years old and under: a systematic review and meta-analysis. Nutrients 2013;5(4):1384-416. [DOI: 10.3390/nu5041384]

\section{Bruun 1981}

Brunn J, Block U, Ruf G, Bos I, Kunze WP, Scriba PC. Volumetric analysis of thyroid lobes by real-time ultrasound [Volume-trie der schilddrusenlappen mittels real-time sonographie]. Deutsche Medizinische Wochenschrift (1946) 1981;106(41):1338-40.

\section{Deeks 2011}

Deeks JJ, Higgins JPT, Altman DG (editors). Chapter 9: Analysing data and undertaking meta-analyses. In: Higgins JPT, Green $\mathrm{S}$ (editors). Cochrane Handbook for Systematic Reviews of Interventions Version 5.1.0 (updated March 2011). The Cochrane Collaboration, 2011. Available from handbook.cochrane.org.

\section{Delange 1998}

Delange F. Screening for congenital hypothyroidism used as an indicator of the degree of iodine deficiency and of its control. Thyroid 1998;8(12):1185-92.

\section{Dunn 1993}

Dunn JT. lodine supplementation and the prevention of cretinism. Annals of New York Academy of Sciences 1993;678:158-68.

\section{Dunn 2001}

Dunn JT, Delange F. Damaged reproduction: the most important consequence of iodine deficiency. Journal of Clinical Endocrinology and Metabolism 2001;86(6):2360-3.

\section{EFSA 2014}

European Food Safety Authority (EFSA). Scientific opinion on dietary reference values for iodine. www.efsa.europa.eu/en/ efsajournal/doc/3660.pdf (accessed 17 October 2014).

\section{Farebrother 2015}

Farebrother J, Naude CE, Nicol L, Sang Z, Yang Z, Andersson M, et al. Systematic review of the effects of iodised salt and iodine supplements on prenatal and postnatal growth: study protocol. BMJ Open 2015;5:e007238.

\section{Glinoer 1997}

Glinoer D. The regulation of thyroid function in pregnancy: pathways of endocrine adaptation from physiology to pathology. Endocrine Reviews 1997;18(3):404-33.

\section{Glinoer 2000}

Glinoer D, Delange F. The potential repercussions of maternal, fetal, and neonatal hypothyroxinemia on the progeny. Thyroid 2000;10(10):871-7.

\section{Glinoer 2007}

Glinoer D. The importance of iodine nutrition during pregnancy. Public Health Nutrition 2007;10(12A):1542-6.

\section{Gordon 2009}

Gordon RC, Rose MC, Skeaff SA, Gray AR, Morgan KM, Ruffman T. lodine supplementation improves cognition in mildly iodinedeficient children. American Journal of Clinical Nutrition 2009;90(5):1264-71.

\section{Haider 2015}

Haider BA, Bhutta ZA. Multiple-micronutrient supplementation for women during pregnancy. Cochrane Database of Systematic Reviews 2015, Issue 11. [DOI: 10.1002/14651858.CD004905.pub4]

\section{Hess 2002}

Hess SY, Zimmermann MB, Adou P, Torresani T, Hurrell RF. Treatment of iron deficiency in goitrous children improves the efficacy of iodized salt in Côte d'Ivoire. American Journal of Clinical Nutrition 2002;75(4):743-8.

\section{Hetzel 1983}

Hetzel BS. lodine deficiency disorders (IDD) and their eradication. Lancet 1983;2(8359):1126-9.

\section{Higgins 2003}

Higgins JPT, Thompson SG, Deeks JJ, Altman DG. Measuring inconsistency in meta-analyses. BMJ 2003;327:557-60.

\section{Higgins 2011}

Higgins JPT, Green S, editors. Cochrane Handbook for Systematic Reviews of Interventions Version 5.1.0 [updated March 2011]. The Cochrane Collaboration, 2011. Available from www.cochrane-handbook.org.

\section{Higgins 2011a}

Higgins JPT, Altman DG, Sterne JAC (editors). Chapter 8: Assessing risk of bias in included studies. In: Higgins JPT, Green $\mathrm{S}$ (editors). Cochrane Handbook for Systematic Reviews of Interventions Version 5.1.0 (updated March 2011). The Cochrane Collaboration, 2011. Available from handbook.cochrane.org.

\section{Higgins 2011b}

Higgins JPT, Deeks JJ, Altman DG (editors). Chapter 16: Special topics in statistics. In: Higgins JPT, Green S (editors), Cochrane Handbook for Systematic Reviews of Interventions Version 5.1.0 (updated March 2011). The Cochrane Collaboration, 2011. Available from handbook.cochrane.org.

\section{Ibrahim 2006}

Ibrahim M, Sinn J, McGuire W. lodine supplementation for the prevention of mortality and adverse neurodevelopmental outcomes in preterm infants. Cochrane Database of Systematic Reviews 2006, Issue 2. [DOI: 10.1002/14651858.CD005253.pub2]

\section{IOM 2001}

Institute of Medicine (IOM). Dietary reference intakes for vitamin $\mathrm{A}$, vitamin $\mathrm{K}$, arsenic, boron, chromium, copper, iodine, iron, manganese, molybdenum, nickel, silicon, vanadium, and zinc. Washington, D.C.: National Academy Press, 2001. 


\section{Jameson 2005}

Jameson JL, Weetman AP. Disorders of the thyroid gland. In: Kasper DL, Harrison TR editor(s). Harrison's Principles of Internal Medicine. 16th Edition. New York: McGraw-Hill, 2005.

\section{Land 2013}

Land MA, Christoforou A, Downs S, Webster J, Billot L, $\mathrm{Li} \mathrm{M}$, et al. lodine fortification of foods and condiments, other than salt, for preventing iodine deficiency disorders. Cochrane Database of Systematic Reviews 2013, Issue 9. [DOI: 10.1002/14651858.CD010734]

\section{Laurberg 2007}

Laurberg P, Andersen S, Bjarnadóttir RI, Carlé A, Hreidarsson AB, Knudsen $\mathrm{N}$, et al. Evaluating iodine deficiency in pregnant women and young infants - complex physiology with a risk of misinterpretation. Public Health Nutrition 2007;10(12A):1547-52.

\section{Leung 2009}

Leung AM, Pearce EN, Braverman LE. lodine content of prenatal multivitamins in the United States. New England Journal of Medicine 2009;360(9):939-40.

\section{Leung 2011}

Leung AM, Pearce EN, Braverman LE. Iodine nutrition in pregnancy and lactation. Endocrinology and Metabolism Clinics of North America 2011;40(4):765-77.

\section{Melse-Boonstra 2010}

Melse-Boonstra A, Jaiswal N. Iodine deficiency in pregnancy, infancy and childhood and its consequences for brain development. Clinical Endocrinology and Metabolism 2010;24(1):29-38.

\section{Moher 2009}

Moher D, Liberati A, Tetzlaff J, Altman DG, The PRISMA Group. Preferred Reporting Items for Systematic Reviews and Meta-Analyses: The PRISMA Statement. PLoS Medicine 2009;6(7):e1000097. [DOI: 10.1371/journal.pmed1000097]

\section{NHMRC 2010}

Australian Government National Health and Medical Research Council (NHMRC). NHMRC Public Statement: lodine Supplementation for Pregnant and Breastfeeding Women. www.nhmrc.gov.au/_files_nhmrc/publications/attachments/ new45_statement.pdf (accessed 17 October 2014).

\section{Pezzino 1981}

Pezzino V, Filetti S, Belfiore A, Proto S, Donzelli G, Vigneri R. Serum thyroglobulin levels in the newborn. Journal of Clinical Endocrinology and Metabolism 1981; Vol. 52, issue 2:364-6.

\section{Pharoah 1971}

Pharoah PO, Buttfield IH, Hetzel BS. Neurological damage to the fetus resulting from severe iodine deficiency during pregnancy. Lancet 1971;1(7694):308-10.

\section{Prado 2014}

Prado EL, Dewey KG. Nutrition and brain development in early life. Nutrition Reviews 2014;72(4):267-84. [DOI: doi:10.1111/ nure.12102]

\section{Pretell 1972}

Pretell EA, Torres T, Zenteno V, Cornejo M. Prophylaxis of endemic goiter with iodized oil in rural Peru. Advances in Experimental Medicine and Biology 1972;30:246-65.

\section{RevMan 2014 [Computer program]}

The Nordic Cochrane Centre, The Cochrane Collaboration. Review Manager 5 (RevMan 5). Version 5.3. Copenhagen: The Nordic Cochrane Centre, The Cochrane Collaboration, 2014.

\section{Rohner 2014}

Rohner F, Zimmermann M, Jooste P, Pandav C, Caldwell K, Raghavan R, et al. Biomarkers of nutrition for development iodine review. Journal of Nutrition 2014;144(8):1322S-42S.

\section{SCF 2006}

Scientific Committee on Food (SCF). Tolerable upper intake levels for vitamins and minerals. www.efsa.europa.eu/en/ ndatopics/docs/ndatolerableuil.pdf (accessed 17 October 2014).

\section{Stagnaro-Green 2012}

Stagnaro-Green A. Approach to the patient with postpartum thyroiditis. Journal of Clinical Endocrinology and Metabolism 2012;97(2):334-42.

\section{Stinca 2016}

Stinca S, Andersson M, Weibel S, Aeberli-Herter I, Fingerhut R, Gowachirapant S, et al. Dried blood spot thyroglobulin as a biomarker of iodine status in pregnant women. Journal of Clinical Endocrinology and Metabolism 2016;Epub ahead of print:jc20162829.

\section{Suchdev 2015}

Suchdev PS, Peña-Rosas JP, De-Regil LM. Multiple micronutrient powders for home (point-of-use) fortification of foods in pregnant women. Cochrane Database of Systematic Reviews 2015, Issue 6. [DOI: 10.1002/14651858.CD011158.pub2]

\section{Sullivan 2008}

Sullivan KM. The interaction of agricultural pesticides and marginal iodine nutrition status as a cause of autism spectrum disorders. Environmental Health Perspectives 2008; Vol. 116, issue 4:A155.

\section{Taylor 2013}

Taylor PN, Okosieme OE, Dayan CM, Lazarus JH. Therapy of endocrine disease: impact of iodine supplementation in mildto-moderate iodine deficiency: systematic review and metaanalysis. European Journal of Endocrinology 2013;170(1):R1-15.

\section{UNICEF 2008}

United Nations Children's Fund. Sustainable elimination of iodine deficiency. www.unicef.org/iran/Sustainable Elimination_of_lodine_Deficiency_053008(1).pdf (accessed 17 October 2014).

\section{UNICEF/WHO 1994}

United Nations Children's Fund - World Health Organization Joint Committee on Health Policy. World Summit for Children - Mid-Decade Goal: 
lodine Deficiency Disorders (IDD). www.ceecis.org/ iodine/01_global/01_pl/01_01_1994_summit.pdf (accessed 17 October 2014).

\section{Untoro 2007}

Untoro J, Mangasaryan N, de Benoist B, Darnton-Hill I. Reaching optimal iodine nutrition in pregnant and lactating women and young children: programmatic recommendations. Public Health Nutrition 2007;10(12A):1527-9.

\section{WHA 2012}

World Health Assembly. Resolution WHA65.6. Comprehensive implementation plan on maternal, infant and young child nutrition. Sixty-fifth World Health Assembly, Geneva, 21-26 May 2012. Resolutions and decisions, annexes. Vol. WHA65/2012/ REC/1, Geneva: World Health Organization, 2012:55-68.

\section{WHO 2013}

World Health Organization. Urinary iodine concentrations for determining iodine status deficiency in populations. www.who.int/nutrition/vmnis/indicators/urinaryiodine (accessed 18 October 2014).

\section{WHO 2014}

WHO. Guideline: fortification of food-grade salt with iodine for the prevention and control of iodine deficiency disorders. Geneva: World Health Organization, 2014.

\section{WHO/UNICEF 2007}

World Health Organization and United Nations Children's Fund. Reaching optimal iodine nutrition in pregnant and lactating women and young children. www.who.int/nutrition/ publications/WHOStatement__IDD_pregnancy.pdf (accessed 17 October 2014).

\section{WHO/UNICEF/ICCIDD 2007}

World Health Organization, United Nations Children's Fund, and International Council for Control of Iodine Deficiency Disorders. Assessment of iodine deficiency disorders and monitoring their elimination. World Health Organization, 2007.

\section{Williams 2008}

Williams GR. Neurodevelopmental and neurophysiological actions of thyroid hormone. Journal of Neuroendocrinology 2008;20(6):784-94.

\section{Wong 2011}

Wong EM, Sullivan KM, Perrine CG, Rogers LM, Peña-Rosas JP. Comparison of median urinary iodine concentration as an indicator of iodine status among pregnant women, school-age children, and nonpregnant women. Food and Nutrition Bulletin 2011;32(3):206-12.

\section{Zhou 2013}

Zhou SJ, Anderson AJ, Gibson RA, Makrides M. Effect of iodine supplementation in pregnancy on child development and other clinical outcomes: a systematic review of randomized controlled trials. American Journal of Clinical Nutrition 2013;98(5):1241-54. [DOI: 10.3945/ajcn.113.065854]

\section{Zimmermann 2000}

Zimmermann M, Adou P, Torresani T, Zeder C, Hurrell R. Iron supplementation in goitrous, iron-deficient children improves their response to oral iodized oil. European Journal of Endocrinology 2000;142(3):217-23.

\section{Zimmermann 2002}

Zimmermann MB, Köhrle J. The impact of iron and selenium deficiencies on iodine and thyroid metabolism: biochemistry and relevance to public health. Thyroid 2002;12(10):867-78.

\section{Zimmermann 2004}

Zimmermann MB, Hess SY, Molinari L, de Benoist B, Delange F, Braverman LE, et al. New reference values for thyroid volume by ultrasound in iodine-sufficient schoolchildren: a World Health Organization/Nutrition for Health and Development lodine Deficiency Study Group Report. American Journal of Clinical Nutrition 2004;79(2):231-7.

\section{Zimmermann 2007}

Zimmermann MB. The impact of iodised salt or iodine supplements on iodine status during pregnancy, lactation and infancy. Public Health Nutrition 2007;10(12A):1584-95.

\section{Zimmermann 2008}

Zimmermann MB. Methods to assess iron and iodine status. British Journal of Nutrition 2008;99(Suppl 3):S2-9.

\section{Zimmermann 2009}

Zimmermann MB. lodine deficiency in pregnancy and the effects of maternal iodine supplementation on the offspring: a review. American Journal of Clinical Nutrition 2009;89(2):668S-72S.

\section{Zimmermann 2012a}

Zimmermann MB. The effects of iodine deficiency in pregnancy and infancy. Paediatric and Perinatal Epidemiology 2012;26(Suppl 1):108-17.

\section{Zimmermann 2012b}

Zimmermann MB, Andersson M. Assessment of iodine nutrition in populations: past, present, and future. Nutrition Reviews 2012;70(10):553-70.

\section{References to other published versions of this review De-Regil 2015}

De-Regil LM, Harding KB, Peña-Rosas JP, Webster AC. lodine supplementation for women during the preconception, pregnancy and postpartum period. Cochrane Database of Systematic Reviews 2015, Issue 6. [DOI: 10.1002/14651858.CD011761]

\section{Mahomed 2006}

Mahomed K, Gülmezoglu AM. Maternal iodine supplements in areas of deficiency. Cochrane Database of Systematic Reviews 2006, Issue 3. [DOI: 10.1002/14651858.CD000135.pub2]

* Indicates the major publication for the study 


\section{CHARACTERISTICS OF STUDIES}

\section{Characteristics of included studies [ordered by study ID]}

Bouhouch 2014 (C)

Methods

- Study design: double-blind cluster-randomized, placebo-controlled trial with 2 arms

- Unit of allocation: clinic (cluster)

- Time period of recruitment and data collection: Morocco: recruitment went from 25 February-10 August 2010 and data collection went from 25 February 2010-6 August 2011

Participants

Interventions
- Description: 239 healthy postpartum women-infant pairs at their first vaccination visit

- Location/setting: the provincial hospital of Amizmiz, the Atlas Mountains of southern Morocco

- How participants were recruited and selected: women attending the clinic (cluster) on the same day were enrolled into the same group. Randomization was done by vaccination clinic dates

- Inclusion criteria: with no history of major medical illnesses or thyroid dysfunction, taking no longterm medications; no history of iodine supplementation during pregnancy or lactation; infant born full term; infant birthweight 2500 g or greater; breastfeeding mother; and infant 8 weeks of age or younger

- Exclusion criteria:

- Sample size: 239

- Age: at baseline, the median age was 26 years (IQR 22-32)

- Socioeconomic status: most women were reported to be illiterate

- Nutritional status: at baseline, median maternal weight was $63 \mathrm{~kg}$ (56-69), height $155 \mathrm{~cm}$ (152-161), and BMI $25.6 \mathrm{~kg} / \mathrm{m} 2(23.1-28.2)$

- Baseline iodine status of participants/area: national median UIC in children is $69 \mu \mathrm{g} / \mathrm{L}$

- Baseline coverage of iodized salt: national mandatory salt iodization but poor compliance by salt industry and lack of enforcement. No baseline data available for study but participants brought in salt sample at 3 or 6 month visit - 68 samples available: 4 out of $68(6 \%)$ were adequately iodized, 35 out of $68(51 \%)$ were inadequately iodized and 29 out of $68(43 \%)$ had no measurable iodine. (Adequate salt iodization: at least $15 \mathrm{ppm}$ )

- Breastfeeding practices (if applicable): a total of $95.8 \%(228 / 238)$ of the women were exclusively breastfeeding at baseline and the rate reduced to $66.3 \%$ at 6 months postpartum

Experimental intervention: women received one dose of $400 \mathrm{mg}$ of oral iodine as 2 soft-gel capsules of iodized poppyseed oil (each containing $200 \mathrm{mg}$ of iodine; Lipiodol ${ }^{\circledR}$, Guerbet, Paris, France) and the infant received placebo. This was considered the "indirect infant supplementation" group.

- Total number randomised: $\mathrm{n}=121$

- Timing: first visit (infant immunization visit, before 8 weeks of age or younger), and at 9 months of age

- Form: 2 soft-gel capsules for women, for oral intake

- Frequency and duration: once

- lodine compound: potassium iodate

- lodine dose: $400 \mathrm{mg}$ elemental iodine in a single dose

- Other nutrients: none

- Adherence: not specified

Control/comparison intervention: placebo

- Total number randomised: $\mathrm{n}=118$

- Description: women received placebo (2 oral placebo capsules) and the infant received about $100 \mathrm{mg}$ of oral iodine, which was given as half of the contents of a soft-gel capsule of iodized poppyseed oil (containing $200 \mathrm{mg}$ of iodine; Lipiodol ${ }^{\circledR}$, Guerbet, Paris, France). The supplements were provided at baseline to the women and after 9 months for the infants only. This was considered the "direct infant supplementation" group

- Adherence: not specified 
Bouhouch 2014 (C) (Continued)

Co-intervention(s): none reported

Outcomes $\quad$ - Postpartum: maternal UIC, breast milk iodine concentration, maternal TSH and T4, weight and height, subclinical hypothyroidism, overt hypothyroidism, hypothyroxinaemia

- Infant/child: infant UIC, infant TSH and T4, infant growth

Notes

- Because 1 study arm (the control group) received an infant intervention (direct iodine supplementation to the infant), we did not include any infant data from this trial

- 241 mother-infant pairs were recruited. 2 were excluded before randomisation because the infants were older than 8 weeks at enrolment into the study

- The analysis in this report adjusts for clustering, therefore no additional adjustments were required for this review

- Source of funding: ETH Zurich, Switzerland and the Medicor Foundation, Vaduz, Lichtenstein. Guerbet (Paris, France) provided the iodized oil supplements and Burgerstein (Rapperswil, Switzerland) provided the placebo capsules free of charge

\section{Risk of bias}

\section{Bias Authors' judgement Support for judgement}

Random sequence genera- Low risk tion (selection bias)
Randomly assigned (using block randomisation) numbers to vaccination clinic dates and mother-infant pairs attending the clinic on the same day were enrolled into the same group. The randomisation was done by computer-generated random numbers (study author communication)

\begin{tabular}{|c|c|c|}
\hline $\begin{array}{l}\text { Allocation concealment } \\
\text { (selection bias) }\end{array}$ & Low risk & Randomization at cluster level is unlikely to produce selection bias \\
\hline $\begin{array}{l}\text { Blinding of participants } \\
\text { and personnel (perfor- } \\
\text { mance bias) } \\
\text { All outcomes }\end{array}$ & Low risk & $\begin{array}{l}\text { "Randomization was masked so that the participants, the investigators, and } \\
\text { the sponsor did not know which supplement was administered to which } \\
\text { groups." }\end{array}$ \\
\hline $\begin{array}{l}\text { Blinding of outcome as- } \\
\text { sessment (detection bias) } \\
\text { All outcomes }\end{array}$ & Unclear risk & Insufficient information reported to determine \\
\hline $\begin{array}{l}\text { Incomplete outcome data } \\
\text { (attrition bias) } \\
\text { All outcomes }\end{array}$ & High risk & $\begin{array}{l}\text { Loss to follow-up greater than } 20 \% \text { (9-month outcome data for } 75 \%(91 / 121) \text { in } \\
\text { iodine group and } 70 \%(83 / 118) \text { in the control group) }\end{array}$ \\
\hline $\begin{array}{l}\text { Selective reporting (re- } \\
\text { porting bias) }\end{array}$ & High risk & $\begin{array}{l}\text { Primary outcomes described in the report are different from those in the clini- } \\
\text { cal trial registration }\end{array}$ \\
\hline Other bias & Unclear risk & The study appears to be free of other sources of bias \\
\hline
\end{tabular}

Brucker-Davis 2013

$\begin{array}{ll}\text { Methods } & \text { Study design: randomised controlled trial with } 2 \text { arms } \\ \text { - Unit of allocation: individual } \\ \text { - Time period of recruitment and data collection: recruitment took place from July 2007-July 2008 }\end{array}$

Participants

- Description: pregnant women in their first trimester

- Location/setting: Nice, France

- How participants were recruited and selected: women presenting at their first obstetrical visit 
- Inclusion criteria: no personal history of thyroid disease, seen before 12 weeks of amenorrhoea, singleton pregnancy, normal thyroid tests on a systematic screening: FT4 higher than $12 \mathrm{pmol} / \mathrm{L}$ (10th percentile for first trimester in this population), TSH lower than $2.5 \mathrm{mIU} / \mathrm{L}$, and TPO-ab below $100 \mathrm{UI} /$ $\mathrm{mL}$

- Exclusion criteria: iodine supplementation before inclusion in this study and UIE $\geq 400 \mu \mathrm{g} / \mathrm{L}$

- Sample size: 111

- Age: control: 27 (18-39) years; treated population: 28 (21-37) years

- Socioeconomic status: not specified

- Nutritional status: BMI control: $22.3(16.0-39.5) \mathrm{kg} / \mathrm{m}^{2}$; BMI treated population: 21.9 (17.9-30.8) kg/ $\mathrm{m}^{2}$

- Baseline iodine status of participants/area: area of mild iodine deficiency. Baseline UIE control: 103 (14-355) $\mu \mathrm{g} / \mathrm{L}$; treated population: 111 (28-399) $\mu \mathrm{g} / \mathrm{L}$

- Baseline coverage of iodized salt: $84 \%$ of women reported to consume iodized salt, no significant differences between groups

- Breastfeeding practices: not specified

- Other important information about participants or setting: none

Interventions

Experimental intervention: daily iodine-containing multiple-micronutrient supplements

- Total number randomised: $\mathrm{n}=53$

- Timing:day of enrolment (in first trimester) until 3-months postpartum

- Form: tablet

- Frequency and duration: daily

- Iodine compound: Oligobs Maxiode ${ }^{\circledR}, 150 \mu \mathrm{g}$ of iodine, Laboratoire CCD, Paris, France

- lodine dose: $150 \mu \mathrm{g} / \mathrm{d}$

- Other nutrients: $1.8 \mathrm{mg}$ vitamin $\mathrm{B} 1,1.6 \mathrm{mg}$ vitamin $\mathrm{B}_{2}, 2 \mathrm{mg}$ vitamin $\mathrm{B}_{6}, 100 \mu \mathrm{g}$ inositol, $400 \mu \mathrm{g}(0.4$ $\mathrm{mg}$ ) folic acid, $3 \mu \mathrm{g}$ vitamin $\mathrm{B}_{12}, 5 \mu \mathrm{g}$ vitamin D3, $15 \mathrm{mg}$ zinc, $0.5 \mathrm{mg}$ copper, $25 \mu \mathrm{g}$ selenium

- Adherence: assessed by the hospital pharmacist based on the number of pills brought back at each visit. "good compliance established by pharmacist records"

Control/comparison intervention: multiple-micronutrient supplement without iodine

- Total number randomised: $\mathrm{n}=58$

- Description: daily multiple-micronutrient supplement (Oligobs Grossesse ${ }^{\circledR}$, Laboratoire CCD) but without iodine from the day of enrolment until the 3-month postpartum visit

- Adherence: same as experimental intervention

Co-intervention(s): all women received a document from a dietician on how to optimize their dietary iodine intake

Outcomes

- Pregnancy, postpartum: maternal thyroid tests (including FT4, total T4, TBG, TSH, FT3, reverse T3, $\mathrm{Tg}$, anti-Tg antibodies, anti-TPO antibodies) and UIE at baseline and 2nd and 3rd trimester and 3 months postpartum. Thyroid volume was also assessed at baseline, 3rd trimester and 3 months postpartum

- Infant/child: not reported

\begin{tabular}{ll}
\hline Notes & Of 111 women included, 86 were followed until delivery \\
- & 1 woman in the iodine group was excluded soon after inclusion because her UIE was $>400 \mu \mathrm{g} / \mathrm{L}$ \\
& - Source of funding: French Ministry of Health, Direction of Clinical Research of Nice University Hospital. \\
& Pharmaceutical Laboratory CCD (Paris, France) provided free supplement
\end{tabular}

\section{Risk of bias}


Brucker-Davis 2013 (Continued)
Random sequence genera- Low risk
The table of randomisation was obtained by a method of drawing of lots by tion (selection bias) blocks, using tables of permutation

Allocation concealment $\quad$ Unclear risk
(selection bias)

Blinding of participants High risk "This was an open study."
and personnel (perfor-
mance bias)
All outcomes

\begin{tabular}{|c|c|c|}
\hline $\begin{array}{l}\text { Blinding of outcome as- } \\
\text { sessment (detection bias) } \\
\text { All outcomes }\end{array}$ & High risk & The study was open \\
\hline $\begin{array}{l}\text { Incomplete outcome data } \\
\text { (attrition bias) } \\
\text { All outcomes }\end{array}$ & High risk & $\begin{array}{l}24 \text { women did not complete the study ( } 20 \text { intervention group and } 4 \text { control } \\
\text { group). Loss to follow-up was unbalanced. In the iodine group, out of } 53 \text { ran- } \\
\text { domised there were } 4 \text { miscarriages, } 1 \text { induced abortion (for trisomy 18), } 10 \\
\text { cases of digestive intolerance (nausea/vomiting), } 3 \text { cases of consent withdraw- } \\
\text { al and } 2 \text { missed data collection. In the control group, out of } 58 \text { randomised, } \\
\text { there were } 3 \text { miscarriages and } 1 \text { case of digestive intolerance }\end{array}$ \\
\hline
\end{tabular}

Selective reporting (re- High risk $\quad$ Baseline information was only provided for those who completed the study
porting bias)
porting bias)

\begin{tabular}{|c|c|c|}
\hline Other bias & Unclear risk & The study appears to be free of other sources of bias \\
\hline
\end{tabular}

\section{Glinoer 1993}

$\begin{array}{ll}\text { Methods } & \text { Study design: double-blind randomised controlled trial with } 3 \text { arms } \\ \text { - Unit of allocation: individual } & \\ \text { - Time period of recruitment and data collection: screening went from June } 1990-\text { December } 1992\end{array}$

Participants

- Description: pregnant women (mean 10.7, SEM 0.3 weeks' gestation)

- Location/setting: prenatal clinic in Brussels, Belgium

- How participants were recruited and selected: women visiting the prenatal clinic for the first time were screened and only those with excessive thyroidal stimulation (see below criteria) were selected

- Inclusion criteria: no known thyroid disease, less than 16 weeks' gestational age and biochemical evidence of excessive thyroidal stimulation (elevated serum $\mathrm{Tg}$ level $(>20 \mu \mathrm{g} / \mathrm{L}$ ) with either 1 or both of low normal free T, index $(\leq 1.23)$ as calculated from the T4/TBG ratio, and elevated molar ratio T3/ $\mathrm{T} 4\left(\geq 25 \times 10^{-3}\right)$

- Exclusion criteria: women with abnormal serum TSH level (<0.2 or $>4.0 \mathrm{mu} / \mathrm{L})$ and/or positive thyroid antibodies

- Sample size: 180 (120 in the iodine and control groups)

- Age: not specified

- Socioeconomic status: not specified

- Nutritional status: not specified

- Baseline iodine status of participants/area: baseline median UIC $36 \mu \mathrm{g} / \mathrm{L}$

- Baseline coverage of iodized salt: report describes it being typical of most Western European countries at the time, with no systematic addition of iodine to the diet

- Breastfeeding practices: not specified

- Other important information about participants or setting: none 
Glinoer 1993 (Continued)

- Total number randomised: $\mathrm{n}=60$

- Timing: from day of enrolment until day of delivery

- Form: tablets from Christiaens-Pharma

- Frequency and duration: daily

- lodine compound: potassium iodide (KI)

- Iodine dose: $131 \mu \mathrm{g} \mathrm{KI} \mathrm{\mu g/day,} \mathrm{corresponding} \mathrm{to} 100 \mu \mathrm{g} /$ day elemental iodine per day

- Other nutrients: no other nutrients

- Adherence: not specified

Experimental intervention 2: oral iodine and L-thyroxine (L-T4) supplementation

- Total number randomised: $\mathrm{n}=60$

- Timing: from day of enrolment until day of delivery

- Form: tablets from Christiaens-Pharma

- Frequency and duration: daily

- lodine compound: potassium iodide (KI)

- lodine dose: $131 \mu \mathrm{g} \mathrm{KI} /$ day, corresponding to $100 \mu \mathrm{g} /$ day elemental iodine

- Other nutrients: $100 \mu \mathrm{g} \mathrm{L-T4} \mathrm{per} \mathrm{day}$

- Adherence: not specified

Control/comparison intervention: placebo

- Total number randomised: $n=60$

- Description: daily tablets from day of enrolment until day of delivery

- Adherence: not specified

Co-intervention(s): none reported

- Pregnancy: maternal total T3 and T4, TBG, free T4, TG, TSH, UIC, and thyroid volume were assessed at baseline. Serum and urine determinations were repeated in the $2^{\text {nd }}$ and $3^{\text {rd }}$ trimesters

- Postpartum: 2-6 days after delivery the same tests were repeated and a second ultrasound was performed. lodine was determined in breast milk

- Infant/child: thyroid function parameters were determined in the neonates on cord blood, and thyroid ultrasound was performed at the age of 3-6 days

- The iodine and L-T4 arm of the trial was not eligible for inclusion in this review. Only data from the iodine and control arms were included

- The researchers quoted: "It is important to recognize that the women investigated here do not represent an average pregnant woman, but are a highly selected group, corresponding to the extreme fringe of the normal population". They selected 9\% (180/2000) of the women screened for the study, based on the inclusion/exclusion criteria

- A diffuse goitre (TV > $23 \mathrm{~mL}$ ) was present in $10 \%$ of the cases, with TV ranging between $23-64 \mathrm{~mL}$; a goitre $(n=17)$ have not been included in the above calculations. Researchers said the number of cases was too small in each group to allow statistical analysis

- Source of funding: Fonds de la Recherche Scientifique Medicale Belge (contract 3.4531.91 to DG), Solvay Duphar Gynaecology (Brussels, Belgium) and E. Merck Co (Darmstadt, Germany)

\section{Risk of bias}

\begin{tabular}{lll}
\hline Bias & Authors' judgement & Support for judgement \\
\hline $\begin{array}{l}\text { Random sequence genera- } \\
\text { tion (selection bias) }\end{array}$ & Unclear risk & $\begin{array}{l}\text { The report does not provide sufficient information on random sequence gen- } \\
\text { eration to determine risk: "women were subdivided into } 3 \text { equal groups" }\end{array}$ \\
\hline $\begin{array}{l}\text { Allocation concealment } \\
\text { (selection bias) }\end{array}$ & Unclear risk & $\begin{array}{l}\text { Insufficient information about allocation concealment to permit judgement of } \\
\text { 'Low risk' or 'High risk'. }\end{array}$ \\
\hline
\end{tabular}


Glinoer 1993 (Continued)

Blinding of participants Unclear risk Described as a double-blind randomised trial however there is insufficient inand personnel (perforformation to determine who was blinded mance bias)

All outcomes

Blinding of outcome as-
sessment (detection bias) $\quad$ Unclear risk Insufficient information to determine who was blinded

All outcomes

Incomplete outcome data Unclear risk Insufficient information to make judgement

(attrition bias)

All outcomes

Selective reporting (re- Unclear risk Insufficient information to make judgement
porting bias)

Other bias Unclear risk The study appears to be free of other sources of bias

Gowachirapant 2014

\begin{tabular}{ll}
\hline Methods & Study design: randomised double-blind controlled trial with 2 arms \\
- Unit of allocation: individual \\
- Time period of recruitment and data collection: Thailand: October 2008-June 2013
\end{tabular}

Participants

- Description: pregnant women in the first trimester

- Location/setting: Ramathibodi Hospital of Mahidol University in Bangkok, Thailand

- How participants were recruited and selected: recruited among those who registered at the Ramathibodi Hospital

- Inclusion criteria: singleton pregnancy, 18-40 years of age, gestational age $\leq 14$ weeks, non-lactating, generally healthy (no history of thyroid disorders), and not taking any iodine supplement

- Exclusion criteria: TSH $>6.0 \mathrm{mIU} / \mathrm{L}$ at screening

- Sample size: 511 women enrolled and randomised in Thailand

- Age: not reported

- Socioeconomic status: not reported

- Nutritional status: $4 \%$ obese and $10 \%-13 \%$ overweight

- Baseline iodine status of participants/area: described by authors as mild deficiency (UIC 110-112 $\mu \mathrm{g} / \mathrm{L})$

- Baseline coverage of iodized salt: $88 \%-89 \%$ purchased iodized salt for the household

- Breastfeeding practices: not reported

- Other important information about participants or setting: at baseline, $40 \%$ (placebo group) and $47 \%$ (iodine group) were uniparous, $4.7 \%$ has subclinical hyperthyroidism and $8.6 \%$ had subclinical hypothyroidism

Interventions

Experimental intervention: oral iodine supplementation

- Total number randomised: $n=262$

- Timing: starting in the first trimester

- Form: oral iodine tablets

- Frequency and duration: daily until delivery

- lodine compound: potassium iodide

- lodine dose: $200 \mu$ g elemental iodine

- Other nutrients: see co-interventions below 
- Adherence: not reported (assessed by counting the tablets returned after delivery; good compliance was defined as taking $80 \%$ of prescribed treatment)

Control/comparison intervention: placebo

- Total number randomised: $\mathrm{n}=249$

- Description: identical tablet

- Adherence: not reported

Co-intervention(s): multiple vitamin-mineral tablets without iodine, also until delivery

\begin{tabular}{|c|c|}
\hline Outcomes & $\begin{array}{l}\text { - Pregnancy: thyroid function (TSH, free and total T4 and T3, Tg, thyroid antibodies), UIC and thyroid } \\
\text { gland volume in the } 2^{\text {nd }} \text { and } 3^{\text {rd }} \text { trimester } \\
\text { - Postpartum: thyroid function, UIC and thyroid gland volume } 6 \text { weeks postpartum } \\
\text { - Infant/child: birth characteristics (from hospital records) and thyroid gland volume at delivery and } \\
6 \text { weeks of age, thyroid function (TSH only?) at delivery from cord blood, spot UIC at } 6 \text { weeks of age, } \\
\text { Neonatal behavioural assessment scales at } 6 \text { weeks of age (Table } 6 \text { ) }\end{array}$ \\
\hline Notes & - Trial was also conducted in India but we have not yet located any reports with those data \\
\hline
\end{tabular}

\section{Risk of bias}

\begin{tabular}{|c|c|c|}
\hline Bias & Authors' judgement & Support for judgement \\
\hline $\begin{array}{l}\text { Random sequence genera- } \\
\text { tion (selection bias) }\end{array}$ & Low risk & "women were allocated to two treatment groups by simple randomisation." \\
\hline $\begin{array}{l}\text { Allocation concealment } \\
\text { (selection bias) }\end{array}$ & Unclear risk & Allocation concealment method was not clear \\
\hline $\begin{array}{l}\text { Blinding of participants } \\
\text { and personnel (perfor- } \\
\text { mance bias) } \\
\text { All outcomes }\end{array}$ & Low risk & Subjects, caregivers and investigators were blinded \\
\hline $\begin{array}{l}\text { Blinding of outcome as- } \\
\text { sessment (detection bias) } \\
\text { All outcomes }\end{array}$ & Low risk & Outcome assessors were blinded \\
\hline $\begin{array}{l}\text { Incomplete outcome data } \\
\text { (attrition bias) } \\
\text { All outcomes }\end{array}$ & High risk & $\begin{array}{l}\text { Loss to follow-up was } 19 \%-20 \% \text { at the first follow-up visit (second trimester) } \\
\text { and }>20 \% \text { for all subsequent visits, with } 58 \%-59 \% \text { having } 6 \text { weeks' postpartum } \\
\text { data (though loss was balanced between the groups and for similar reasons) }\end{array}$ \\
\hline $\begin{array}{l}\text { Selective reporting (re- } \\
\text { porting bias) }\end{array}$ & Unclear risk & $\begin{array}{l}\text { Unclear. More data were collected (through } 24 \text { months of age and in India) but } \\
\text { to date only this PhD thesis has been published }\end{array}$ \\
\hline Other bias & Unclear risk & Appears to be free of other sources of bias \\
\hline
\end{tabular}

\section{Kevany 1969}

\section{Methods}

- Study design: quasi-randomized trial

- Unit of allocation: appears to be individual

- Time period of recruitment and data collection: unclear about recruitment period but injections were given in the first week of October 1966, and repeated in the original and additional cohort at 3 years after first injection. Data were collected for up to 7 years (as reported in the 1994 study) 
Kevany 1969 (Continued)

Participants
- Description: women of childbearing age

- Location/setting: 3 central sierra villages, Tapo, Huasahuasi and Ataquero in the Province of Tarma, Peru, a mountainous region with an altitude of $\sim 3000 \mathrm{~m}$. Tarma, a nearby town equipped with laboratory and hospital facilities, served as headquarters for the field work and more detailed laboratory work was carried out in Lima, about 5 hours away by automobile.

- How participants were recruited and selected: women of childbearing age 16-45 years of age from 3 central sierra villages

- Inclusion criteria: not specified

- Exclusion criteria: not specified

- Sample size: 792 (this number is given in the 1972 paper, though it is not clear if it is the number that were randomised)

- Age: between 16-45 years

- Socioeconomic status: not specified

- Nutritional status: not specified

- Baseline iodine status of participants/area: mean UIE in the 3 villages $=17 \mu \mathrm{g} / 100 \mathrm{~mL}-$ including pregnant/and non-pregnant cohort; (in the 1969 paper, it was reported as mean UIE ( $\mu \mathrm{g} / 24$ hour): 17.2 \pm 1.1 (for 159 subjects which would include non-pregnant cohort)

- Baseline coverage of iodized salt: report specifies that salt iodization had not been implemented in these areas

- Breastfeeding practices: not specified

- Other important information about participants or setting: none
Interventions
Experimental intervention: injected iodized oil

- Total number randomised: $\mathrm{n}=390$

- Timing: at baseline and after 3 years

- Form: intramuscular injection

- Frequency and duration: 2 times (baseline and after 3 years) single dose

- lodine compound: iodine

- lodine dose: $2 \mathrm{~mL}$ iodized oil containing $950 \mathrm{mg}$ iodine. Adult women with nodular disease were given $0.2 \mathrm{~mL}$ (95 mg iodine)

- Other nutrients: no other nutrients

- Adherence: not specified

Control/comparison intervention: placebo

- Total number randomised: $\mathrm{n}=402$

- Description: intramuscular placebo injection of non-iodized poppy-seed oil (Ethiodol) at baseline and after 3 years

- Adherence: not specified

Co-intervention(s): none reported
- Pregnancy: maternal thyroid hormone concentrations in the last 5 months of pregnancy, blood and urine samples during pregnancy

- Postpartum: iodine content in breast milk, iodine content in breast milk at $19^{\text {th }}$ month post-injection (initial injection), blood and urine sample at the time of delivery and postpartum (not stated when postpartum)

- Infant/child: clinical evaluation, goitre, body weight, stature or supine length, sitting height or crownrump length, head and chest circumference, upper arm circumference, triceps, subscapular and waist skinfold thickness and bi-acromial and bi-ilio cristal diameters, bone maturation by radiologic tests, bone age, motor and neuropsychological by Gesell test, neuropsychological development was measured by the Stanford-Binet and the Brunet-Lezine tests, audiometry, voice, buccofacial praxis, articulation praxis and verbal expression and comprehension tests, EEG, UIE, other blood and urine tests 
Kevany 1969 (Continued)

Notes
- The 1972 report is mainly concerned with the evaluation of children who were born into the iodine programme and have been followed up to 5 years after the injection of their mothers. The 1994 report provides additional details about maternal blood and urine sample as well as infant neurodevelopmental outcomes.

- From the 1969 study, description of follow-up for the entire cohort (i.e. all children, women, men). It is not entirely clear whether childbearing women received follow-up at these specified time points regardless of conception date. Follow-ups were performed on:

- Goitre: at 6, 12, and 18 months after injection (examiners were ignorant of both the prior estimated gland size and the type of injection. The size of goitre and presence of nodularity were recorded)

- Clinical assessment: made by members of the same team throughout the program, looking out for any side effects, especially thyrotoxicosis

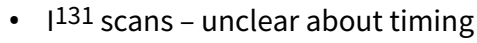

- Thyroid function - unclear about timing

- UIE - at 6, 9, 13, 15, and 19 months after injection (in a subgroup)

\section{Risk of bias}

\begin{tabular}{lll}
\hline Bias & Authors' judgement & Support for judgement \\
\hline $\begin{array}{l}\text { Random sequence genera- } \\
\text { tion (selection bias) }\end{array}$ & High risk & $\begin{array}{l}\text { "In other groups (excluding schoolchildren), random injection of placebo and } \\
\text { iodine was accomplished by consecutive alternation of iodine and placebo in- } \\
\text { jection." }\end{array}$ \\
\hline $\begin{array}{l}\text { Allocation concealment } \\
\text { (selection bias) }\end{array}$ & High risk & Alternate allocation evident \\
\hline
\end{tabular}

\begin{tabular}{lll}
$\begin{array}{l}\text { Blinding of participants } \\
\text { and personnel (perfor- } \\
\text { mance bias) } \\
\text { All outcomes }\end{array}$ & Unclear risk & Not described in sufficient detail to make judgement \\
\hline $\begin{array}{l}\text { Blinding of outcome as- } \\
\text { sessment (detection bias) } \\
\text { All outcomes }\end{array}$ & Unclear risk & $\begin{array}{l}\text { Goitre: "Examiners were ignorant of both the prior estimated gland size and } \\
\text { the type of injection", but unclear about other outcomes such as child devel- } \\
\text { opment }\end{array}$
\end{tabular}

Incomplete outcome data Unclear risk Unclear whether all pregnancies and births were captured: "As many pregnan(attrition bias) cies as possible occurring in both the treatment and placebo groups were fol-

All outcomes lowed throughout gestation"

Only a subgroup of individuals received thyroid function tests, I131 and UIE. No clear description of how these subjects were selected. Also, unclear how many childbearing women continued in the study at subsequent follow-up time points as Table 3 ( $p$ 423) refers to entire cohort

$\begin{array}{ll}\begin{array}{l}\text { Selective reporting (re- } \\ \text { porting bias) }\end{array} & \text { Anclear risk } \\ & \begin{array}{l}\text { In addition, in the } 1994 \text { paper it was mentioned, "Accordingly, in a recalcula- } \\ \text { tion of results, only the children of mothers who had UIE or T4 levels that were } \\ \text { verified and found to be consistent with a definition of iodine deficient or nor- } \\ \text { mal were included" (Table 2) }\end{array}\end{array}$

Other bias High risk

This trial recruited women and provided the intervention before they became pregnant. The intervention may have affected their probability of becoming pregnant, potentially leading to differences between groups and introducing bias 
Kämpe 1990

\begin{tabular}{ll}
\hline Methods & Study design: randomised trial with 3 arms \\
- Unit of allocation: individual \\
- Time period of recruitment and data collection: screening took place during $1984-1985$ \\
- Description: pregnant women \\
- Location/setting: Sweden \\
- How participants were recruited and selected: women screened for rubella and TPO-ab \\
- Inclusion criteria: pregnant women in the first trimester screened for rubella antibodies and TPO-ab \\
- titer of 1:1600 or greater \\
- Samplusion criteria: history of Graves' disease or receiving L-T4 medication \\
- Age: not specified \\
- Socioeconomic status: not specified \\
- Nutritional status: not specified \\
- Baseline iodine status of participants/area: not available \\
- Baseline coverage of iodized salt: not available \\
- Breastfeeding practices: not specified \\
- Other important information about participants or setting: no \\
\hline
\end{tabular}

- Total number randomised: $n=20$

- Timing: from 1-40 weeks postpartum

- Form: oral

- Frequency and duration: daily

- lodine compound: potassium iodide

- lodine dose: $0.15 \mathrm{mg}$ iodide (as potassium iodide)

- Other nutrients: no other nutrients

- Adherence: not specified

Experimental intervention 2: L-thyroxine (L-T4)

- Total number randomised: $\mathrm{n}=18$

- Timing: from 1-40 weeks postpartum

- Form (injected/oral, tablet, drops etc): oral

- Frequency and duration (daily until birth, single dose, etc): daily

- lodine compound: no iodine

- lodine dose (specify if compound or elemental iodine): not applicable

- Other nutrients: L-thyroxine (L-T4)

- Adherence: not specified

Control/comparison intervention: no intervention

- Total number randomised: $\mathrm{n}=18$

- Description: no intervention

- Adherence: not applicable

Co-intervention(s): in women with severe symptoms during the hypothyroid phase, L-T4 supplementation was provided ( $n=6$ in the iodine group and $n=4$ in the control group). This generally occurred at the beginning of week 20 postpartum

Outcomes

- Pregnancy:

- Postpartum: thyroid hormones (TSH, T4, T3) and antibodies (TPO-ab) at 8 time points in the first year postpartum 
Kämpe 1990 (Continued)

\section{- Infant/child}

Notes - To help ensure adherence and the study assessments, a physician regularly called participants by phone

- Source of funding: not reported

\section{Risk of bias}

\begin{tabular}{|c|c|c|}
\hline Bias & Authors' judgement & Support for judgement \\
\hline $\begin{array}{l}\text { Random sequence genera- } \\
\text { tion (selection bias) }\end{array}$ & Unclear risk & $\begin{array}{l}\text { Method for sequence generation not specified ("women were randomly divid- } \\
\text { ed into three groups") }\end{array}$ \\
\hline $\begin{array}{l}\text { Allocation concealment } \\
\text { (selection bias) }\end{array}$ & Unclear risk & Allocation concealment method not specified \\
\hline $\begin{array}{l}\text { Blinding of participants } \\
\text { and personnel (perfor- } \\
\text { mance bias) } \\
\text { All outcomes }\end{array}$ & High risk & Control group received no intervention therefore blinding was not possible \\
\hline $\begin{array}{l}\text { Blinding of outcome as- } \\
\text { sessment (detection bias) } \\
\text { All outcomes }\end{array}$ & Unclear risk & Report does not describe whether assessors were blinded to group assignment \\
\hline $\begin{array}{l}\text { Incomplete outcome data } \\
\text { (attrition bias) } \\
\text { All outcomes }\end{array}$ & Unclear risk & $\begin{array}{l}\text { Insufficient information to make judgement. Data were not reported in a way } \\
\text { that showed the numbers for each postpartum assessment for each outcome }\end{array}$ \\
\hline $\begin{array}{l}\text { Selective reporting (re- } \\
\text { porting bias) }\end{array}$ & Unclear risk & Insufficient information to make judgement \\
\hline Other bias & Unclear risk & The study appears to be free of other sources of bias \\
\hline
\end{tabular}

Liesenkotter 1996

- Study design: quasi-randomized trial with 2 arms (iodine supplementation and no intervention).
Women were assigned to a trial arm according to which day of the week (Monday or Tuesday) they
first attended the hospital for antenatal care
- Unit of allocation: individual
- Time period of recruitment and data collection: not specified

Participants

- Description: pregnant women

- Location/setting: Benjamin Franklin Hospital at the Free University in Berlin, Germany

- How participants were recruited and selected: women consulting the pregnancy care unit of the hospital

- Inclusion criteria: pregnant women with a mean 11.2 weeks' gestation and with no clinical evidence of autoimmune thyroid disease

- Exclusion criteria: history of Graves' disease or receiving L-T4 medication

- Sample size: 108

- Age: mean age of participants 32.4 (21-40) years

- Socioeconomic status: not specified

- Nutritional status: not specified 
- Baseline iodine status of participants/area: described as "moderate deficiency". Overall median UIC was $64 \mu \mathrm{g} / \mathrm{L}$, with no statistically significant difference between groups. $42 \%$ had goitre at baseline (according to author definition of thyroid volume $>18 \mathrm{~mL}$ based on German population normal ranges)

- Baseline coverage of iodized salt: not available

- Breastfeeding practices: not specified

- Other important information about participants or setting: none

\begin{tabular}{|c|c|}
\hline Interventions & $\begin{array}{l}\text { Experimental intervention: iodine } \\
\text { - Total number randomised: } \mathrm{n}=228 \\
\text { - Timing: throughout pregnancy and postpartum } \\
\text { - Form (injected/oral, tablet, drops etc): oral } \\
\text { - Frequency and duration (daily until birth, single dose, etc): daily } \\
\text { - Iodine compound: potassium iodine } \\
\text { - Iodine dose (specify if compound or elemental iodine): } 300 \mu \text { g elemental iodine } \\
\text { - Other nutrients: no other nutrients } \\
\text { - Adherence: not specified } \\
\text { Control/comparison intervention: no iodine } \\
\text { - Total number randomised: } n=70 \\
\text { - Description: no iodine supplementation } \\
\text { - Adherence: } n \text { ot specified } \\
\text { Co-intervention(s): none reported }\end{array}$ \\
\hline Outcomes & $\begin{array}{l}\text { - Pregnancy: urinary iodine, blood (thyroid peroxidase antibodies, TSH, T3, T4, TBG, Tg) and thyroid } \\
\text { volume at the beginning of pregnancy (mean } 11.2 \text { weeks of gestation) } \\
\text { - Postpartum: urinary iodine, blood (TPO-ab, TSH, T3, T4, TBG, Tg) and thyroid volume at mean } 11 \text { days } \\
\text { (range 2-21) postpartum } \\
\text { - Infant/child: infant urinary iodine and TPO-ab in blood at } 5 \text { days of age, thyroid volume at } 2 \text { weeks } \\
\text { of age }\end{array}$ \\
\hline Notes & $\begin{array}{l}\text { - More women in the control group than the intervention group were TPO-ab-positive at baseline (6/70 } \\
\text { versus } 1 / 38 \text { ) } \\
\text { - Source of funding: grant from the Deutsche Forschungsgesellschaft (SFB) }\end{array}$ \\
\hline
\end{tabular}

Risk of bias

\begin{tabular}{|c|c|c|}
\hline Bias & Authors' judgement & Support for judgement \\
\hline $\begin{array}{l}\text { Random sequence genera- } \\
\text { tion (selection bias) }\end{array}$ & High risk & $\begin{array}{l}\text { Quasi-randomized. "The women were randomly assigned to two groups ac- } \\
\text { cording to the two different days of the week when they presented first in the } \\
\text { Pregnancy Care Unit" }\end{array}$ \\
\hline $\begin{array}{l}\text { Allocation concealment } \\
\text { (selection bias) }\end{array}$ & Low risk & Randomization at cluster level is unlikely to produce selection bias \\
\hline $\begin{array}{l}\text { Blinding of participants } \\
\text { and personnel (perfor- } \\
\text { mance bias) } \\
\text { All outcomes }\end{array}$ & High risk & No blinding or use of placebo was reported \\
\hline $\begin{array}{l}\text { Blinding of outcome as- } \\
\text { sessment (detection bias) } \\
\text { All outcomes }\end{array}$ & Unclear risk & $\begin{array}{l}\text { Person who conducted thyroid volume assessment was blinded to group as- } \\
\text { signment however the report did not specify whether assessments of other } \\
\text { outcomes were blinded }\end{array}$ \\
\hline
\end{tabular}


Liesenkotter 1996 (Continued)

Incomplete outcome data Unclear risk Insufficient information to permit judgement. Report stated that the study in-

(attrition bias)

cluded 108 women and reports outcome data for 108 women. However the

All outcomes number randomised to each group and whether any (and how many) were lost to follow-up was not reported

Selective reporting (re- Unclear risk Insufficient information to permit judgement
porting bias)

Other bias Unclear risk The study appears to be free of other sources of bias

\section{Mulrine 2010}

Methods

- Study design: double-blind, placebo-controlled trial with imbalanced randomisation and 3 arms (placebo, 75 or $150 \mu$ g iodine/d)

- Unit of allocation: individual

- Time period of recruitment and data collection: March 2004-October 2005

\section{Participants}

- Description: pregnant women in the third trimester (intervention began postpartum)

- Location/setting: Dunedin, New Zealand

- How participants were recruited and selected: women were recruited in their final month of pregnancy through advertisements in a local newspaper and maternity hospital

- Inclusion criteria: healthy, no history of thyroid disease, singleton birth, not currently taking a dietary supplement containing iodine, due to deliver their infant between May 2004 and April 2005, and intend to breastfeed for $\geq 24$ weeks

- Exclusion criteria:

- Sample size: 109

- Age: mean age 31-32 years

- Socioeconomic status: $39 \%-55 \%$ had total household income $>$ NZ\$50,000, 65\%-83\% were tertiary educated

- Nutritional status: not reported

- Baseline iodine status of participants/area: overall median (25th, 75 th percentiles) UIC in the final month of pregnancy was $42(25,58) \mu \mathrm{g} / \mathrm{L}$

- Baseline coverage of iodized salt: use of iodized salt as reported in final month of pregnancy was $82 \%$ in the $75 \mu \mathrm{g}$ group, $92 \%$ in the $150 \mu \mathrm{g}$ group and $89 \%$ in the placebo group

- Breastfeeding practices (if applicable): at 24 weeks postpartum, $69 \%$ of infants were currently breastfed and had not received any infant formula, and $27 \%$ were currently fed both breast milk and infant formula

- Other important information about participants or setting: $88 \%-95 \%$ white, $36 \%-48 \%$ nulliparous, $21 \%-52 \%$ exposed to iodine-containing antiseptic in labour. Mean birthweight was $>3500$ and $46 \%-53 \%$ of infants were male

- Total number randomised: $75 \mu \mathrm{g} / \mathrm{d}: \mathrm{n}=19,150 \mu \mathrm{g} / \mathrm{d}: \mathrm{n}=21$

- Timing: began as soon as possible after delivery (mean $5 \pm 4.2$ days postpartum)

- Form: oral tablets

- Frequency and duration: daily for 24 weeks

- lodine compound: potassium iodate

- lodine dose: $75 \mu \mathrm{g} / \mathrm{d}$ or $150 \mu \mathrm{g} / \mathrm{d}$ elemental iodine

- Other nutrients: none

- Adherence: mean $86 \% \pm 17 \%$ overall (no difference between groups). Adherence defined as proportion of the intended tablets consumed, measured by counting remaining tablets in the monthly bottle at the end of each month 
Mulrine 2010 (Continued)

Control/comparison intervention: placebo

- Total number randomised: $n=56$

- Description: placebo tablet

- Adherence: see above

Co-intervention(s): none reported

\begin{tabular}{|c|c|}
\hline Outcomes & $\begin{array}{l}\text { - Postpartum: urine (casual sample) and breast milk (foremilk sample) iodine content at the end of } 1 \text {, } \\
\text { 2, 4, 8, 12, 16, 20, and } 24 \text { weeks postpartum. Serum TSH and free T4 from finger prick blood sample } \\
\text { at week } 24 \text { (between 09:00 and 17:00) } \\
\text { - Infant/child: urine (casual sample) iodine content at the end of } 1,2,4,8,12,16,20 \text {, and } 24 \text { weeks } \\
\text { postpartum } \\
\text { - All urine and breast milk samples were collected between 09:00 and 12:00, except for } 5 \text { maternal urine } \\
\text { and breast milk samples ( } 0.6 \% \text { ) and } 17 \text { infant urine samples (2.6\%) }\end{array}$ \\
\hline Notes & $\begin{array}{l}\text { - 3-arm trial (placebo, } 75 \mu \mathrm{g} \text { and } 150 \mu \mathrm{g} \text { iodine) with unequal distribution (2:1:1). Because of imbalanced } \\
\text { randomisation and to maintain blinding, placebo arm was split into } 2 \text { groups and women were ran- } \\
\text { domised to } 1 \text { of } 4 \text { groups } \\
\text { - Block randomisation was used. Each block contained } 5 \text { allocations for each of the } 2 \text { placebo groups } \\
\text { and the } 75 \mu \mathrm{g} / \mathrm{d} \text { and } 150 \mu \mathrm{g} / \mathrm{d} \text { iodine groups } \\
\text { - Tablets described as indistinguishable from each other. Quality control testing confirmed placebo } \\
\text { tablets contained }<0.001 \mu \mathrm{g} \text { iodine, } 75 \mu \mathrm{g} \text { tablet contained mean (range) } 79(73-86) \mu \mathrm{g} \text { iodine, and } 150 \\
\mu \mathrm{g} \text { contained mean (range) } 154(146-164) \mu \mathrm{g} \text { iodine } \\
\text { - This study contributes no outcome data to the review analyses }\end{array}$ \\
\hline
\end{tabular}

\section{Risk of bias}

\begin{tabular}{lll}
\hline Bias & Authors' judgement & Support for judgement \\
\hline $\begin{array}{ll}\text { Random sequence genera- } \\
\text { tion (selection bias) }\end{array}$ & Unclear risk & $\begin{array}{l}\text { Block randomisation was “planned and generated by a researcher not directly } \\
\text { involved in data collection”. Although the method of sequence generation was } \\
\text { not described }\end{array}$ \\
\hline
\end{tabular}

$\begin{aligned} & \text { Allocation concealment } \\ & \text { (selection bias) }\end{aligned}$
Unclear risk Method of concealment not described

\begin{tabular}{ll}
\hline $\begin{array}{l}\text { Blinding of participants } \\
\text { and personnel (perfor- }\end{array}$ & "Both risk researchers and participants were blinded to treatment until all data \\
collection and biochemical analyses were completed."
\end{tabular}
mance bias)

All outcomes

\begin{tabular}{lll}
\hline $\begin{array}{l}\text { Blinding of outcome as- } \\
\text { sessment (detection bias) } \\
\text { All outcomes }\end{array}$ & Unclear risk & $\begin{array}{l}\text { Trial described as double-blind with participants and researchers blinded } \\
\text { however it was not described whether outcome assessors were blinded as well }\end{array}$ \\
\hline $\begin{array}{l}\text { Incomplete outcome data } \\
\text { (attrition bias) }\end{array}$ & High risk & $\begin{array}{l}>20 \% \text { incomplete outcome data due to attrition (23\%) as well as missing da- } \\
\text { ta (ranging from } 3 \%-10 \% \text { depending on outcome, and due to samples unable } \\
\text { to be collected or analysed). However there were no statistically significant dif- } \\
\text { ferences between those who withdrew and remained for treatment group, ed- } \\
\text { ucation level, compliance, household income, parity or maternal medical con- } \\
\text { ditions }\end{array}$
\end{tabular}

Selective reporting (re- Unclear risk Insufficient information to permit judgement
porting bias)

Other bias Unclear risk The study appears to be free of other sources of bias


Nohr 2000

Methods - Study design: placebo-controlled, randomised, double-blind trial with 3 arms. Used stratified randomisation according to TPO-ab level

- Unit of allocation: individual

- Time period of recruitment and data collection: not reported

Participants

Interventions
- Description: TPO-ab-positive pregnant women

- Location/setting: Aalborg Hospital in Denmark

- How participants were recruited and selected: a consecutive cohort of 1284 healthy pregnant Danish women (18-35 years of age) referred to Aalborg Hospital for a routine obstetrical ultrasound in early pregnancy (median 11th gestational week) were screened for serum TPO-ab. TPO-ab was found in 117 or $9.1 \%$

- Inclusion criteria: pregnant women with (TPO-ab $\geq 100 \mathrm{~mL}$ ) no history of thyroid disease or clinical symptoms of thyroid dysfunction (not specified as inclusion criteria)

- Exclusion criteria:

- Sample size: 72

- Age: median age ranged from 29-30 years across groups

- Socioeconomic status: not reported

- Nutritional status: median baseline weight ranged from $67 \mathrm{~kg}-68 \mathrm{~kg}$ across groups

- Baseline iodine status of participants/area: described by authors as mild to moderate deficiency. Baseline UIC was median $50 \mu \mathrm{g} / \mathrm{L}-52 \mu \mathrm{g} / \mathrm{L}$ across the groups

- Baseline coverage of iodized salt: not reported

- Breastfeeding practices: not reported

- Other important information about participants or setting: proportion of smokers ranged from $13 \%-27 \%$ across groups (there was a statistical trend towards fewer smokers in the control group). $68 \%$ of participants had previously taken vitamin-mineral supplements ( $75 \%$ of these women took supplements containing iodine) though all reportedly stopped once entering the study. Median parity was 2

Experimental intervention: oral iodine supplement

- Total number randomised: $n=46$ (22 to pregnancy and postpartum supplementation group, 24 to pregnancy-only supplementation group)

- Timing: 2 groups: pregnancy and postpartum, pregnancy-only. Women were randomised at median $11^{\text {th }}$ week gestation

- Form: oral tablet

- Frequency and duration: daily throughout pregnancy and postpartum or daily throughout pregnancy (exact start and end of supplementation not specified)

- lodine compound: not specified

- Iodine dose: $150 \mu$ g elemental iodine (same for both groups)

- Other nutrients: "Recommended daily allowances of various vitamins and minerals, including $50 \mu \mathrm{g}$ selenium" (other nutrients and values not specified) (same for both groups)

- Adherence: assessed with 24-h urinary iodine excretion during pregnancy (week 35) and postpartum (7 months). During pregnancy, urinary iodine was higher in the 2 supplementation groups than the control group. Postpartum, urinary iodine was higher in the pregnancy + postpartum supplementation group than the pregnancy-only supplementation and the control groups

Control/comparison intervention: oral multiple-micronutrient supplement with no iodine

- Total number randomised: $n=26$

- Description: oral tablets with same formulation as experimental intervention but no iodine

- Adherence: not reported

Co-intervention(s): none reported 
Nohr 2000 (Continued)

Outcomes

- Pregnancy: serum total and free T4, total and free T3, TSH, Tg, TPO-ab, Tg-antibodies, and 24-h urinary iodine excretion at week 35 of gestation

- Postpartum: serum total and free T4, total and free T3, TSH, Tg, TPO-ab, Tg-antibodies and postpartum thyroid disorder (clinical or subclinical hypo or hyperthyroidism) and biochemical dysfunction score at 3, 5, 7, and 9 months postpartum, 24-h urinary iodine excretion at 7 months postpartum. Thyroid disease 3 years postpartum

- Infant/child: none reported

$$
\text { Notes }
$$

\section{Risk of bias}

\begin{tabular}{|c|c|c|}
\hline Bias & Authors' judgement & Support for judgement \\
\hline $\begin{array}{l}\text { Random sequence genera- } \\
\text { tion (selection bias) }\end{array}$ & Unclear risk & $\begin{array}{l}\text { Described as "randomised, stratified according to TPO-ab level, to three } \\
\text { groups" though method for sequence generation was not reported }\end{array}$ \\
\hline $\begin{array}{l}\text { Allocation concealment } \\
\text { (selection bias) }\end{array}$ & Unclear risk & Method of concealment not described \\
\hline $\begin{array}{l}\text { Blinding of participants } \\
\text { and personnel (perfor- } \\
\text { mance bias) } \\
\text { All outcomes }\end{array}$ & Unclear risk & Study was described as "double blind". Unclear exactly who was blinded \\
\hline $\begin{array}{l}\text { Blinding of outcome as- } \\
\text { sessment (detection bias) } \\
\text { All outcomes }\end{array}$ & Unclear risk & Study was described as "double blind". Unclear exactly who was blinded \\
\hline $\begin{array}{l}\text { Incomplete outcome data } \\
\text { (attrition bias) } \\
\text { All outcomes }\end{array}$ & Low risk & $\begin{array}{l}\text { Data for } 12 \text { participants }(<20 \%) \text { missing. } 6 \text { dropped out after pregnancy ( } 4 \text { in } \\
\text { the pregnancy-only supplementation group, } 2 \text { in control group) and data from } \\
6 \text { were censored due to missing postpartum data (these women were more } \\
\text { likely to be smokers) }\end{array}$ \\
\hline $\begin{array}{l}\text { Selective reporting (re- } \\
\text { porting bias) }\end{array}$ & Unclear risk & Insufficient information to make judgement \\
\hline Other bias & Unclear risk & The study appears to be free of other sources of bias \\
\hline
\end{tabular}

\section{Pedersen 1993}

\begin{tabular}{ll}
\hline Methods & Study design: randomised controlled trial, 2 arms \\
- Unit of allocation: individuals \\
- Time period of recruitment and data collection: not specified \\
\hline Participants & Description: pregnant women \\
- Location/setting: outpatient clinic of the Department of Obstetrics and Gynaecology, Rander Cen- \\
tralsygehus, East Jutland, Denmark \\
- How participants were recruited and selected: through outpatient clinic \\
- Inclusion criteria: White women with normal pregnancy with no previous thyroid disorder and not \\
on iodine supplementation \\
- Exclusion criteria: as above \\
- Sample size: initially 74 but 20 withdrew after the first visit, and 54 were randomised \\
- Age: iodine-supplemented group: median 25 years (95\% Cl 24-27); control 26.3 years (25-29)
\end{tabular}


- Socioeconomic status: not reported

- Nutritional status: weight of iodine supplemented group: median $61.9 \mathrm{~kg}$ (58.5-67.2); controls $64 \mathrm{~kg}$ (59.5-70

- Baseline iodine status of participants/area: median UIC 55 (iodine supplemented group) and $51 \mu \mathrm{g} /$ $\mathrm{L}$ (controls)

- Baseline coverage of iodized salt: not available

- Breastfeeding practices: not reported

- Other important information about participants or setting: none

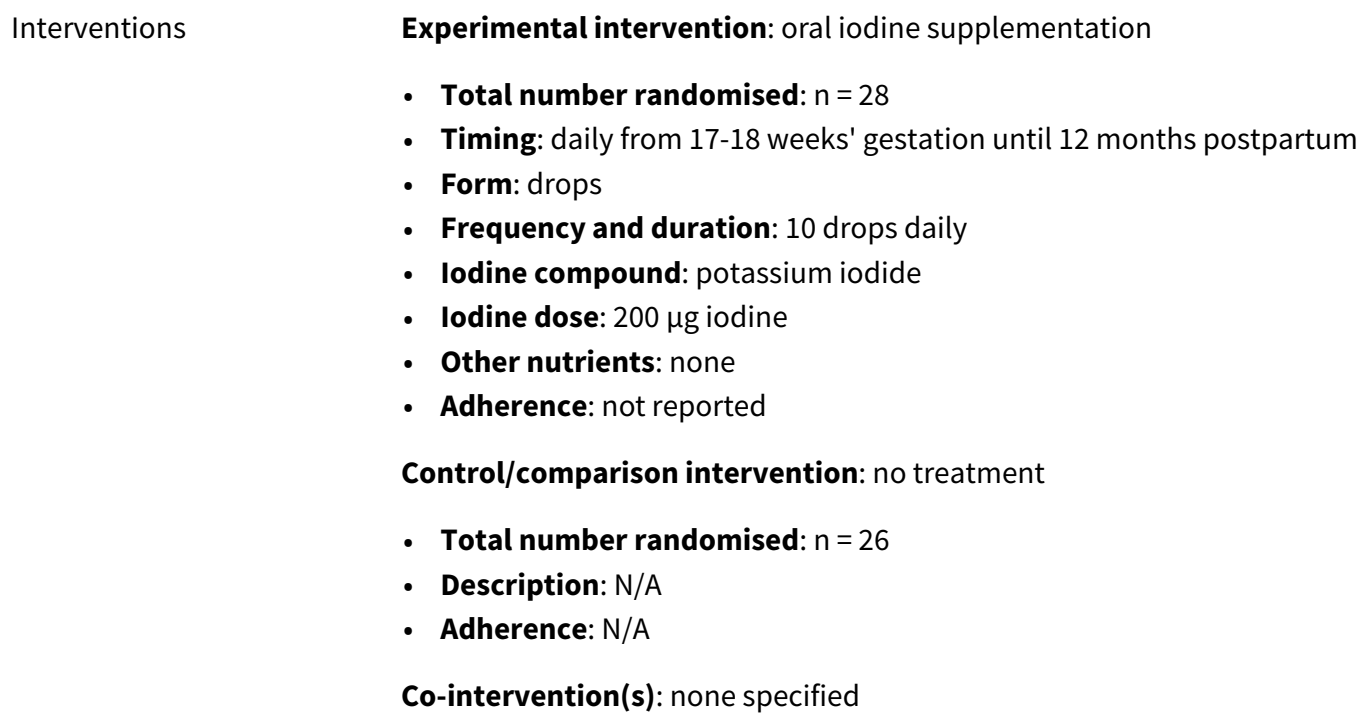

Control/comparison intervention: no treatment

- Total number randomised: $\mathrm{n}=26$

- Description: N/A

- Adherence: N/A

Co-intervention(s): none specified

- Thyroid volume (by ultrasound, method as per Bruun 1981) at 17-18, 28 and 37 weeks' gestation

- Serum T3, T4, free T4, T4/T3, Tg, TSH, TPO-ab and urinary iodine concentration at 17-18, 28 and 37 weeks' gestation

\section{Postpartum:}

- Thyroid volume at day 5 postpartum, 26 weeks postpartum, 52 weeks postpartum

- Serum T3, T4, free T4, T4/T3, Tg, TSH, TPO-ab and urinary iodine concentration at 13 and 39 weeks postpartum. Also, urinary iodine concentration at 52 weeks postpartum (after stopping iodine supplementation)

- Breastmilk iodine concentration at day 5 postpartum

\section{Infant/child:}

- Urinary iodine concentration at day 5 postpartum

- Cord blood T3, T4, free T4, Tg, TSH

\begin{tabular}{ll}
\hline Notes & Smokers: iodine supplement group: $\mathrm{n}=9$; controls $\mathrm{n}=7$ \\
- & High dropout at initial visit $20 / 74(27 \%)$ - reason provided was that the women felt that it would in- \\
& terfere with their jobs - as it occurred prior to randomisation, unlikely to have significant impact on \\
& study results since baseline data between the 2 groups were not different $(\mathrm{p} 1079)$
\end{tabular}

\section{Risk of bias}

\begin{tabular}{lll}
\hline Bias & Authors' judgement & Support for judgement \\
\hline $\begin{array}{l}\text { Random sequence genera- } \\
\text { tion (selection bias) }\end{array}$ & Unclear risk & Not described in the text \\
\hline \hline
\end{tabular}


Pedersen 1993 (Continued)

Allocation concealment Unclear risk Method of concealment not described (selection bias)

Blinding of participants

High risk

Control group received no intervention

and personnel (perfor-

mance bias)

All outcomes

Blinding of outcome as-
sessment (detection bias)

sessment (detection bias)

All outcomes

Thyroid volume assessment was blinded: "The investigators performing the volume measurements did not know which subjects received iodine or the results of previous volume determinations." Report did not specify for other outcomes though

Incomplete outcome data Unclear risk

(attrition bias)

After the first visit, 20 women left the study (mainly because they felt that it

All outcomes would interfere with their jobs) but this took place prior to randomisation. Report did not provide adequate information to assess incomplete outcome data

Selective reporting (re- Unclear risk Protocol not available
porting bias)

Other bias Unclear risk The study appears to be free of other sources of bias

Pharoah 1971 (C)

Methods - Study design: double-blind, cluster, quasi-randomized placebo-controlled trial with 2 arms. Alternate families were injected with either iodized oil or saline solution

- Unit of allocation: family

- Time period of recruitment and data collection: trial took place in August-September 1966. Subsequent follow-ups were carried out in 1967, 1969, 1970 and 1974-1982

\section{Participants}

- Description: entire families including pregnant and non-pregnant women

- Location/setting: Jimi River valley in the highlands of Papua New Guinea (at the time accessible only by light aircraft)

- How participants were recruited and selected: through a census conducted for the purposes of the study in 27 villages

- Inclusion criteria: none reported

- Exclusion criteria: none reported

- Sample size: approximately 16,500 individuals in total (including pregnant and non-pregnant women)

- Age: not reported

- Socioeconomic status: subsistence economy

- Nutritional status: not reported

- Baseline iodine status of participants/area: severe deficiency (the area had high incidence of endemic cretinism and high prevalence of goitre). $20 \%$ of participants had goitre at baseline.

- Baseline coverage of iodized salt: not reported

- Breastfeeding practices: not reported

- Other important information about participants or setting: none

\footnotetext{
Interventions
}

Experimental intervention: injected iodized oil

- Total number randomised: $\mathrm{n}=$ not reported

- Timing: before and during pregnancy. Included pregnant women (pregnancy was self-reported) and women who later became pregnant

- Form: injected iodized oil 
Pharoah 1971 (C) (Continued)

- Frequency and duration: single dose

- lodine compound: not reported

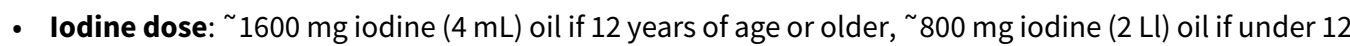
years of age (approximately $400 \mathrm{mg}$ elemental iodine per $\mathrm{mL}$ )

- Other nutrients: none

- Adherence: not reported

Control/comparison intervention: placebo

- Total number randomised: $\mathrm{n}=$ not reported

- Description: injected saline solution

- Adherence: not reported

Co-intervention(s): none reported

- Pregnancy: pregnancy total T4 and TBG assessed in 1970 and 1971
- Postpartum: serum-protein-bound-iodine in a subsample of mothers of children with cretinism in
1970
- Infant/child: child motor milestones, hearing and speech and squint were assessed from $1967-1971$.
Endemic cretinism was diagnosed initially based on motor retardation with deafness and/or squint
(though later follow-ups used different definition). Motor performance was assessed in 1978 and
cognitive and motor performance from 1974-1982. Cretinism (definite versus possible) was assessed
again later in a sub-sample. Since 1972, follow-ups took place in 5 of the original villages for logistical
reasons. Births and deaths were also recorded. Unable to extract infant mortality because it was not
reported separately

Notes - We did not adjust for clustering because it was not possible to know if there was more than 1 pregnant woman per family and therefore any clustering effect

- After it became clear that iodine was an effective prophylactic for endemic cretinism, iodinated oil injections were given to all women of child-bearing age in each of the villages in 1972.

- Different reports provide different numbers for cretinism. We used numbers from the Pharoah 1971 report as it provided both the number of children with diagnosed cretinism and the number of children examined and included more villages than later assessments (though the assessments could have taken place beyond 2 years of age, cretinism is a permanent condition so would not have changed after that age)

- In 6/7 cases of cretinism in the iodine group and 5/26 in the control group, the mothers received the injection during pregnancy

\section{Risk of bias}

\begin{tabular}{lll}
\hline Bias & Authors' judgement & Support for judgement \\
\hline $\begin{array}{l}\text { Random sequence genera- } \\
\text { tion (selection bias) }\end{array}$ & High risk & Quasi-randomized allocation (alternate families) \\
\hline $\begin{array}{l}\text { Allocation concealment } \\
\text { (selection bias) }\end{array}$ & High risk & Quasi-randomized allocation (alternate families) \\
\hline $\begin{array}{l}\text { Blinding of participants } \\
\text { and personnel (perfor- } \\
\text { mance bias) }\end{array}$ & Unclear risk & $\begin{array}{l}\text { Insufficient information to make judgement. Described as double-blind. Moth- } \\
\text { ers reportedly did not know which group they belonged to though no report } \\
\text { specified anything about study personnel }\end{array}$ \\
\hline $\begin{array}{l}\text { Blinding of outcome as- } \\
\text { sessment (detection bias) } \\
\text { All outcomes }\end{array}$ & Low risk & $\begin{array}{l}\text { The initial follow-up assessments and diagnosis of cretinism were made with- } \\
\text { out knowledge of whether the mother received iodine or saline. Cretinism is } \\
\text { the only trial outcome included in this review }\end{array}$ \\
\hline
\end{tabular}


Pharoah 1971 (C) (Continued)

Incomplete outcome data High risk Due to remoteness of the region, only 13 or 16 of the original 27 villages were (attrition bias) visited for the initial follow-up visits where cretinism was originally assessed

All outcomes (different numbers provided in different reports). Later follow-up assessments were only performed in 5 villages for logistical reasons

Selective reporting (re- Unclear risk Insufficient information to make judgement
porting bias)

Other bias High risk

This trial recruited some women (and provided the intervention to these women) before they became pregnant. The intervention may have affected their probability of becoming pregnant, potentially leading to differences between groups and introducing bias

\section{Silva 1981}

Methods
- Study design: quasi-randomized trial with 2 arms. 1 of every 4 participating women was not treated (control group)

- Unit of allocation: individuals

- Time period of recruitment and data collection: not specified
- Description: pregnant women of various gestational ages (baseline gestational ages of final sample of 46 women ranged from 9-32 weeks)

- Location/setting: Eastern greater Santiago, Chile (women came from various suburban and rural areas)

- How participants were recruited and selected: recruited women who attended prenatal outpatient clinics (did not specify how they were selected)

- Inclusion criteria: not specified

- Exclusion criteria: not specified

- Sample size: 250

- Age: not specified

- Socioeconomic status: not specified

- Nutritional status: not specified

- Baseline iodine status of participants/area: half of participants had "significant degree" of iodine deficiency (50/ $\mu \mathrm{g} \mathrm{l} / \mathrm{g}$ creatinine or less), $25 \%$ had moderate deficiency and $15 \%$ had adequate intake

- Baseline coverage of iodized salt: previous analysis of salt from this area of Chile showed wide variation in iodine concentration (50 samples ranged from 0-135 $\mu \mathrm{g}$ iodine/g salt with $50 \%$ being below $10 \mu \mathrm{g}$ and $12 \%$ between 60 and $135 \mu \mathrm{g}$ )

- Breastfeeding practices: not specified

- Other important information about participants or setting:
Experimental intervention: iodine drops

- Total number randomised: unclear (report says 160 , though this is not the expected $75 \%$ of 250 , or 188)

- Timing: baseline gestational ages of final sample of 36 women ranged from 9-32 weeks

- Form: drops

- Frequency and duration: daily, duration in women who completed study ranged from 4-16 weeks

- lodine compound: potassium iodide (KI)

- lodine dose: approximately $300 \mu \mathrm{g}$ iodine/d (10 drops $785 \mu \mathrm{g} / \mathrm{mL} \mathrm{KI}$ solution)

- Other nutrients: none specified

- Adherence: $22 \%$ (36 of 160) of women in intervention group successfully completed protocol and adherence was validated by urinary iodine excretion

Control/comparison intervention: no intervention 
Silva 1981 (Continued)

- Total number randomised: unclear

- Description: no intervention

Co-intervention(s): none specified

\begin{tabular}{ll}
\hline Outcomes & Pregnancy: urinary iodine, serum T4, T3, rT3, TSH \\
& - Postpartum: urinary iodine, serum T4, T3, rT3, TSH at delivery \\
& - Infant/child: serum T4, T3, rT3, TSH at delivery in cord blood \\
\hline Notes & None
\end{tabular}

\section{Risk of bias}

\begin{tabular}{lll}
\hline Bias & Authors' judgement & Support for judgement \\
\hline $\begin{array}{l}\text { Random sequence genera- } \\
\text { tion (selection bias) }\end{array}$ & High risk & $\begin{array}{l}\text { Quasi-randomized controlled trial ("One of every four women was not treated, } \\
\text { forming a control group") }\end{array}$ \\
\hline $\begin{array}{l}\text { Allocation concealment } \\
\text { (selection bias) }\end{array}$ & High risk & $\begin{array}{l}\text { Quasi-randomized. Participants and personnel may have known their alloca- } \\
\text { tion before the intervention }\end{array}$ \\
\hline $\begin{array}{l}\text { Blinding of participants } \\
\text { and personnel (perfor- } \\
\text { mance bias) } \\
\text { All outcomes }\end{array}$ & High risk & $\begin{array}{l}\text { The intervention (or lack of intervention) would have been evident to partici- } \\
\text { pants and personnel }\end{array}$ \\
\hline
\end{tabular}

\begin{tabular}{lll}
\hline $\begin{array}{l}\text { Blinding of outcome as- } \\
\text { sessment (detection bias) } \\
\text { All outcomes }\end{array}$ & Unclear risk & No information provided in the text about blinding of outcome assessment \\
\hline $\begin{array}{l}\text { Incomplete outcome data } \\
\begin{array}{l}\text { (attrition bias) } \\
\text { All outcomes }\end{array}\end{array}$ & High risk & $\begin{array}{l}\text { Only } 36(22.5 \%) \text { out of } 160 \text { completed the intervention, and a similar propor- } \\
\text { tion (only 10) remained in the control group }\end{array}$ \\
\hline $\begin{array}{l}\text { Selective reporting (re- } \\
\text { porting bias) }\end{array}$ & Unclear risk & $\begin{array}{l}\text { We did not have access to the protocol. Insufficient information to make } \\
\text { judgement }\end{array}$ \\
\hline Other bias & Unclear risk & $\begin{array}{l}\text { We could not assess baseline differences between the intervention and control } \\
\text { groups }\end{array}$ \\
\hline
\end{tabular}

\section{Thilly 1978}

\begin{tabular}{ll}
\hline Methods & Study design: randomised controlled trial, 2 arms \\
- Unit of allocation: individual \\
- Time period of recruitment and data collection: enrolment took place from $1973-1977$ \\
\hline Participants & Description: pregnant women \\
- Location/setting: Ubangi, northern Zaire \\
- How participants were recruited and selected: participants attending their first prenatal visit at the \\
maternity ward of Karawa hospital. They originated form the city of Karawa and from the rural villages \\
- Surrounding Karawa \\
- Inclusion criteria: pregnancy \\
- Sample size: 671 women randomised \\
- Age: control: $22.8 \pm 5.9$ years; treated population: $23.4 \pm 6.3$ years
\end{tabular}


Thilly 1978 (Continued)

- Socioeconomic status: not specified

- Nutritional status: not specified

- Baseline iodine status of participants/area: region of Ubangi had a high goitre prevalence. The prevalence of goitre was $70.2 \%$ in the intervention group and $70.6 \%$ in the control group

- Baseline coverage of iodized salt: not specified

- Breastfeeding practices: not specified

- Other important information about participants or setting: None relevant.

Experimental intervention: iodized oil injection
- Total number randomised: $\mathrm{n}=339$
- Timing: second or third trimester, on average 28th week
- Form: injected intramuscularly
- Frequency and duration: single dose
- Iodine compound: not specified (lipiodol)
- Iodine dose: 475 mg slowly resorbable iodine
- Other nutrients: none
- Adherence: not specified

Control/comparison intervention: placebo (described in some reports as multivitamin injection free of iodine)

- Total number randomised: $n=332$

- Description: single dose injected intramuscularly

- Adherence: not specified

Co-intervention(s): no other co-interventions specified

\begin{tabular}{ll}
\hline Outcomes & Pregnancy: serum T3, T4, TSH, TBG (assessed at baseline prior to intervention) \\
- & Postpartum: serum T3, T4, TSH, and TBG at delivery \\
of success for certain tasks, time of acquisition for 4 specific tasks) at 4-9 months, 10-15 months, and \\
$16-23$ months, and neonatal T3, T4, TSH
\end{tabular}

\section{Risk of bias}

\begin{tabular}{lll}
\hline Bias & Authors' judgement & Support for judgement \\
\hline $\begin{array}{l}\text { Random sequence genera- } \\
\text { tion (selection bias) }\end{array}$ & Low risk & $\begin{array}{l}\text { "The two groups were constituted at random using random number tables } \\
\text { and numbered envelopes" }\end{array}$ \\
\hline $\begin{array}{l}\text { Allocation concealment } \\
\text { (selection bias) }\end{array}$ & Unclear risk & $\begin{array}{l}\text { Numbered envelopes were used, with no reference to the envelopes being se- } \\
\text { quentially numbered, opaque, or sealed, therefore the risk is unclear }\end{array}$ \\
\hline $\begin{array}{l}\text { Blinding of participants } \\
\text { and personnel (perfor- } \\
\text { mance bias) }\end{array}$ & Low risk & $\begin{array}{l}\text { Investigators and participants were blinded: "performed all interviews and } \\
\text { examinations under strict double-blind precautions, i.e., neither the mother } \\
\text { nor the investigator knew whether the mother had received the iodine supple- } \\
\text { ment" }\end{array}$ \\
\hline $\begin{array}{l}\text { Blinding of outcome as- } \\
\text { sessment (detection bias) } \\
\begin{array}{l}\text { All outcomes } \\
\hline \hline\end{array}\end{array}$ & Unclear risk & $\begin{array}{l}\text { The study was described as "double-blind" but the reports did not mention } \\
\text { blinding on outcome assessors, therefore insufficient information to permit } \\
\text { judgement }\end{array}$ \\
\hline
\end{tabular}


Thilly 1978 (Continued)

$\begin{array}{ll}\begin{array}{l}\text { Incomplete outcome data } \\ \text { (attrition bias) }\end{array} & \text { High risk } \\ \text { All outcomes } & \begin{array}{l}\text { High loss to follow-up. For example development quotient results were report- } \\ \text { the control group (332 women randomised) }\end{array}\end{array}$

(attrition bias)

Selective reporting (reporting bias)

Unclear risk

The study protocol was not available therefore we had insufficient information to permit judgement

Other bias Unclear risk The study appears to be free of other sources of bias

Zhou 2015

Methods

Participants

- Description: pregnant women

- Location/setting: Women's \& Children's Hospital and the Flinders Medical Centre in Adelaide, Australia

- How participants were recruited and selected:

- Inclusion criteria: singleton pregnancy, less than 20 weeks' gestation

- Exclusion criteria: taking supplements containing iodine, history of thyroid disease or drug or alcohol abuse, fetus with known major abnormality, or English not the main language spoken at home

- Sample size: 59 (planned $n=1089$ )

- Age: iodine group $29.1 \pm 5.7$, placebo group $29.8 \pm 5.1$ (mean \pm SD) years old

- Socioeconomic status: no difference at baseline

- Nutritional status (e.g. BMI, \% under or overweight): iodine group, pre-pregnancy BMI $23.6 \pm 5.5$, placebo group $22.2 \pm 4.3($ mean $\pm \mathrm{SD}) \mathrm{kg} / \mathrm{m}^{2}$

- Baseline iodine status of participants/area: not specified

- Baseline coverage of iodized salt: not specified

- Breastfeeding practices (if applicable): not specified

- Other important information about participants or setting: infant sex was significantly different between groups: 20 male infants (71.4\%) for iodine group, 9 male infants (31.0\%) in control group

Interventions

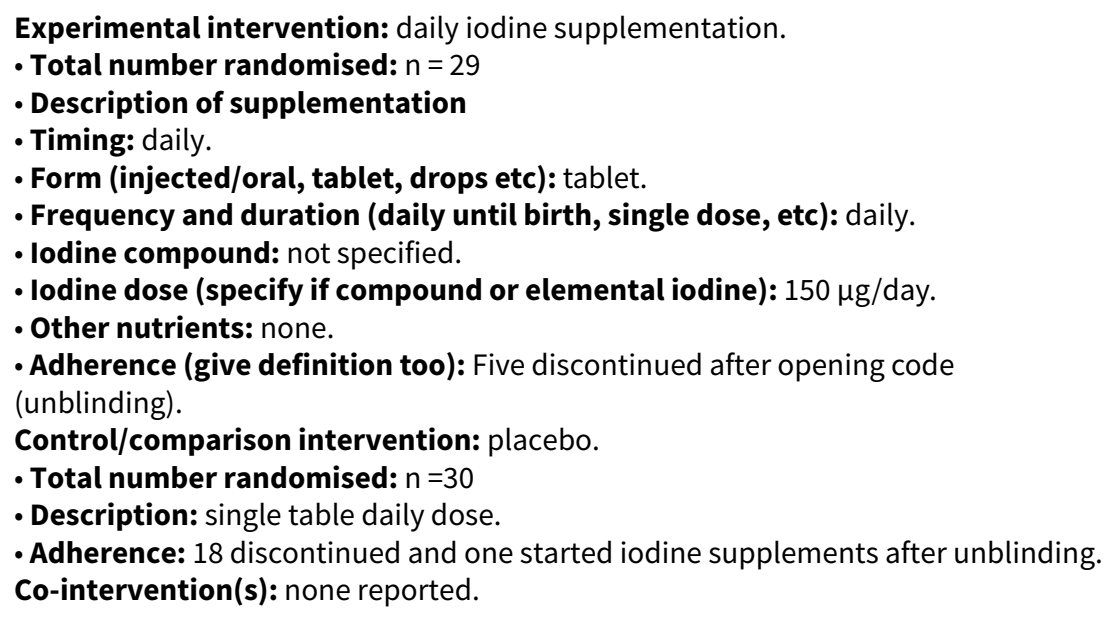

Outcomes

Pregnancy: general health and well being of mothers using validated questionnaires (SF-36 \& Depression, Anxiety and Stress) at 36 weeks and 6 weeks postpartum.

- Postpartum: none reported.

- Infant/child: child development assessed at 18 months: bailey Scale of Infant and Toddler Development III At birth: information on birthweight, length, head circumference, gestational age; pregnancy related morbidities including still birth 
Zhou 2015 (Continued)

preterm birth.

Notes

- The trial was stopped after 59 participants recruited (planned $n=1098$ ). Funding body the National Health and Medical Research Council (NHRMC) withdrew its support for the trial due to being inconsistent with recommendation for iodine supplementation in pregnancy

- Women were informed of their group allocation (mean gestational age at unblinding was $33 \pm 7$ weeks)

- 2 women dropped (1 from each group) from studies, 18 women stopped taking placebo in the placebo group, and 1 woman in the placebo group commenced iodine supplements after unblinding. 5 women discontinued intervention for iodine group after unblinding

\section{Risk of bias}

Bias Authors' judgement Support for judgement

Random sequence genera- Low risk

tion (selection bias)

"Women were randomly assigned to iodine or placebo in the ratio of $1: 1$ through a web-based randomisation service. The randomisation schedule was generated independently with balanced, variable-sized blocks and was stratified by centre, parity ( 0 versus $\geq 1$ ), and gestational age at randomisation ( $\leq 16$ weeks' versus > 16 weeks')"

\begin{tabular}{|c|c|c|}
\hline $\begin{array}{l}\text { Allocation concealment } \\
\text { (selection bias) }\end{array}$ & Low risk & $\begin{array}{l}\text { Quote: "Randomization will be done through central allocation by computer } \\
\text { from a custom built Management Information System" }\end{array}$ \\
\hline
\end{tabular}

\begin{tabular}{|c|c|c|}
\hline $\begin{array}{l}\text { Blinding of participants } \\
\text { and personnel (perfor- } \\
\text { mance bias) }\end{array}$ & High risk & $\begin{array}{l}\text { Participants were told of their group assignment when the trial was stopped - } \\
\text { "mean gestational age at unblinding was } 33 \pm 7 \text { weeks. The mean duration of } \\
\text { intervention before unblinding was } 16 \text { weeks (range } 2-23 \text { weeks) }\end{array}$ \\
\hline
\end{tabular}

\begin{tabular}{|c|c|c|}
\hline $\begin{array}{l}\text { Blinding of outcome as- } \\
\text { sessment (detection bias) } \\
\text { All outcomes }\end{array}$ & High risk & $\begin{array}{l}\text { Some self-reported outcomes were unblinded and likely to have detection } \\
\text { bias. Also, personnel would have been unblinded for some outcome assess- } \\
\text { ments (due to participants being told about group assignment when trial was } \\
\text { stopped early). Though "pregnancy and birth outcome data were collected by } \\
\text { blinded review of medical records", our review includes other outcome as well }\end{array}$ \\
\hline
\end{tabular}

Incomplete outcome data Low risk $\quad$ lodine group 27/29 (93.1\%), placebo group 26/30 (86.7\%)
(attrition bias)
All outcomes

\begin{tabular}{lll}
\hline $\begin{array}{l}\text { Selective reporting (re- } \\
\text { porting bias) }\end{array}$ & Low risk & All outcomes reported in the trial registry ACTRN12610000411044 \\
\hline Other bias & Unclear risk & Appears to be free of other sources of bias \\
\hline
\end{tabular}

BMI: body mass index

EEG: electroencephalogram

IQR: interquartile range

KI: potassium iodide

SEM: standard error of the mean

T3: triiodothyronine

T4: thyroxine

TBG: thyroxine-binding globulin

TSH: thyroid-stimulating hormone

TPO-ab: thyroid peroxidase antibodies

TV: total volume

UIC: urinary iodine concentration

UIE: urinary iodine excretion 
Characteristics of excluded studies [ordered by study ID]

\section{Study Reason for exclusion}

Amiri 2016

100 pregnant women attending 5 healthcare centres in the southern region of Tehran, Iran were randomly assigned to 1 of 2 groups: group $1(n=50)$ received a 4-month educational programme; group $2(n=50)$ received regular counselling. There was no provision of iodine supplementation. This study was excluded because the type of intervention (education) was outside the scope of this review.

490 pregnant women of lower socioeconomic status belonging to goitre-endemic and non-goitre areas in Pakistan were studied.

Group 1 (control): $(n=156)$ subjects from non-endemic goitre areas of Rawalpindi. All women were clinically euthyroid and had no previous known thyroid disorders.

Group 2: $(n=154)$ subjects of the goitre-endemic areas of Muzaffarabad and Skardu with and without thyroid enlargement.

Group 3: $(n=150)$ subjects of goitre-endemic areas of Muzaffarabad and Skardu with thyroid enlargement up to stage 2. These women were given a single dose of 2 capsules of iodized oil (iodized ethyl esters of poppy-seed oil; Lipoidal Ultrafluid, $400 \mathrm{mg}$ of iodine, Guerbet Laboratories, Paris, France) orally in the first trimester from weeks 6-8 of pregnancy

Primary outcome measures included serum T4, T3, TSH and birthweight of newborns

The study was excluded because participants were not randomised (or quasi-randomized) and therefore the design was outside the scope of this review.

86 pregnant women, ages ranged from 20-38 years (mean 31 years) were enrolled from the 10th-16th week of gestation, between February 1995-March 1998

Group A: ( $n=32)$ women, received $200 \mu$ g iodine daily for up to 6 months

Group B: $(n=35)$ women, received $50 \mu$ g iodine daily

Primary outcomes included urinary iodine concentration, thyroid volume and thyroid function (changes in serum FT4 and FT3 levels), and clinical events. Thyroid volume, thyroid functional parameters and urinary iodine concentration were determined in all subjects at booking, at the 18th26th, and the 29th-33rd week of gestation, and at the 3rd and 6th month after delivery.

Both groups received iodine.

This study was excluded because it did not include a placebo/no intervention group therefore the comparison was outside the scope of this review.

The study was a cross-sectional study performed on schoolchildren and pregnant women in 4 cities in the Islamic Republic of Iran. The study evaluated UIE in 438 school children and 403 pregnant women. In Isfahan City, thyroid volume was also measured by sonography for 30 pregnant women in each trimester of pregnancy and for 90 non-pregnant women who also had urinary iodine measurement.

This study was excluded because it was cross-sectional, therefore the design was outside the scope of this review. 


\section{Study Reason for exclusion}

Group 2: ( $n=102)$, enrolled at their first pregnancy visit, children of mildly hypothyroxinaemic women diagnosed during the first 12-14 gestational weeks and with FT4 above the 20th percentile at full-term

Group 3: $(n=151)$, children born to mildly hypothyroxinaemic women at full-term, without iodine supplementation during gestation

The study used the Brunet-Lezine scale to evaluate neurocognitive performance at 18 months of age

All women were supplemented orally with iodine ( $200 \mu \mathrm{g} \mathrm{KI}$ per day) from the day of enrolment to the end of lactation

The study was excluded because participants were not randomised (or quasi-randomized), therefore the study design was outside the scope of this review.

Cao 1994 This study was a review on the efficacy of iodination of irrigation water as a method of supplying iodine to a severely iodine-deficient population in Xin Jiang, China. This study was excluded because it assessed iodination of water, therefore it was outside the scope of this review.

The aim of the study was to determine the effectiveness of 3 treatment regimens of orally administered iodized oil. Participants were recruited in the mountainous region of Algeria. 3 groups of treated mother-newborn pairs were compared with an untreated group.

Group A: $(n=213)$, mothers treated before pregnancy; $0.5 \mathrm{~mL}$ of iodized oil (lipiodol ${ }^{\circledR}, 240 \mathrm{mg}$ of iodine)

Group B: $(n=190)$, mothers treated during the first month of pregnancy; $0.5 \mathrm{~mL}$ of iodized oil (lipiodol $^{\circledR}, 240 \mathrm{mg}$ of iodine)

Group C: $(n=151)$, mothers treated during the 3rd month of pregnancy; $0.5 \mathrm{~mL}$ of iodized oil (lipiodol $^{\circledR}, 240 \mathrm{mg}$ of iodine)

Group D: $(\mathrm{n}=982)$, no treatment

Primary outcome measures included urinary and milk iodine concentration, TSH, FT4 and birthweight

This study was excluded because participants were not randomised (or quasi-randomized), therefore the design was outside the scope of this review. Europe. Specifically the article focused on the experiences of Spain and Italy in reducing the prevalence of iodine disorders.

The article was excluded because it was a descriptive paper, therefore the study design was outside the scope of this review.

The study reported the cases of 3 infants with congenital hypothyroidism detected with the use of a newborn screening program. Evidence supported excess maternal iodine ingestion $(12.5 \mathrm{mg} / \mathrm{d})$ as the etiology. Levels of whole blood iodine extracted from their newborn screening specimens were 10 times above mean control levels.

The article was excluded because it was a case study, therefore the study design was outside the scope of this review. groups. However the numbers were greatly reduced before the final analysis of the results. Intervention mothers were given 12 drops of iodine solution twice a day in milk for 4 days starting on the morning of the 6 th day after delivery. The solution was made by dissolving $10 \mathrm{~g}$ of potassium iodide in $100 \mathrm{~mL}$ of distilled water, then adding $5 \mathrm{~g}$ of iodine. Initially women in the control 


\section{Study Reason for exclusion}

group were given dummy milk drinks containing no iodine, but that practice was discontinued.

The health of the mother and child were investigated 3 months post-delivery. During this visit cases were discarded if any illness or abnormality were disclosed. 5 women had a moderately enlarged thyroid but no signs of thyrotoxicosis; 2 were given iodine and 3 received no treatment.

The study was excluded because participants were not randomised (or quasi-randomized), therefore the study design was outside the scope of this review. cy.

The article was excluded because it was a review paper, therefore the study design was outside the scope of this review.

This paper reviewed the data from the literature on the iodine requirements during pregnancy, lactation and the neonatal period, and provided recommendations regarding the median concentrations of urinary iodine indicating optimal iodine nutrition during these critical periods of life.

The article was excluded because it was a review paper, therefore the study design was outside the scope of this review.

Fierro-Benitez 1988

Children (8-15 years of age) of mothers who received injections of iodinated oil prior to the end of the first trimester of pregnancy were compared with children of the same age from a comparable neighbouring community whose mothers had received no iodinated oil. The authors used test of intellectual function, psychomotor maturation, school dropout rates, grades achieved, grades repeated, and overall performance as judged by teacher notes in school records.

The article was excluded because participants were not randomised or quasi-randomized, therefore the study design was outside the scope of this review.

Gruñeiro-Papendieck 2004

The aim of the study was to estimate whether the WHO-recommended neonatal TSH screening cutoff, when applied to newborns older than 48 hours of age (native to Buenos Aires), coincides with the traditional ones (goitre and urinary iodine in school-age children). The study also assessed if the evaluation varies based on the methodology used for TSH measurement and/or the time of specimen sampling. Primary outcome measures included TSH levels, thyroid volume (direct palpation) and urinary iodine levels.

The study was excluded because it assesses a screening methodology, therefore the study design outside the scope of this review.

This paper reported on the progress towards eliminating iodine deficiency, with particular reference to the role of the International Council for Control of Iodine Deficiency Disorders, a nongovernmental organization founded in 1986.

The article was excluded because it was a descriptive paper, therefore the study design was outside the scope of this review.

Treatment group: 60 schoolchildren and 13 pregnant mothers were examined at the baseline. During the first visit iodized oil orally (Lipiodol; Laboratoire Guerbert, Paris, France) in the form of capsules after the baseline data had been collected.

Control group: 105 schoolchildren and 18 pregnant mothers

Only areas with moderate-severe prevalence of iodine deficiency disease were selected. Legap Post and Yum Post were selected as the intervention areas by purposive sampling. Areas selected for control, namely Perwor Post and Poi Post, were also purposely selected as these areas were inhabited by a similar tribe with similar IDD endemicity.

The study was excluded because participants were not randomised or quasi-randomized, therefore the study design was outside the scope of this review. 


\section{Study Reason for exclusion}

Joshi 2011

The study assessed the effect of iodine supplementation during second half pregnancy and its effect on perinatal outcomes (maternal and neonatal health). The intervention group was of 60 pregnant women of first and second trimester those who were registered in Chautara Hospital and district ANC centre; the control group was of 60 pregnant women of similar pregnancy status, admitted in the maternity ward of same hospital. The intervention group was provided with a mineral capsule containing $150 \mu \mathrm{g}$ of iodine to take orally every day from the day of enrolment till delivery along with iron plus folic acid tablets and maternal and neonatal healthcare package. The control received no intervention.

The study was excluded because participants were not randomised or quasi-randomized, therefore the study design was outside the scope of this review.

Kamiński 2003

The aim of the study was to determine the degree of iodine deficiency and thyroid function in pregnant women prior to and after the introduction of iodized salt. Primary outcomes included urinary iodine excretion and serum levels of TSH, FT3 and FT4. They were determined in pregnant women divided into 2 groups - with and without iodine supplementation.

The study was excluded because it was an observational study on iodized salt, therefore the study design and intervention were outside the scope of this review.

This was a cross-sectional study to assess the correlation between maternal iodine intake and neonatal thyroid volume in 89 mother-child pairs. 32 mothers (36\%) took iodide tablets on a regular basis during pregnancy (average daily iodine dose was $175 \mu \mathrm{g} \mathrm{K}$-iodide).

57 mothers did not use iodine supplements.

Outcomes in mothers and neonates included thyroid volume and urinary iodine excretion

The study was excluded because it was cross-sectional, therefore the study design was outside the scope of this review.

Kurtoglu 2004

The study assessed the iodine status and the thyroid function of pregnant women and their neonates in the region of Kayseri (central Anatolia of Turkey).

Included 70 pregnant women (18-37 years of age) and their full term neonates

Outcomes included urinary iodine concentration, FT4, FT3, TSH and Tg of mothers and neonates, breast milk iodine concentration

The study was excluded because it was cross-sectional, therefore the study design was outside the scope of this review.

The aim of the study was to assess iodine status and goitre prevalence in a sample of schoolchildren (5-12 years) in Melbourne.

Primary outcome measures included urinary iodine concentration and presence of goitre (determined by thyroid gland palpation).

The study was excluded because it was cross-sectional, therefore the study design was outside the scope of this review. from the Amhara region of Ethiopia.

44 communities were randomly assigned to early access to iodized salt (intervention) or later through market forces (control).

1220 pregnant women were recruited.

Primary outcome was child development (Bayley scales: cognition, expressive language, receptive language and fine motor scales) 


\section{Study}

Reason for exclusion

The study was excluded because it assessed iodized salt, therefore the comparison was outside the scope of this review.

Moleti 2008

The study examined the effects of long-term iodized salt consumption on maternal thyroid function during gestation.

Thyroid function was prospectively evaluated in 100 consecutive TPO-ab-negative pregnant women from a mildly iodine-deficient area in northeastern Sicily, Italy.

62 had regularly used iodized salt for at least 2 years prior to pregnancy (long-term iodine supplemented).

38 had commenced iodized salt consumption upon becoming pregnant (short-term iodine supplemented).

The study was excluded because it was observational, therefore the study design was outside the scope of this review.

Morreale de Escobar 1993

This paper was a review of the literature on the role of maternal thyroxin transfer in the relationship between iodine deficiency and thyroid hormone metabolism and the brain in fetal rats.

The study was excluded because it was an animal study and a review paper, therefore the study design was outside the scope of this review.

Murcia 2011

The authors assessed the association of maternal iodine intake from diet and supplements during pregnancy and of maternal and neonatal thyroid function with infant neurodevelopment.

The Mental Development Index and Psychomotor Development Index (PDI) for 691 children was obtained between 2005-2007 using the Bayley Scales of Infant Development at age 1 year in Valencia, Spain.

The study was excluded because it was observational, therefore the study design was outside the scope of this review.

The aim of the present study was to assess the extent to which iodine requirements were met in pregnant women living in different regions throughout Denmark.

152 healthy pregnant women admitted to 5 different Danish departments of obstetrics participated in the study. lodine status was evaluated by measurement of urinary iodine 5 days postpartum. Urinary iodine excretion and intake of iodine-containing vitamin/mineral tablets were assessed.

The study was excluded because it was observational, therefore the study design was outside the scope of this review.

O'Donnell 2002 The study assessed the growth and development of children whose mothers received iodine during pregnancy, and children who received iodine first in their 2 nd year of life. Children were from the southern part of China's Xinjiang Province which has the lowest levels of iodine in water and soil ever recorded.

Outcome measures included psychological development (Raven Progressive Matrices and the Developmental Test of Visual Motor Integration), fine motor planning and speed (Purdue Pegboard Test) and anthropometric measures.

The study was excluded because it was observational, therefore the study design was outside the scope of this review.

The paper described findings from neonatal TSH screening in hospitals in Poland, in relation to the use of iodine-containing antiseptics.

The study was excluded because it was observational, therefore the study design was outside the scope of this review. 


\section{Study Reason for exclusion}

Qian 2005

This study was a systematic review and meta-analysis on the effects of iodine on the intellectual development of children in China.

The study was excluded because it was a systematic review, therefore the study design was outside the scope of this review.

\section{Rebagliato 2013}

This study assessed the association between iodine supplementation in pregnancy and infant psychomotor development. It was a multicentre mother and child cohort study in Spain in the regions of Valencia, Sabadell (Catalonia), Asturias, and Gipuzkoa (Basque Country). Neuropsychological development was assessed using the Bayley Scales of Infant Development in 1519 infants (median age, 16 months).

The study was excluded because it was observational, therefore the design was outside the scope of this review.

The study evaluated the effect of iodine supplementation, using 2 different doses (50 and $200 \mu \mathrm{g}$ ), on the prevalence of postpartum thyroiditis and the decrease in thyroid volume up to 8 months postpartum, in an area of mild iodine deficiency. It involved 2 studies:

Study 1: 56 women were evaluated 5 days and 3 months after delivery.

Study 2: 70 women were randomised to receive 50 and $200 \mu \mathrm{g}$ of potassium iodide for 8 months postpartum, beginning 5 days after delivery. Outcomes included thyroid volume and thyroid hormone parameters (T3, T4, FT4 and TSH), measured 5 days, 3 months, and 8 months postpartum.

Study 1 was excluded because it was observational, therefore the study design was outside the scope of this review. Study 2 was excluded because it compared 2 iodine doses and lacked a placebo/no intervention control group, therefore the comparison was outside the scope of this review.

This study assessed the effect of iodized salt on thyroid size during pregnancy.

Intervention: 17 women who received iodized salt (equivalent to $120 \mu \mathrm{g}-180 \mu \mathrm{g}$ of iodine/d)

Control: 18 women who received no iodized salt

Outcomes included thyroid volume and urinary iodine concentration in each trimester.

The study was excluded because it compared iodized salt to no intervention, therefore the comparison was outside the scope of this review.

Study compared thyroid function of neonates/infants born to women who had received iodized oil to those of a control group.

Intervention: 669 healthy pregnant women received $1 \mathrm{~mL}$ containing $480 \mathrm{mg}$ injected iodized oil (Lipidol, Laboratory Guerbet, France) intramuscularly.

Controls: randomly selected among non-injected (at the time of this study) pregnant women's infants. Outcome included serum T4, T3 and TSH concentrations.

The study was excluded because it was not randomised (or quasi-randomized), therefore the study design was outside the scope of this review.

This study examined factors that may have an impact on iodine economy in postpartum women, including pregnancy duration, infant body weight, and recovery of TSH levels postnatally (data came from a randomised controlled trial on the Kangaroo Care Method).

The study was excluded because it was observational, therefore the study design was outside the scope of this review. children. It was a retrospective study of 40 schoolchildren aged 7-13 years, from the previously iodine deficient villages of Kiga and Randan, Iran. The children were divided into 3 subgroups: sub- 
group 1: the mother had received iodized oil 1-4 years prior to conception and infant consumed iodized salt from the age 1-4 years onwards; subgroup 2: mothers received iodized oil during pregnancy and the child received iodized salt from the age 2-4 years and subgroup 3: the child received iodized oil injection from age 1-3 years iodized salt from 3-6 years of age onwards.

A group of 40 age and sex matched schoolchildren from Tehran served as controls.

Outcome measures included the Bender Gestalt (BG) test, urinary iodine concentration and serum concentrations of T4, T3, TSH.

The study was excluded because it was observational, therefore the study design was outside the scope of this review.

This study assessed the effects of improving iodine intakes with iodized salt or different iodine supplement doses. 131 pregnant women before week 10 of pregnancy, from a healthy pregnancy programme at primary care centres in Jaen (Spain), were randomly assigned to 3 groups: group 1: (n $=38$ ), iodized salt group; group 2: $(n=55)$, supplementation with $200 \mu \mathrm{g}$ potassium iodide/d; and group 3: $(\mathrm{n}=38)$, supplementation with $300 \mathrm{mg} \mu \mathrm{g}$ potassium iodide/d.

Outcome measures included urinary iodine concentration, thyroid volume, TSH, FT4, FT3, thyroglobulin and breast milk iodine concentration.

The study was excluded because it compared two iodine supplemental doses with iodized salt and included no placebo/no intervention group, therefore the comparison was outside the scope of this review.

The study aimed to examine the relationship between thyroid volume and urinary iodine excretion during pregnancy in Ireland, an area of moderate iodine intake, and to study urinary iodine excretion in neonates of mother who breast- and formula-fed. It included 2 groups:

Group A: 115 women, selected opportunistically, in that each trimester's study group comprised different individuals. An additional group of 108 women had urine sampled 3 days after delivery; 64 of these were breastfeeding and 44 were formula feeding. A further 84 women were studied during the late puerperium (approximately 40 days postpartum.

Group B: 38 , women's urine samples collected sequentially during the 3 trimesters of pregnancy and at approximately 6 weeks postpartum. Of those 38 subjects, 20 had thyroid ultrasound scans during each trimester of pregnancy and at 6 weeks postpartum.

The study was excluded because it was observational, therefore the study design was outside the scope of this review.

The study assessed whether the high titers of thyroid antibodies previously reported in Sri Lankan schoolgirls were also present in adult females, and also to assess alterations in antibody titer during normal pregnancy and possible relationships to iodide intake.

25 pregnant Sri Lankan women aged 20-44 years had sequential blood samples taken during each of the 3 trimesters of pregnancy and at 6 weeks postpartum.

57 nonpregnant females aged 21-38 years old served as controls.

Outcomes included thyroglobulin antibodies, thyroid peroxidase antibodies and urinary iodine concentration

The study was excluded because it was observational, therefore the study design was outside the scope of this review. deficiency in pregnant women and to develop a standard prophylactic iodine dose schedule for these women.

Group 1: $(\mathrm{n}=52)$, treated with $200 \mu \mathrm{g}$ potassium iodide/d 


\section{$\begin{array}{ll}\text { Study } & \text { Reason for exclusion }\end{array}$}

Group 2: ( $n=69)$, treated with $300 \mu$ g potassium iodide/d

Outcome measures included TSH, free thyroxin and antithyroid peroxidase antibody levels, urinary iodine and thyroid volume.

This study was excluded because it compared 2 different iodine doses with no placebo/no intervention group, therefore the comparison was outside the scope of this review.

One of the study objectives was to assess the impact of iodine supplements in pregnancy on urinary iodine excretion of women and their newborns.

54 women were divided into 2 groups

Group 1: $(n=26)$ women who took multivitamin supplements that contained $150 / \mu \mathrm{g}$ potassium iodide in pregnancy and their newborns

Group 1: $(n=28)$ parturient women who did not take any iodine supplements, and their newborns (report does not specify whether they took a supplement containing other vitamins/minerals)

Urinary iodine excretions studied in both groups (in women a few days before childbirth or during labour, and on newborns during 1st or 2 nd 24 hours of life

This study was excluded because it was a prospective study with allocation to groups (intervention and control) (with no indication of random or quasi-random allocation), therefore the study design was outside the scope of this review.

Velasco 2009

Study aim was to evaluate the psychological development of infants (3-18 months of age) whose mothers received iodine supplements during the first trimester of pregnancy, and compare with those whose mothers received no iodine.

Intervention: (133 women) infants ( 3 to 18 mo of age) whose mothers received $300 \mu \mathrm{g}$ iodine during the first trimester.

Control: (61 women) infants whose mothers did not receive any iodine supplementation during pregnancy.

Main outcomes included child neuropsychological status (evaluated with the Bayley Scales of Infant Development), TSH, free T3, free T4, and urinary iodine concentration.

The study was excluded because it was a non-randomized controlled trial, therefore the study design was outside the scope of this review.

Vermiglio 2004

The study aim was to identify the long-term effects of iodine deficiency-related maternal hypothyroxinaemia on child development (behavioral, psychoneurological, and intellectual).

16 children born to healthy mothers living in a moderately iodine-deficient area were compared to 11 children born to age-matched women from an area with marginally sufficient iodine intake. Thyroid function of the mothers was monitored during early gestation.

Outcome measures included behavioral and neuropsychological evaluation and attention deficit and hyperactivity disorder screening, intelligence testing (Wechsler Intelligence Scale for Children, 3rd edition), and maternal and child thyroid function tests.

This study was excluded because it was a prospective observational study, therefore the study design was outside the scope of this review.

Versloot 1997

The aim of this study was to clarify the effects of iodine deficiency and pregnancy on iodide uptake by the thyroid. Radioiodide was injected intravenously into non-pregnant and 19-day pregnant rats (Wistar rats (CPB/WU,IFFA CREDO, Brussels) receiving a normal or marginally iodine-deficient diet.

The study was excluded because it was an animal study, therefore the participants were outside the scope of this review. 


\section{Study Reason for exclusion}

Vitnerova 2000

Study aim was to estimate the iodine supply for pregnant women in Teplice district, Czech Republic.

A cohort of 348 pregnant women who received daily iodine supplementation during pregnancy and the control groups was 231 women of similar age. The main outcome was urinary iodine concentration.

This study was excluded because it was not randomised (or quasi-randomized), therefore the study design was outside the scope of this review.

Study aim was to analyse neuropsychological performance of schoolchildren living in areas with different iodine intake, and in an area before and after iodine prophylaxis.

Outcomes included various neuropsychological tests: 1) reaction time, 2) the block design subtest of the WISC-R, 3) the coding subtest of the WISC-R.

The study was excluded because it was observational, therefore the study design was outside the scope of this review. cially for pregnant and lactating women. The researchers examined iodine content of household salt and drinking water in 11 Chinese provinces.

Outcome measures included iodine content of household salt and drinking water, thyroid volume, urinary iodine concentration, and iodine in breast milk and thyroid size in adult women.

The study was excluded because it was observational, therefore the study design was outside the scope of this review.

Urine samples from 950 young women from iodine deficient areas and urinary iodine concentration determined. 150 of the 347 included pregnant women were selected and divided into 3 groups: Group A - normal control (urinary iodine $>0.788 \mu \mathrm{mol} / \mathrm{L}$ ); Group B - an iodine-deficient placebo control and Group C - iodine-deficient supplemented with iodine. The intervention was iodine supplementation (not specified in the English language abstract).

Outcomes included infant height, weight and head circumference.

The study was excluded because it was not randomised (or quasi-randomized), therefore the study design was outside the scope of this review. tration.

Nationally representative sample of primary schoolchildren and pregnant women were selected in 1999 and 2004 and the iodine content of household salt and urine were determined. Neonatal elevated thyrotropin concentration from a screening program was evaluated before and after the change.

The study was excluded because it was observational, therefore the study design was outside the scope of this review.

FT3: free triiodothyronine

FT4: free thyroxine

IDD: iodine deficiency disorder

$\mathrm{KI}$ : potassium iodide

Tg: thyroglobulin

TPO-ab: thyroid peroxidase antibodies

TSH: thyroid-stimulating hormone 
UIE: urinary iodine excretion

Characteristics of studies awaiting assessment [ordered by study ID]

\section{Belykh 2014}

Methods

The study objective was to evaluate iodine status in pregnant women and their newborns and the effectiveness of antenatal iodine prophylaxis. A total of 183 pregnant women and their newborns were enrolled and assigned to 3 groups: 46 mothers (1st group) were in the iodine supplementation during pregnancy and lactation group ( $200 \mu \mathrm{g} /$ day potassium iodide), 96 women did not receive supplementation ( 2 nd group) and 58 were in the iodized salt group (3rd group). The abstract also mentioned a study in 1052 women, pregnant in the third trimester of gestation (where urinary iodine concentration (UIC), BMIC, serum TSH and FT4 were determined) and also iodine status in newborns evaluated as part of neonatal screening for congenital hypothyroidism ( $n=948)$.

\begin{tabular}{ll}
\hline Participants & Pregnant and lactating women (for the iodine supplementation component of the study) \\
\hline Interventions & lodine supplementation ( $200 \mu \mathrm{g} /$ day potassium iodide) and iodized salt \\
\hline Outcomes & $\begin{array}{l}\text { UIC, TSH and FT4 in pregnancy, elevated TSH in newborns, UIC in infants, BMIC in postpartum } \\
\text { women }\end{array}$ \\
\hline Notes & $\begin{array}{l}\text { Conference proceedings abstract (from the European Thyroid Association 38th Annual Meeting, } \\
\text { Santiago de Compostela, September 2014). We cannot locate a published manuscript from this } \\
\text { study. } \\
\text { The method of allocation is unclear therefore this study is awaiting classification until further infor- } \\
\text { mation is available. }\end{array}$
\end{tabular}

Hronek 2001

\begin{tabular}{ll}
\hline Methods & $\begin{array}{l}\text { The article describes the physiology of the thyroid gland, consequences of low iodine intake, and } \\
\text { the importance and risk of iodine supplementation in pregnancy. }\end{array}$ \\
\hline Participants & Information not available \\
\hline Interventions & Information not available \\
\hline Outcomes & Information not available \\
\hline Notes & $\begin{array}{l}\text { Article is written in Czech and requires translation. Only the abstract is available in English and it } \\
\text { does not contain sufficient information to determine whether the study is eligible therefore it is } \\
\text { awaiting classification until further information is available. }\end{array}$ \\
\hline
\end{tabular}

BMIC: breast milk iodine concentration

FT4: free thyroxine

TSH: thyroid-stimulating hormone

UIC: urinary iodine concentration

Characteristics of ongoing studies [ordered by study ID]

\section{Caron 2006}

Trial name or title
Phase III: Preventing lack of iodine during pregnancy. Effect of supplying women with potassium iodide to the neuro-cognitive children development until 2 years. 
Caron 2006 (Continued)

Methods

Pregnant women randomised to 2 parallel groups before 12 weeks amenorrhoea (each group with 187 participants). 1 group receives iodine and the other receives a placebo. Follow up visits at the 5th and 8th month of pregnancy, the day of birth, and 6, 12, and 24 months postpartum
374 pregnant women. Inclusion criteria: pregnancy less 12 weeks amenorrhoea with clinically normal pregnancy, agree to take part in the study and able to sign an informed consent form
Interventions Intervention group: daily dose of $200 \mu \mathrm{g}$ of potassium iodide

Control group: placebo

\section{Outcomes}

Primary outcome: neuro-cognitive development of children. Secondary outcomes: prevalence of hypothyroxinaemia and hypothyroidism during pregnancy, change in the functional thyroid parameters of mother during iodine treatment, psychometric development of children, quantify the iodine supply from the woman to the baby during breast feeding

\begin{tabular}{ll}
\hline Starting date & December 2006 \\
\hline Contact information & Principal Investigator: Philippe Caron/Endocrinology - University Hospital Toulouse, France, 31059 \\
\hline Notes & None \\
\hline
\end{tabular}

\section{Nyström 2015a}

Trial name or title lodine status in Swedish pregnant women - effect of iodine supplementation in the thyroid function of mother and infant

\section{Methods}

This is a prospective, double-blinded placebo-controlled trial of 200 pregnant women and their children. Mothers are randomised to $150 \mathrm{\mu g} /$ day iodide supplementation or placebo for 26 weeks. In parallel 90 healthy female controls are recruited from the same community stratified for age and smoking habits. Participants are included after the first mother health care (MVC) visit by the midwife at Skövde. UIC, U-creatinine, thyroid hormones, TSH, Tg and TPO-ab are collected and a simple questionnaire is filled in week $10 \pm 2$ of pregnancy and placebo/iodide is started. Selenium and iron will also be measured. The same measurements are collected in week $25 \pm 1$ week and week 36 \pm 2 weeks. Directly after delivery (within 5 days), BMIC and UIC in the mother as well as UIC and TSH in the newborn child are collected and a simple questionnaire is filled in. Weight, length and APGAR in the child and pregnancy complications are registered. Blood is also frozen for future analyses. Controls are collected from a randomised sample attained by the Swedish Tax Agency of premenopausal women from the same community stratified for age and smoking habits. UIC, u-creatinine, FT4, TSH, Tg, TPO-ab, selenium, iron and samples to be frozen are collected and a questionnaire is filled in. The primary purpose for having a control population is to ascertain that the normal population in the area of Skövde is iodine sufficient.

Participants

Pregnant women (<11 weeks' gestation), aged 18-40 years, intent on a full-term pregnancy, who agree to taking no iodine-containing supplements during the study except for the study medication

Interventions Intervention group: iodine-containing multivitamin (150 $\mu$ g iodine), 1 tablet daily starting at $10 \pm 2$ weeks' gestation

Control group: non-iodine containing multivitamin, 1 tablet daily

\section{Outcomes}

Primary outcomes: milk iodine concentration in colostrum, urinary iodine concentration in the newborn child, TSH in the newborn child

Secondary outcomes: urinary iodine concentration in the mother (weeks $10 \pm 2,25 \pm 1$, and $36 \pm 2$ of pregnancy), $\mathrm{Tg}$ in the mother (weeks $10 \pm 2,25 \pm 1$, and $36 \pm 2$ of pregnancy), FT4 in the mother 
Nyström 2015a (Continued)

(week $10 \pm 2,25 \pm 1$, and $36 \pm 2$ of pregnancy), TSH in the mother (weeks $10 \pm 2,25 \pm 1$, and $36 \pm 2$ of pregnancy)

\begin{tabular}{|c|c|}
\hline Starting date & November 2012 \\
\hline \multirow[t]{4}{*}{ Contact information } & $\begin{array}{l}\text { Location: Center for Endocrinology and Metabolism, Sahlgrenska University Hospital, Gothenburg, } \\
\text { Sweden }\end{array}$ \\
\hline & Principal Investigator: Helena Filipsson Nyström, Ass. Prof. \\
\hline & Contact: Åsa Nilsson, Nurse +46500 - 432500 asa.maria.nilsson@vgergion.se \\
\hline & $\begin{array}{l}\text { Contact: Sofia Manousou, PhD student +46700595310 sofia.manousou@vgergion.se } \\
\text { Contact: Lena Hulthén, Prof +46708574991 lena.hulthén@gu.se }\end{array}$ \\
\hline Notes & Helena Filipsson Nyström is conducting a similar trial with breastfeeding women (Nyström 2015b) \\
\hline
\end{tabular}

\section{Nyström 2015b}

$\begin{array}{ll}\text { Trial name or title } & \begin{array}{l}\text { lodine status in Swedish lactating women - effect of iodine supplementation in the thyroid function } \\ \text { of mother and infant }\end{array}\end{array}$

This is as a prospective, double-blind, placebo-controlled study of 200 mothers and their infants. In
parallel, 90 age-matched healthy non-pregnant women are recruited. Mothers are randomised to
$150 \mu \mathrm{g} /$ day iodide supplementation or placebo. Pregnant women are asked to participate during
a visit in pregnancy week 35, at the mother health care (MVC) at Mölnlycke and Skövde. The study
will run for approximately 6 months for each individual and begins by sampling 1 (UIC, TSH, FT4,
TPO-ab) at week 37 of the pregnancy. 1 week after birth, when sample 2 is collected (as above in-
clusively BMIC), women get randomised to $150 \mu$ iodine or placebo. New sampling 3 (UIC, TSH,
FT4, BMIC) and 4 (same as sampling 2) is collected after 3 and 6 months respectively. 6 months af-
ter birth the study is completed for every individual. In parallel, 90 healthy non-pregnant, non-lac-
tating women in the same age range are recruited and followed with UIC, TSH, FT4, TPO-ab for 6
months as a control group. In each case a simple questionnaire is filled and blood is also frozen for
future analyses.
Participants Pregnant women aged 18-40 years, > 36 weeks' gestation with singleton pregnancy, who intend to breastfeed, have no thyroid disease, and agree to take no iodine-containing supplements during the study except as provided through the study. Women are recruited during pregnancy and the in- tervention begins 1 week postpartum.

\begin{tabular}{ll}
\hline Interventions & Intervention group: iodine-containing multivitamin (150 $\mu$ g iodine), 1 tablet daily \\
Control group: non-iodine containing multivitamin, 1 tablet daily
\end{tabular}

Outcomes Primary outcomes: milk iodine concentration ( 3 and 6 months after birth), urinary iodine concentration in the infant ( 3 and 6 months after birth)

Secondary outcomes: TSH in the mother ( 3 and 6 months after birth), FT4 in the mother ( 3 and 6 months after birth), TPO-ab in the mother ( 6 months after birth), urinary iodine concentration in the mother ( 3 and 6 months after birth)

\begin{tabular}{ll}
\hline Starting date & October 2011 \\
\hline Contact information & Location: Center for Endocrinology and Metabolism, Sahlgrenska University Hospital, Gothenburg, \\
& Sweden. \\
& Principal Investigator: Ass. Prof. Helena Filipsson Nyström \\
& Contact: Mille Milakovic, MD, PhD +4610 4733610 mille.milakovic@vgregion.se \\
\hline
\end{tabular}


Nyström 2015b (Continued)

Contact: Sofia Manousou, PhD student +4670 0595310 sofia.manousou@vgregion.se

Contact: Robert Eggertsen, Prof +46708782250 robert.eggertsen@vgregion.

Notes

Helena Filipsson Nyström is conducting a similar trial with pregnant women (Nyström 2015a)

\section{Teng 2013}

Trial name or title

Screening and intervention for iodine deficiency, iron deficiency and subclinical thyroid insufficiency in women planning pregnancy and in early pregnant women

Methods

Randomized parallel-controlled trial. Women randomised to the following groups. Group A: iodine supplement in pregnant women with mild iodine deficiency (sample size: 300), Group B: no intervention in pregnant women with mild iodine deficiency (sample size: 300 ), Group C: no intervention in pregnant women with adequate iodine status (sample size: 300 ), Group D: iodine supplement in women with mild iodine deficiency before pregnancy (sample size: 300 ), Group E: no intervention in women with mild iodine deficiency before pregnancy (sample size: 300), Group F: no intervention in women with adequate iodine status before pregnancy (sample size: 300), Group G: no intervention in TPO-ab+ pregnant women (sample size: 200), Group H: levothyroxine treatment in TPO$a b+$ pregnant women (sample size: 200 ), Group I: no intervention in TPO-ab+ women before pregnancy (sample size: 200), Group J: levothyroxine treatment in TPO-ab+ women before pregnancy (sample size: 200), Group K: no intervention in pregnant women with hypothyroxinaemia (sample size: 200), Group I: levothyroxine treatment in pregnant women with hypothyroxinaemia (sample size: 200 ), Group J: no intervention in women with hypothyroxinaemia before pregnancy (sample size: 200$)$

\begin{tabular}{ll}
\hline Participants & Pregnant women before the 8th gestational week (or women planning pregnancy) \\
\hline Interventions & As described in methods \\
\hline Outcomes & $\begin{array}{l}\text { Primary outcomes: thyrotropin, T4, TPO-ab, UIC, urine creatine, pregnant and obstetric complica- } \\
\text { tions, delivery condition, neonatal quality, neonatal birth defects, neurodevelopmental index }\end{array}$ \\
& Secondary outcomes: iodine in hair or nail and ferritin \\
\hline Starting date & December 2013 \\
\hline Contact information & Study leader: Weiping Teng/+86 24 83283294/twp@vip.163.com/ \\
& $\begin{array}{l}\text { Institute of Endocrinology of 1st Affiliated Hospital of China Medical University, Shenyang City, Chi- } \\
\text { na }\end{array}$ \\
\hline Notes & Applicant: Xiaohui Yu / $862483282152 /$ cmuyuxh@163.com / same address as study leader \\
\hline
\end{tabular}

\section{Torres 2010}

Trial name or title Nutritional status of iodine in the pregnant population of Catalonia: a study dietary habits and urinary iodine

\section{Methods}

Cluster randomised, controlled, multicentre trial. Randomization unit: Primary Care Team. Statistical analysis: descriptive analysis of all variables will be performed as well as multilevel logistic regression. All analyses will be carried out on an intention-to-treat basis and will be fitted for potential confounding factors and variables of clinical importance 
Torres 2010 (Continued)

Participants

Interventions

898 pregnant women over the age of 17 years attending consultation to a midwife during the first trimester of pregnancy in the participating primary care centres

Intervention group: group education during the first trimester of gestation on healthy hygiene-dietetic habits and the importance of adequate iodine nutritional status

Control group: Usual care

\begin{tabular}{ll}
\hline Outcomes & $\begin{array}{l}\text { Primary outcomes: iodine deficiency (urinary iodine excretion below } 150 \mu \mathrm{g} / \mathrm{L} \text { ) at } 24 \text { and } 36 \mathrm{weeks} \\
\text { of pregnancy } \\
\text { Secondary outcome: many including iodized salt consumption, iodine supplementation consump- } \\
\text { tion, and consumption of iodine-rich foods }\end{array}$ \\
\hline Starting date & November 2008 \\
\hline Contact information & Principal Investigator: Maria Teresa Torres Costa, Midwife, Institut Català de la Salut (ICS) \\
\hline Notes & None \\
\hline
\end{tabular}

BMIC: breast milk iodine concentration

FT4: free thyroxine

Tg: thyroglobulin

TPO-ab: thyroid peroxidase antibodies

TSH: thyroid stimulating hormone

UIC: urinary iodine concentration

\section{DATA AND ANALYSES}

Comparison 1. Any supplement containing iodine versus same supplement without iodine or no intervention/ placebo

\begin{tabular}{|c|c|c|c|c|}
\hline Outcome or subgroup title & No. of studies & $\begin{array}{l}\text { No. of partici- } \\
\text { pants }\end{array}$ & Statistical method & Effect size \\
\hline 1 Maternal hypothyroidism - pregnancy & 1 & 365 & $\begin{array}{l}\text { Risk Ratio (M-H, Random, } \\
95 \% \mathrm{Cl})\end{array}$ & $1.9[0.57,6.38]$ \\
\hline $\begin{array}{l}2 \text { Maternal hypothyroidism - postpar- } \\
\text { tum }\end{array}$ & 3 & 540 & $\begin{array}{l}\text { Risk Ratio (M-H, Random, } \\
95 \% \mathrm{Cl})\end{array}$ & $0.44[0.06,3.42]$ \\
\hline 3 Preterm birth & 2 & 376 & $\begin{array}{l}\text { Risk Ratio (M-H, Random, } \\
95 \% \mathrm{Cl})\end{array}$ & $0.71[0.30,1.66]$ \\
\hline $\begin{array}{l}4 \text { Maternal adverse effect: elevated thy- } \\
\text { roid peroxidase antibodies - pregnancy }\end{array}$ & 1 & 359 & $\begin{array}{l}\text { Risk Ratio (M-H, Random, } \\
95 \% \mathrm{Cl})\end{array}$ & $0.95[0.44,2.07]$ \\
\hline $\begin{array}{l}5 \text { Maternal adverse effect: elevated thy- } \\
\text { roid peroxidase antibodies - postpartum }\end{array}$ & 3 & 397 & $\begin{array}{l}\text { Risk Ratio (M-H, Random, } \\
95 \% \mathrm{Cl})\end{array}$ & $1.01[0.78,1.30]$ \\
\hline $\begin{array}{l}6 \text { Maternal adverse effect: hyperthy- } \\
\text { roidism - pregnancy }\end{array}$ & 1 & 365 & $\begin{array}{l}\text { Risk Ratio (M-H, Random, } \\
95 \% \mathrm{Cl})\end{array}$ & $1.9[0.57,6.38]$ \\
\hline $\begin{array}{l}7 \text { Maternal adverse effect: hyperthy- } \\
\text { roidism - postpartum }\end{array}$ & 3 & 543 & $\begin{array}{l}\text { Risk Ratio (M-H, Random, } \\
95 \% \mathrm{Cl})\end{array}$ & $0.32[0.11,0.91]$ \\
\hline
\end{tabular}

Iodine supplementation for women during the preconception, pregnancy and postpartum period (Review) 


\begin{tabular}{|c|c|c|c|c|}
\hline Outcome or subgroup title & No. of studies & $\begin{array}{l}\text { No. of partici- } \\
\text { pants }\end{array}$ & Statistical method & Effect size \\
\hline $\begin{array}{l}8 \text { Maternal adverse effect: digestive in- } \\
\text { tolerance - pregnancy }\end{array}$ & 1 & 76 & $\begin{array}{l}\text { Risk Ratio (M-H, Random, } \\
95 \% \mathrm{Cl})\end{array}$ & $\begin{array}{l}15.33[2.07 \\
113.70]\end{array}$ \\
\hline 9 Perinatal mortality & 2 & 457 & $\begin{array}{l}\text { Risk Ratio (M-H, Random, } \\
95 \% \mathrm{CI})\end{array}$ & $0.66[0.42,1.03]$ \\
\hline 10 Low birthweight & 2 & 377 & $\begin{array}{l}\text { Risk Ratio (M-H, Random, } \\
95 \% \mathrm{Cl})\end{array}$ & $0.56[0.26,1.23]$ \\
\hline $\begin{array}{l}11 \text { Neonatal hypothyroidism or elevated } \\
\text { TSH }\end{array}$ & 2 & 260 & $\begin{array}{l}\text { Risk Ratio (M-H, Random, } \\
95 \% \mathrm{Cl})\end{array}$ & $0.58[0.11,3.12]$ \\
\hline $\begin{array}{l}12 \text { Neonatal adverse effect: elevated } \\
\text { thyroid peroxidase antibodies }\end{array}$ & 1 & 108 & $\begin{array}{l}\text { Risk Ratio (M-H, Random, } \\
95 \% \mathrm{Cl})\end{array}$ & $0.61[0.07,5.70]$ \\
\hline 13 Spontaneous miscarriage & 3 & 645 & $\begin{array}{l}\text { Risk Ratio (M-H, Random, } \\
95 \% \mathrm{Cl})\end{array}$ & $1.31[0.64,2.69]$ \\
\hline 14 Maternal goitre - pregnancy & 2 & 486 & $\begin{array}{l}\text { Risk Ratio (M-H, Random, } \\
95 \% \mathrm{Cl} \text { ) }\end{array}$ & $1.00[0.33,3.06]$ \\
\hline 15 Maternal goitre - postpartum & 2 & 370 & $\begin{array}{l}\text { Risk Ratio (M-H, Random, } \\
95 \% \mathrm{Cl} \text { ) }\end{array}$ & $1.17[0.64,2.16]$ \\
\hline $\begin{array}{l}16 \text { Maternal insufficient iodine intake - } \\
\text { pregnancy }\end{array}$ & 2 & 432 & $\begin{array}{l}\text { Risk Ratio (M-H, Random, } \\
95 \% \mathrm{Cl})\end{array}$ & $0.64[0.51,0.80]$ \\
\hline $\begin{array}{l}17 \text { Maternal insufficient iodine intake - } \\
\text { postpartum }\end{array}$ & 2 & 425 & $\begin{array}{l}\text { Risk Ratio (M-H, Random, } \\
95 \% \mathrm{Cl} \text { ) }\end{array}$ & $0.81[0.70,0.93]$ \\
\hline $\begin{array}{l}18 \text { Maternal excessive iodine intake - } \\
\text { pregnancy }\end{array}$ & 1 & 356 & $\begin{array}{l}\text { Risk Ratio (M-H, Random, } \\
95 \% \mathrm{Cl} \text { ) }\end{array}$ & $4.33[1.24,15.07]$ \\
\hline 19 Small-for-gestational age & 2 & 377 & $\begin{array}{l}\text { Risk Ratio (M-H, Random, } \\
95 \% \mathrm{Cl} \text { ) }\end{array}$ & $1.26[0.77,2.05]$ \\
\hline 20 Congenital anomalies & 2 & 875 & $\begin{array}{l}\text { Risk Ratio (M-H, Random, } \\
95 \% \mathrm{CI})\end{array}$ & $0.27[0.12,0.60]$ \\
\hline 21 Neonatal goitre & 3 & 684 & $\begin{array}{l}\text { Risk Ratio (M-H, Random, } \\
95 \% \mathrm{Cl})\end{array}$ & $0.11[0.02,0.56]$ \\
\hline 22 Neonatal thyroid volume (in $\mathrm{mL}$ ) & 3 & 359 & $\begin{array}{l}\text { Mean Difference (IV, Ran- } \\
\text { dom, } 95 \% \mathrm{CI} \text { ) }\end{array}$ & $\begin{array}{l}-0.34[-0.58 \\
-0.11]\end{array}$ \\
\hline 23 Neonatal insufficient iodine intake & 1 & 159 & $\begin{array}{l}\text { Risk Ratio (M-H, Random, } \\
95 \% \mathrm{Cl})\end{array}$ & $2.14[1.04,4.37]$ \\
\hline $\begin{array}{l}24 \text { Child mental or motor development } \\
\text { (IQ points) }\end{array}$ & 2 & 174 & $\begin{array}{l}\text { Mean Difference (IV, Ran- } \\
\text { dom, } 95 \% \mathrm{CI} \text { ) }\end{array}$ & $\begin{array}{l}11.21[7.96 \\
14.46]\end{array}$ \\
\hline $\begin{array}{l}25 \text { Child mental or motor development } \\
\text { (cognitive score) }\end{array}$ & 1 & 53 & $\begin{array}{l}\text { Mean Difference (IV, Ran- } \\
\text { dom, } 95 \% \mathrm{CI} \text { ) }\end{array}$ & $-2.30[-7.88,3.28]$ \\
\hline
\end{tabular}




\begin{tabular}{|c|c|c|c|c|}
\hline Outcome or subgroup title & No. of studies & $\begin{array}{l}\text { No. of partici- } \\
\text { pants }\end{array}$ & Statistical method & Effect size \\
\hline $\begin{array}{l}26 \text { Child mental or motor development } \\
\text { (language score) }\end{array}$ & 1 & 53 & $\begin{array}{l}\text { Mean Difference (IV, Ran- } \\
\text { dom, } 95 \% \mathrm{CI} \text { ) }\end{array}$ & $-0.70[-7.08,5.68]$ \\
\hline $\begin{array}{l}27 \text { Child mental or motor development } \\
\text { (motor score) }\end{array}$ & 1 & 53 & $\begin{array}{l}\text { Mean Difference (IV, Ran- } \\
\text { dom, } 95 \% \mathrm{Cl} \text { ) }\end{array}$ & $1.5[-4.02,7.02]$ \\
\hline $\begin{array}{l}28 \text { Child mental or motor development } \\
\text { (social-emotional score) }\end{array}$ & 1 & 53 & $\begin{array}{l}\text { Mean Difference (IV, Ran- } \\
\text { dom, } 95 \% \mathrm{Cl} \text { ) }\end{array}$ & $0.40[-8.25,9.05]$ \\
\hline $\begin{array}{l}29 \text { Child mental or motor development } \\
\text { (adaptive behaviour score) }\end{array}$ & 1 & 53 & $\begin{array}{l}\text { Mean Difference (IV, Ran- } \\
\text { dom, } 95 \% \mathrm{CI} \text { ) }\end{array}$ & $1.70[-6.40,9.80]$ \\
\hline $\begin{array}{l}30 \text { Child mental or motor development } \\
\text { (cognitive score < 85) }\end{array}$ & 1 & 53 & $\begin{array}{l}\text { Risk Ratio (M-H, Random, } \\
95 \% \mathrm{Cl} \text { ) }\end{array}$ & $2.89[0.12,67.96]$ \\
\hline $\begin{array}{l}31 \text { Child mental or motor development } \\
\text { (cognitive score < } 70 \text { ) }\end{array}$ & 1 & 53 & $\begin{array}{l}\text { Risk Ratio (M-H, Random, } \\
95 \% \mathrm{Cl})\end{array}$ & $2.89[0.12,67.96]$ \\
\hline $\begin{array}{l}32 \text { Child mental or motor development } \\
\text { (language score }<85 \text { ) }\end{array}$ & 1 & 53 & $\begin{array}{l}\text { Risk Ratio (M-H, Random, } \\
95 \% \mathrm{Cl})\end{array}$ & $0.96[0.21,4.35]$ \\
\hline $\begin{array}{l}33 \text { Child mental or motor development } \\
\text { (language score }<70 \text { ) }\end{array}$ & 1 & 53 & $\begin{array}{l}\text { Risk Ratio (M-H, Random, } \\
95 \% \mathrm{Cl})\end{array}$ & $0.0[0.0,0.0]$ \\
\hline $\begin{array}{l}34 \text { Child mental or motor development } \\
\text { (motor score }<85 \text { ) }\end{array}$ & 1 & 53 & $\begin{array}{l}\text { Risk Ratio (M-H, Random, } \\
95 \% \mathrm{Cl} \text { ) }\end{array}$ & $0.39[0.08,1.81]$ \\
\hline $\begin{array}{l}35 \text { Child mental or motor development } \\
\text { (motor score }<70 \text { ) }\end{array}$ & 1 & 53 & $\begin{array}{l}\text { Risk Ratio (M-H, Random, } \\
95 \% \mathrm{Cl} \text { ) }\end{array}$ & $2.89[0.12,67.96]$ \\
\hline
\end{tabular}

Analysis 1.1. Comparison 1 Any supplement containing iodine versus same supplement without iodine or no intervention/placebo, Outcome 1 Maternal hypothyroidism - pregnancy.

\begin{tabular}{|c|c|c|c|c|c|}
\hline Study or subgroup & $\begin{array}{c}\text { Any iodine } \\
\mathrm{n} / \mathrm{N} \\
\end{array}$ & $\begin{array}{c}\text { No iodine } \\
\mathrm{n} / \mathrm{N}\end{array}$ & $\begin{array}{c}\text { Risk Ratio } \\
\text { M-H, Random, } 95 \% \mathrm{CI}\end{array}$ & Weight & $\begin{array}{c}\text { Risk Ratio } \\
\text { M-H, Random, } 95 \% \mathrm{Cl}\end{array}$ \\
\hline Gowachirapant 2014 & $7 / 175$ & $4 / 190$ & $-1+2$ & $100 \%$ & $1.9[0.57,6.38]$ \\
\hline Total $(95 \% \mathrm{CI})$ & 175 & 190 & & $100 \%$ & $1.9[0.57,6.38]$ \\
\hline \multicolumn{6}{|c|}{ Total events: 7 (Any iodine), 4 (No iodine) } \\
\hline \multicolumn{6}{|c|}{ Heterogeneity: Not applicable } \\
\hline & & rs an y iodine $\quad 0.01$ & 1 & urs no iodine & \\
\hline
\end{tabular}


Analysis 1.2. Comparison 1 Any supplement containing iodine versus same supplement without iodine or no intervention/placebo, Outcome 2 Maternal hypothyroidism - postpartum.

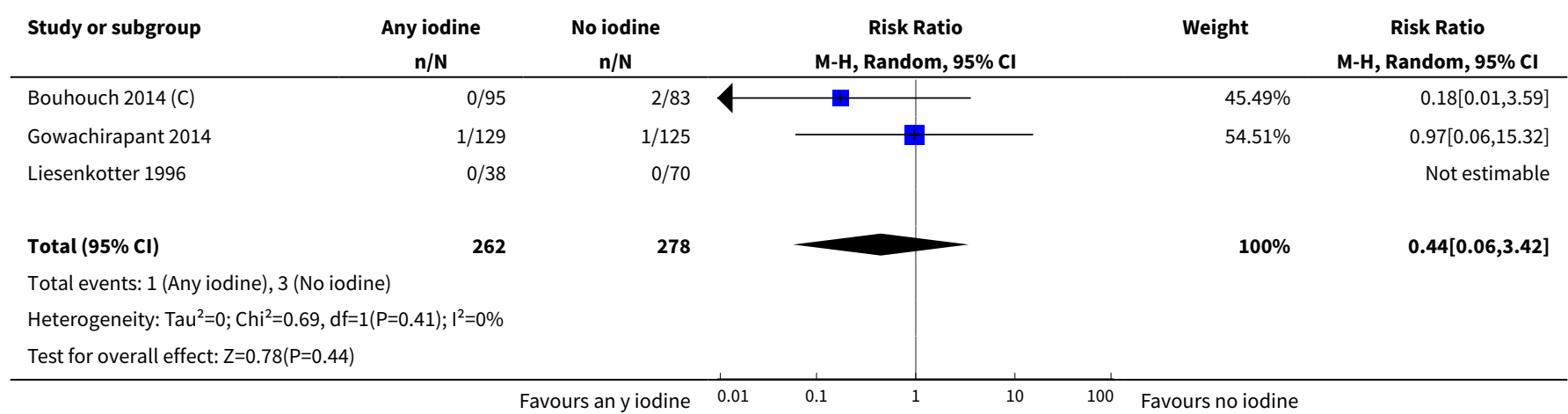

Analysis 1.3. Comparison 1 Any supplement containing iodine versus same supplement without iodine or no intervention/placebo, Outcome 3 Preterm birth.

\begin{tabular}{|c|c|c|c|c|c|}
\hline Study or subgroup & $\begin{array}{c}\text { Any iodine } \\
n / N\end{array}$ & $\begin{array}{c}\text { No iodine } \\
n / N\end{array}$ & $\begin{array}{c}\text { Risk Ratio } \\
\text { M-H, Random, 95\% Cl }\end{array}$ & Weight & $\begin{array}{c}\text { Risk Ratio } \\
\text { M-H, Random, } 95 \% \mathrm{Cl}\end{array}$ \\
\hline Gowachirapant 2014 & $8 / 148$ & $18 / 170$ & $\rightarrow$ & $63.23 \%$ & $0.51[0.23,1.14]$ \\
\hline Zhou 2015 & $5 / 29$ & $4 / 29$ & + & $36.77 \%$ & $1.25[0.37,4.19]$ \\
\hline Total $(95 \% \mathrm{Cl})$ & 177 & 199 & & $100 \%$ & $0.71[0.3,1.66]$ \\
\hline \multicolumn{6}{|c|}{ Total events: 13 (Any iodine), 22 (No iodine) } \\
\hline \multicolumn{6}{|c|}{ Heterogeneity: $\mathrm{Tau}^{2}=0.13 ; \mathrm{Chi}^{2}=1.47, \mathrm{df}=1(\mathrm{P}=0.23) ; \mathrm{I}^{2}=31.85 \%$} \\
\hline \multicolumn{6}{|c|}{ Test for overall effect: $Z=0.79(P=0.43)$} \\
\hline
\end{tabular}

Analysis 1.4. Comparison 1 Any supplement containing iodine versus same supplement without iodine or no intervention/placebo, Outcome 4 Maternal adverse effect: elevated thyroid peroxidase antibodies - pregnancy.

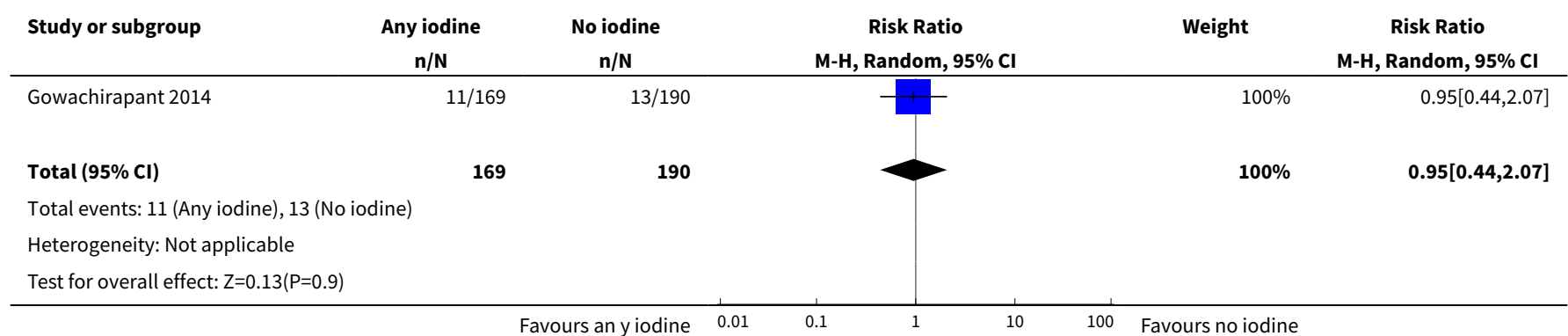


Analysis 1.5. Comparison 1 Any supplement containing iodine versus same supplement without iodine or no intervention/placebo, Outcome 5 Maternal adverse effect: elevated thyroid peroxidase antibodies - postpartum.

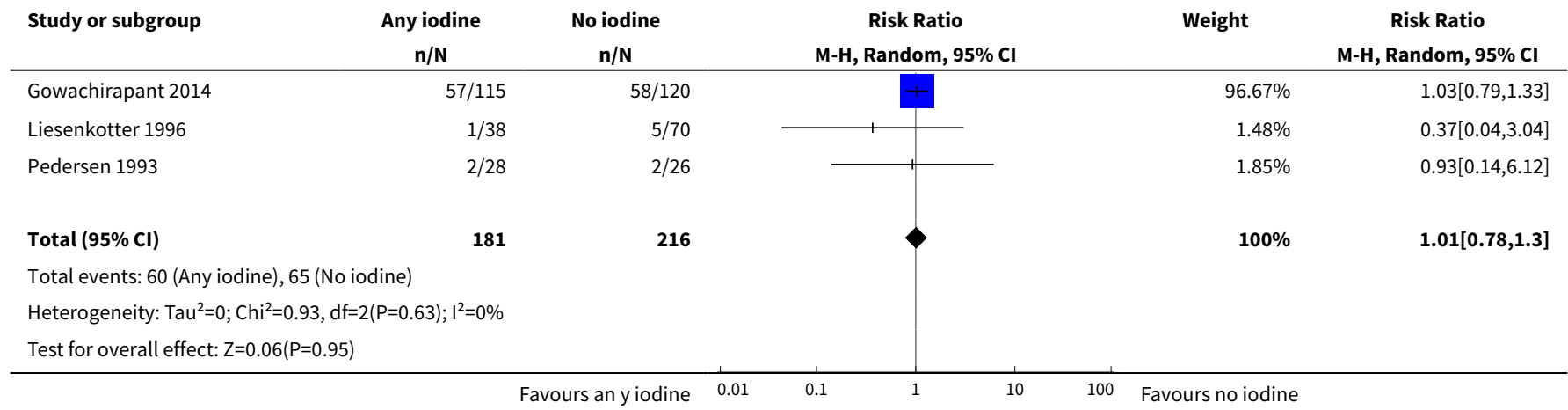

Analysis 1.6. Comparison 1 Any supplement containing iodine versus same supplement without iodine or no intervention/placebo, Outcome 6 Maternal adverse effect: hyperthyroidism - pregnancy.

\begin{tabular}{|c|c|c|c|c|c|}
\hline Study or subgroup & $\begin{array}{c}\text { Any iodine } \\
n / N\end{array}$ & $\begin{array}{c}\text { No iodine } \\
n / N\end{array}$ & $\begin{array}{c}\text { Risk Ratio } \\
\text { M-H, Random, } 95 \% \mathrm{Cl}\end{array}$ & Weight & $\begin{array}{c}\text { Risk Ratio } \\
\text { M-H, Random, } 95 \% \mathrm{Cl}\end{array}$ \\
\hline Gowachirapant 2014 & $7 / 175$ & $4 / 190$ & 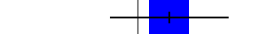 & $100 \%$ & $1.9[0.57,6.38]$ \\
\hline Total $(95 \% \mathrm{Cl})$ & 175 & 190 & & $100 \%$ & $1.9[0.57,6.38]$ \\
\hline \multicolumn{6}{|c|}{ Total events: 7 (Any iodine), 4 (No iodine) } \\
\hline \multicolumn{6}{|c|}{ Heterogeneity: Not applicable } \\
\hline Test for overall effect: & & & & & \\
\hline
\end{tabular}

Analysis 1.7. Comparison 1 Any supplement containing iodine versus same supplement without iodine or no intervention/placebo, Outcome 7 Maternal adverse effect: hyperthyroidism - postpartum.

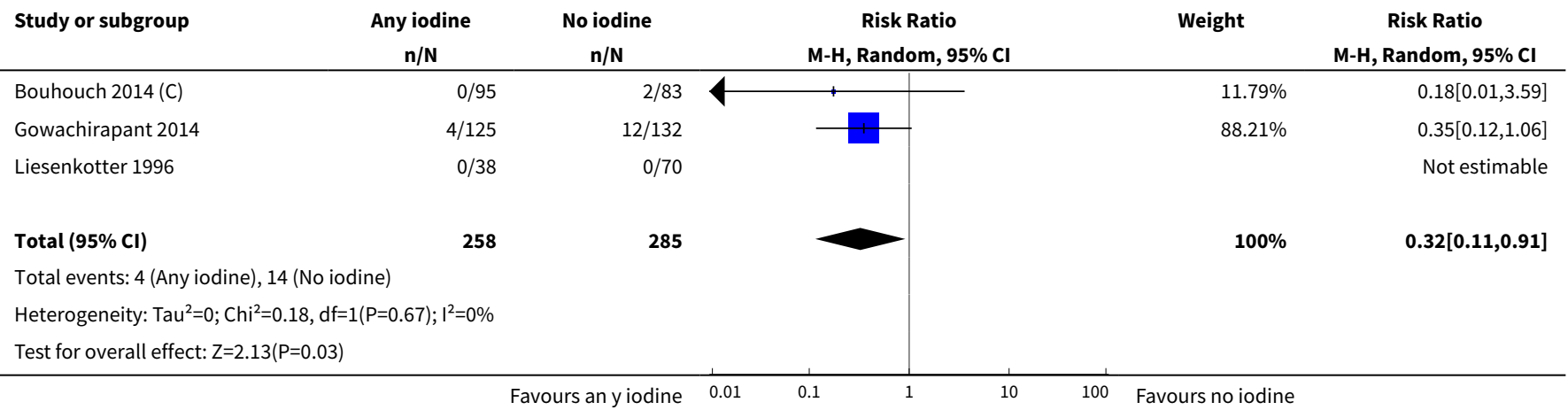


Analysis 1.8. Comparison 1 Any supplement containing iodine versus same supplement without iodine or no intervention/placebo, Outcome 8 Maternal adverse effect: digestive intolerance - pregnancy.

\begin{tabular}{|c|c|c|c|c|c|}
\hline Study or subgroup & $\begin{array}{c}\text { Any iodine } \\
n / N\end{array}$ & $\begin{array}{c}\text { No iodine } \\
\mathrm{n} / \mathrm{N}\end{array}$ & $\begin{array}{c}\text { Risk Ratio } \\
\text { M-H, Random, } 95 \% \mathrm{CI} \\
\end{array}$ & Weight & $\begin{array}{c}\text { Risk Ratio } \\
\text { M-H, Random, } 95 \% \text { CI } \\
\end{array}$ \\
\hline Brucker-Davis 2013 & $10 / 30$ & $1 / 46$ & & $100 \%$ & $15.33[2.07,113.7]$ \\
\hline Total $(95 \% \mathrm{Cl})$ & 30 & 46 & & $100 \%$ & $15.33[2.07,113.7]$ \\
\hline \multicolumn{6}{|c|}{ Total events: 10 (Any iodine), 1 (No iodine) } \\
\hline \multicolumn{6}{|c|}{ Heterogeneity: Not applicable } \\
\hline
\end{tabular}

Analysis 1.9. Comparison 1 Any supplement containing iodine versus same supplement without iodine or no intervention/placebo, Outcome 9 Perinatal mortality.

\begin{tabular}{|c|c|c|c|c|c|}
\hline Study or subgroup & $\begin{array}{c}\text { Any iodine } \\
\mathrm{n} / \mathrm{N}\end{array}$ & $\begin{array}{c}\text { No iodine } \\
n / N\end{array}$ & $\begin{array}{c}\text { Risk Ratio } \\
\text { M-H, Random, } 95 \% \mathrm{CI}\end{array}$ & Weight & $\begin{array}{c}\text { Risk Ratio } \\
\text { M-H, Random, 95\% Cl }\end{array}$ \\
\hline Thilly 1978 & $27 / 197$ & $42 / 202$ & & $100 \%$ & $0.66[0.42,1.03]$ \\
\hline Zhou 2015 & $0 / 29$ & $0 / 29$ & & & Not estimable \\
\hline Total $(95 \% \mathrm{Cl})$ & 226 & 231 & & $100 \%$ & $0.66[0.42,1.03]$ \\
\hline \multicolumn{6}{|c|}{ Total events: 27 (Any iodine), 42 (No iodine) } \\
\hline Test for overall effect & & & & & \\
\hline
\end{tabular}

Analysis 1.10. Comparison 1 Any supplement containing iodine versus same supplement without iodine or no intervention/placebo, Outcome 10 Low birthweight.

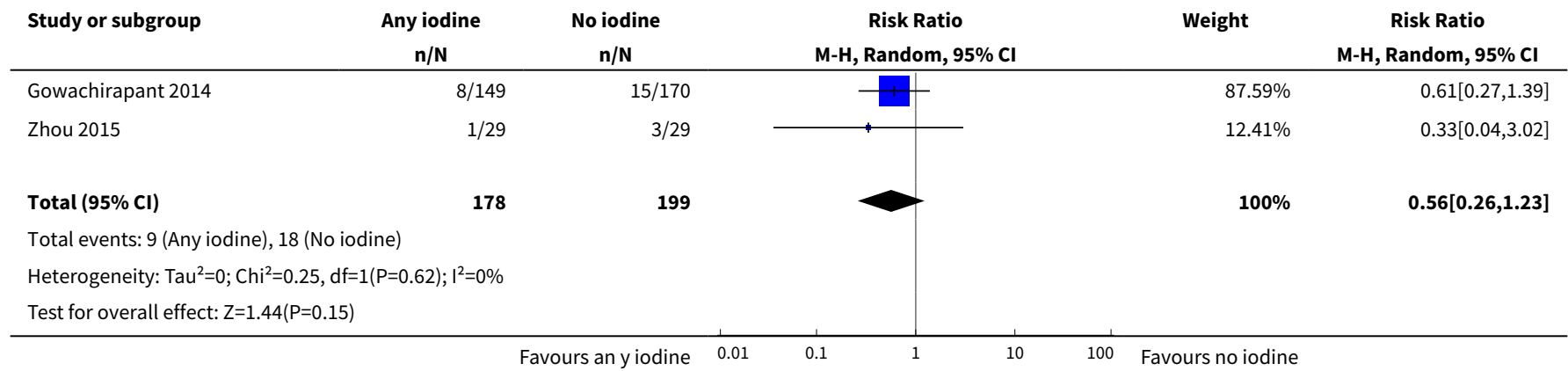

Analysis 1.11. Comparison 1 Any supplement containing iodine versus same supplement without iodine or no intervention/placebo, Outcome 11 Neonatal hypothyroidism or elevated TSH.

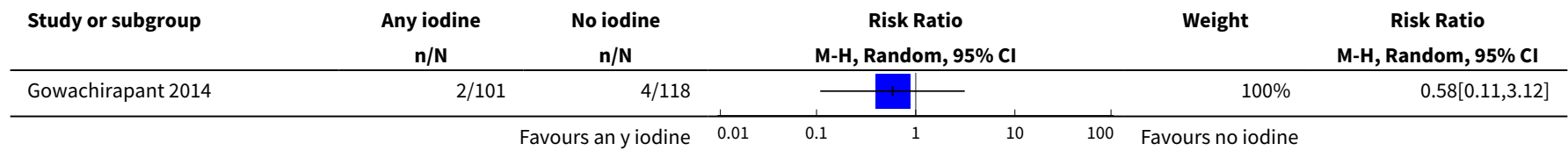




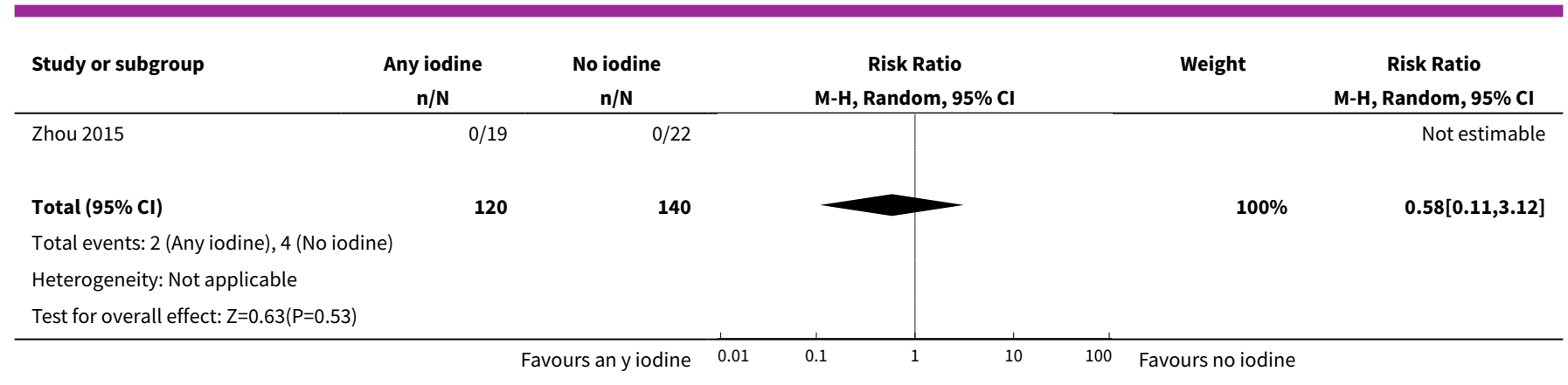

Analysis 1.12. Comparison 1 Any supplement containing iodine versus same supplement without iodine or no intervention/placebo, Outcome 12 Neonatal adverse effect: elevated thyroid peroxidase antibodies.

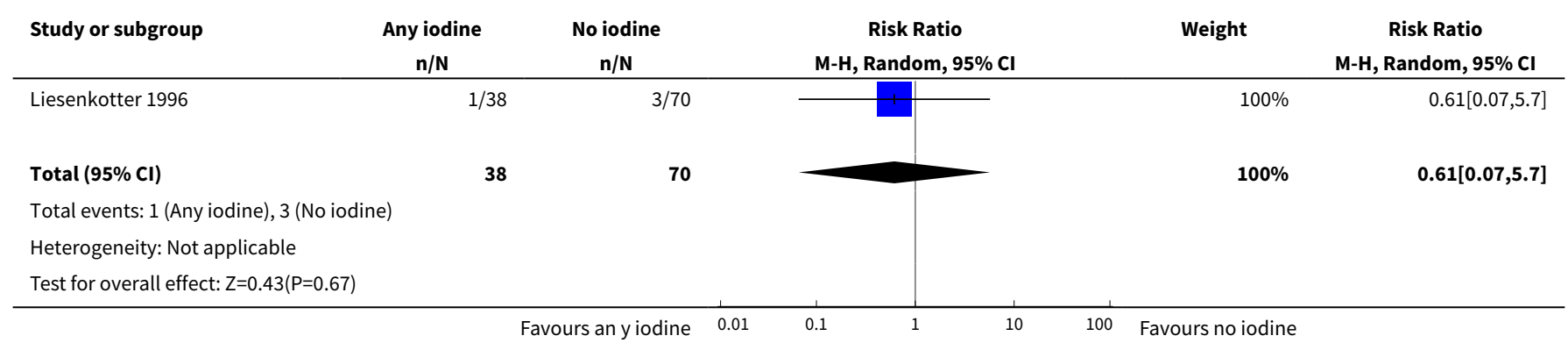

Analysis 1.13. Comparison 1 Any supplement containing iodine versus same supplement without iodine or no intervention/placebo, Outcome 13 Spontaneous miscarriage.

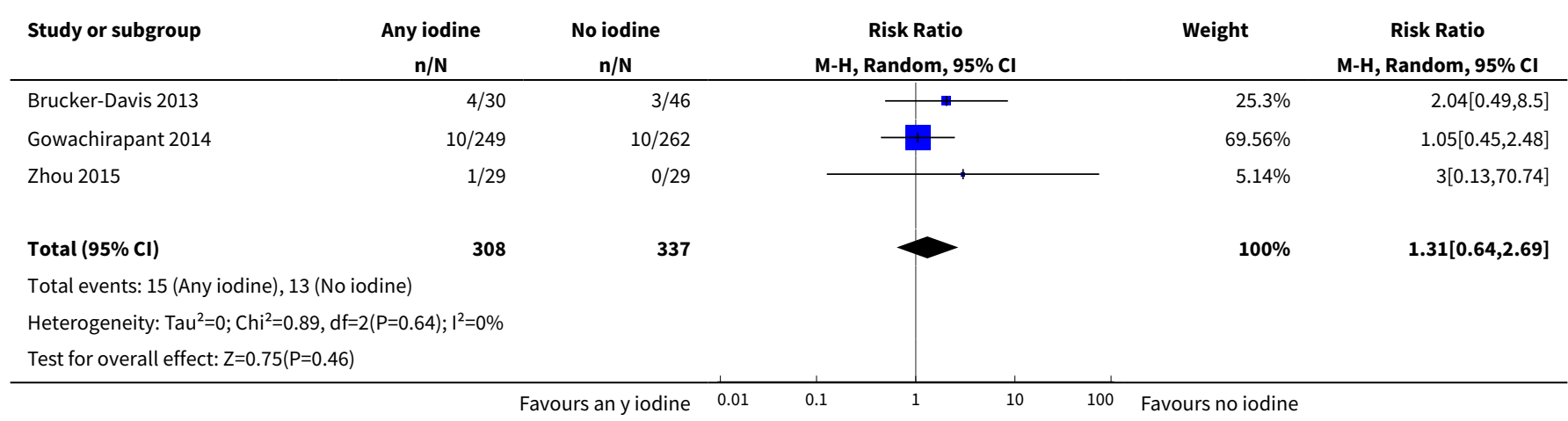

Analysis 1.14. Comparison 1 Any supplement containing iodine versus same supplement without iodine or no intervention/placebo, Outcome 14 Maternal goitre - pregnancy.

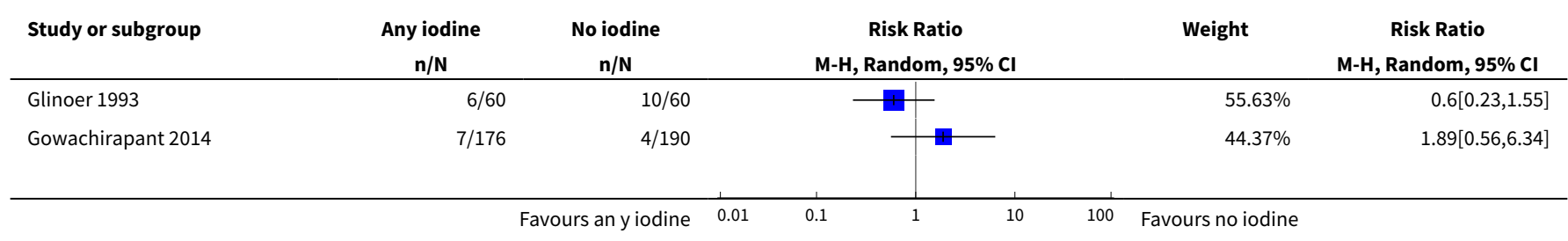




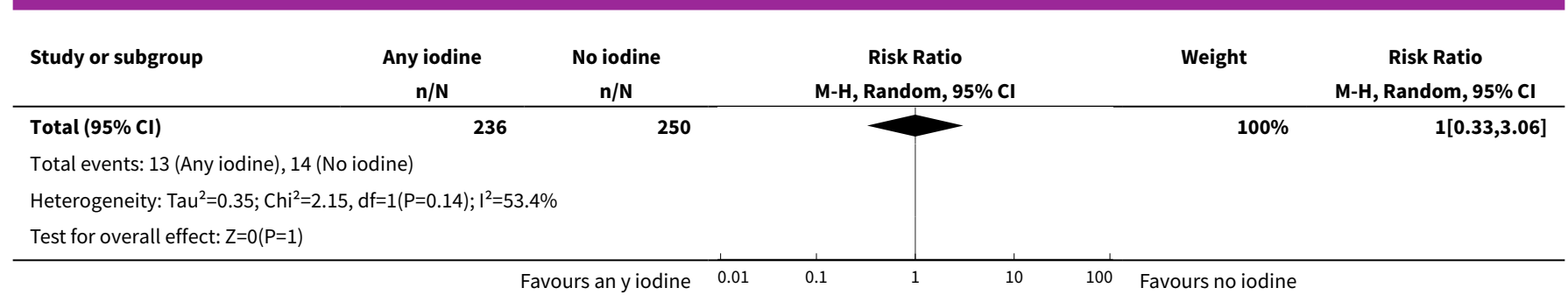

Analysis 1.15. Comparison 1 Any supplement containing iodine versus same supplement without iodine or no intervention/placebo, Outcome 15 Maternal goitre - postpartum.

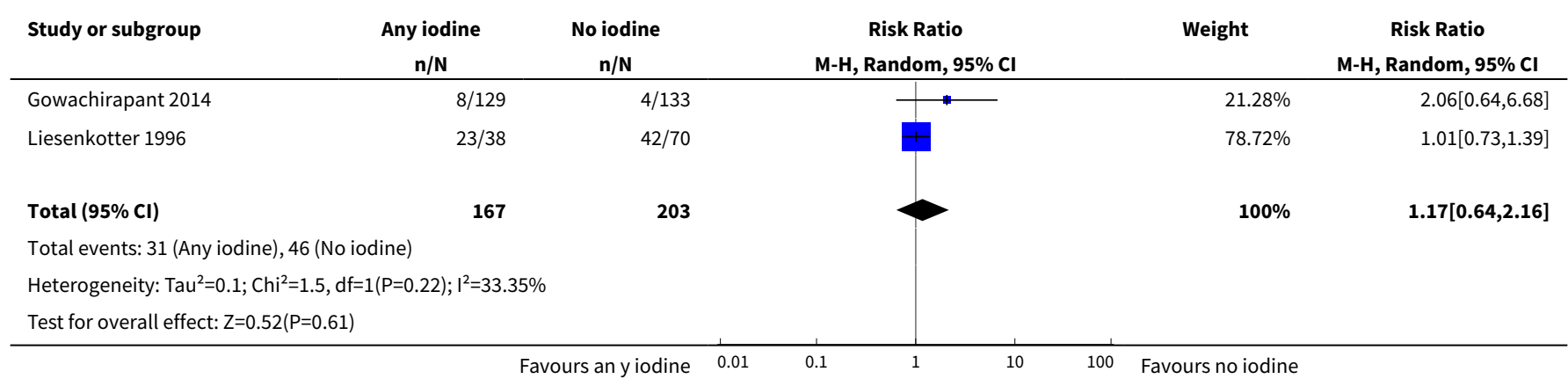

Analysis 1.16. Comparison 1 Any supplement containing iodine versus same supplement without iodine or no intervention/placebo, Outcome 16 Maternal insufficient iodine intake - pregnancy.

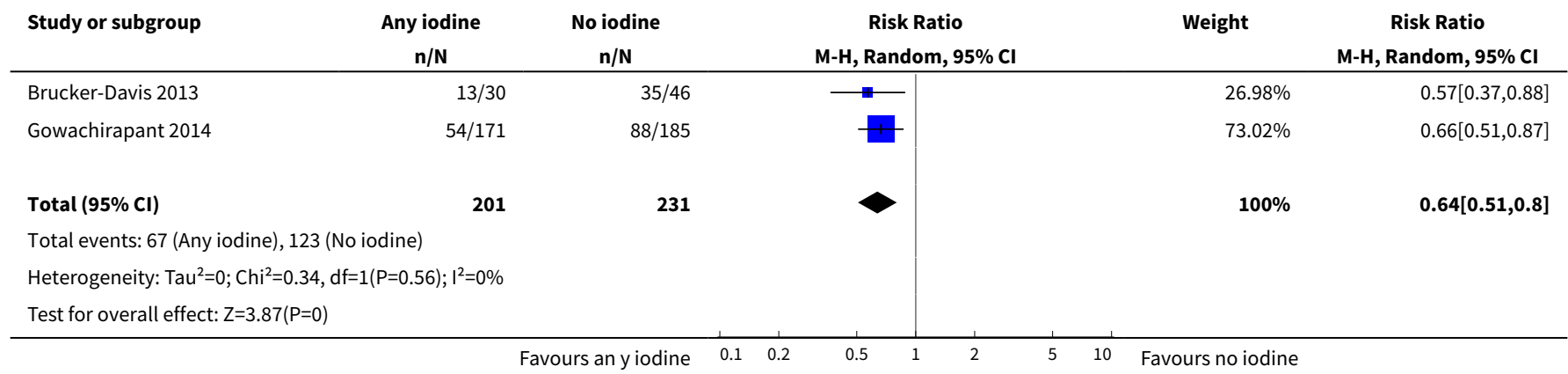

Analysis 1.17. Comparison 1 Any supplement containing iodine versus same supplement without iodine or no intervention/placebo, Outcome 17 Maternal insufficient iodine intake - postpartum.

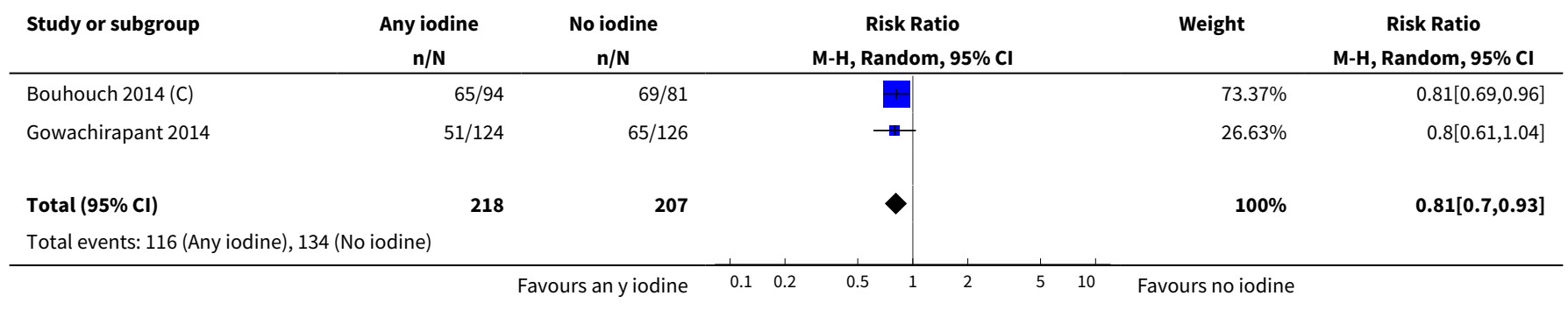




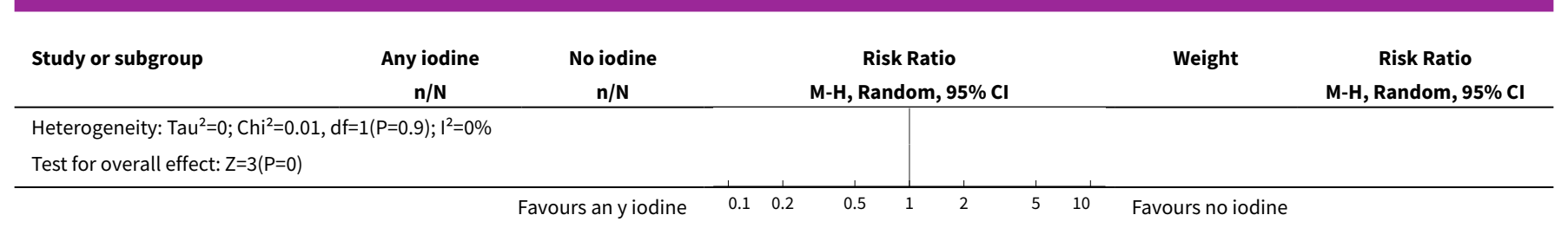

Analysis 1.18. Comparison 1 Any supplement containing iodine versus same supplement without iodine or no intervention/placebo, Outcome 18 Maternal excessive iodine intake - pregnancy.

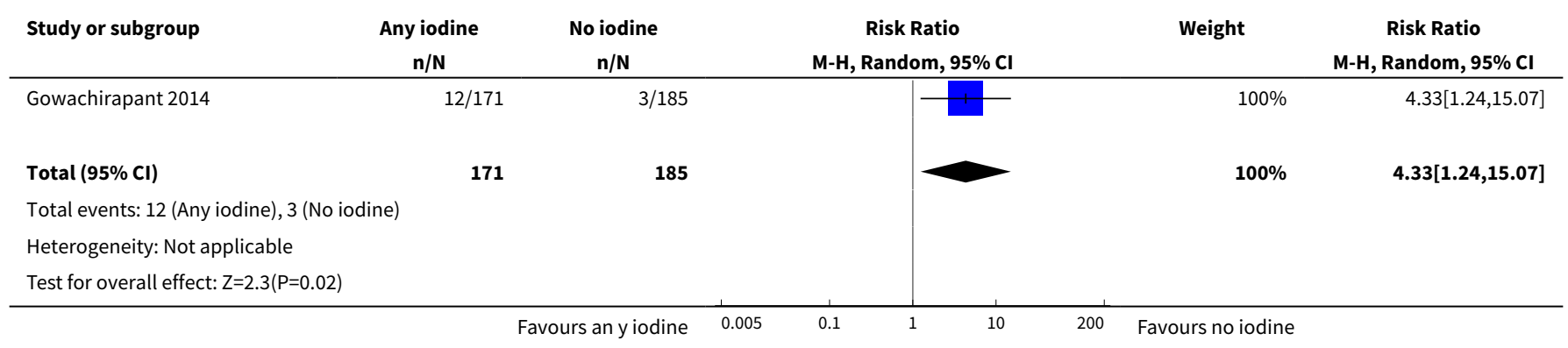

Analysis 1.19. Comparison 1 Any supplement containing iodine versus same supplement without iodine or no intervention/placebo, Outcome 19 Small-for-gestational age.

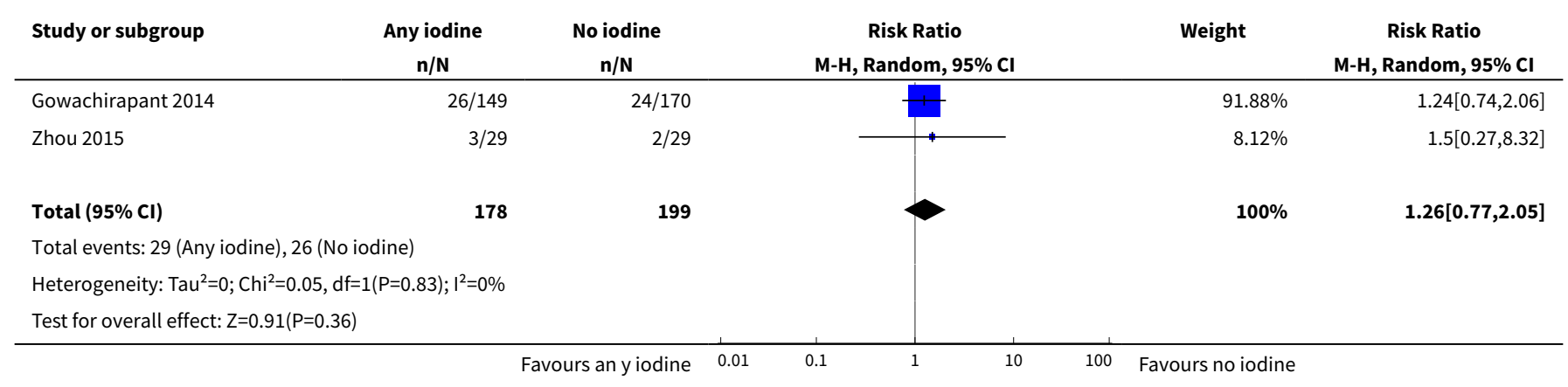

Analysis 1.20. Comparison 1 Any supplement containing iodine versus same supplement without iodine or no intervention/placebo, Outcome 20 Congenital anomalies.

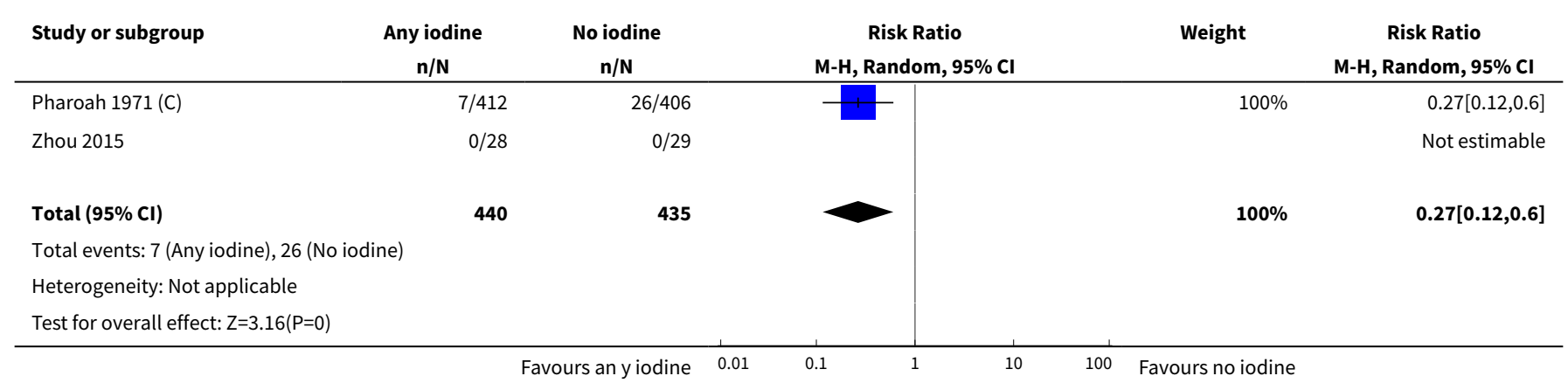


Analysis 1.21. Comparison 1 Any supplement containing iodine versus same supplement without iodine or no intervention/placebo, Outcome 21 Neonatal goitre.

\begin{tabular}{|c|c|c|c|c|c|}
\hline Study or subgroup & $\begin{array}{c}\text { Any iodine } \\
\mathrm{n} / \mathrm{N}\end{array}$ & $\begin{array}{c}\text { No iodine } \\
n / N\end{array}$ & $\begin{array}{c}\text { Risk Ratio } \\
\text { M-H, Random, } 95 \% \mathrm{CI}\end{array}$ & Weight & $\begin{array}{c}\text { Risk Ratio } \\
\text { M-H, Random, } 95 \% \mathrm{CI}\end{array}$ \\
\hline Glinoer 1993 & $0 / 60$ & $6 / 60$ & $=$ & $32.71 \%$ & $0.08[0,1.34]$ \\
\hline Kevany 1969 & $0 / 254$ & $0 / 202$ & & & Not estimable \\
\hline Liesenkotter 1996 & $1 / 38$ & $14 / 70$ & 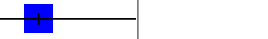 & $67.29 \%$ & $0.13[0.02,0.96]$ \\
\hline Total $(95 \% \mathrm{CI})$ & 352 & 332 & & $100 \%$ & $0.11[0.02,0.56]$ \\
\hline \multicolumn{6}{|c|}{ Heterogeneity: $\mathrm{Tau}^{2}=0 ; \mathrm{Chi}^{2}=0.09, \mathrm{df}=1(\mathrm{P}=0.76) ; \mathrm{I}^{2}=0 \%$} \\
\hline Test for overall effect & & & & & \\
\hline
\end{tabular}

Analysis 1.22. Comparison 1 Any supplement containing iodine versus same supplement without iodine or no intervention/placebo, Outcome 22 Neonatal thyroid volume (in $\mathrm{mL}$ ).

\begin{tabular}{|c|c|c|c|c|c|c|c|}
\hline \multirow{3}{*}{$\begin{array}{l}\text { Study or subgroup } \\
\text { Glinoer } 1993\end{array}$} & \multicolumn{2}{|c|}{ Favours an y iodine } & \multicolumn{2}{|c|}{ No iodine } & \multirow{2}{*}{$\begin{array}{l}\text { Mean Difference } \\
\text { Random, } 95 \% \mathrm{Cl}\end{array}$} & \multirow[t]{2}{*}{ Weight } & \multirow{2}{*}{$\begin{array}{l}\text { Mean Difference } \\
\text { Random, } 95 \% \mathrm{Cl}\end{array}$} \\
\hline & $\mathbf{N}$ & Mean(SD) & $\mathbf{N}$ & Mean(SD) & & & \\
\hline & 60 & $0.8(0.2)$ & 60 & $1.1(0.2)$ & 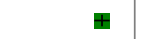 & $37.95 \%$ & $-0.29[-0.36,-0.22]$ \\
\hline Gowachirapant 2014 & 64 & $0.6(0.3)$ & 67 & $0.7(0.2)$ & $\#$ & $37.18 \%$ & $-0.09[-0.18,-0]$ \\
\hline Liesenkotter 1996 & 38 & $0.7(0.4)$ & 70 & $1.5(1.1)$ & —- & $24.86 \%$ & $-0.8[-1.09,-0.51]$ \\
\hline Total $* \star \star$ & 162 & & 197 & & & $100 \%$ & $-0.34[-0.58,-0.11]$ \\
\hline Test for overall effect: & & & & & & & \\
\hline
\end{tabular}

Analysis 1.23. Comparison 1 Any supplement containing iodine versus same supplement without iodine or no intervention/placebo, Outcome 23 Neonatal insufficient iodine intake.

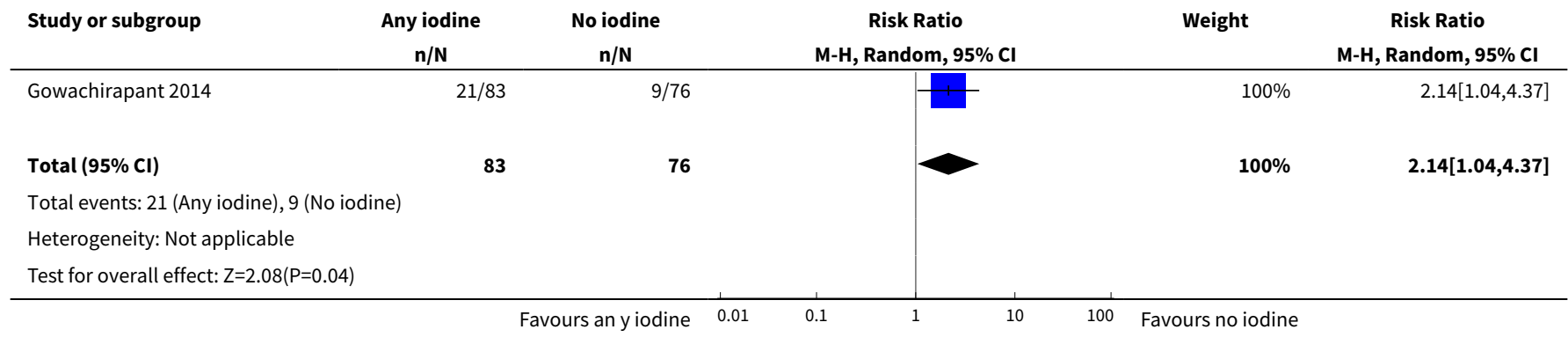


Analysis 1.24. Comparison 1 Any supplement containing iodine versus same supplement without iodine or no intervention/placebo, Outcome 24 Child mental or motor development (IQ points).

\begin{tabular}{|c|c|c|c|c|c|c|c|}
\hline \multirow[t]{2}{*}{ Study or subgroup } & \multicolumn{2}{|c|}{ Any iodine } & \multicolumn{2}{|c|}{ No iodine } & \multirow{2}{*}{$\begin{array}{l}\text { Mean Difference } \\
\text { Random, 95\% Cl }\end{array}$} & \multirow[t]{2}{*}{ Weight } & \multirow{2}{*}{$\begin{array}{l}\text { Mean Difference } \\
\text { Random, } 95 \% \mathrm{CI}\end{array}$} \\
\hline & $\mathbf{N}$ & Mean(SD) & $\mathbf{N}$ & Mean(SD) & & & \\
\hline Kevany 1969 & 14 & $84.4(15.3)$ & 22 & $71.3(15.5)$ & $\rightarrow$ & $9.93 \%$ & $13.1[2.8,23.4]$ \\
\hline Thilly 1978 & 66 & $115(7.9)$ & 72 & $104(12.3)$ & + & $90.07 \%$ & $11[7.58,14.42]$ \\
\hline Total $\star \star \star$ & 80 & & 94 & & $\diamond$ & $100 \%$ & $11.21[7.96,14.46]$ \\
\hline \multicolumn{8}{|c|}{ Heterogeneity: $\operatorname{Tau}^{2}=0 ; \mathrm{Chi}^{2}=0.14, \mathrm{df}=1(\mathrm{P}=0.7) ; \mathrm{I}^{2}=0 \%$} \\
\hline
\end{tabular}

Analysis 1.25. Comparison 1 Any supplement containing iodine versus same supplement without iodine or no intervention/placebo, Outcome 25 Child mental or motor development (cognitive score).

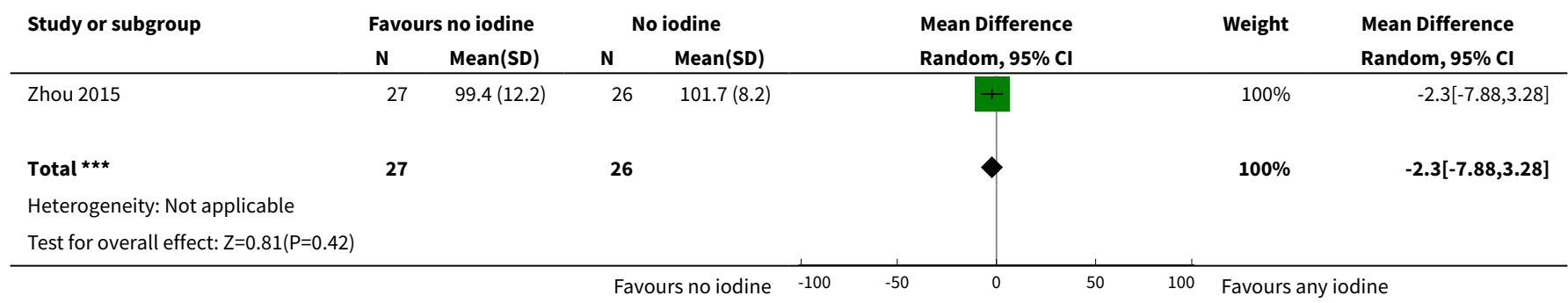

Analysis 1.26. Comparison 1 Any supplement containing iodine versus same supplement without iodine or no intervention/placebo, Outcome 26 Child mental or motor development (language score).

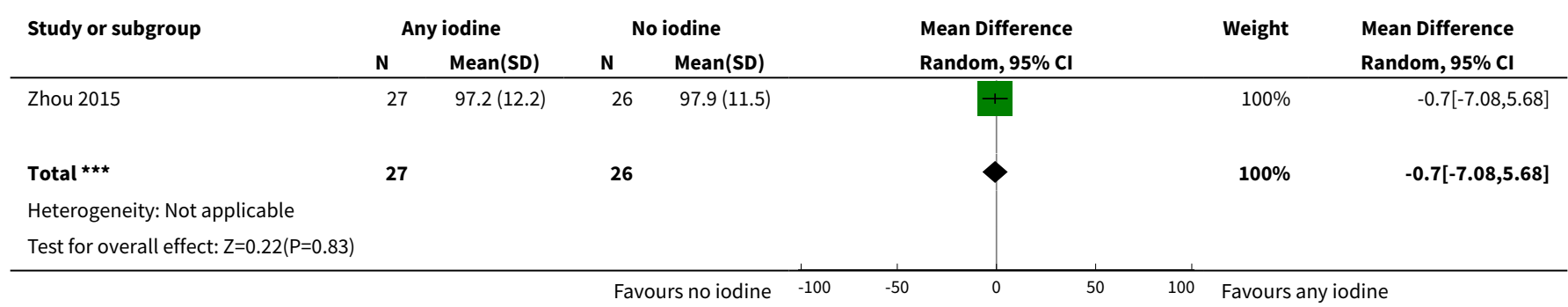

Analysis 1.27. Comparison 1 Any supplement containing iodine versus same supplement without iodine or no intervention/placebo, Outcome 27 Child mental or motor development (motor score).

\begin{tabular}{|c|c|c|c|c|c|c|c|c|}
\hline \multirow[t]{2}{*}{ Study or subgroup } & \multicolumn{2}{|c|}{ Any iodine } & \multicolumn{2}{|c|}{ No iodine } & & \multirow{2}{*}{$\begin{array}{l}\text { Mean Difference } \\
\text { Random, 95\% Cl }\end{array}$} & \multirow[t]{2}{*}{ Weight } & \multirow{2}{*}{$\begin{array}{l}\text { Mean Difference } \\
\text { Random, } 95 \% \mathrm{Cl}\end{array}$} \\
\hline & $\mathbf{N}$ & Mean(SD) & $\mathbf{N}$ & $\operatorname{Mean}(S D)$ & & & & \\
\hline Zhou 2015 & 27 & $93.9(10.8)$ & 26 & $92.4(9.7)$ & & & $100 \%$ & $1.5[-4.02,7.02]$ \\
\hline 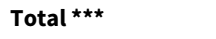 & 27 & & 26 & & & & $100 \%$ & $1.5[-4.02,7.02]$ \\
\hline \multicolumn{9}{|c|}{ Heterogeneity: Not applicable } \\
\hline \multicolumn{9}{|c|}{ Test for overall effect: $Z=0.53(P=0.59)$} \\
\hline
\end{tabular}


Analysis 1.28. Comparison 1 Any supplement containing iodine versus same supplement without iodine or no intervention/placebo, Outcome 28 Child mental or motor development (social-emotional score).

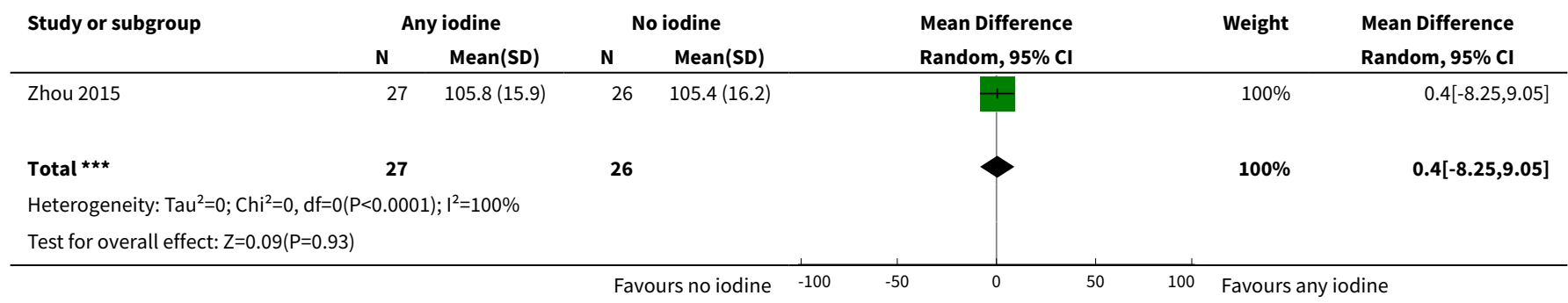

Analysis 1.29. Comparison 1 Any supplement containing iodine versus same supplement without iodine or no intervention/placebo, Outcome 29 Child mental or motor development (adaptive behaviour score).

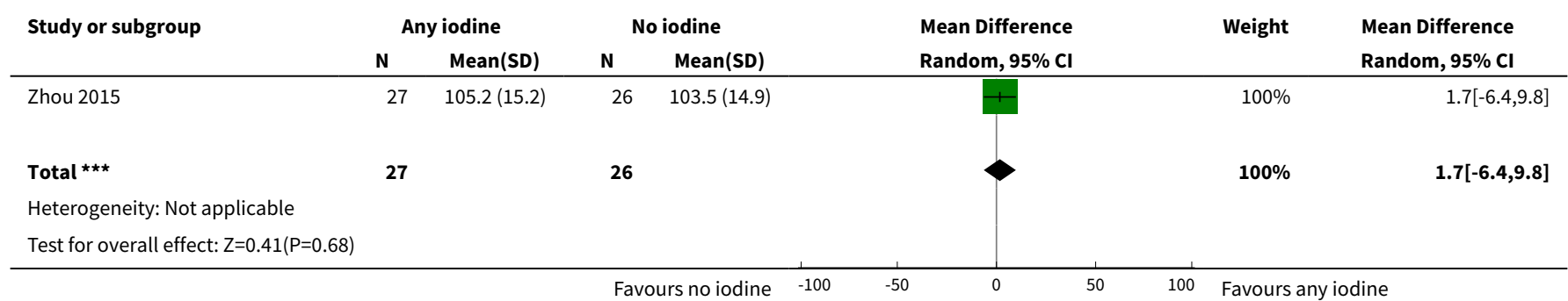

Analysis 1.30. Comparison 1 Any supplement containing iodine versus same supplement without iodine or no intervention/placebo, Outcome 30 Child mental or motor development (cognitive score $<85$ ).

\begin{tabular}{|c|c|c|c|c|c|}
\hline Study or subgroup & $\begin{array}{c}\text { Any iodine } \\
n / N\end{array}$ & $\begin{array}{c}\text { No iodine } \\
n / N\end{array}$ & $\begin{array}{c}\text { Risk Ratio } \\
\text { M-H, Random, } 95 \% \mathrm{Cl}\end{array}$ & Weight & $\begin{array}{c}\text { Risk Ratio } \\
\text { M-H, Random, } 95 \% \mathrm{CI}\end{array}$ \\
\hline Zhou 2015 & $1 / 27$ & $0 / 26$ & t & $100 \%$ & $2.89[0.12,67.96]$ \\
\hline Total $(95 \% \mathrm{Cl})$ & 27 & 26 & & $100 \%$ & $2.89[0.12,67.96]$ \\
\hline \multicolumn{6}{|c|}{ Total events: 1 (Any iodine ), 0 (No iodine) } \\
\hline \multicolumn{6}{|c|}{ Heterogeneity: Not applicable } \\
\hline
\end{tabular}

Analysis 1.31. Comparison 1 Any supplement containing iodine versus same supplement without iodine or no intervention/placebo, Outcome 31 Child mental or motor development (cognitive score $<70$ ).

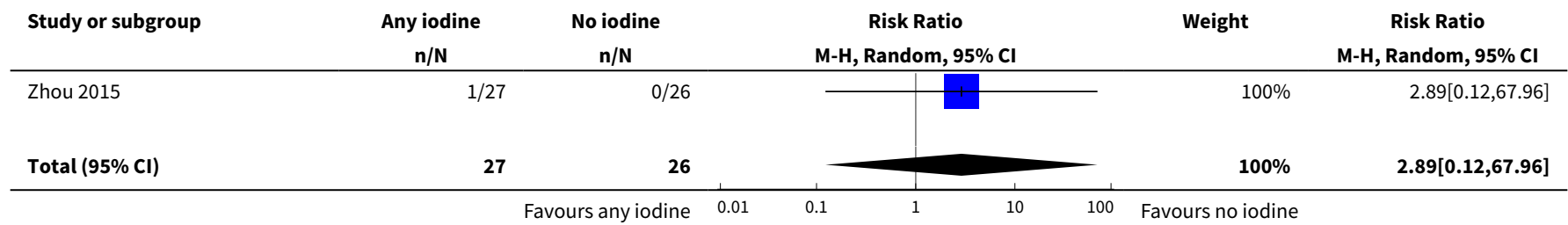




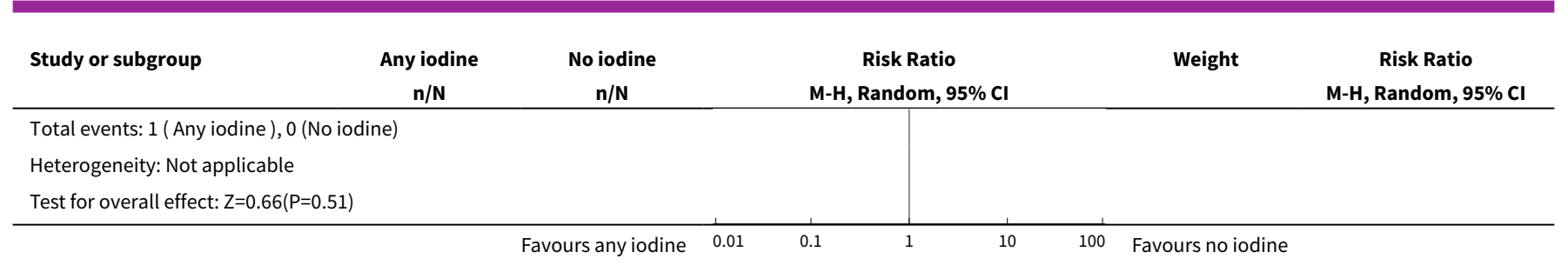

Analysis 1.32. Comparison 1 Any supplement containing iodine versus same supplement without iodine or no intervention/placebo, Outcome 32 Child mental or motor development (language score $<85$ ).

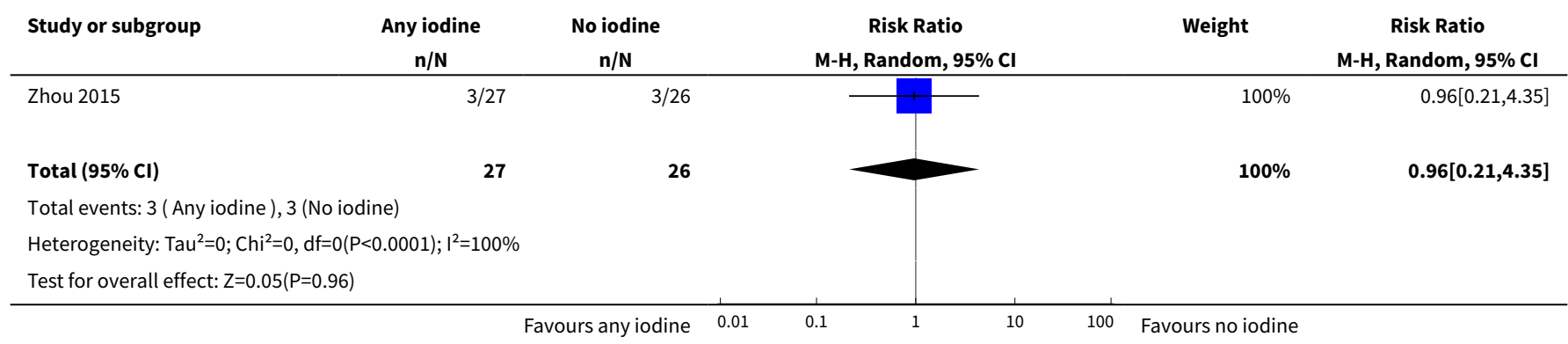

Analysis 1.33. Comparison 1 Any supplement containing iodine versus same supplement without iodine or no intervention/placebo, Outcome 33 Child mental or motor development (language score $<70$ ).

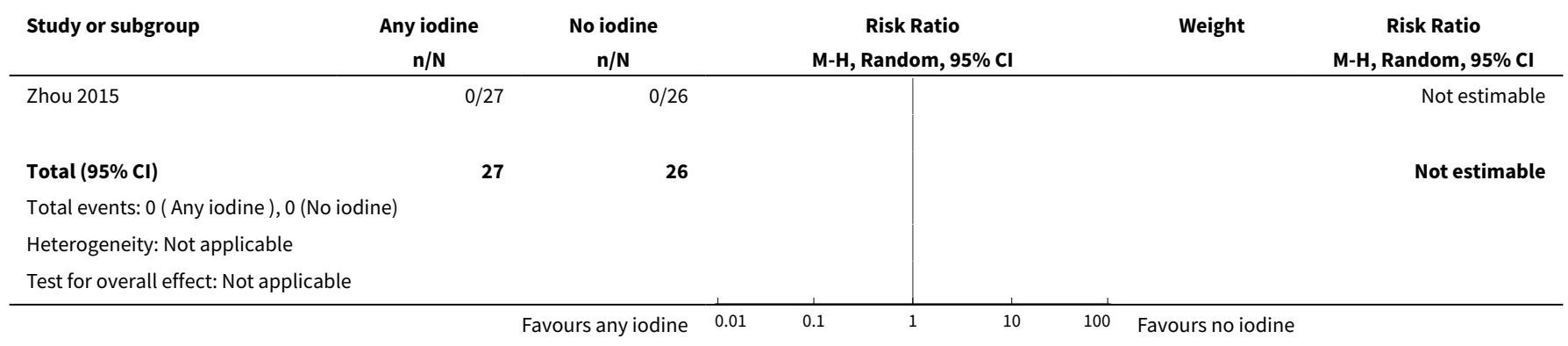

Analysis 1.34. Comparison 1 Any supplement containing iodine versus same supplement without iodine or no intervention/placebo, Outcome 34 Child mental or motor development (motor score $<85$ ).

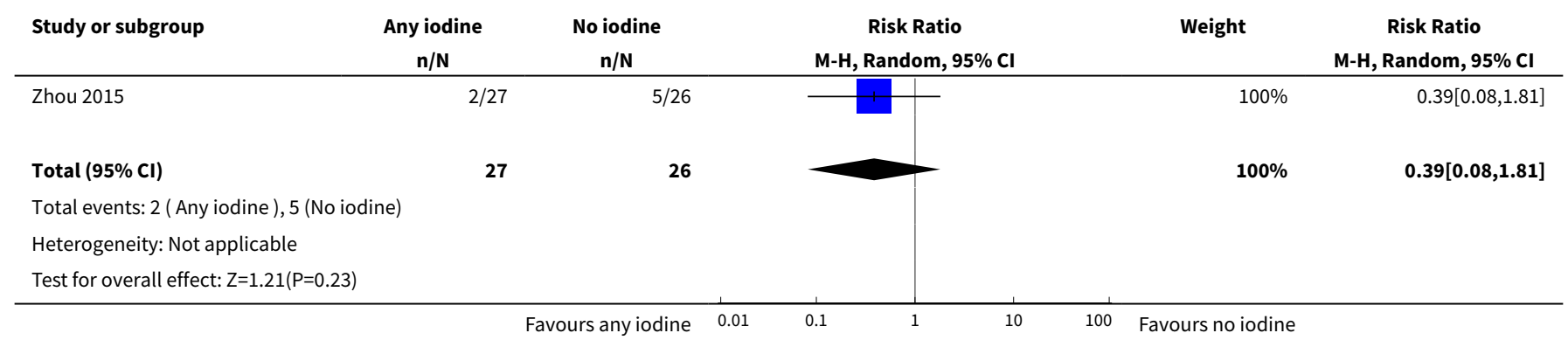


Analysis 1.35. Comparison 1 Any supplement containing iodine versus same supplement without iodine or no intervention/placebo, Outcome 35 Child mental or motor development (motor score $<70$ ).

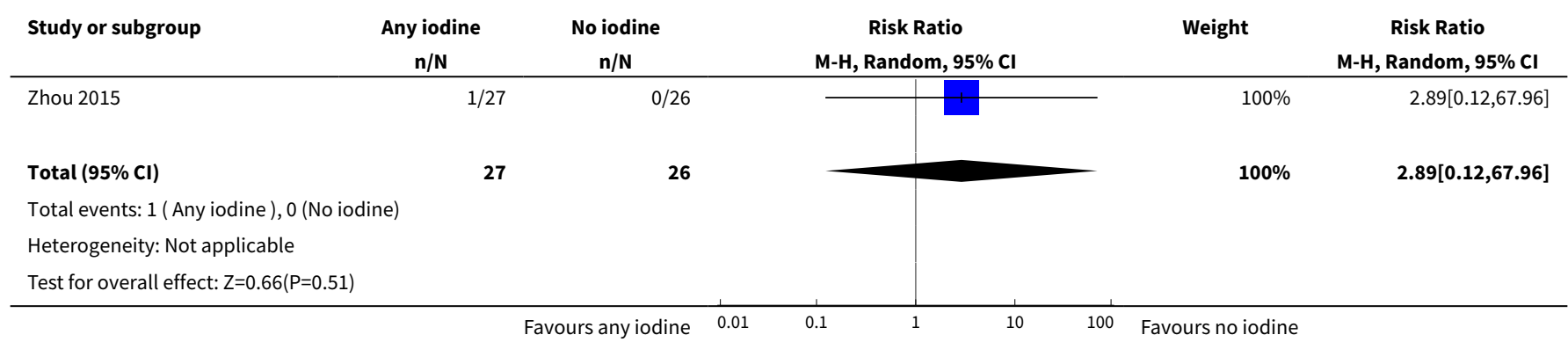

Comparison 2. Any oral iodine supplement versus same supplement without iodine or no intervention/placebo

\begin{tabular}{|c|c|c|c|c|}
\hline Outcome or subgroup title & No. of studies & $\begin{array}{l}\text { No. of partici- } \\
\text { pants }\end{array}$ & Statistical method & Effect size \\
\hline 1 Maternal hypothyroidism - pregnancy & 1 & 365 & $\begin{array}{l}\text { Risk Ratio (M-H, Random, } \\
95 \% \mathrm{Cl})\end{array}$ & $1.9[0.57,6.38]$ \\
\hline $\begin{array}{l}2 \text { Maternal hypothyroidism - postpar- } \\
\text { tum }\end{array}$ & 3 & 540 & $\begin{array}{l}\text { Risk Ratio (M-H, Random, } \\
95 \% \mathrm{Cl})\end{array}$ & $0.44[0.06,3.42]$ \\
\hline 3 Preterm birth & 2 & 376 & $\begin{array}{l}\text { Risk Ratio (M-H, Random, } \\
95 \% \mathrm{Cl})\end{array}$ & $0.71[0.30,1.66]$ \\
\hline $\begin{array}{l}4 \text { Maternal adverse effect: elevated thy- } \\
\text { roid peroxidase antibodies - pregnancy }\end{array}$ & 1 & 359 & $\begin{array}{l}\text { Risk Ratio (M-H, Random, } \\
95 \% \mathrm{Cl})\end{array}$ & $0.95[0.44,2.07]$ \\
\hline $\begin{array}{l}5 \text { Maternal adverse effect: elevated thy- } \\
\text { roid peroxidase antibodies - postpartum }\end{array}$ & 3 & 397 & $\begin{array}{l}\text { Risk Ratio (M-H, Random, } \\
95 \% \mathrm{Cl})\end{array}$ & $1.01[0.78,1.30]$ \\
\hline $\begin{array}{l}6 \text { Maternal adverse effect: hyperthy- } \\
\text { roidism - pregnancy }\end{array}$ & 1 & 365 & $\begin{array}{l}\text { Risk Ratio (M-H, Random, } \\
95 \% \mathrm{Cl} \text { ) }\end{array}$ & $1.9[0.57,6.38]$ \\
\hline $\begin{array}{l}7 \text { Maternal adverse effect: hyperthy- } \\
\text { roidism - postpartum }\end{array}$ & 3 & 543 & $\begin{array}{l}\text { Risk Ratio (M-H, Random, } \\
95 \% \mathrm{Cl} \text { ) }\end{array}$ & $0.32[0.11,0.91]$ \\
\hline $\begin{array}{l}8 \text { Maternal adverse effect: digestive in- } \\
\text { tolerance - pregnancy }\end{array}$ & 1 & 76 & $\begin{array}{l}\text { Risk Ratio (M-H, Random, } \\
95 \% \mathrm{Cl})\end{array}$ & $\begin{array}{l}15.33[2.07 \\
113.70]\end{array}$ \\
\hline 9 Perinatal mortality & 1 & 58 & $\begin{array}{l}\text { Risk Ratio (M-H, Random, } \\
95 \% \mathrm{Cl})\end{array}$ & $0.0[0.0,0.0]$ \\
\hline 10 Low birthweight & 2 & 377 & $\begin{array}{l}\text { Risk Ratio (M-H, Random, } \\
95 \% \mathrm{CI})\end{array}$ & $0.56[0.26,1.23]$ \\
\hline $\begin{array}{l}11 \text { Neonatal hypothyroidism or elevated } \\
\text { TSH }\end{array}$ & 2 & 260 & $\begin{array}{l}\text { Risk Ratio (M-H, Random, } \\
95 \% \mathrm{Cl} \text { ) }\end{array}$ & $0.58[0.11,3.12]$ \\
\hline $\begin{array}{l}12 \text { Neonatal adverse effect: elevated } \\
\text { thyroid peroxidase antibodies }\end{array}$ & 1 & 108 & $\begin{array}{l}\text { Risk Ratio (M-H, Random, } \\
95 \% \mathrm{Cl} \text { ) }\end{array}$ & $0.61[0.07,5.70]$ \\
\hline
\end{tabular}




\begin{tabular}{|c|c|c|c|c|}
\hline Outcome or subgroup title & No. of studies & $\begin{array}{l}\text { No. of partici- } \\
\text { pants }\end{array}$ & Statistical method & Effect size \\
\hline 13 Spontaneous miscarriage & 3 & 645 & $\begin{array}{l}\text { Risk Ratio (M-H, Random, } \\
95 \% \mathrm{Cl})\end{array}$ & $1.31[0.64,2.69]$ \\
\hline 14 Maternal goitre - pregnancy & 2 & 486 & $\begin{array}{l}\text { Risk Ratio (M-H, Random, } \\
95 \% \mathrm{CI})\end{array}$ & $1.00[0.33,3.06]$ \\
\hline 15 Maternal goitre - postpartum & 2 & 370 & $\begin{array}{l}\text { Risk Ratio (M-H, Random, } \\
95 \% \mathrm{Cl})\end{array}$ & $1.17[0.64,2.16]$ \\
\hline $\begin{array}{l}16 \text { Maternal insufficient iodine intake - } \\
\text { pregnancy }\end{array}$ & 2 & 432 & $\begin{array}{l}\text { Risk Ratio (M-H, Random, } \\
95 \% \mathrm{Cl})\end{array}$ & $0.64[0.51,0.80]$ \\
\hline $\begin{array}{l}17 \text { Maternal insufficient iodine intake - } \\
\text { postpartum }\end{array}$ & 2 & 425 & $\begin{array}{l}\text { Risk Ratio (M-H, Random, } \\
95 \% \mathrm{Cl})\end{array}$ & $0.81[0.70,0.93]$ \\
\hline $\begin{array}{l}18 \text { Maternal excessive iodine intake - } \\
\text { pregnancy }\end{array}$ & 1 & 356 & $\begin{array}{l}\text { Risk Ratio (M-H, Random, } \\
95 \% \mathrm{Cl})\end{array}$ & $4.33[1.24,15.07]$ \\
\hline 19 Small-for-gestational age & 2 & 377 & $\begin{array}{l}\text { Risk Ratio (M-H, Random, } \\
95 \% \mathrm{Cl} \text { ) }\end{array}$ & $1.26[0.77,2.05]$ \\
\hline 20 Congenital anomalies & 1 & 57 & $\begin{array}{l}\text { Risk Ratio (M-H, Random, } \\
95 \% \mathrm{Cl} \text { ) }\end{array}$ & $0.0[0.0,0.0]$ \\
\hline 21 Neonatal goitre & 2 & 228 & $\begin{array}{l}\text { Risk Ratio (M-H, Random, } \\
95 \% \mathrm{Cl})\end{array}$ & $0.11[0.02,0.56]$ \\
\hline 22 Neonatal thyroid volume (in $\mathrm{mL}$ ) & 3 & 359 & $\begin{array}{l}\text { Mean Difference (IV, Ran- } \\
\text { dom, } 95 \% \mathrm{CI} \text { ) }\end{array}$ & $\begin{array}{l}-0.34[-0.58 \\
-0.11]\end{array}$ \\
\hline 23 Neonatal insufficient iodine intake & 1 & 159 & $\begin{array}{l}\text { Risk Ratio (M-H, Random, } \\
95 \% \mathrm{Cl} \text { ) }\end{array}$ & $2.14[1.04,4.37]$ \\
\hline $\begin{array}{l}24 \text { Child mental or motor development } \\
\text { (cognitive score) }\end{array}$ & 1 & 53 & $\begin{array}{l}\text { Mean Difference (IV, Ran- } \\
\text { dom, } 95 \% \mathrm{CI} \text { ) }\end{array}$ & $-2.30[-7.88,3.28]$ \\
\hline $\begin{array}{l}25 \text { Child mental or motor development } \\
\text { (language score) }\end{array}$ & 1 & 53 & $\begin{array}{l}\text { Mean Difference (IV, Ran- } \\
\text { dom, } 95 \% \mathrm{CI} \text { ) }\end{array}$ & $-0.70[-7.08,5.68]$ \\
\hline $\begin{array}{l}26 \text { Child mental or motor development } \\
\text { (motor score) }\end{array}$ & 1 & 53 & $\begin{array}{l}\text { Mean Difference (IV, Ran- } \\
\text { dom, } 95 \% \mathrm{CI} \text { ) }\end{array}$ & $1.5[-4.02,7.02]$ \\
\hline $\begin{array}{l}27 \text { Child mental or motor development } \\
\text { (social-emotional score) }\end{array}$ & 1 & 53 & $\begin{array}{l}\text { Mean Difference (IV, Ran- } \\
\text { dom, } 95 \% \mathrm{CI} \text { ) }\end{array}$ & $0.40[-8.25,9.05]$ \\
\hline $\begin{array}{l}28 \text { Child mental or motor development } \\
\text { (adaptive behaviour score) }\end{array}$ & 1 & 53 & $\begin{array}{l}\text { Mean Difference (IV, Ran- } \\
\text { dom, } 95 \% \mathrm{CI} \text { ) }\end{array}$ & $1.70[-6.40,9.80]$ \\
\hline $\begin{array}{l}29 \text { Child mental or motor development } \\
\text { (cognitive score }<85 \text { ) }\end{array}$ & 1 & 53 & $\begin{array}{l}\text { Risk Ratio (M-H, Random, } \\
95 \% \mathrm{Cl} \text { ) }\end{array}$ & $2.89[0.12,67.96]$ \\
\hline $\begin{array}{l}30 \text { Child mental or motor development } \\
\text { (cognitive score }<70 \text { ) }\end{array}$ & 1 & 53 & $\begin{array}{l}\text { Risk Ratio (M-H, Random, } \\
95 \% \mathrm{Cl})\end{array}$ & $2.89[0.12,67.96]$ \\
\hline
\end{tabular}




\begin{tabular}{lllll}
\hline Outcome or subgroup title & No. of studies & $\begin{array}{l}\text { No. of partici- } \\
\text { pants }\end{array}$ & Statistical method & Effect size \\
\hline $\begin{array}{l}31 \text { Child mental or motor development } \\
\text { (language score }<85)\end{array}$ & 1 & 53 & $\begin{array}{l}\text { Risk Ratio (M-H, Random, } \\
95 \% \mathrm{Cl})\end{array}$ & $0.96[0.21,4.35]$ \\
\hline $\begin{array}{l}32 \text { Child mental or motor development } \\
\text { (language score }<70)\end{array}$ & 1 & 53 & $\begin{array}{l}\text { Risk Ratio (M-H, Random, } \\
95 \% \mathrm{Cl})\end{array}$ & $0.0[0.0,0.0]$ \\
\hline $\begin{array}{l}33 \text { Child mental or motor development } \\
\text { (motor score }<85)\end{array}$ & 1 & 53 & $\begin{array}{l}\text { Risk Ratio (M-H, Random, } \\
95 \% \mathrm{Cl})\end{array}$ & $0.39[0.08,1.81]$ \\
\hline $\begin{array}{l}34 \text { Child mental or motor development } \\
\text { (motor score }<70)\end{array}$ & 1 & 53 & $\begin{array}{l}\text { Risk Ratio (M-H, Random, } \\
95 \% \mathrm{Cl})\end{array}$ & $2.89[0.12,67.96]$ \\
\hline
\end{tabular}

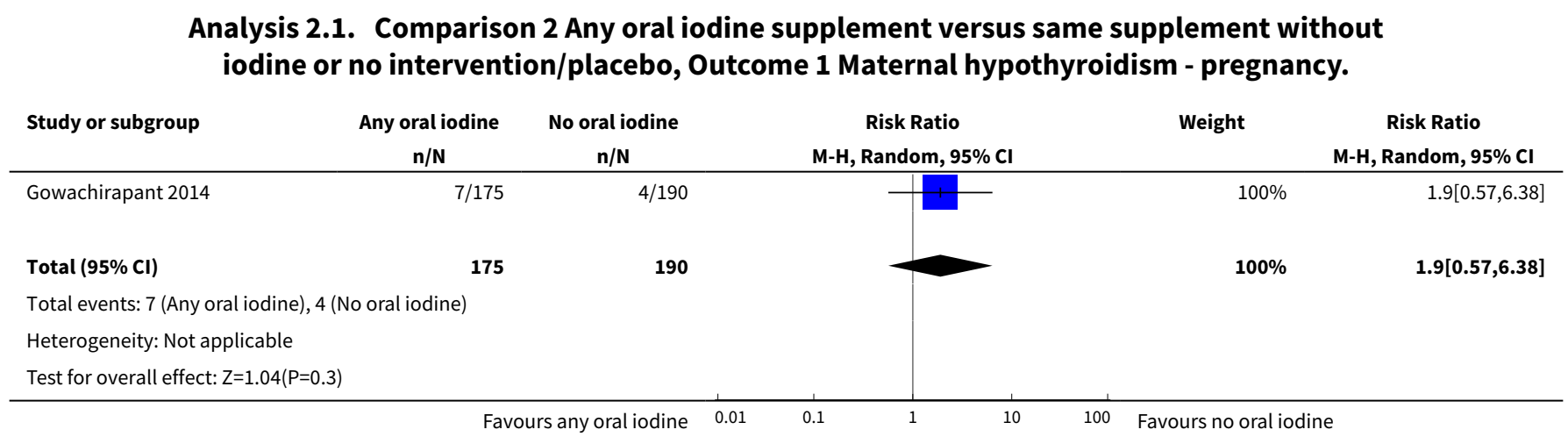

\section{Analysis 2.2. Comparison 2 Any oral iodine supplement versus same supplement without iodine or no intervention/placebo, Outcome 2 Maternal hypothyroidism - postpartum.}

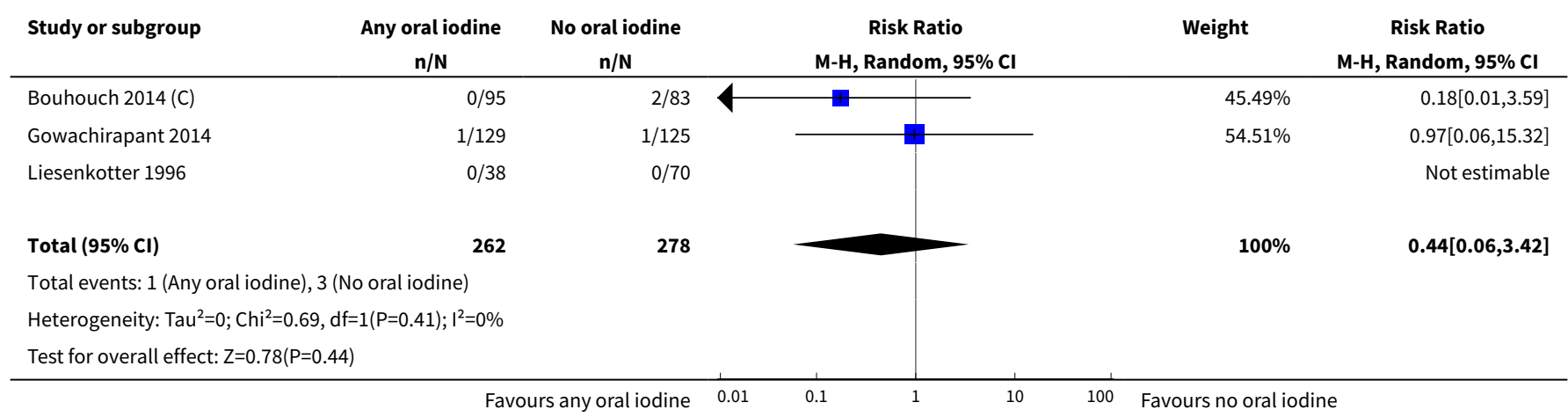


Analysis 2.3. Comparison 2 Any oral iodine supplement versus same supplement without iodine or no intervention/placebo, Outcome 3 Preterm birth.

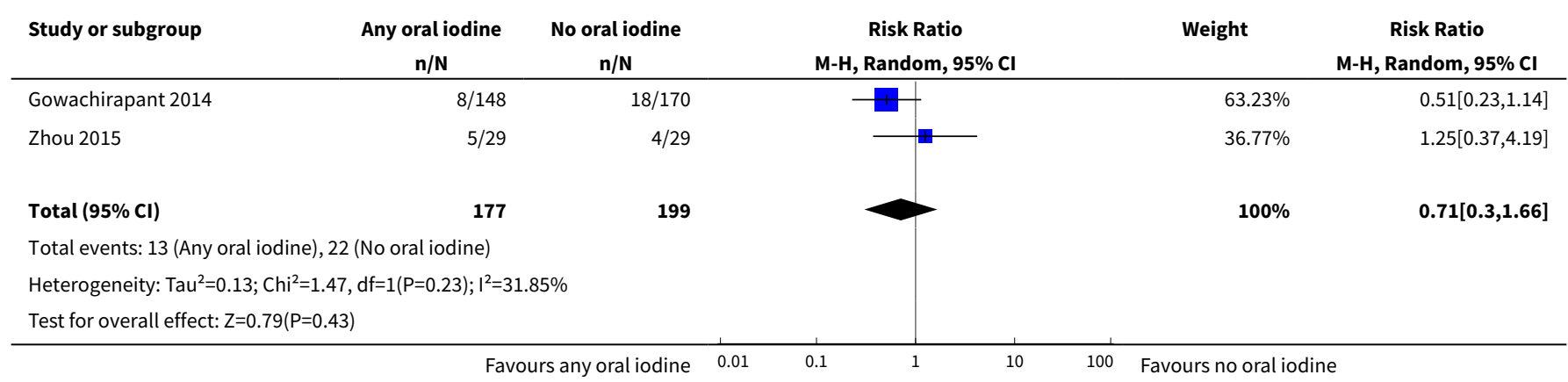

Analysis 2.4. Comparison 2 Any oral iodine supplement versus same supplement without iodine or no intervention/placebo, Outcome 4 Maternal adverse effect: elevated thyroid peroxidase antibodies - pregnancy.

\begin{tabular}{|c|c|c|c|c|c|}
\hline Study or subgroup & $\begin{array}{c}\text { Any oral iodine } \\
\mathrm{n} / \mathrm{N}\end{array}$ & $\begin{array}{c}\text { No oral iodine } \\
n / N \\
\end{array}$ & $\begin{array}{c}\text { Risk Ratio } \\
\text { M-H, Random, 95\% Cl }\end{array}$ & Weight & $\begin{array}{c}\text { Risk Ratio } \\
\text { M-H, Random, 95\% Cl }\end{array}$ \\
\hline Gowachirapant 2014 & $11 / 169$ & $13 / 190$ & & $100 \%$ & $0.95[0.44,2.07]$ \\
\hline Total $(95 \% \mathrm{CI})$ & 169 & 190 & & $100 \%$ & $0.95[0.44,2.07]$ \\
\hline \multicolumn{6}{|c|}{ Total events: 11 (Any oral iodine), 13 (No oral iodine) } \\
\hline \multicolumn{6}{|c|}{ Heterogeneity: Not applicable } \\
\hline
\end{tabular}

Analysis 2.5. Comparison 2 Any oral iodine supplement versus same supplement without iodine or no intervention/placebo, Outcome 5 Maternal adverse effect: elevated thyroid peroxidase antibodies - postpartum.

\begin{tabular}{|c|c|c|c|c|c|}
\hline Study or subgroup & $\begin{array}{c}\text { Any oral iodine } \\
n / N\end{array}$ & $\begin{array}{c}\text { No oral iodine } \\
n / N\end{array}$ & $\begin{array}{c}\text { Risk Ratio } \\
\text { M-H, Random, } 95 \% \mathrm{CI}\end{array}$ & Weight & $\begin{array}{c}\text { Risk Ratio } \\
\text { M-H, Random, } 95 \% \text { CI }\end{array}$ \\
\hline Gowachirapant 2014 & $57 / 115$ & $58 / 120$ & & $96.67 \%$ & $1.03[0.79,1.33]$ \\
\hline Liesenkotter 1996 & $1 / 38$ & $5 / 70$ & & $1.48 \%$ & $0.37[0.04,3.04]$ \\
\hline Pedersen 1993 & $2 / 28$ & $2 / 26$ & & $1.85 \%$ & $0.93[0.14,6.12]$ \\
\hline Total $(95 \% \mathrm{Cl})$ & 181 & 216 & & $100 \%$ & $1.01[0.78,1.3]$ \\
\hline \multicolumn{6}{|c|}{ Heterogeneity: $\operatorname{Tau}^{2}=0 ; \mathrm{Chi}^{2}=0.93, \mathrm{df}=2(\mathrm{P}=0.63) ; \mathrm{I}^{2}=0 \%$} \\
\hline Test for overall effect: & & & & & \\
\hline
\end{tabular}


Analysis 2.6. Comparison 2 Any oral iodine supplement versus same supplement without iodine or no intervention/placebo, Outcome 6 Maternal adverse effect: hyperthyroidism - pregnancy.

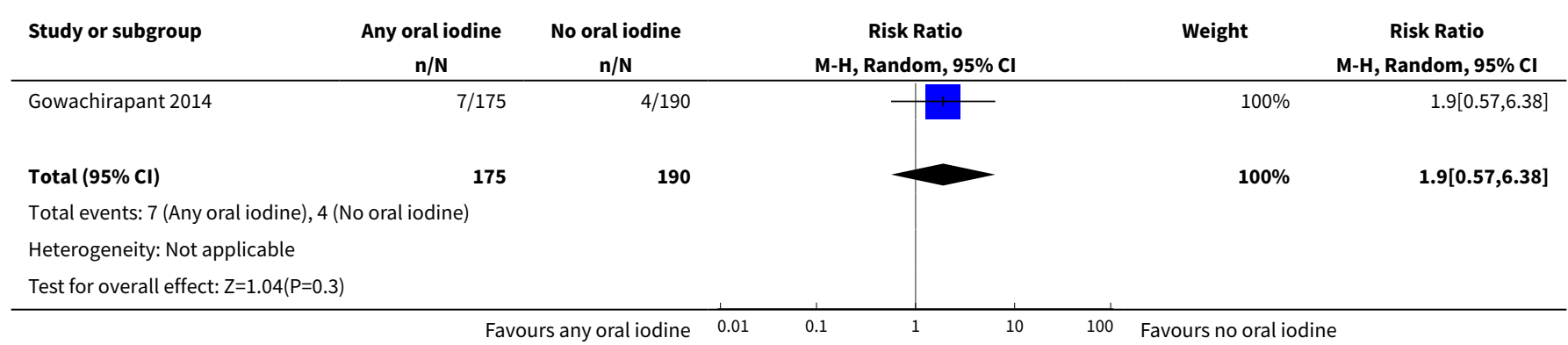

Analysis 2.7. Comparison 2 Any oral iodine supplement versus same supplement without iodine or no intervention/placebo, Outcome 7 Maternal adverse effect: hyperthyroidism - postpartum.

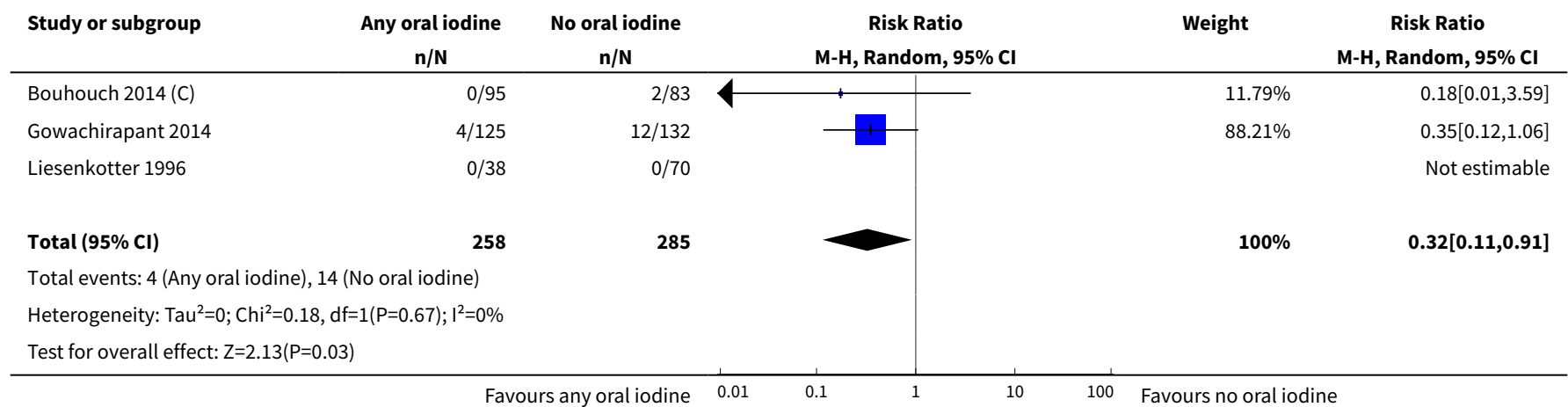

Analysis 2.8. Comparison 2 Any oral iodine supplement versus same supplement without iodine or no intervention/placebo, Outcome 8 Maternal adverse effect: digestive intolerance - pregnancy.

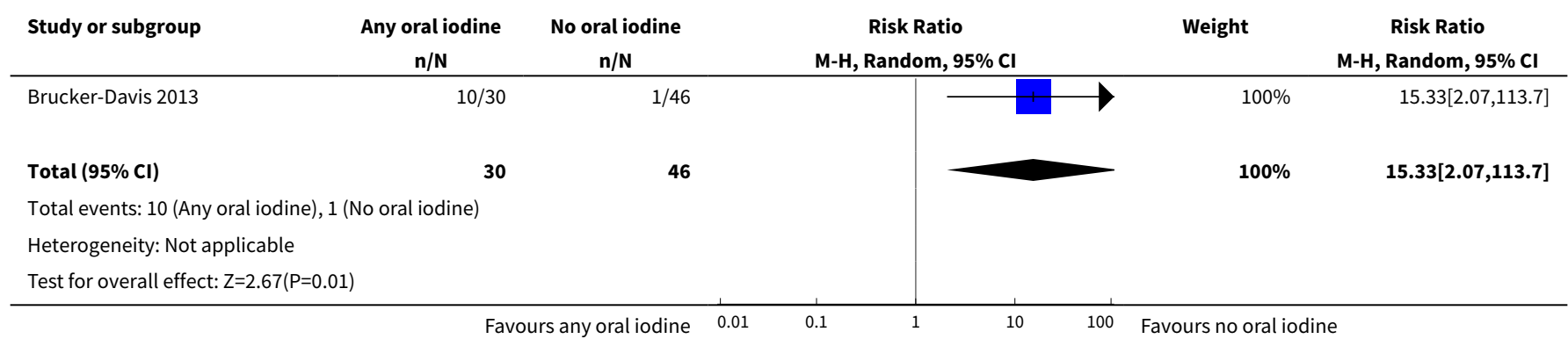

Analysis 2.9. Comparison 2 Any oral iodine supplement versus same supplement without iodine or no intervention/placebo, Outcome 9 Perinatal mortality.

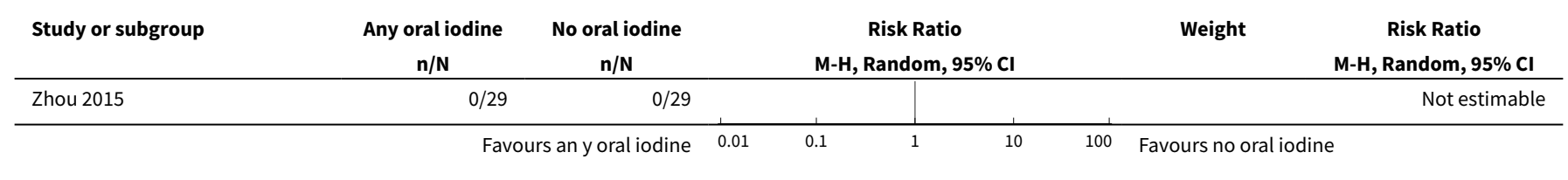




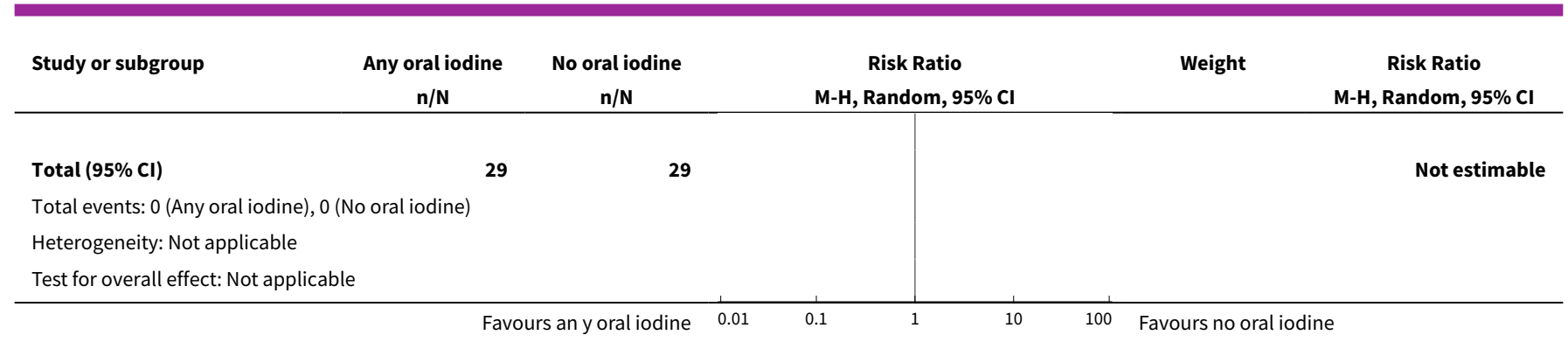

Analysis 2.10. Comparison 2 Any oral iodine supplement versus same supplement without iodine or no intervention/placebo, Outcome 10 Low birthweight.

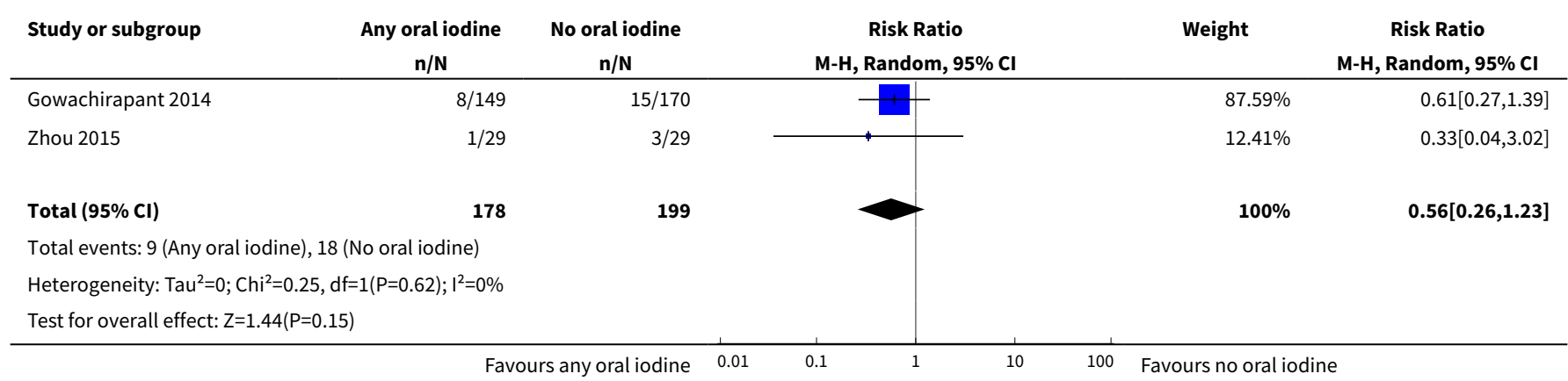

Analysis 2.11. Comparison 2 Any oral iodine supplement versus same supplement without iodine or no intervention/placebo, Outcome 11 Neonatal hypothyroidism or elevated TSH.

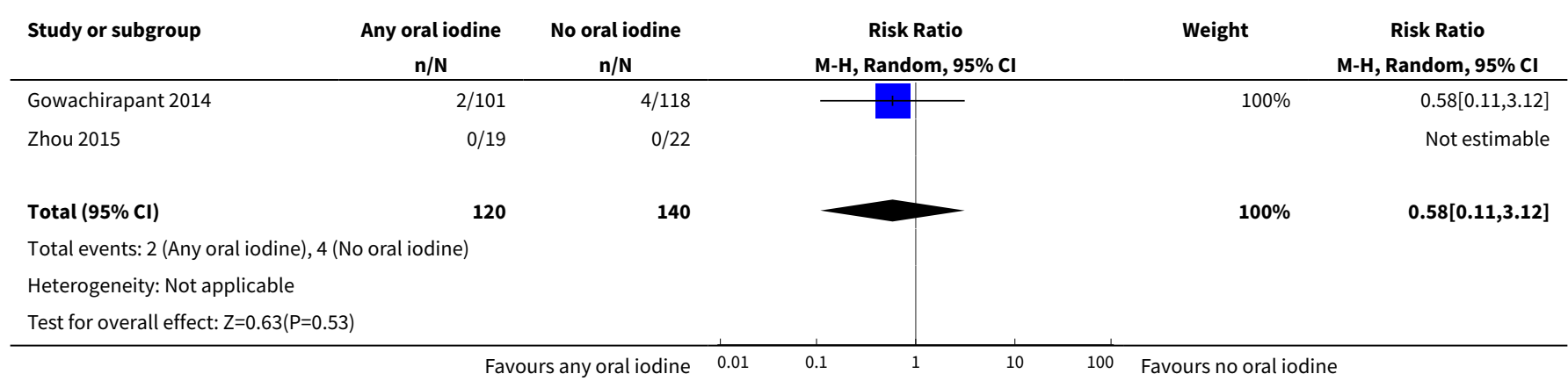

Analysis 2.12. Comparison 2 Any oral iodine supplement versus same supplement without iodine or no intervention/placebo, Outcome 12 Neonatal adverse effect: elevated thyroid peroxidase antibodies.

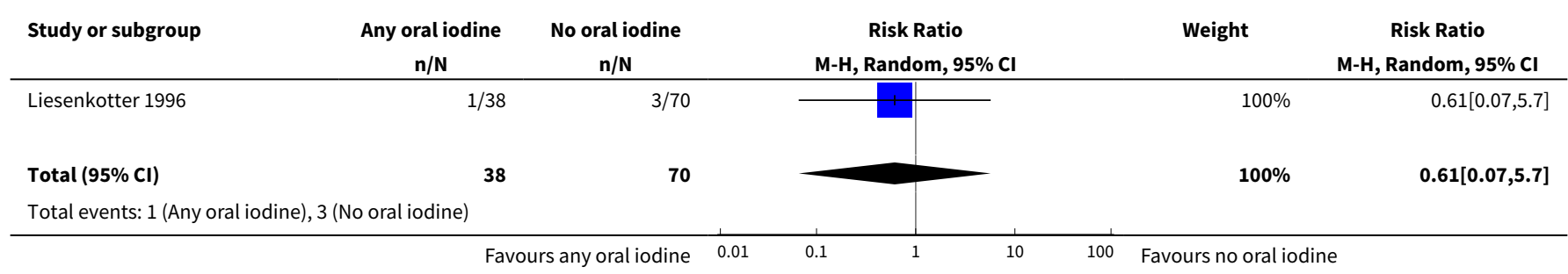




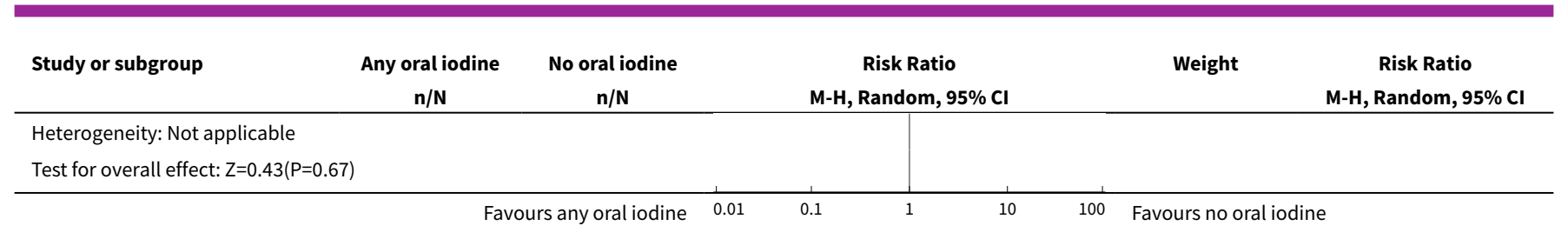

Analysis 2.13. Comparison 2 Any oral iodine supplement versus same supplement without iodine or no intervention/placebo, Outcome 13 Spontaneous miscarriage.

\begin{tabular}{|c|c|c|c|c|c|}
\hline Study or subgroup & $\begin{array}{c}\text { Any oral iodine } \\
n / N\end{array}$ & $\begin{array}{c}\text { No oral iodine } \\
n / N\end{array}$ & $\begin{array}{c}\text { Risk Ratio } \\
\text { M-H, Random, } 95 \% \mathrm{CI}\end{array}$ & Weight & $\begin{array}{c}\text { Risk Ratio } \\
\text { M-H, Random, } 95 \% \mathrm{CI}\end{array}$ \\
\hline Brucker-Davis 2013 & $4 / 30$ & $3 / 46$ & \begin{tabular}{l|l} 
& $\square$ \\
\end{tabular} & $25.3 \%$ & $2.04[0.49,8.5]$ \\
\hline Gowachirapant 2014 & $10 / 249$ & $10 / 262$ & & $69.56 \%$ & $1.05[0.45,2.48]$ \\
\hline Zhou 2015 & $1 / 29$ & $0 / 29$ & 1 & $5.14 \%$ & $3[0.13,70.74]$ \\
\hline Total $(95 \% \mathrm{CI})$ & 308 & 337 & & $100 \%$ & $1.31[0.64,2.69]$ \\
\hline \multicolumn{6}{|c|}{ Total events: 15 (Any oral iodine), 13 (No oral iodine) } \\
\hline \multicolumn{6}{|c|}{ Heterogeneity: $\mathrm{Tau}^{2}=0 ; \mathrm{Chi}^{2}=0.89, \mathrm{df}=2(\mathrm{P}=0.64) ; \mathrm{I}^{2}=0 \%$} \\
\hline Test for overall effect: & & & & & \\
\hline
\end{tabular}

Analysis 2.14. Comparison 2 Any oral iodine supplement versus same supplement without iodine or no intervention/placebo, Outcome 14 Maternal goitre - pregnancy.

\begin{tabular}{|c|c|c|c|c|c|}
\hline Study or subgroup & $\begin{array}{c}\text { Any oral iodine } \\
n / N\end{array}$ & $\begin{array}{c}\text { No oral iodine } \\
n / N\end{array}$ & $\begin{array}{c}\text { Risk Ratio } \\
\text { M-H, Random, 95\% Cl }\end{array}$ & Weight & $\begin{array}{c}\text { Risk Ratio } \\
\text { M-H, Random, } 95 \% \mathrm{CI}\end{array}$ \\
\hline Glinoer 1993 & $6 / 60$ & $10 / 60$ & प1 & $55.63 \%$ & $0.6[0.23,1.55]$ \\
\hline Gowachirapant 2014 & $7 / 176$ & $4 / 190$ & & $44.37 \%$ & $1.89[0.56,6.34]$ \\
\hline Total $(95 \% \mathrm{Cl})$ & 236 & 250 & & $100 \%$ & $1[0.33,3.06]$ \\
\hline \multicolumn{6}{|c|}{ Total events: 13 (Any oral iodine), 14 (No oral iodine) } \\
\hline Test for overall effect: & & & & & \\
\hline
\end{tabular}

Analysis 2.15. Comparison 2 Any oral iodine supplement versus same supplement without iodine or no intervention/placebo, Outcome 15 Maternal goitre - postpartum.

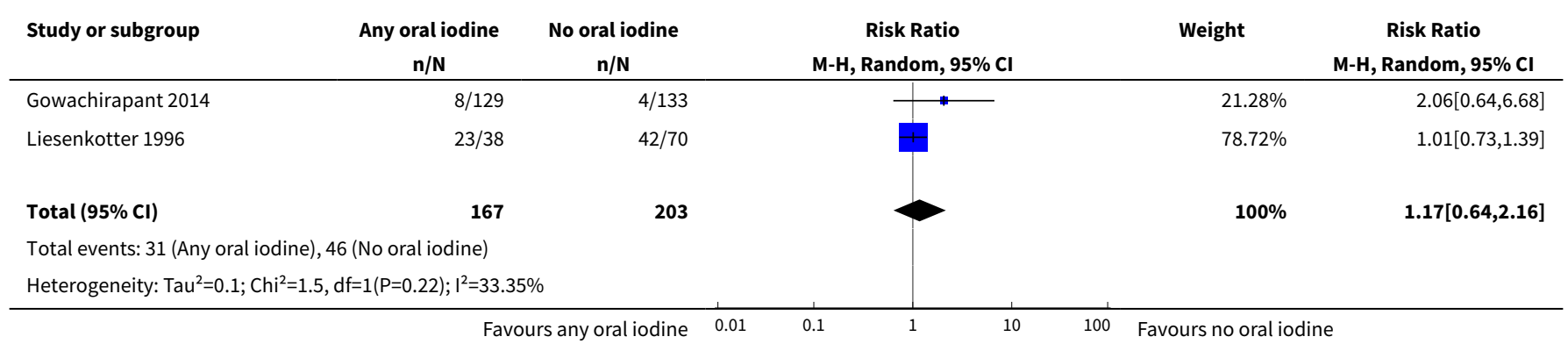




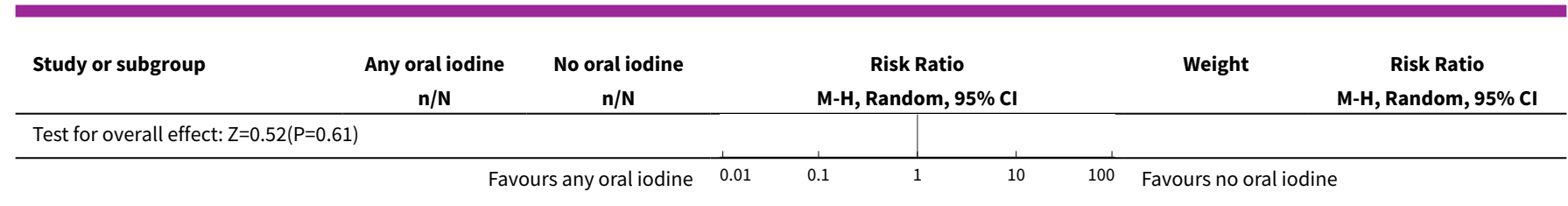

Analysis 2.16. Comparison 2 Any oral iodine supplement versus same supplement without iodine or no intervention/placebo, Outcome 16 Maternal insufficient iodine intake - pregnancy.

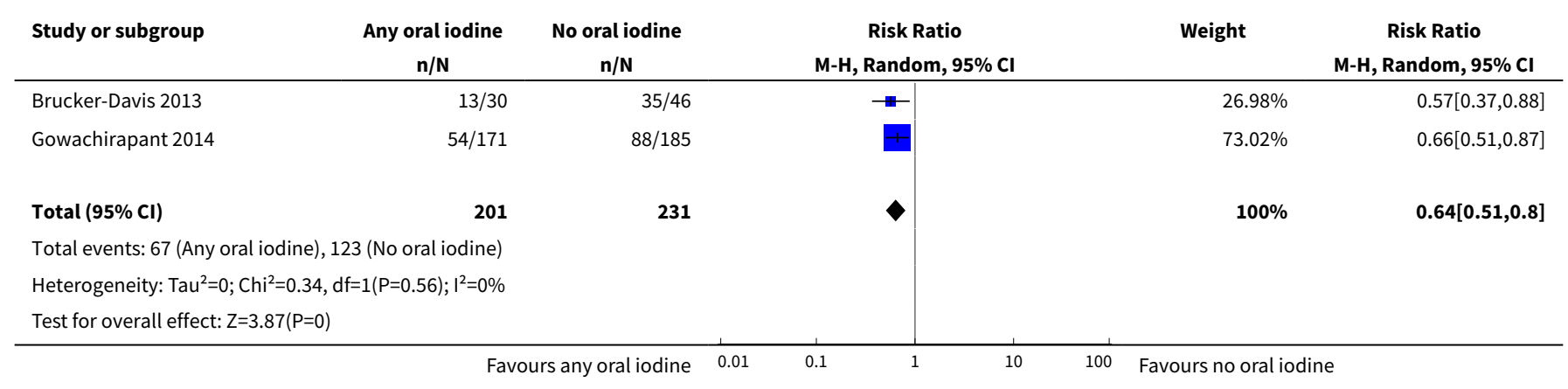

Analysis 2.17. Comparison 2 Any oral iodine supplement versus same supplement without iodine or no intervention/placebo, Outcome 17 Maternal insufficient iodine intake - postpartum.

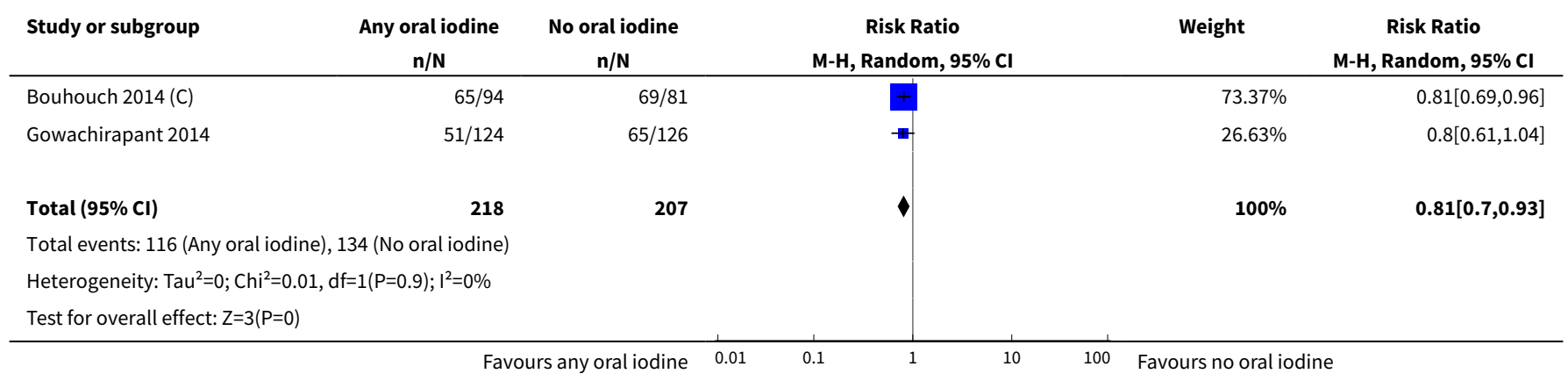

Analysis 2.18. Comparison 2 Any oral iodine supplement versus same supplement without iodine or no intervention/placebo, Outcome 18 Maternal excessive iodine intake - pregnancy.

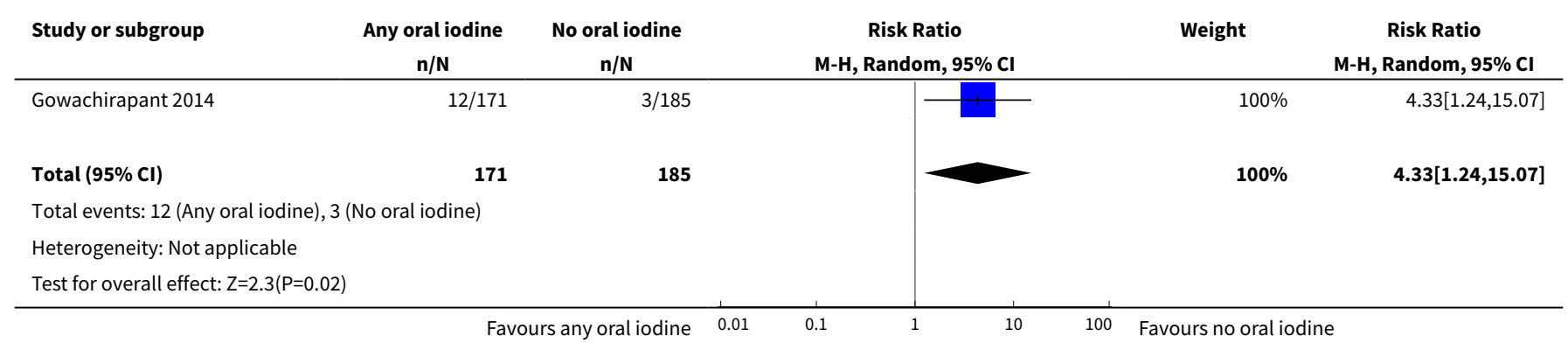


Analysis 2.19. Comparison 2 Any oral iodine supplement versus same supplement without iodine or no intervention/placebo, Outcome 19 Small-for-gestational age.

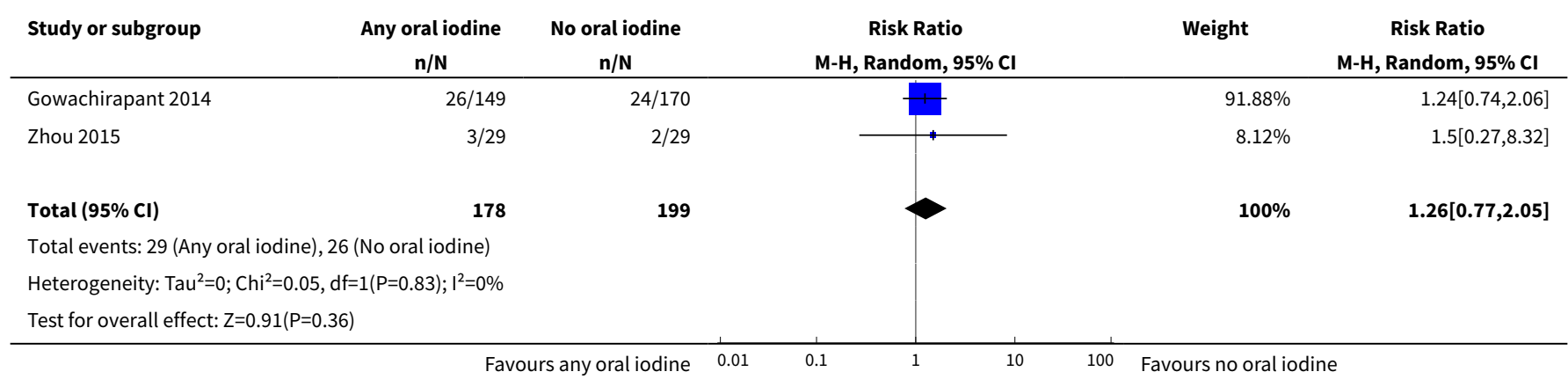

Analysis 2.20. Comparison 2 Any oral iodine supplement versus same supplement without iodine or no intervention/placebo, Outcome 20 Congenital anomalies.

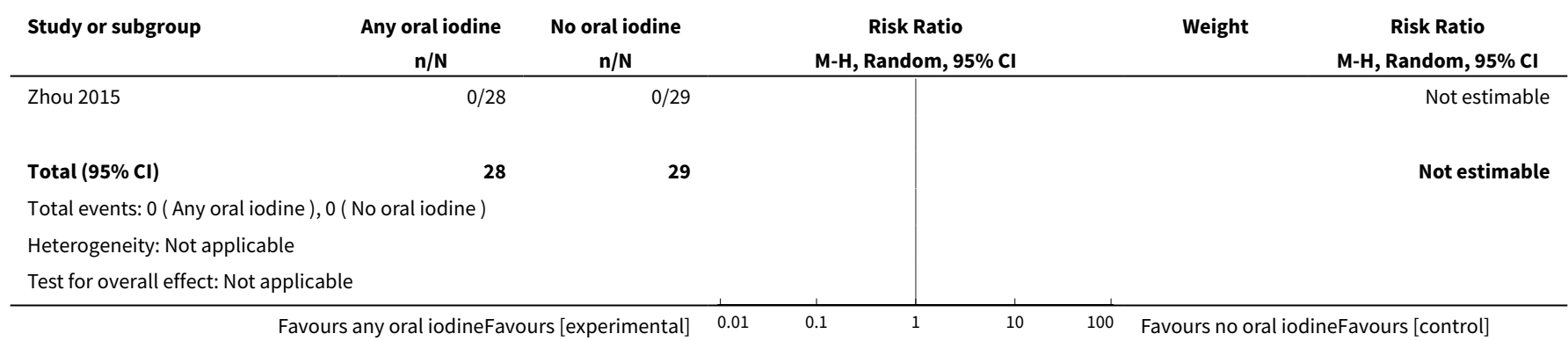

Analysis 2.21. Comparison 2 Any oral iodine supplement versus same supplement without iodine or no intervention/placebo, Outcome 21 Neonatal goitre.

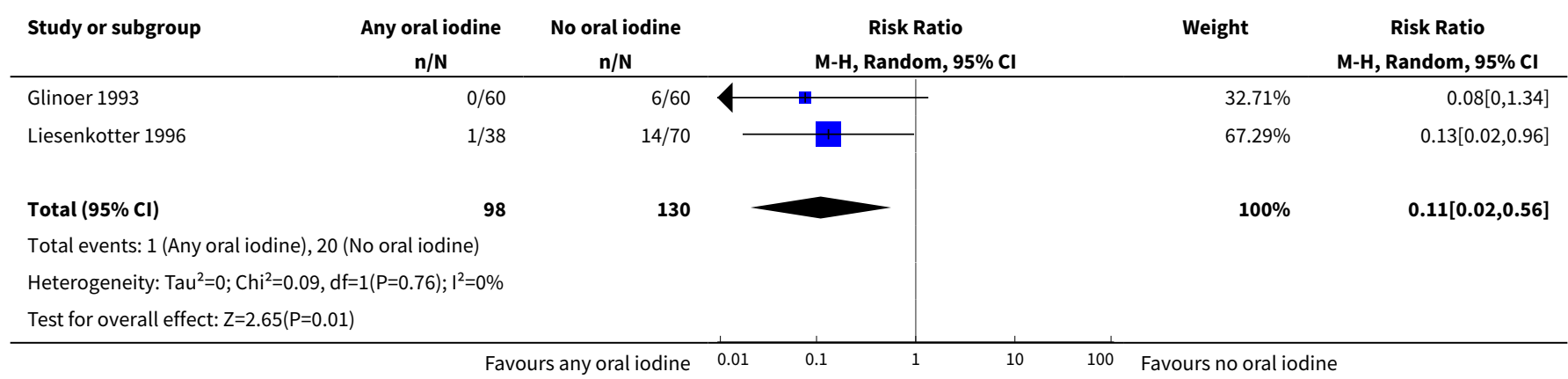


Analysis 2.22. Comparison 2 Any oral iodine supplement versus same supplement without iodine or no intervention/placebo, Outcome 22 Neonatal thyroid volume (in $\mathrm{mL}$ ).

\begin{tabular}{|c|c|c|c|c|c|c|c|}
\hline \multirow[t]{2}{*}{ Study or subgroup } & \multicolumn{2}{|c|}{ Any oral iodine } & \multicolumn{2}{|c|}{ No oral iodine } & \multirow{2}{*}{$\begin{array}{l}\text { Mean Difference } \\
\text { Random, } 95 \% \mathrm{CI}\end{array}$} & \multirow[t]{2}{*}{ Weight } & \multirow{2}{*}{$\begin{array}{l}\text { Mean Difference } \\
\text { Random, } 95 \% \mathrm{CI}\end{array}$} \\
\hline & $\mathbf{N}$ & $\operatorname{Mean}(S D)$ & $\mathbf{N}$ & $\operatorname{Mean}(S D)$ & & & \\
\hline Glinoer 1993 & 60 & $0.8(0.2)$ & 60 & $1.1(0.2)$ & 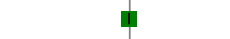 & $37.95 \%$ & $-0.29[-0.36,-0.22]$ \\
\hline Gowachirapant 2014 & 64 & $0.6(0.3)$ & 67 & $0.7(0.2)$ & $\Phi$ & $37.18 \%$ & $-0.09[-0.18,-0]$ \\
\hline Liesenkotter 1996 & 38 & $0.7(0.4)$ & 70 & $1.5(1.1)$ & 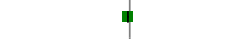 & $24.86 \%$ & $-0.8[-1.09,-0.51]$ \\
\hline 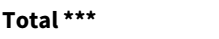 & 162 & & 197 & & & $100 \%$ & $-0.34[-0.58,-0.11]$ \\
\hline \multicolumn{8}{|c|}{ Test for overall effect: $Z=2.83(P=0)$} \\
\hline
\end{tabular}

Analysis 2.23. Comparison 2 Any oral iodine supplement versus same supplement without iodine or no intervention/placebo, Outcome 23 Neonatal insufficient iodine intake.

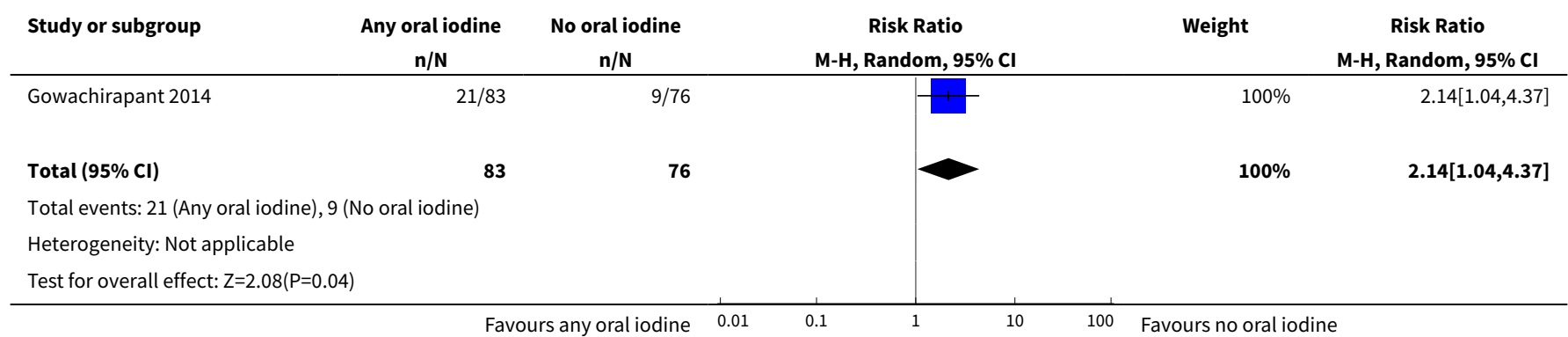

Analysis 2.24. Comparison 2 Any oral iodine supplement versus same supplement without iodine or no intervention/placebo, Outcome $\mathbf{2 4}$ Child mental or motor development (cognitive score).

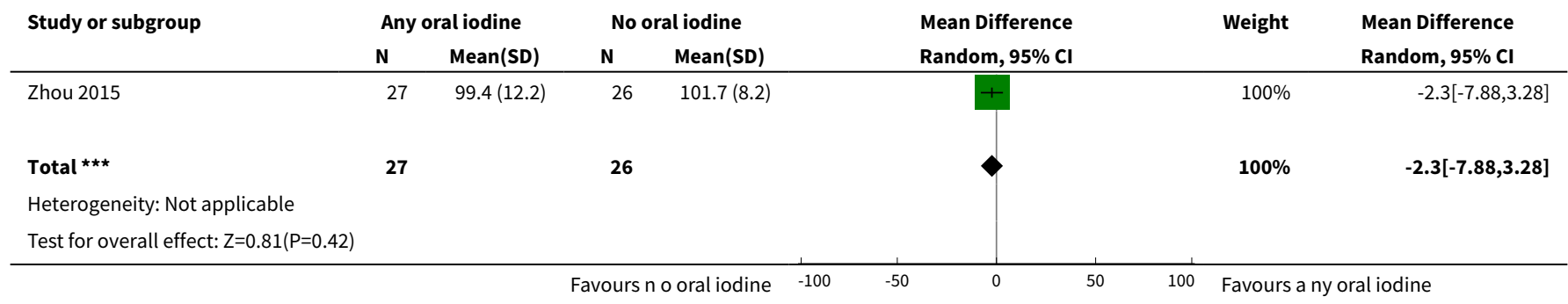

Analysis 2.25. Comparison 2 Any oral iodine supplement versus same supplement without iodine or no intervention/placebo, Outcome $\mathbf{2 5}$ Child mental or motor development (language score).

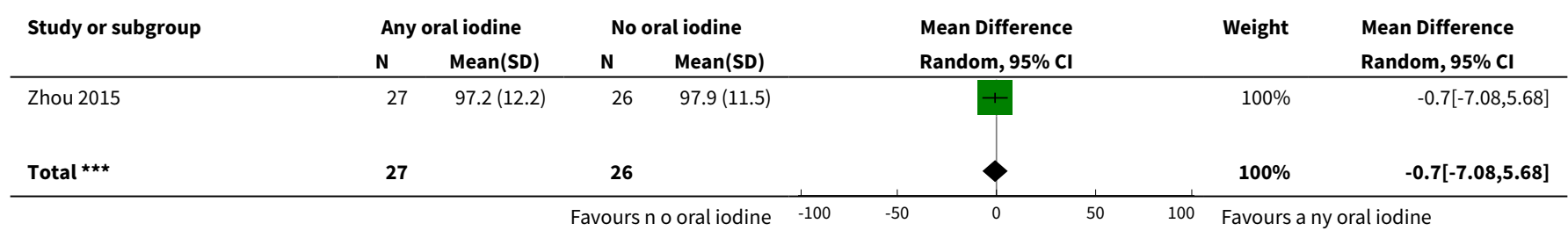




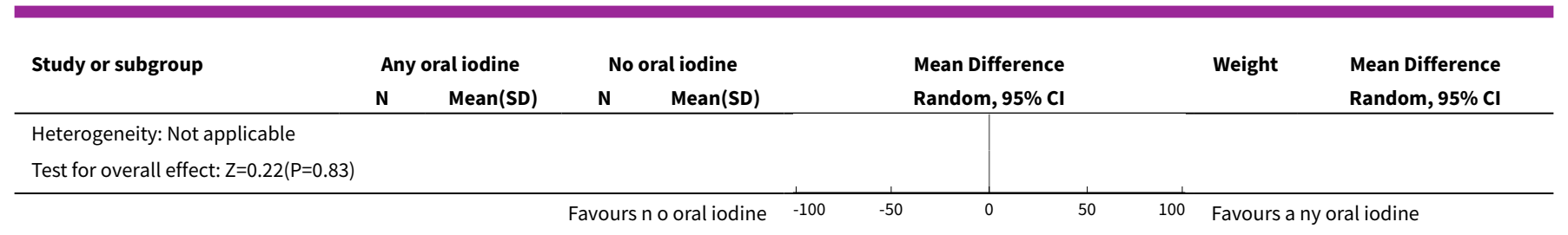

Analysis 2.26. Comparison 2 Any oral iodine supplement versus same supplement without iodine or no intervention/placebo, Outcome 26 Child mental or motor development (motor score).

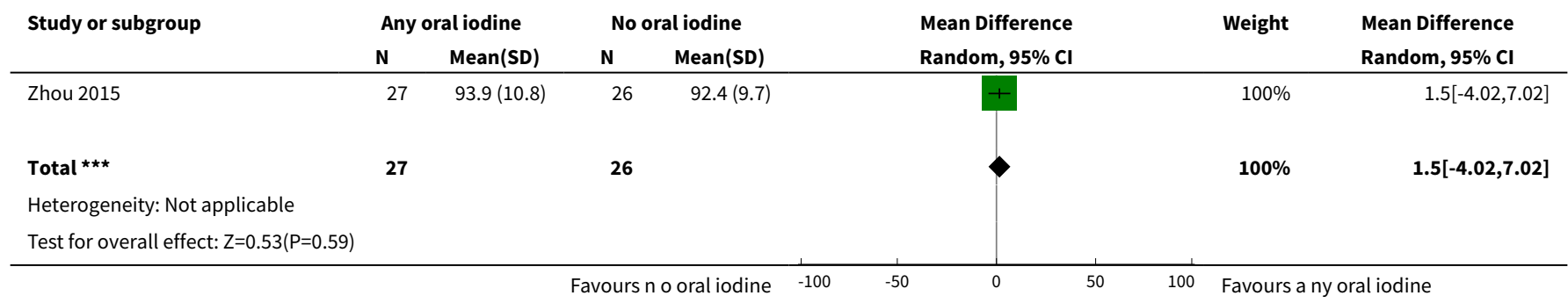

Analysis 2.27. Comparison 2 Any oral iodine supplement versus same supplement without iodine or no intervention/placebo, Outcome 27 Child mental or motor development (social-emotional score).

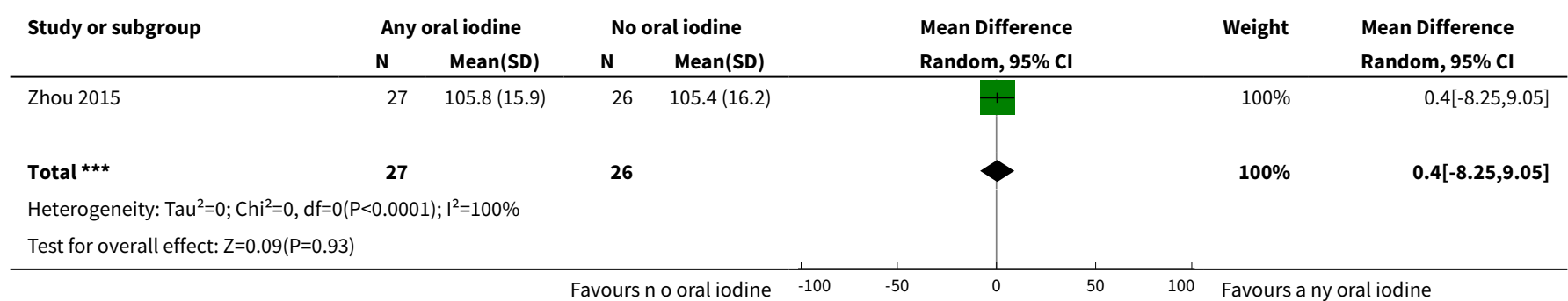

Analysis 2.28. Comparison 2 Any oral iodine supplement versus same supplement without iodine or no intervention/placebo, Outcome $\mathbf{2 8}$ Child mental or motor development (adaptive behaviour score).

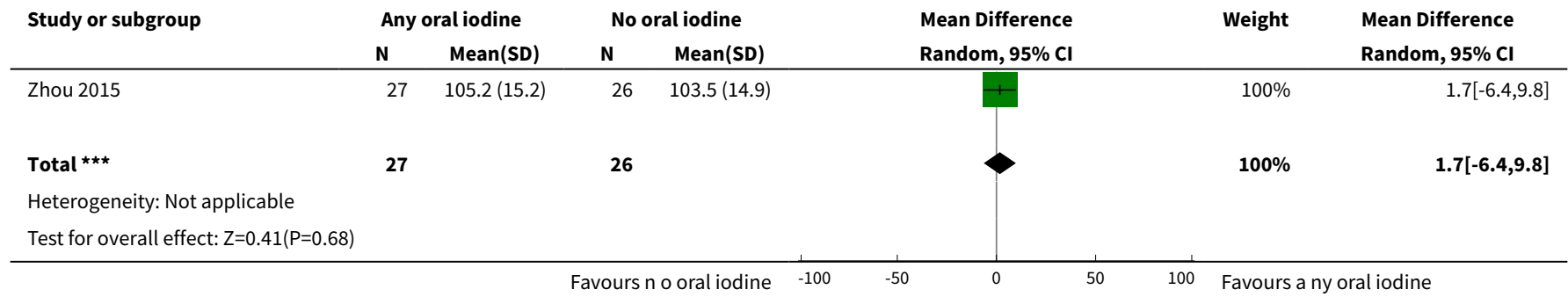


Analysis 2.29. Comparison 2 Any oral iodine supplement versus same supplement without iodine or no intervention/placebo, Outcome 29 Child mental or motor development (cognitive score < 85).

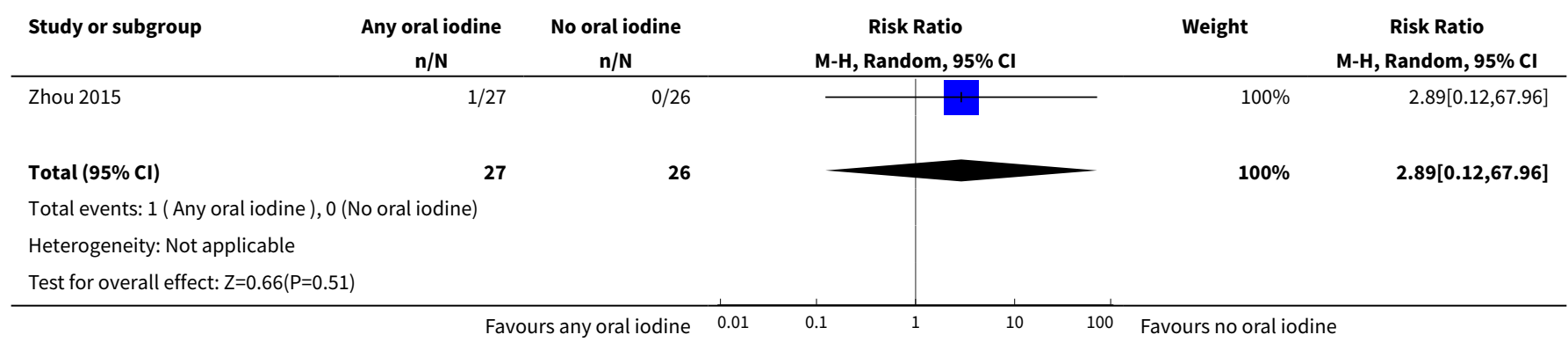

Analysis 2.30. Comparison 2 Any oral iodine supplement versus same supplement without iodine or no intervention/placebo, Outcome $\mathbf{3 0}$ Child mental or motor development (cognitive score $<70$ ).

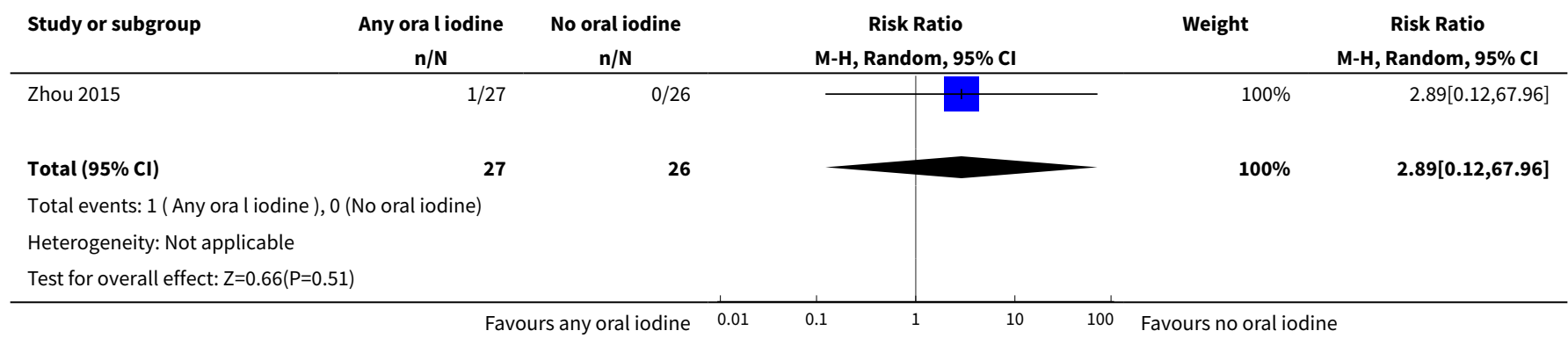

Analysis 2.31. Comparison 2 Any oral iodine supplement versus same supplement without iodine or no intervention/placebo, Outcome $\mathbf{3 1}$ Child mental or motor development (language score $<\mathbf{8 5}$ ).

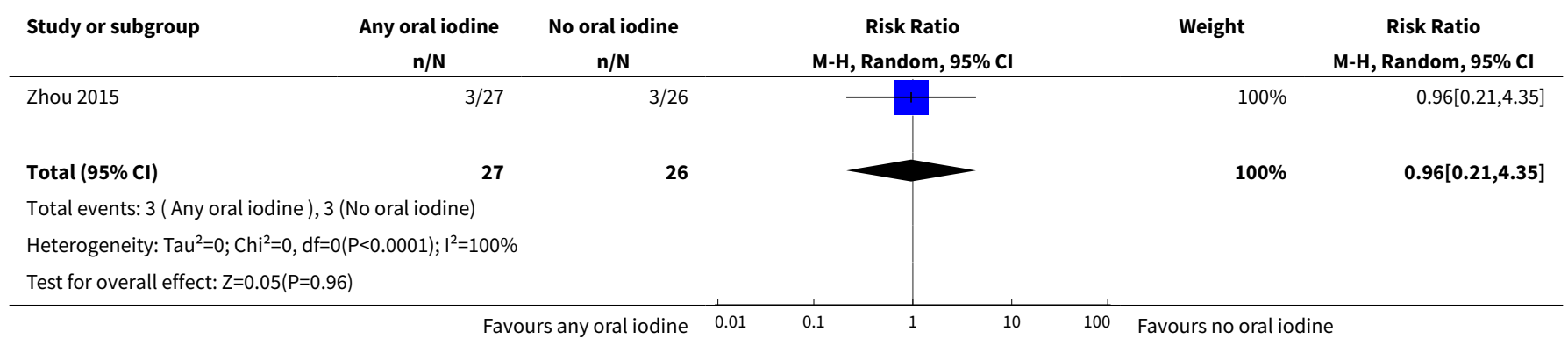

Analysis 2.32. Comparison 2 Any oral iodine supplement versus same supplement without iodine or no intervention/placebo, Outcome 32 Child mental or motor development (language score $<70$ ).

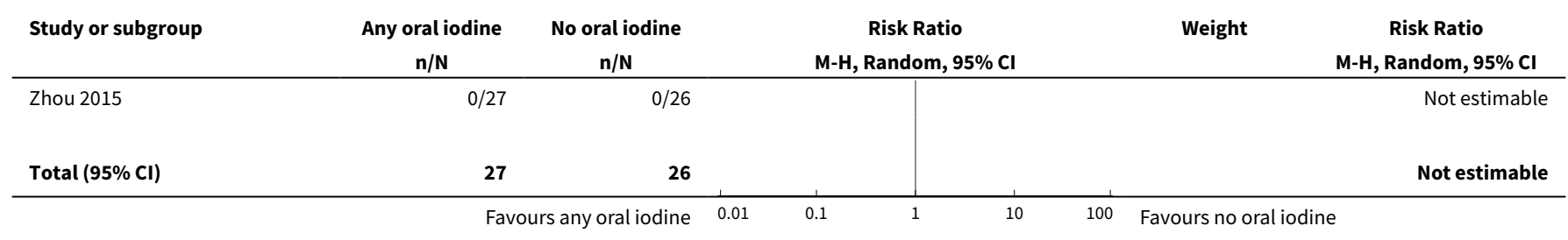




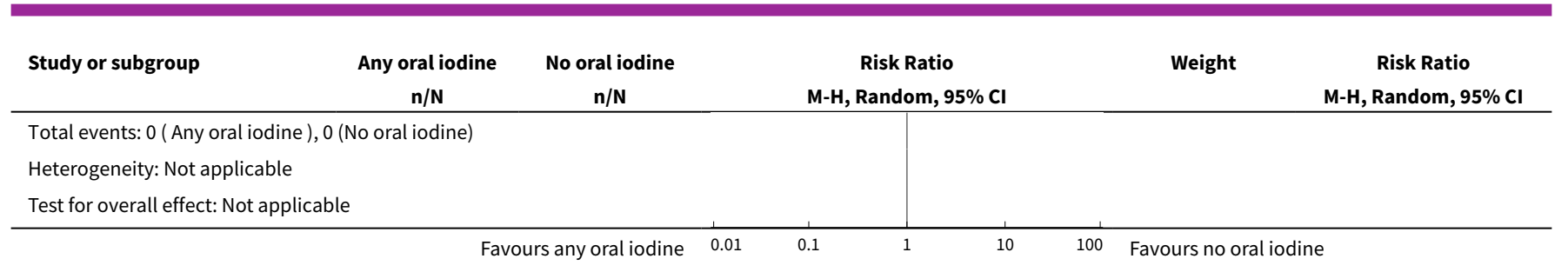

Analysis 2.33. Comparison 2 Any oral iodine supplement versus same supplement without iodine or no intervention/placebo, Outcome 33 Child mental or motor development (motor score < 85).

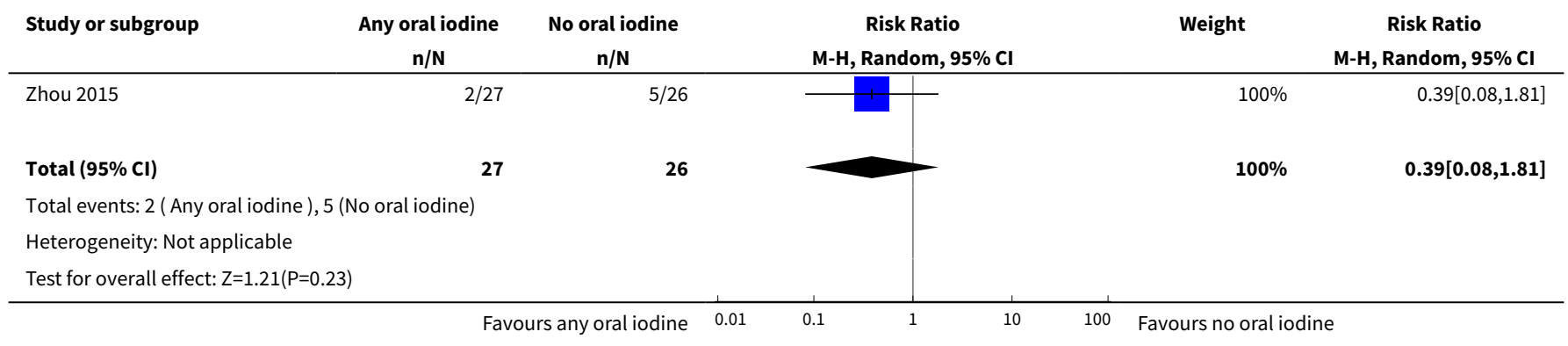

Analysis 2.34. Comparison 2 Any oral iodine supplement versus same supplement without iodine or no intervention/placebo, Outcome 34 Child mental or motor development (motor score $<70$ ).

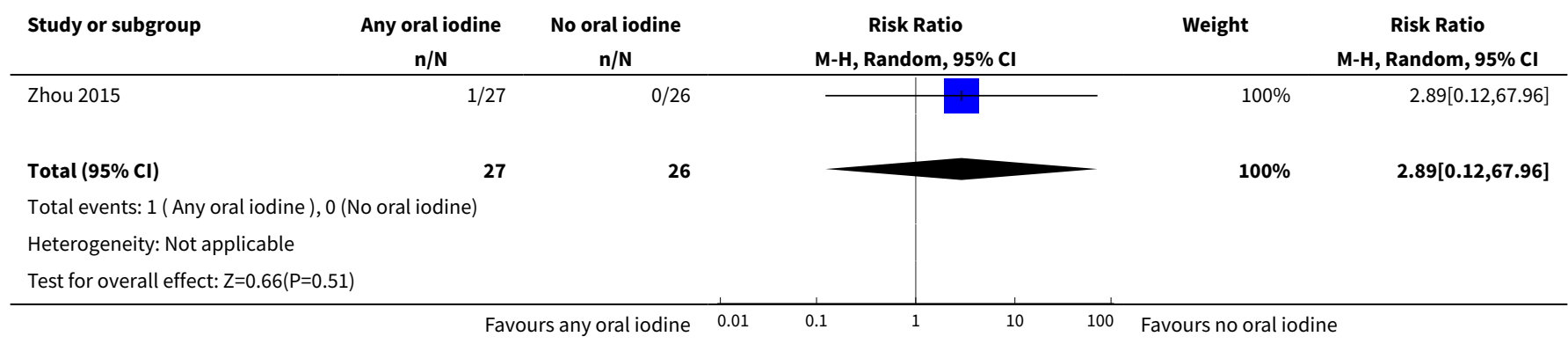

\section{Comparison 3. Oral iodine-only supplement versus no intervention or placebo}

\begin{tabular}{lllll}
\hline Outcome or subgroup title & No. of studies & $\begin{array}{l}\text { No. of partici- } \\
\text { pants }\end{array}$ & Statistical method & Effect size \\
\hline $\begin{array}{l}1 \text { Maternal hypothyroidism - postpar- } \\
\text { tum }\end{array}$ & 3 & 340 & $\begin{array}{l}\text { Risk Ratio (M-H, Random, } \\
95 \% \mathrm{Cl})\end{array}$ & $0.91[0.10,8.60]$ \\
\hline $\begin{array}{l}\text { Preterm birth } \\
\text { P }\end{array}$ & 1 & 58 & $\begin{array}{l}\text { Risk Ratio (M-H, Random, } \\
95 \% \mathrm{Cl})\end{array}$ & $1.25[0.37,4.19]$ \\
\hline $\begin{array}{l}\text { 3 Maternal adverse effect: elevated } \\
\text { thyroid peroxidase antibodies - post- }\end{array}$ & 2 & 162 & $\begin{array}{l}\text { Risk Ratio (M-H, Random, } \\
95 \% \mathrm{Cl})\end{array}$ & $0.62[0.15,2.51]$ \\
\hline
\end{tabular}




\begin{tabular}{|c|c|c|c|c|}
\hline Outcome or subgroup title & No. of studies & $\begin{array}{l}\text { No. of partici- } \\
\text { pants }\end{array}$ & Statistical method & Effect size \\
\hline $\begin{array}{l}4 \text { Maternal adverse effect: hyperthy- } \\
\text { roidism - postpartum }\end{array}$ & 2 & 286 & $\begin{array}{l}\text { Risk Ratio (M-H, Random, } \\
95 \% \mathrm{Cl})\end{array}$ & $0.29[0.01,7.06]$ \\
\hline 5 Perinatal mortality & 1 & 58 & $\begin{array}{l}\text { Risk Ratio (M-H, Random, } \\
95 \% \mathrm{Cl})\end{array}$ & $0.0[0.0,0.0]$ \\
\hline 6 Low birthweight & 1 & 58 & $\begin{array}{l}\text { Risk Ratio (M-H, Fixed, 95\% } \\
\mathrm{Cl})\end{array}$ & $0.33[0.04,3.02]$ \\
\hline $\begin{array}{l}7 \text { Neonatal hypothyroidism or elevat- } \\
\text { ed TSH }\end{array}$ & 1 & 41 & $\begin{array}{l}\text { Risk Ratio (M-H, Random, } \\
95 \% \mathrm{Cl})\end{array}$ & $0.0[0.0,0.0]$ \\
\hline $\begin{array}{l}8 \text { Neonatal adverse effect: elevated } \\
\text { thyroid peroxidase antibodies }\end{array}$ & 1 & 108 & $\begin{array}{l}\text { Risk Ratio (M-H, Random, } \\
95 \% \mathrm{Cl})\end{array}$ & $0.61[0.07,5.70]$ \\
\hline 9 Spontaneous miscarriage & 1 & 58 & $\begin{array}{l}\text { Risk Ratio (M-H, Random, } \\
95 \% \mathrm{Cl})\end{array}$ & $3.0[0.13,70.74]$ \\
\hline 10 Maternal goitre - pregnancy & 1 & 120 & $\begin{array}{l}\text { Risk Ratio (M-H, Random, } \\
95 \% \mathrm{Cl})\end{array}$ & $0.6[0.23,1.55]$ \\
\hline 11 Maternal goitre - postpartum & 1 & 108 & $\begin{array}{l}\text { Risk Ratio (M-H, Random, } \\
95 \% \mathrm{Cl})\end{array}$ & $1.01[0.73,1.39]$ \\
\hline $\begin{array}{l}12 \text { Maternal insufficient iodine intake } \\
\text { - postpartum }\end{array}$ & 1 & 175 & $\begin{array}{l}\text { Risk Ratio (M-H, Random, } \\
95 \% \mathrm{Cl})\end{array}$ & $0.81[0.69,0.96]$ \\
\hline 13 Small-for-gestational age & 1 & 58 & $\begin{array}{l}\text { Risk Ratio (M-H, Fixed, 95\% } \\
\mathrm{Cl})\end{array}$ & $1.5[0.27,8.32]$ \\
\hline 14 Congenital anomalies & 1 & 57 & $\begin{array}{l}\text { Risk Ratio (M-H, Random, } \\
95 \% \mathrm{Cl})\end{array}$ & $0.0[0.0,0.0]$ \\
\hline 15 Neonatal goitre & 2 & 228 & $\begin{array}{l}\text { Risk Ratio (M-H, Random, } \\
95 \% \mathrm{Cl})\end{array}$ & $0.11[0.02,0.56]$ \\
\hline 16 Neonatal thyroid volume (in $\mathrm{mL}$ ) & 2 & 228 & $\begin{array}{l}\text { Mean Difference (IV, Random, } \\
95 \% \mathrm{CI} \text { ) }\end{array}$ & $-0.53[-1.02,-0.03]$ \\
\hline $\begin{array}{l}17 \text { Child mental or motor develop- } \\
\text { ment (cognitive score) }\end{array}$ & 1 & 53 & $\begin{array}{l}\text { Mean Difference (IV, Random, } \\
95 \% \mathrm{CI} \text { ) }\end{array}$ & $-2.30[-7.88,3.28]$ \\
\hline $\begin{array}{l}18 \text { Child mental or motor develop- } \\
\text { ment (language score) }\end{array}$ & 1 & 53 & $\begin{array}{l}\text { Mean Difference (IV, Random, } \\
95 \% \mathrm{CI})\end{array}$ & $-0.70[-7.08,5.68]$ \\
\hline $\begin{array}{l}19 \text { Child mental or motor develop- } \\
\text { ment (motor score) }\end{array}$ & 1 & 53 & $\begin{array}{l}\text { Mean Difference (IV, Random, } \\
95 \% \mathrm{Cl})\end{array}$ & $1.5[-4.02,7.02]$ \\
\hline $\begin{array}{l}20 \text { Child mental or motor develop- } \\
\text { ment (social-emotional score) }\end{array}$ & 1 & 53 & $\begin{array}{l}\text { Mean Difference (IV, Random, } \\
95 \% \mathrm{Cl} \text { ) }\end{array}$ & $0.40[-8.25,9.05]$ \\
\hline $\begin{array}{l}21 \text { Child mental or motor develop- } \\
\text { ment (adaptive behaviour score) }\end{array}$ & 1 & 53 & $\begin{array}{l}\text { Mean Difference (IV, Random, } \\
95 \% \mathrm{Cl} \text { ) }\end{array}$ & $1.70[-6.40,9.80]$ \\
\hline
\end{tabular}




\begin{tabular}{|c|c|c|c|c|}
\hline Outcome or subgroup title & No. of studies & $\begin{array}{l}\text { No. of partici- } \\
\text { pants }\end{array}$ & Statistical method & Effect size \\
\hline $\begin{array}{l}22 \text { Child mental or motor develop- } \\
\text { ment (cognitive score }<85 \text { ) }\end{array}$ & 1 & 53 & $\begin{array}{l}\text { Risk Ratio (M-H, Random, } \\
95 \% \mathrm{Cl})\end{array}$ & $2.89[0.12,67.96]$ \\
\hline $\begin{array}{l}23 \text { Child mental or motor develop- } \\
\text { ment (cognitive score }<70 \text { ) }\end{array}$ & 1 & 53 & $\begin{array}{l}\text { Risk Ratio (M-H, Random, } \\
95 \% \mathrm{Cl})\end{array}$ & $2.89[0.12,67.96]$ \\
\hline $\begin{array}{l}24 \text { Child mental or motor develop- } \\
\text { ment (language score }<85 \text { ) }\end{array}$ & 1 & 53 & $\begin{array}{l}\text { Risk Ratio (M-H, Random, } \\
95 \% \mathrm{Cl})\end{array}$ & $0.96[0.21,4.35]$ \\
\hline $\begin{array}{l}25 \text { Child mental or motor develop- } \\
\text { ment (language score }<70 \text { ) }\end{array}$ & 1 & 53 & $\begin{array}{l}\text { Risk Ratio (M-H, Random, } \\
95 \% \mathrm{Cl})\end{array}$ & $0.0[0.0,0.0]$ \\
\hline $\begin{array}{l}26 \text { Child mental or motor develop- } \\
\text { ment (motor score }<85 \text { ) }\end{array}$ & 1 & 53 & $\begin{array}{l}\text { Risk Ratio (M-H, Random, } \\
95 \% \mathrm{Cl})\end{array}$ & $0.39[0.08,1.81]$ \\
\hline $\begin{array}{l}27 \text { Child mental or motor develop- } \\
\text { ment (motor score }<70 \text { ) }\end{array}$ & 1 & 53 & $\begin{array}{l}\text { Risk Ratio (M-H, Random, } \\
95 \% \mathrm{Cl})\end{array}$ & $2.89[0.12,67.96]$ \\
\hline
\end{tabular}

Analysis 3.1. Comparison 3 Oral iodine-only supplement versus no intervention or placebo, Outcome 1 Maternal hypothyroidism - postpartum.

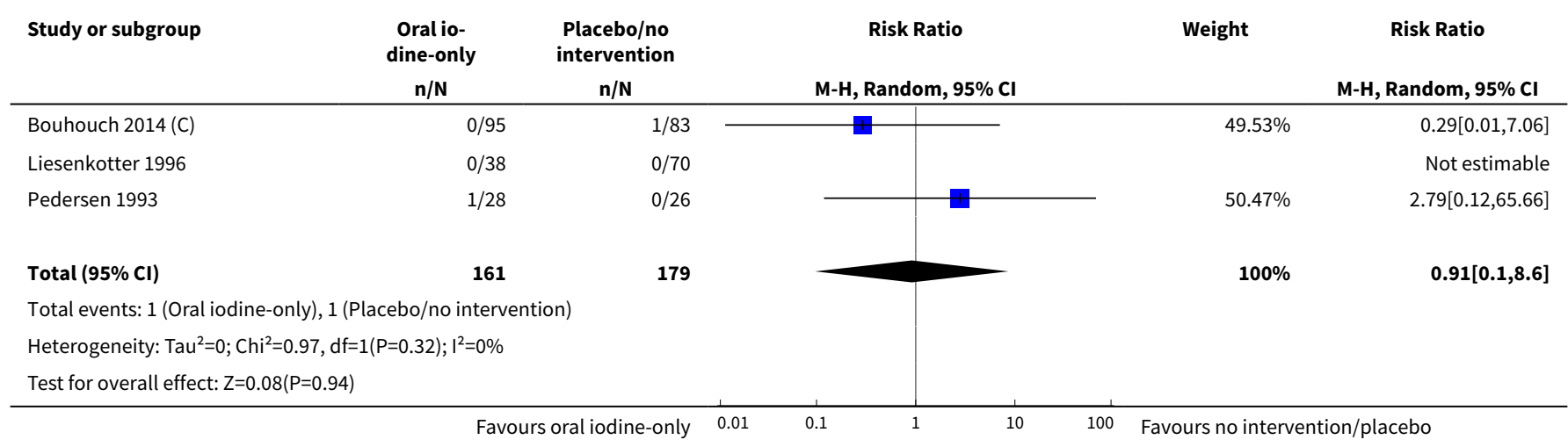

Analysis 3.2. Comparison 3 Oral iodine-only supplement versus no intervention or placebo, Outcome 2 Preterm birth.

\begin{tabular}{|c|c|c|c|c|c|}
\hline Study or subgroup & $\begin{array}{c}\text { Oral- io- } \\
\text { dine only } \\
n / N\end{array}$ & $\begin{array}{c}\mathrm{N} o \text { interven- } \\
\text { tion/placebo } \\
\mathrm{n} / \mathrm{N} \\
\end{array}$ & $\begin{array}{c}\text { Risk Ratio } \\
\text { M-H, Random, } 95 \% \mathrm{Cl}\end{array}$ & Weight & $\begin{array}{c}\text { Risk Ratio } \\
\text { M-H, Random, } 95 \% \mathrm{Cl}\end{array}$ \\
\hline Zhou 2015 & $5 / 29$ & $4 / 29$ & 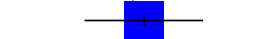 & $100 \%$ & $1.25[0.37,4.19]$ \\
\hline Total $(95 \% \mathrm{Cl})$ & 29 & 29 & & $100 \%$ & $1.25[0.37,4.19]$ \\
\hline \multicolumn{6}{|c|}{ Total events: 5 ( Oral- iodine only ), 4 ( $\mathrm{N}$ o intervention/placebo ) } \\
\hline Test for overall effect & & & & & \\
\hline
\end{tabular}


Analysis 3.3. Comparison 3 Oral iodine-only supplement versus no intervention or placebo, Outcome 3 Maternal adverse effect: elevated thyroid peroxidase antibodies - postpartum.

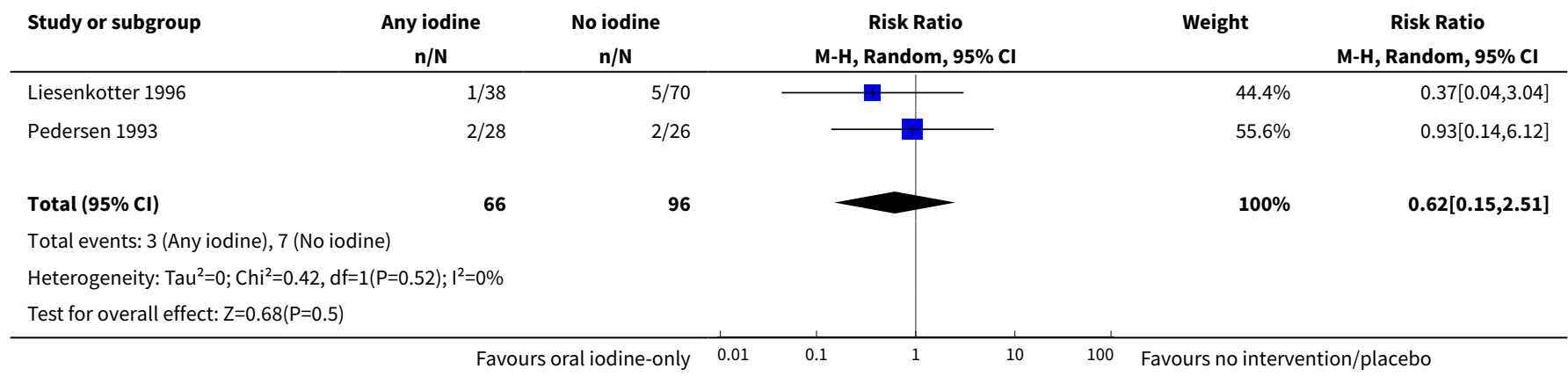

Analysis 3.4. Comparison 3 Oral iodine-only supplement versus no intervention or placebo, Outcome 4 Maternal adverse effect: hyperthyroidism - postpartum.

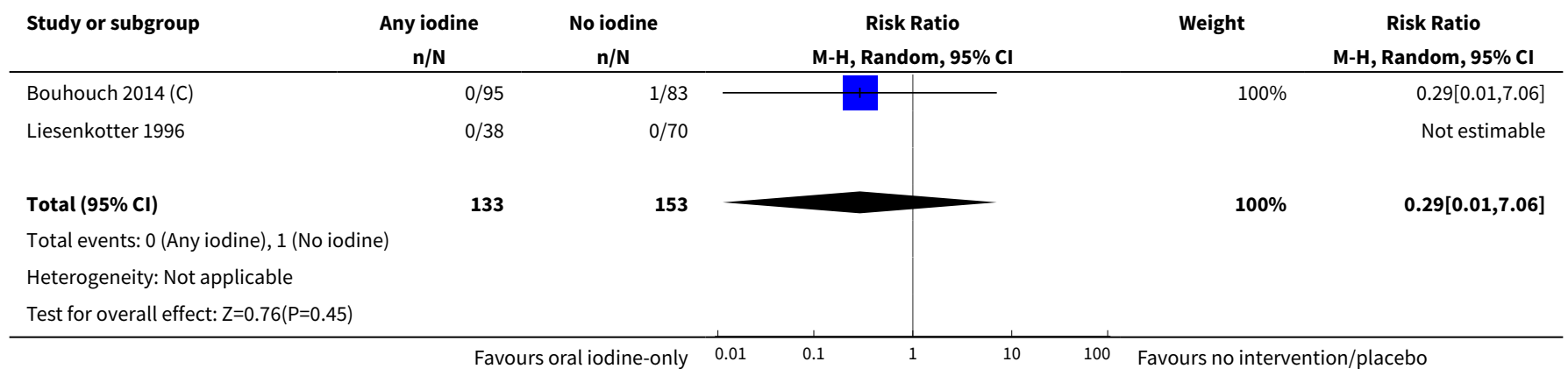

Analysis 3.5. Comparison 3 Oral iodine-only supplement versus no intervention or placebo, Outcome 5 Perinatal mortality.

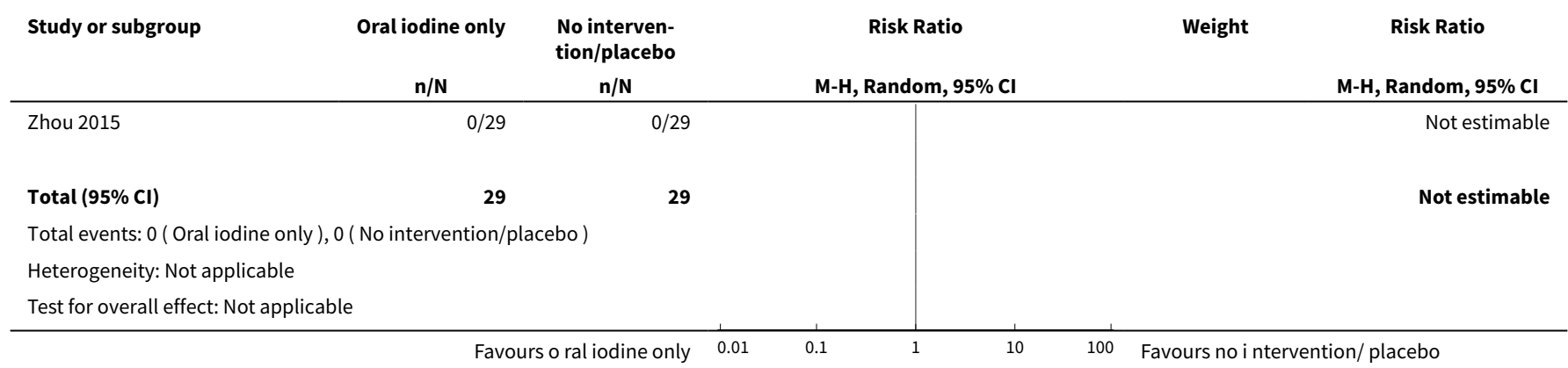


Analysis 3.6. Comparison 3 Oral iodine-only supplement versus no intervention or placebo, Outcome 6 Low birthweight.

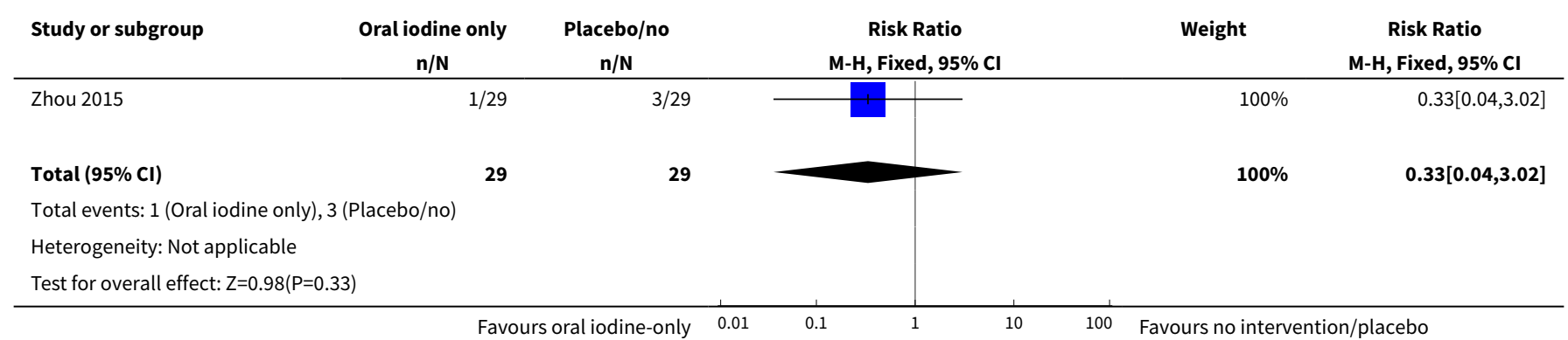

Analysis 3.7. Comparison 3 Oral iodine-only supplement versus no intervention or placebo, Outcome 7 Neonatal hypothyroidism or elevated TSH.

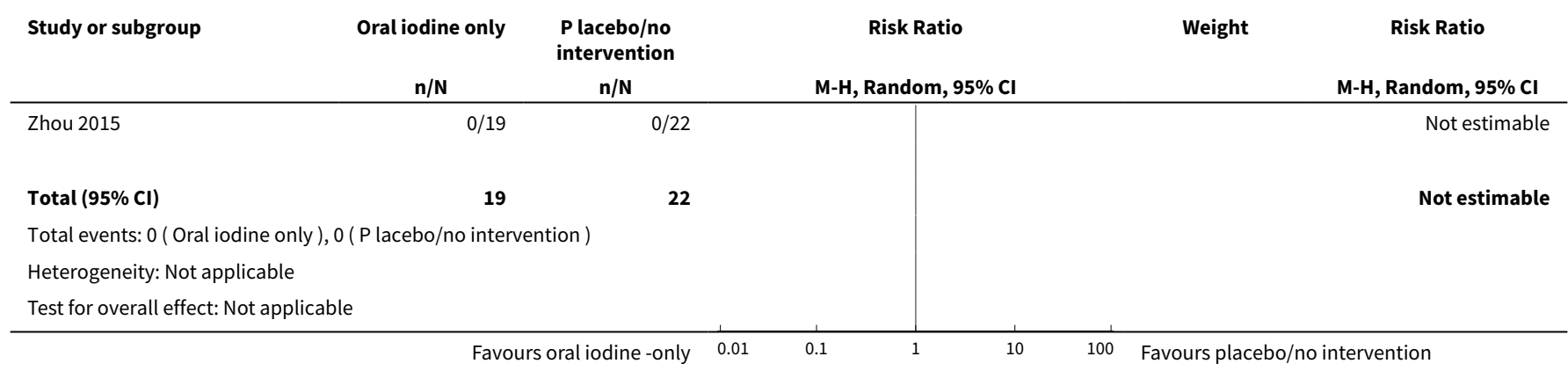

Analysis 3.8. Comparison 3 Oral iodine-only supplement versus no intervention or placebo, Outcome 8 Neonatal adverse effect: elevated thyroid peroxidase antibodies.

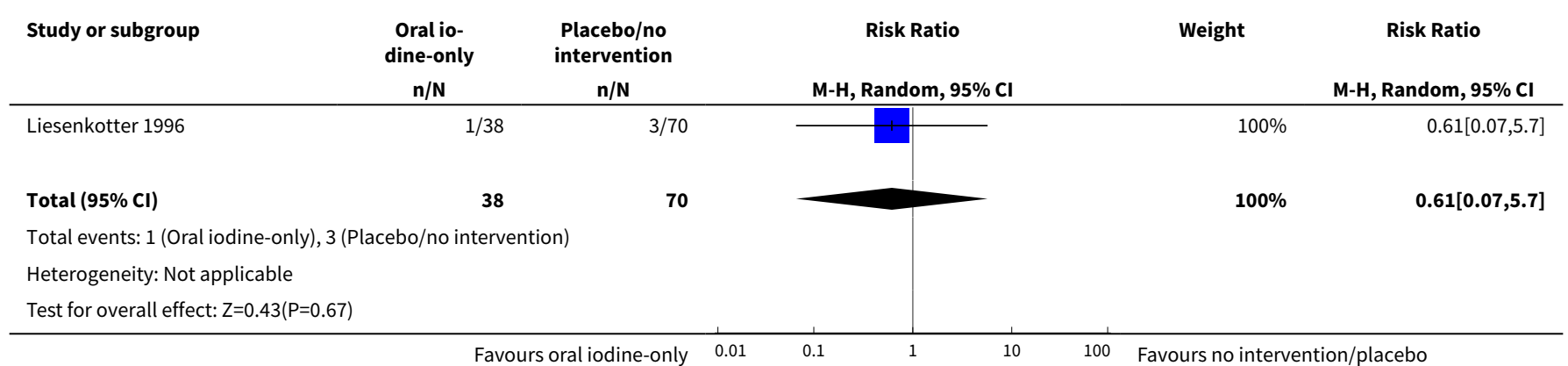


Analysis 3.9. Comparison 3 Oral iodine-only supplement versus no intervention or placebo, Outcome 9 Spontaneous miscarriage.

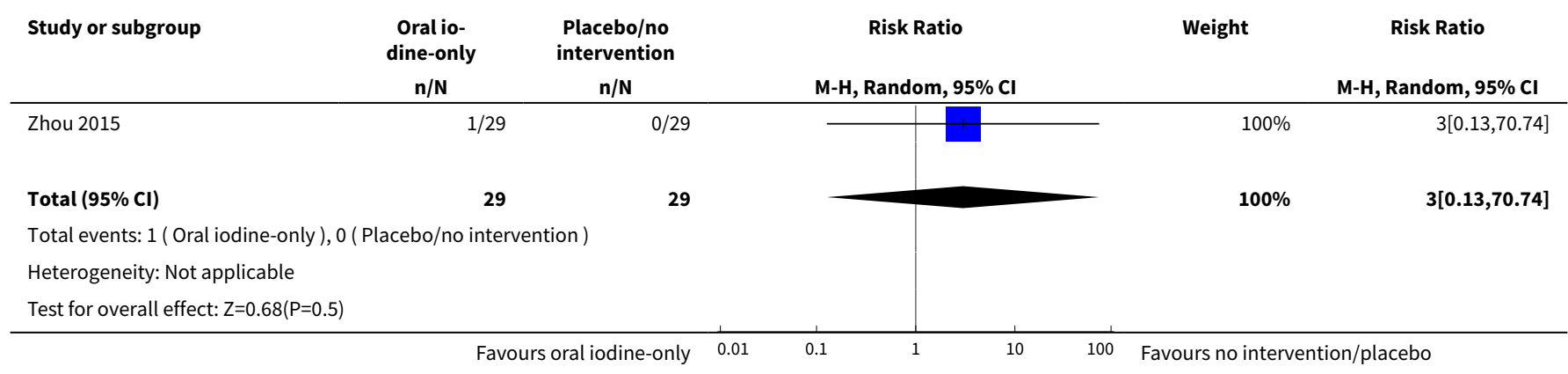

Analysis 3.10. Comparison 3 Oral iodine-only supplement versus no intervention or placebo, Outcome 10 Maternal goitre - pregnancy.

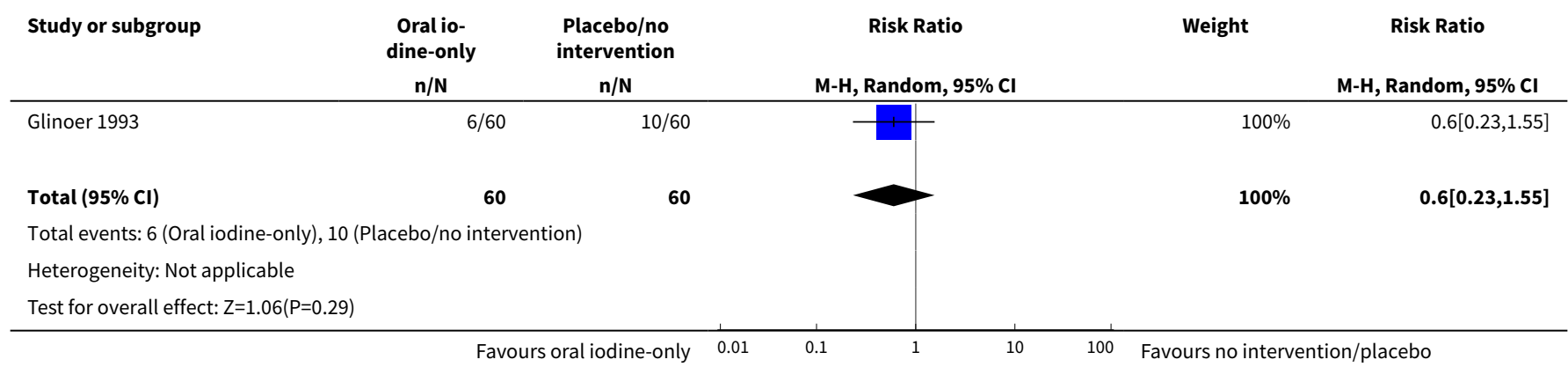

Analysis 3.11. Comparison 3 Oral iodine-only supplement versus no intervention or placebo, Outcome 11 Maternal goitre - postpartum.

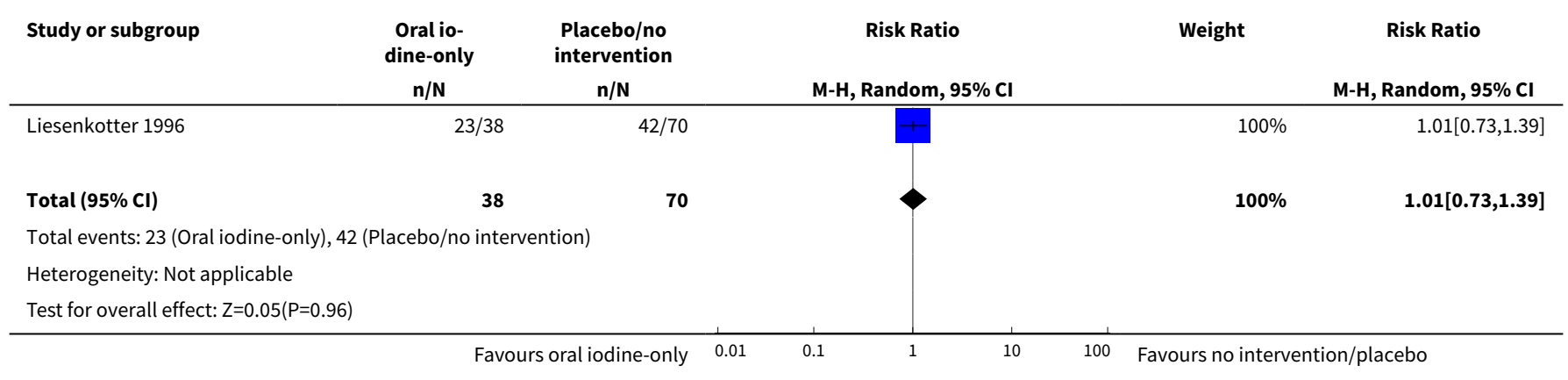


Analysis 3.12. Comparison 3 Oral iodine-only supplement versus no intervention or placebo, Outcome 12 Maternal insufficient iodine intake - postpartum.

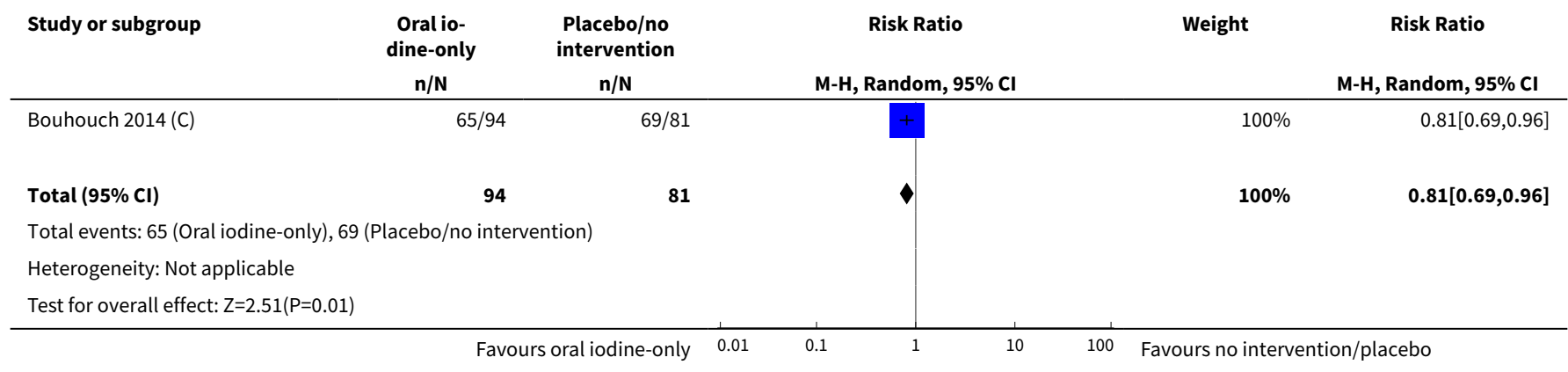

Analysis 3.13. Comparison 3 Oral iodine-only supplement versus no intervention or placebo, Outcome 13 Small-for-gestational age.

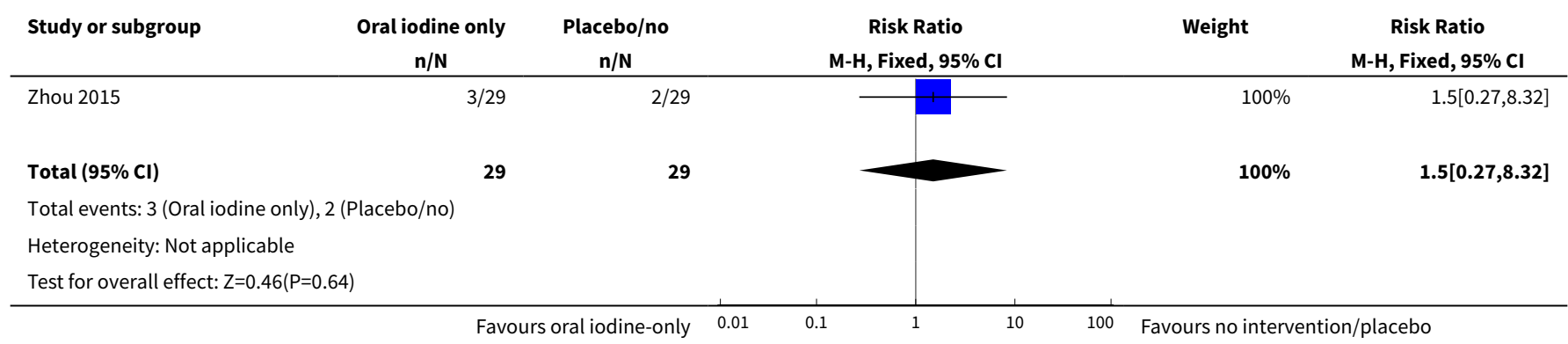

Analysis 3.14. Comparison 3 Oral iodine-only supplement versus no intervention or placebo, Outcome 14 Congenital anomalies.

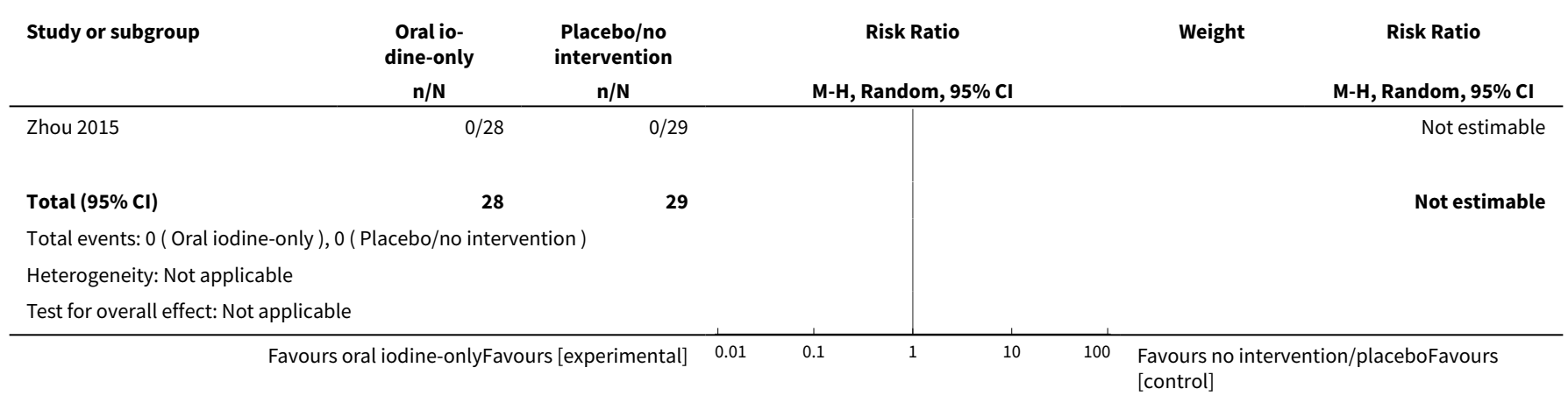


Analysis 3.15. Comparison 3 Oral iodine-only supplement versus no intervention or placebo, Outcome 15 Neonatal goitre.

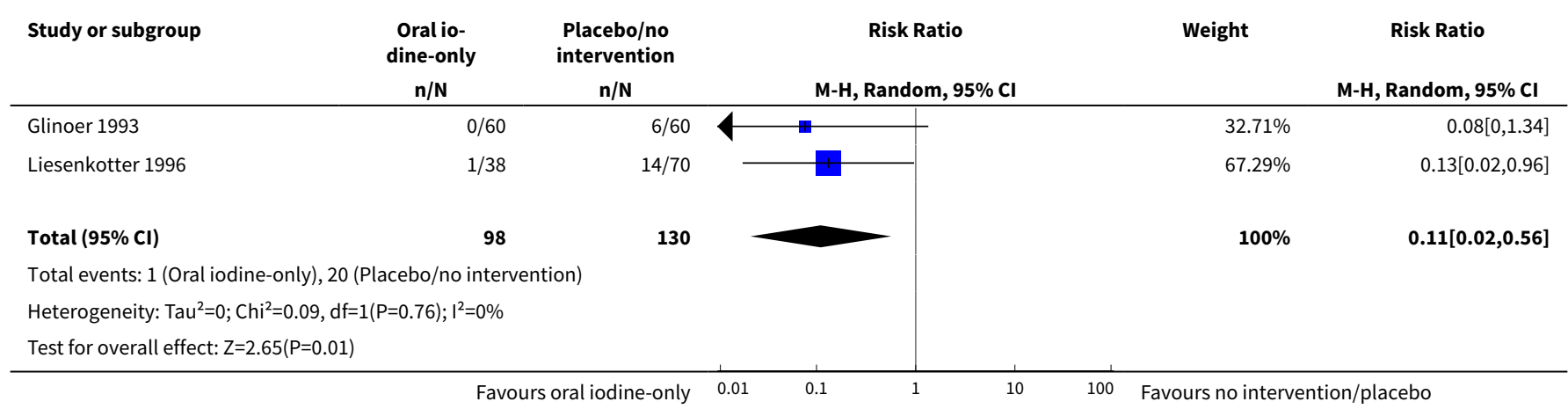

Analysis 3.16. Comparison 3 Oral iodine-only supplement versus no intervention or placebo, Outcome 16 Neonatal thyroid volume (in $\mathrm{mL}$ ).

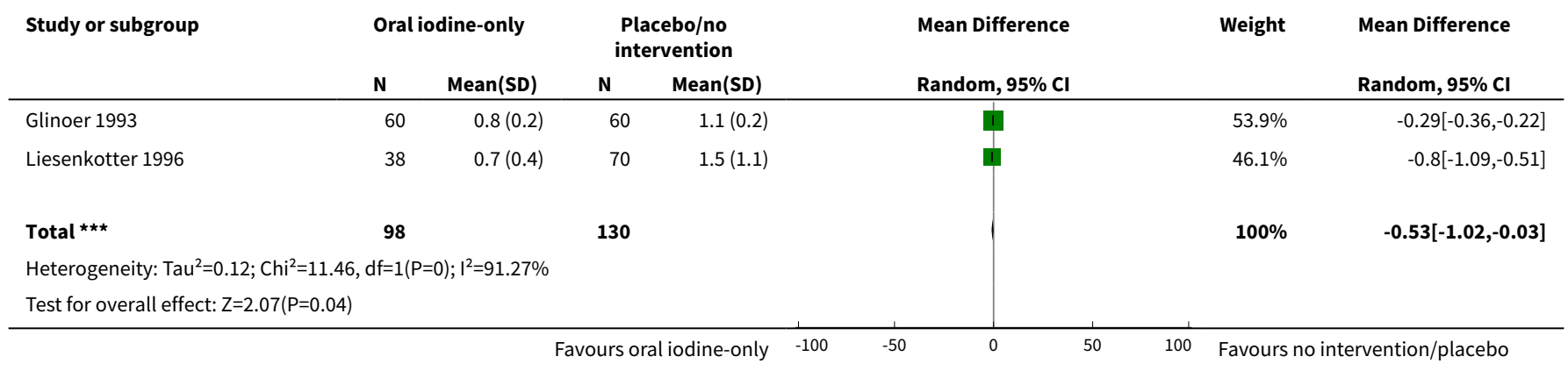

Analysis 3.17. Comparison 3 Oral iodine-only supplement versus no intervention or placebo, Outcome 17 Child mental or motor development (cognitive score).

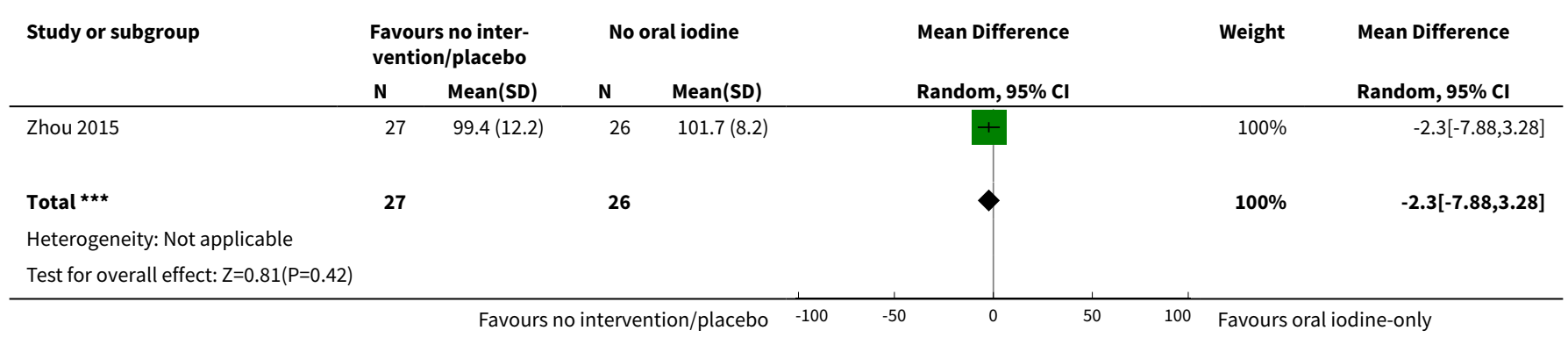


Analysis 3.18. Comparison 3 Oral iodine-only supplement versus no intervention or placebo, Outcome 18 Child mental or motor development (language score).

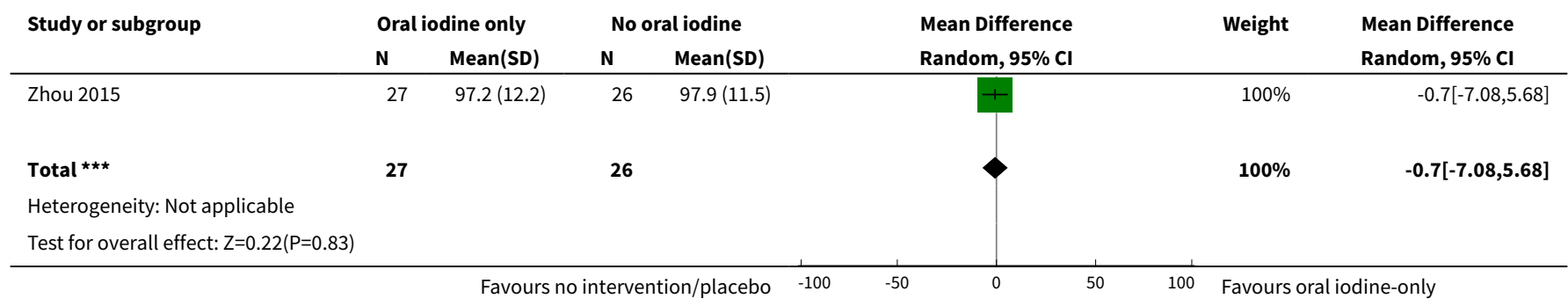

Analysis 3.19. Comparison 3 Oral iodine-only supplement versus no intervention or placebo, Outcome 19 Child mental or motor development (motor score).

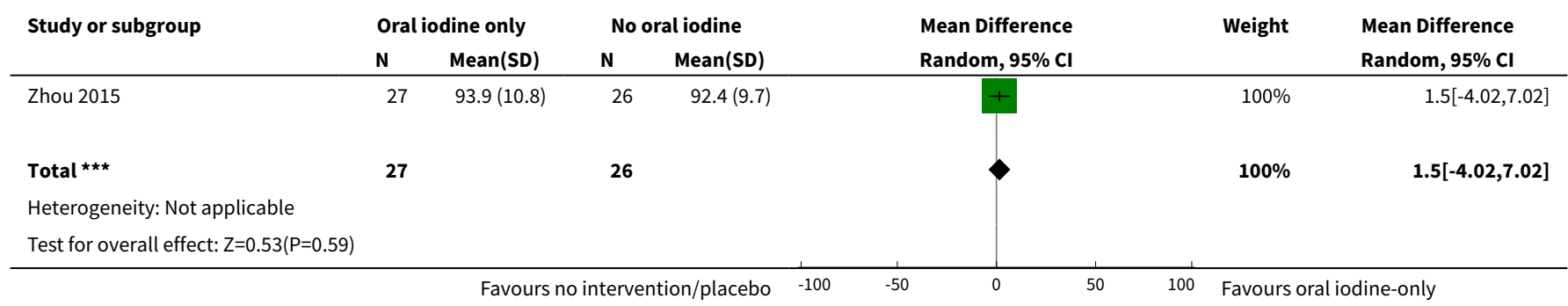

Analysis 3.20. Comparison 3 Oral iodine-only supplement versus no intervention or placebo, Outcome 20 Child mental or motor development (social-emotional score).

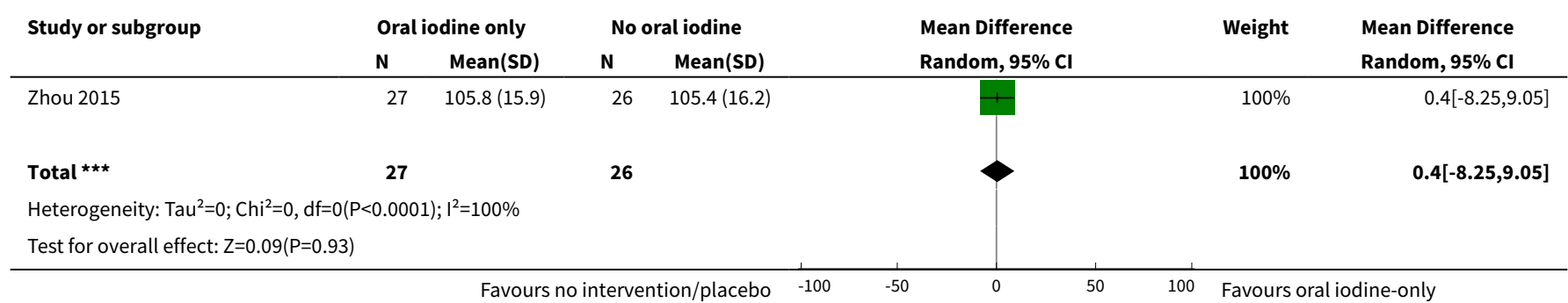

Analysis 3.21. Comparison 3 Oral iodine-only supplement versus no intervention or placebo, Outcome 21 Child mental or motor development (adaptive behaviour score).

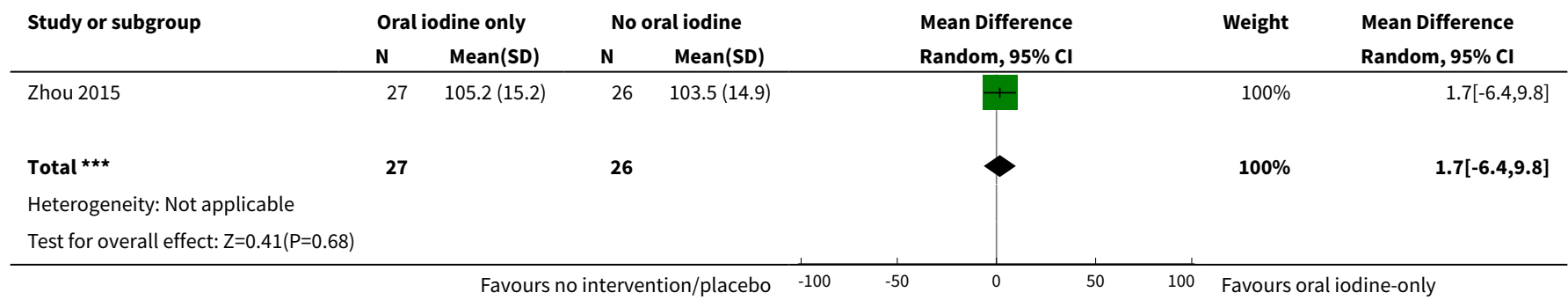


Analysis 3.22. Comparison 3 Oral iodine-only supplement versus no intervention or placebo, Outcome 22 Child mental or motor development (cognitive score < 85).

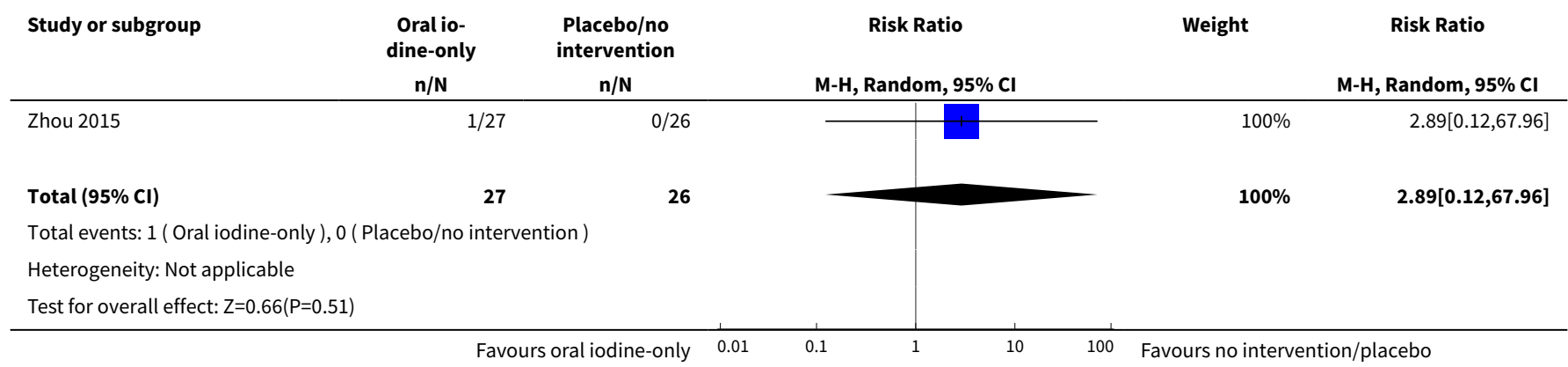

Analysis 3.23. Comparison 3 Oral iodine-only supplement versus no intervention or placebo, Outcome $\mathbf{2 3}$ Child mental or motor development (cognitive score $<70$ ).

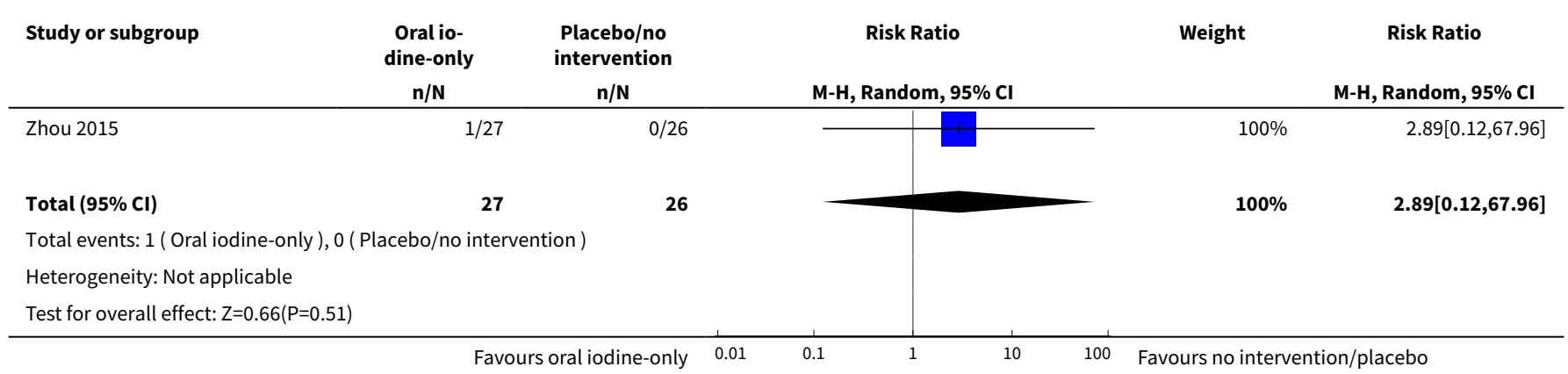

Analysis 3.24. Comparison 3 Oral iodine-only supplement versus no intervention or placebo, Outcome $\mathbf{2 4}$ Child mental or motor development (language score $<85$ ).

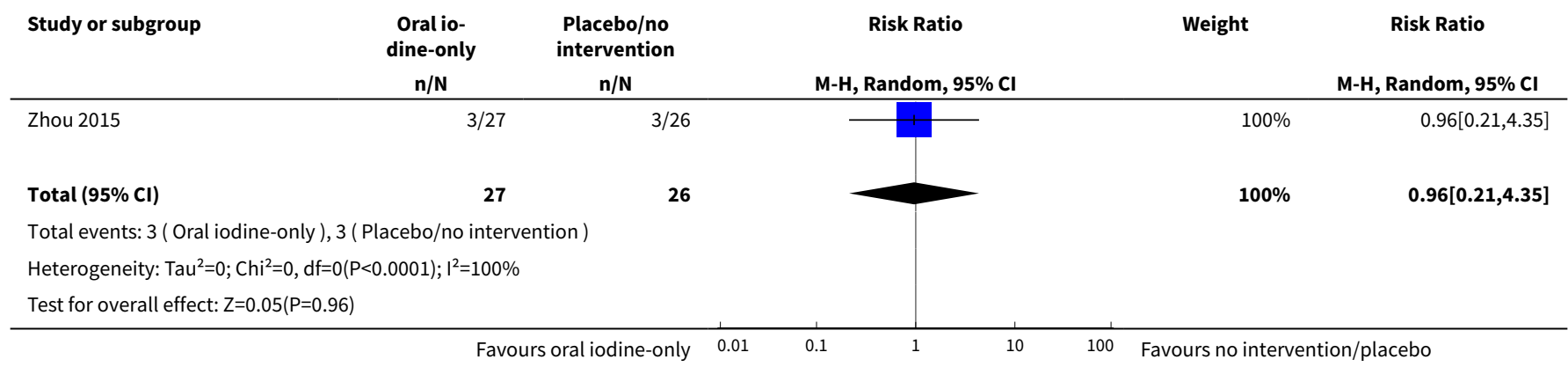


Analysis 3.25. Comparison 3 Oral iodine-only supplement versus no intervention or placebo, Outcome 25 Child mental or motor development (language score $<70$ ).

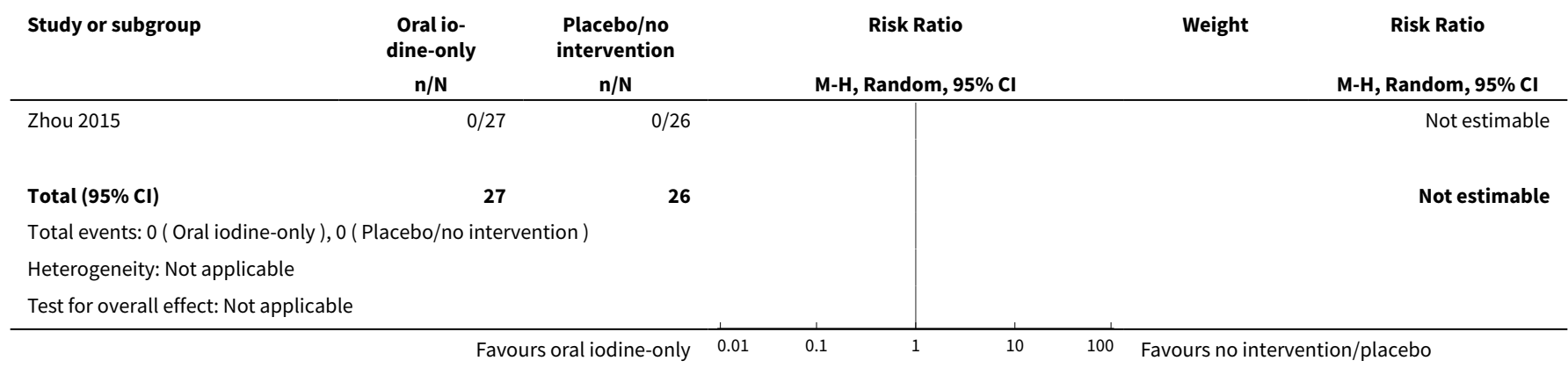

Analysis 3.26. Comparison 3 Oral iodine-only supplement versus no intervention or placebo, Outcome 26 Child mental or motor development (motor score < 85).

\begin{tabular}{|c|c|c|c|c|c|}
\hline Study or subgroup & $\begin{array}{c}\text { Oral io- } \\
\text { dine-only } \\
n / N\end{array}$ & $\begin{array}{c}\text { Placebo/no } \\
\text { intervention } \\
n / N\end{array}$ & $\begin{array}{c}\text { Risk Ratio } \\
\text { M-H, Random, } 95 \% \mathrm{Cl}\end{array}$ & Weight & $\begin{array}{c}\text { Risk Ratio } \\
\text { M-H, Random, } 95 \% \mathrm{Cl}\end{array}$ \\
\hline Zhou 2015 & $2 / 27$ & $5 / 26$ & 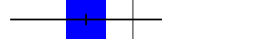 & $100 \%$ & $0.39[0.08,1.81]$ \\
\hline Total $(95 \% \mathrm{Cl})$ & 27 & 26 & & $100 \%$ & $0.39[0.08,1.81]$ \\
\hline \multicolumn{6}{|c|}{ Total events: 2 ( Oral iodine-only), 5 ( Placebo/no intervention ) } \\
\hline Test for overall effect & & & & & \\
\hline
\end{tabular}

Analysis 3.27. Comparison 3 Oral iodine-only supplement versus no intervention

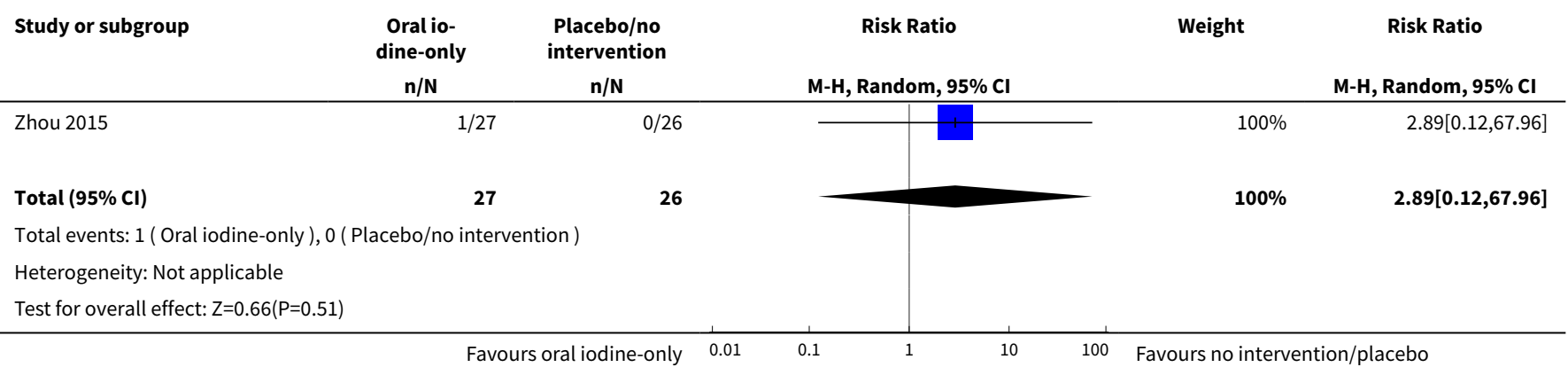


Comparison 4. Oral iodine supplement with other vitamins and/or minerals versus only other vitamins and/or minerals but no iodine

\begin{tabular}{|c|c|c|c|c|}
\hline Outcome or subgroup title & No. of studies & $\begin{array}{l}\text { No. of partici- } \\
\text { pants }\end{array}$ & Statistical method & Effect size \\
\hline $\begin{array}{l}1 \text { Maternal hypothyroidism - preg- } \\
\text { nancy }\end{array}$ & 1 & 365 & $\begin{array}{l}\text { Risk Ratio (M-H, Random, } \\
95 \% \mathrm{Cl})\end{array}$ & $1.9[0.57,6.38]$ \\
\hline $\begin{array}{l}2 \text { Maternal hypothyroidism - postpar- } \\
\text { tum }\end{array}$ & 1 & 254 & $\begin{array}{l}\text { Risk Ratio (M-H, Random, } \\
95 \% \mathrm{Cl} \text { ) }\end{array}$ & $0.97[0.06,15.32]$ \\
\hline 3 Preterm birth & 1 & 318 & $\begin{array}{l}\text { Risk Ratio (M-H, Random, } \\
95 \% \mathrm{Cl})\end{array}$ & $0.51[0.23,1.14]$ \\
\hline $\begin{array}{l}4 \text { Maternal adverse effect: elevated } \\
\text { thyroid peroxidase antibodies - preg- } \\
\text { nancy }\end{array}$ & 1 & 359 & $\begin{array}{l}\text { Risk Ratio (M-H, Random, } \\
95 \% \mathrm{Cl})\end{array}$ & $0.95[0.44,2.07]$ \\
\hline $\begin{array}{l}5 \text { Maternal adverse effect: elevated } \\
\text { thyroid peroxidase antibodies - post- } \\
\text { partum }\end{array}$ & 1 & 235 & $\begin{array}{l}\text { Risk Ratio (M-H, Random, } \\
95 \% \mathrm{Cl})\end{array}$ & $1.03[0.79,1.33]$ \\
\hline $\begin{array}{l}6 \text { Maternal adverse effect: hyperthy- } \\
\text { roidism - pregnancy }\end{array}$ & 1 & 365 & $\begin{array}{l}\text { Risk Ratio (M-H, Random, } \\
95 \% \mathrm{Cl})\end{array}$ & $1.9[0.57,6.38]$ \\
\hline $\begin{array}{l}7 \text { Maternal adverse effect: hyperthy- } \\
\text { roidism - postpartum }\end{array}$ & 1 & 257 & $\begin{array}{l}\text { Risk Ratio (M-H, Random, } \\
95 \% \mathrm{Cl})\end{array}$ & $0.35[0.12,1.06]$ \\
\hline $\begin{array}{l}8 \text { Maternal adverse effect: digestive } \\
\text { intolerance - pregnancy }\end{array}$ & 1 & 76 & $\begin{array}{l}\text { Risk Ratio (M-H, Random, } \\
95 \% \mathrm{Cl})\end{array}$ & $\begin{array}{l}15.33[2.07 \\
113.70]\end{array}$ \\
\hline 9 Low birthweight & 1 & 319 & $\begin{array}{l}\text { Risk Ratio (M-H, Random, } \\
95 \% \mathrm{Cl})\end{array}$ & $0.61[0.27,1.39]$ \\
\hline $\begin{array}{l}10 \text { Neonatal hypothyroidism or ele- } \\
\text { vated TSH }\end{array}$ & 1 & 219 & $\begin{array}{l}\text { Risk Ratio (M-H, Random, } \\
95 \% \mathrm{Cl})\end{array}$ & $0.58[0.11,3.12]$ \\
\hline 11 Spontaneous miscarriage & 2 & 587 & $\begin{array}{l}\text { Risk Ratio (M-H, Random, } \\
95 \% \mathrm{Cl})\end{array}$ & $1.26[0.60,2.62]$ \\
\hline 12 Maternal goitre - pregnancy & 1 & 366 & $\begin{array}{l}\text { Risk Ratio (M-H, Random, } \\
95 \% \mathrm{Cl})\end{array}$ & $1.89[0.56,6.34]$ \\
\hline 13 Maternal goitre - postpartum & 1 & 262 & $\begin{array}{l}\text { Risk Ratio (M-H, Random, } \\
95 \% \mathrm{Cl})\end{array}$ & $2.06[0.64,6.68]$ \\
\hline $\begin{array}{l}14 \text { Maternal insufficient iodine intake } \\
\text { - pregnancy }\end{array}$ & 2 & 432 & $\begin{array}{l}\text { Risk Ratio (M-H, Random, } \\
95 \% \mathrm{Cl})\end{array}$ & $0.64[0.51,0.80]$ \\
\hline $\begin{array}{l}15 \text { Maternal insufficient iodine intake } \\
\text { - postpartum }\end{array}$ & 1 & 250 & $\begin{array}{l}\text { Risk Ratio (M-H, Random, } \\
95 \% \mathrm{Cl})\end{array}$ & $0.80[0.61,1.04]$ \\
\hline $\begin{array}{l}16 \text { Maternal excessive iodine intake - } \\
\text { pregnancy }\end{array}$ & 1 & 356 & $\begin{array}{l}\text { Risk Ratio (M-H, Random, } \\
95 \% \mathrm{Cl})\end{array}$ & $4.33[1.24,15.07]$ \\
\hline 17 Small-for-gestational age & 1 & 319 & $\begin{array}{l}\text { Risk Ratio (M-H, Random, } \\
95 \% \mathrm{Cl})\end{array}$ & $1.24[0.74,2.06]$ \\
\hline
\end{tabular}




\begin{tabular}{lllll}
\hline Outcome or subgroup title & No. of studies & $\begin{array}{l}\text { No. of partici- } \\
\text { pants }\end{array}$ & Statistical method & Effect size \\
\hline 18 Neonatal thyroid volume (in $\mathrm{mL})$ & 1 & 131 & $\begin{array}{l}\text { Mean Difference (IV, Random, } \\
95 \% \mathrm{Cl})\end{array}$ & $-0.09[-0.18,-0.00]$ \\
\hline 19 Neonatal insufficient iodine intake & 1 & 159 & $\begin{array}{l}\text { Risk Ratio (M-H, Random, } \\
95 \% \mathrm{Cl})\end{array}$ & $2.14[1.04,4.37]$ \\
\hline
\end{tabular}

Analysis 4.1. Comparison 4 Oral iodine supplement with other vitamins and/or minerals versus only other vitamins and/or minerals but no iodine, Outcome 1 Maternal hypothyroidism - pregnancy.

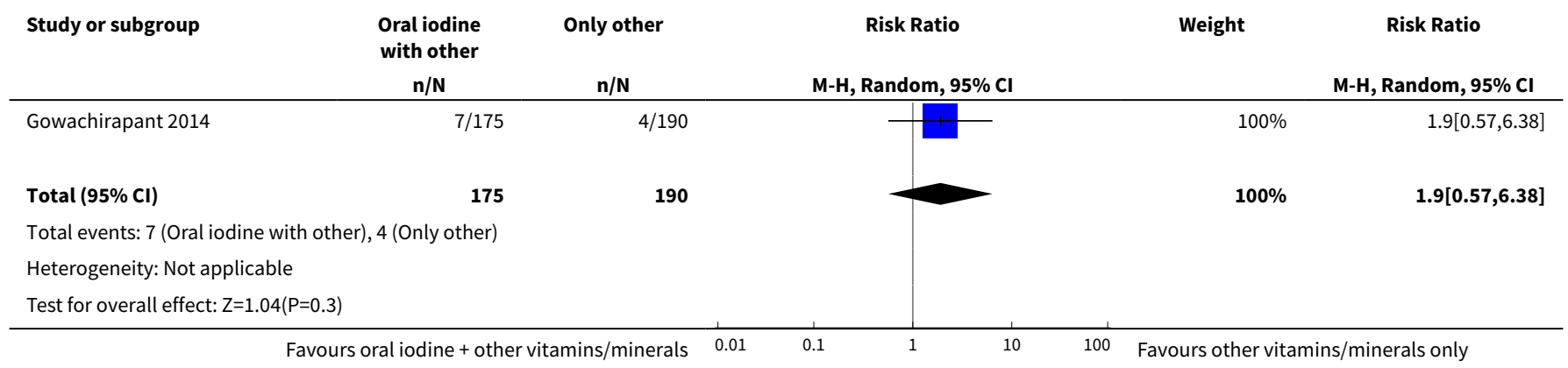

Analysis 4.2. Comparison 4 Oral iodine supplement with other vitamins and/or minerals versus only other vitamins and/or minerals but no iodine, Outcome 2 Maternal hypothyroidism - postpartum.

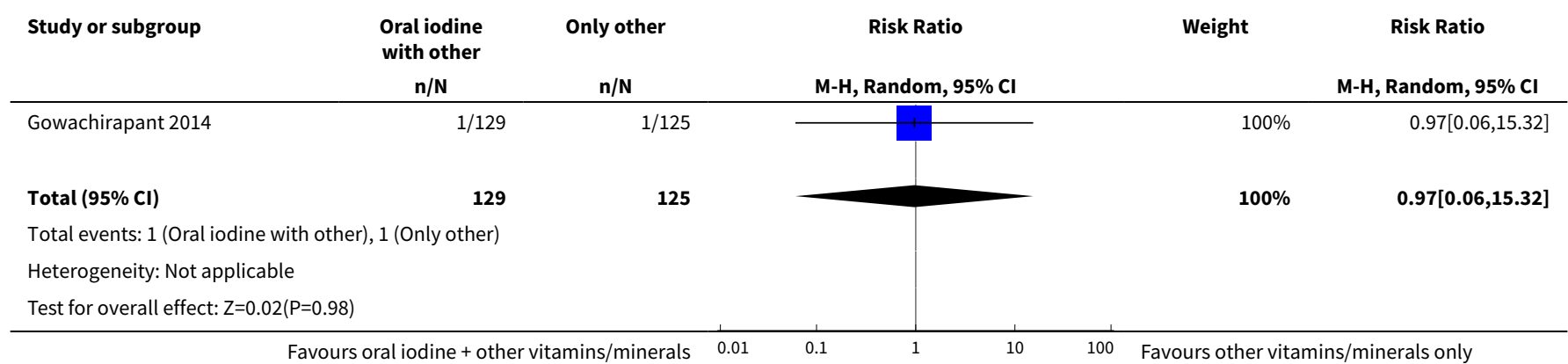

Analysis 4.3. Comparison 4 Oral iodine supplement with other vitamins and/or minerals versus only other vitamins and/or minerals but no iodine, Outcome 3 Preterm birth.

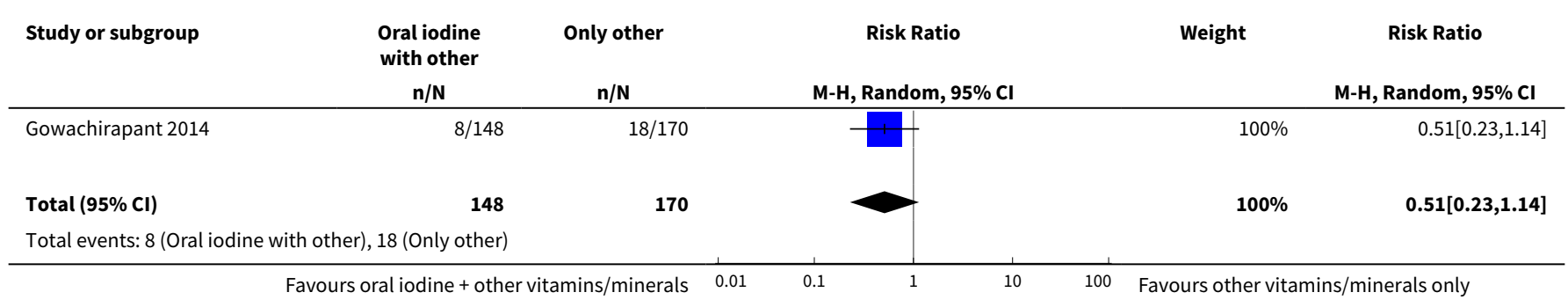




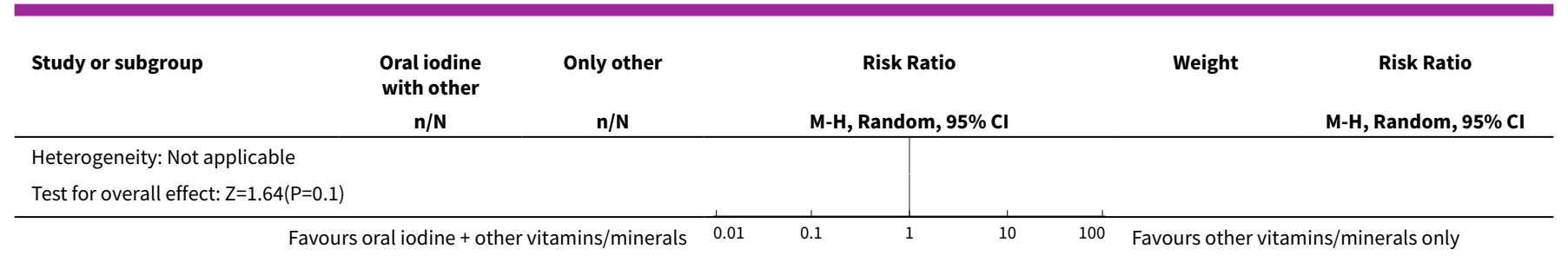

Analysis 4.4. Comparison 4 Oral iodine supplement with other vitamins and/ or minerals versus only other vitamins and/or minerals but no iodine, Outcome 4 Maternal adverse effect: elevated thyroid peroxidase antibodies - pregnancy.

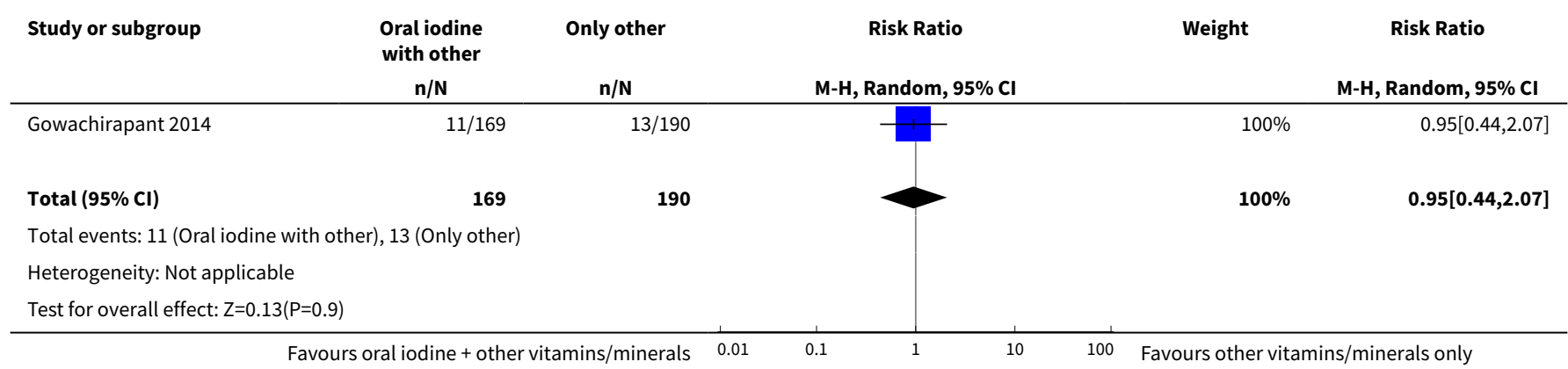

Analysis 4.5. Comparison 4 Oral iodine supplement with other vitamins and/ or minerals versus only other vitamins and/or minerals but no iodine, Outcome 5 Maternal adverse effect: elevated thyroid peroxidase antibodies - postpartum.

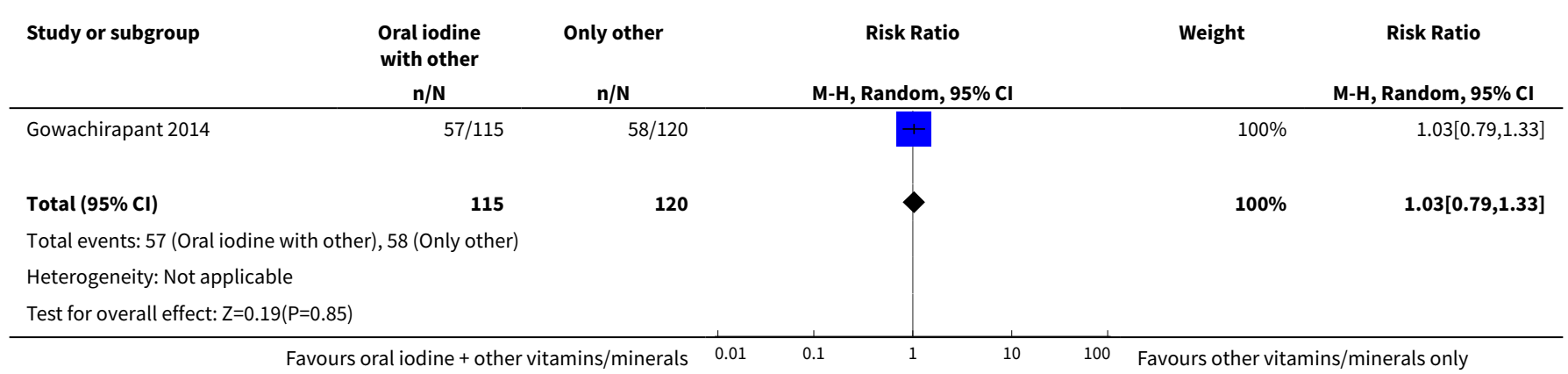

Analysis 4.6. Comparison 4 Oral iodine supplement with other vitamins and/or minerals versus only other vitamins and/or minerals but no iodine, Outcome 6 Maternal adverse effect: hyperthyroidism - pregnancy.

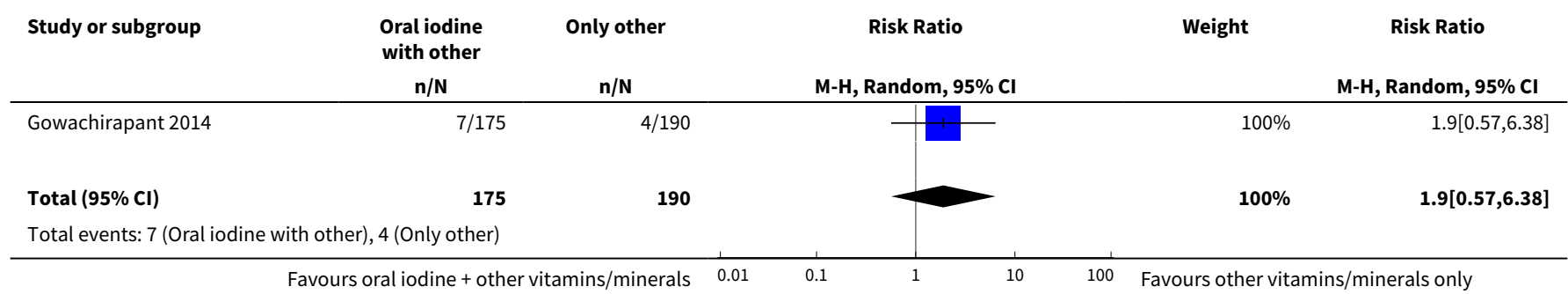




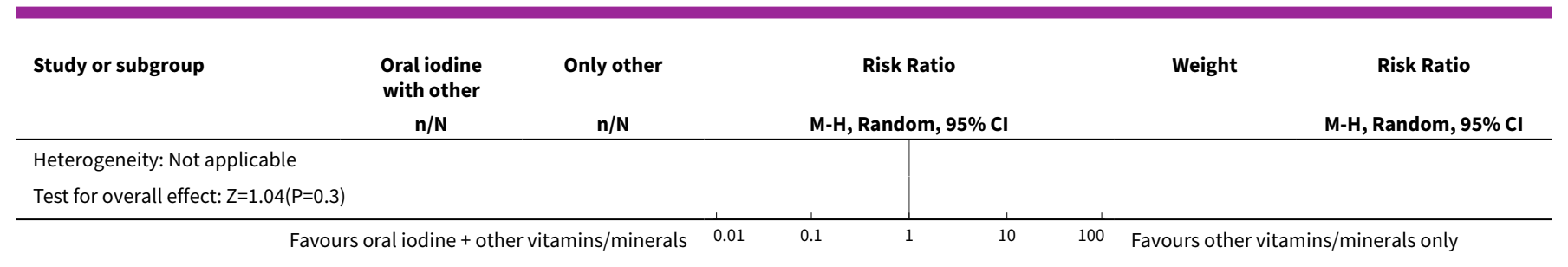

Analysis 4.7. Comparison 4 Oral iodine supplement with other vitamins and/or minerals versus only other vitamins and/or minerals but no iodine, Outcome 7 Maternal adverse effect: hyperthyroidism - postpartum.

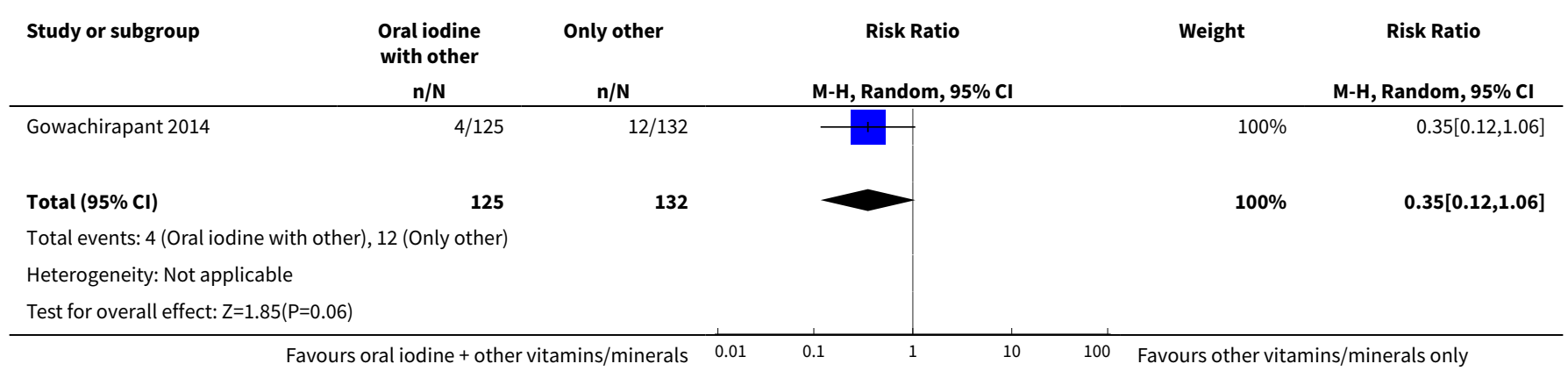

Analysis 4.8. Comparison 4 Oral iodine supplement with other vitamins and/or minerals versus only other vitamins and/or minerals but no iodine, Outcome 8 Maternal adverse effect: digestive intolerance - pregnancy.

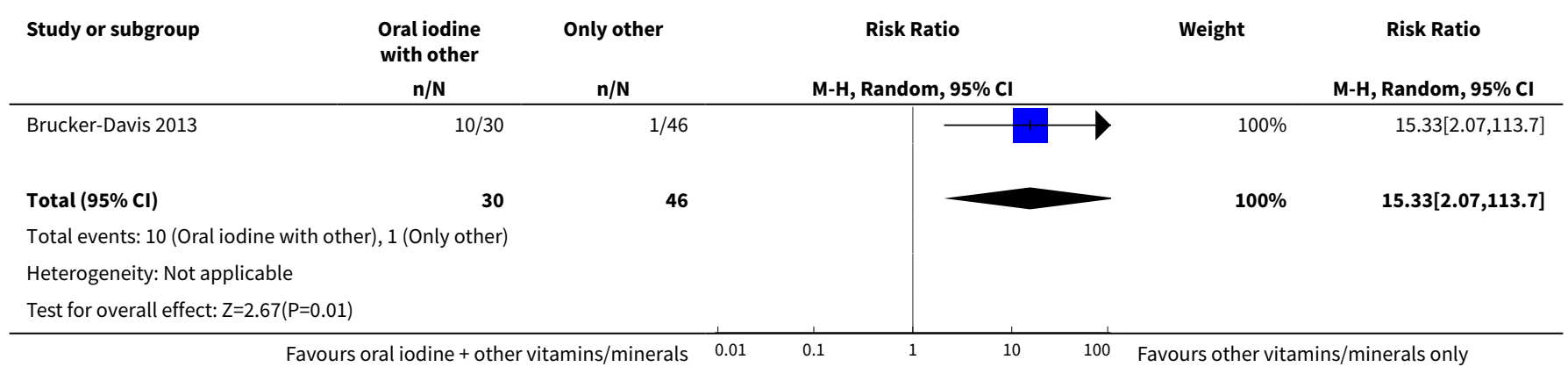

Analysis 4.9. Comparison 4 Oral iodine supplement with other vitamins and/or minerals versus only other vitamins and/or minerals but no iodine, Outcome 9 Low birthweight.

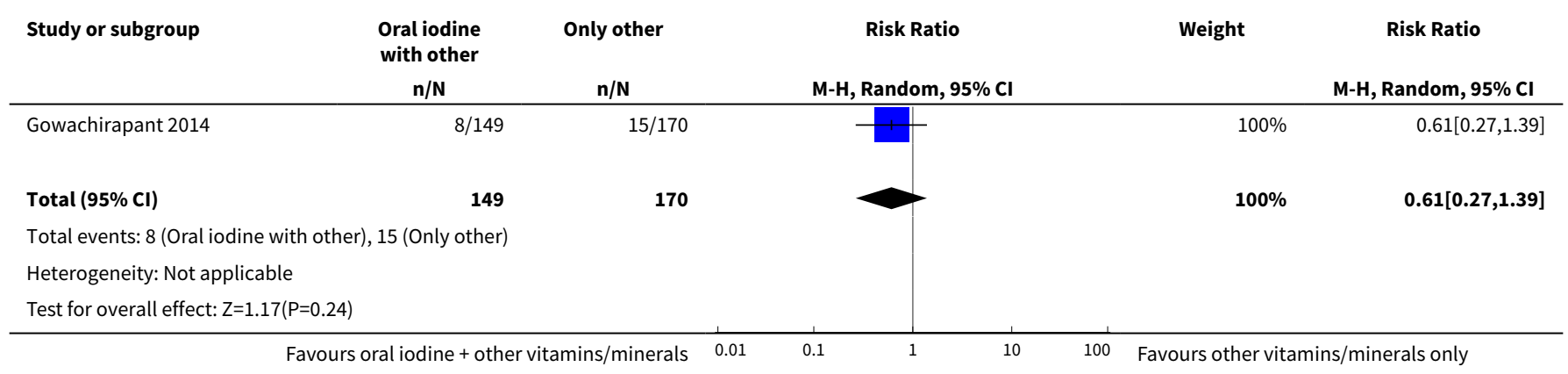


Analysis 4.10. Comparison 4 Oral iodine supplement with other vitamins and/or minerals versus only other vitamins and/or minerals but no iodine, Outcome 10 Neonatal hypothyroidism or elevated TSH.

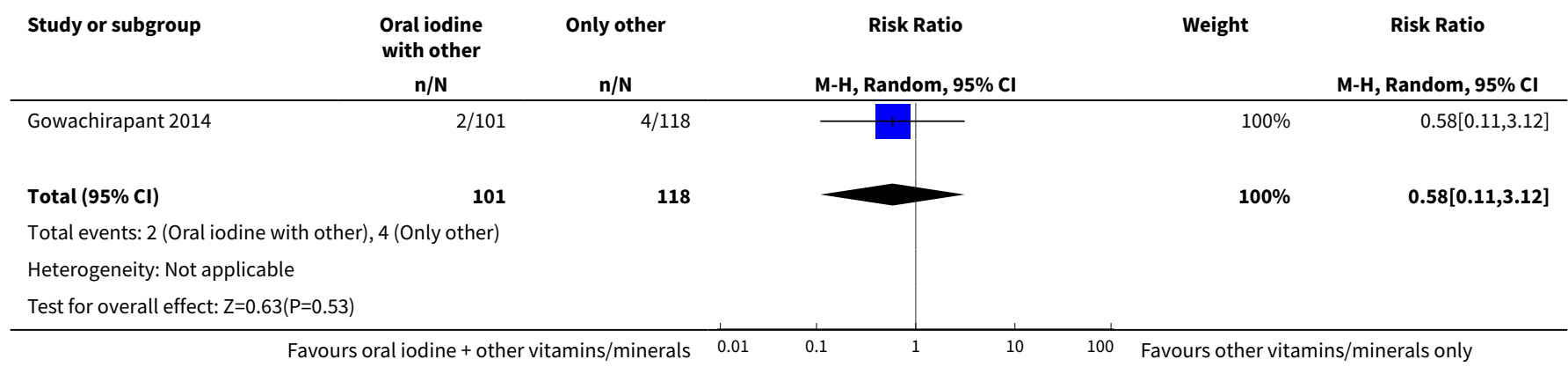

Analysis 4.11. Comparison 4 Oral iodine supplement with other vitamins and/or minerals versus only other vitamins and/or minerals but no iodine, Outcome 11 Spontaneous miscarriage.

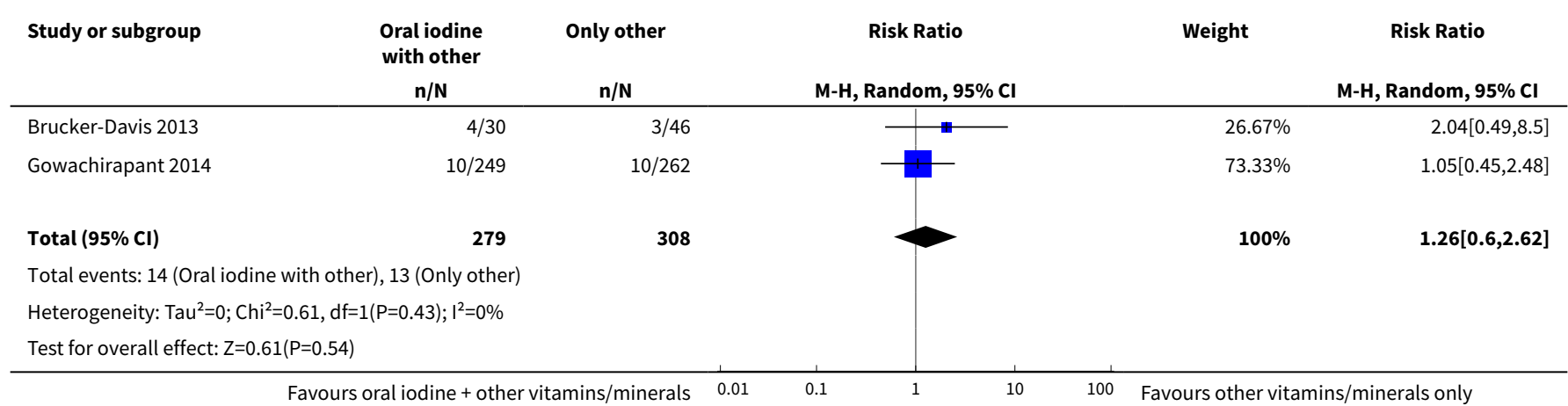

Analysis 4.12. Comparison 4 Oral iodine supplement with other vitamins and/or minerals versus only other vitamins and/or minerals but no iodine, Outcome 12 Maternal goitre - pregnancy.

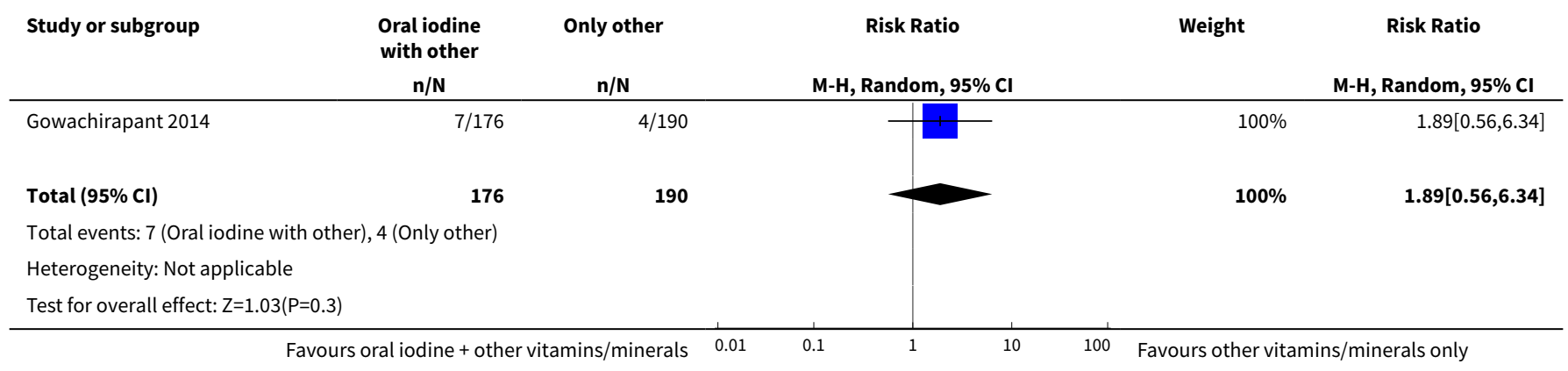


Analysis 4.13. Comparison 4 Oral iodine supplement with other vitamins and/or minerals versus only other vitamins and/or minerals but no iodine, Outcome 13 Maternal goitre - postpartum.

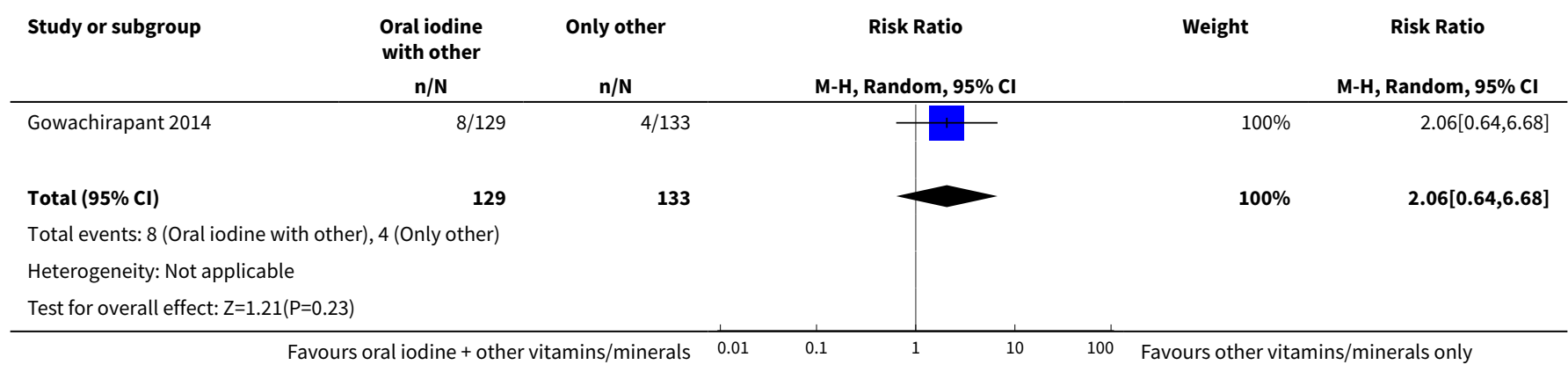

Analysis 4.14. Comparison 4 Oral iodine supplement with other vitamins and/or minerals versus only other vitamins and/or minerals but no iodine, Outcome 14 Maternal insufficient iodine intake - pregnancy.

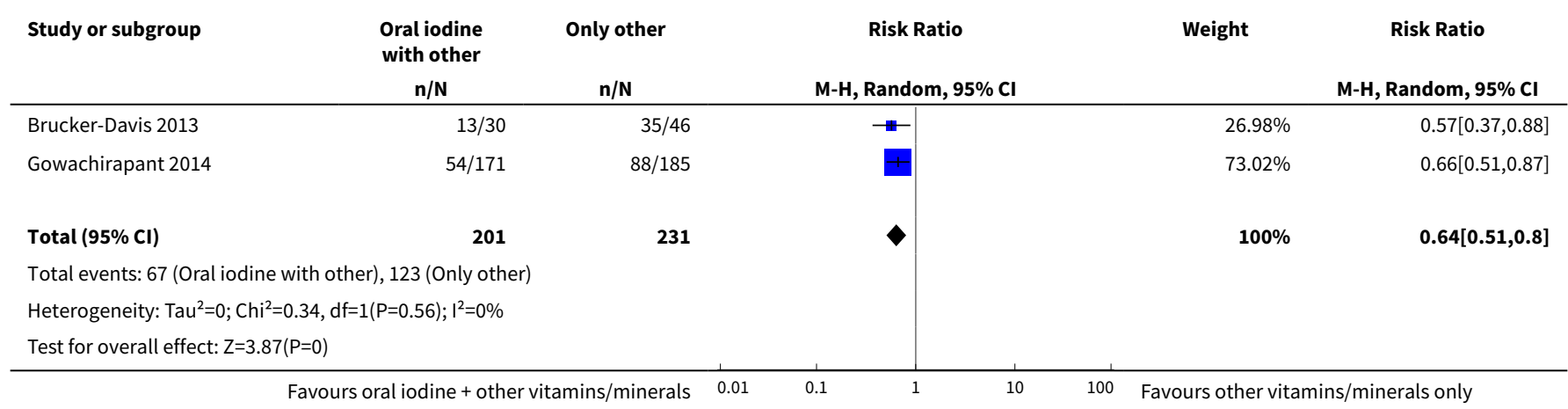

Analysis 4.15. Comparison 4 Oral iodine supplement with other vitamins and/or minerals versus only other vitamins and/or minerals but no iodine, Outcome 15 Maternal insufficient iodine intake - postpartum.

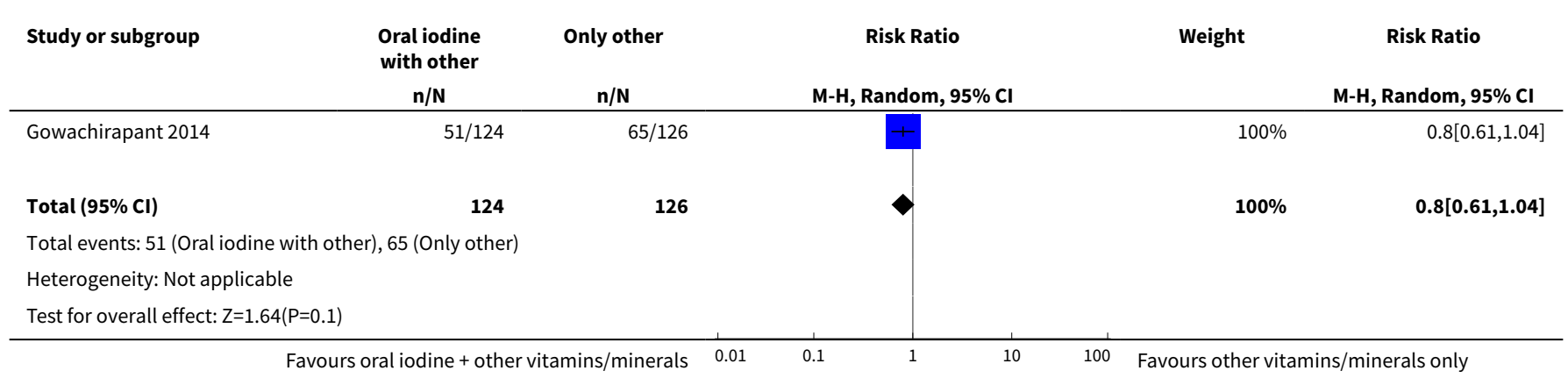


Analysis 4.16. Comparison 4 Oral iodine supplement with other vitamins and/or minerals versus only other vitamins and/or minerals but no iodine, Outcome 16 Maternal excessive iodine intake - pregnancy.

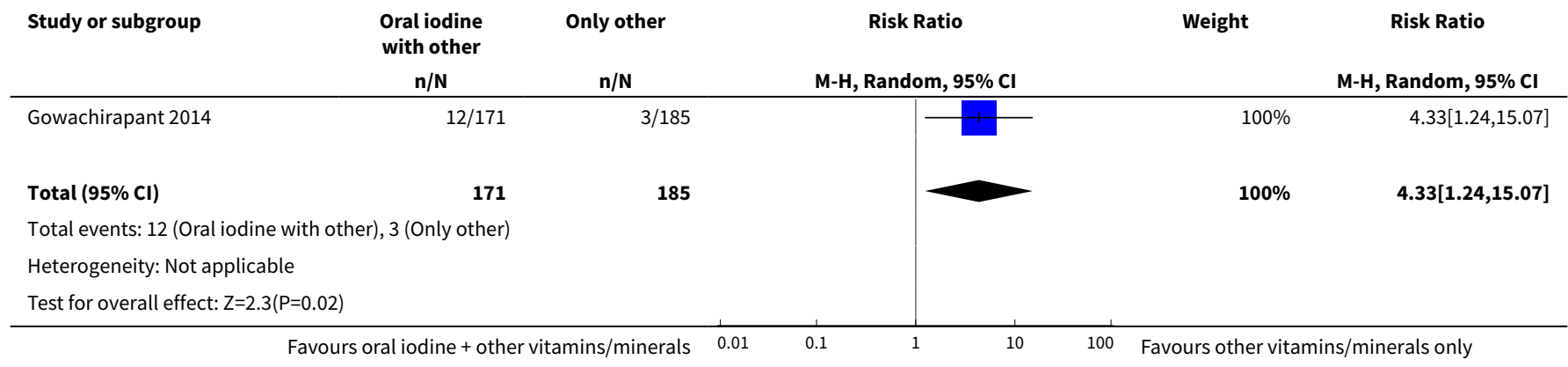

Analysis 4.17. Comparison 4 Oral iodine supplement with other vitamins and/or minerals versus only other vitamins and/or minerals but no iodine, Outcome 17 Small-for-gestational age.

\begin{tabular}{|c|c|c|c|c|c|}
\hline Study or subgroup & $\begin{array}{c}\text { Oral iodine } \\
\text { with other } \\
\text { n/N }\end{array}$ & $\begin{array}{l}\text { Only other } \\
n / N \\
\end{array}$ & $\begin{array}{c}\text { Risk Ratio } \\
\text { M-H, Random, 95\% CI }\end{array}$ & Weight & $\begin{array}{c}\text { Risk Ratio } \\
\text { M-H, Random, } 95 \% \mathrm{CI}\end{array}$ \\
\hline Gowachirapant 2014 & $26 / 149$ & $24 / 170$ & & $100 \%$ & $1.24[0.74,2.06]$ \\
\hline Total $(95 \% \mathrm{Cl})$ & 149 & 170 & & $100 \%$ & $1.24[0.74,2.06]$ \\
\hline \multicolumn{6}{|c|}{ Total events: 26 (Oral iodine with other), 24 (Only other) } \\
\hline Test for overall effect: & & & & & \\
\hline
\end{tabular}

Analysis 4.18. Comparison 4 Oral iodine supplement with other vitamins and/or minerals versus only other vitamins and/or minerals but no iodine, Outcome 18 Neonatal thyroid volume (in $\mathrm{mL}$ ).

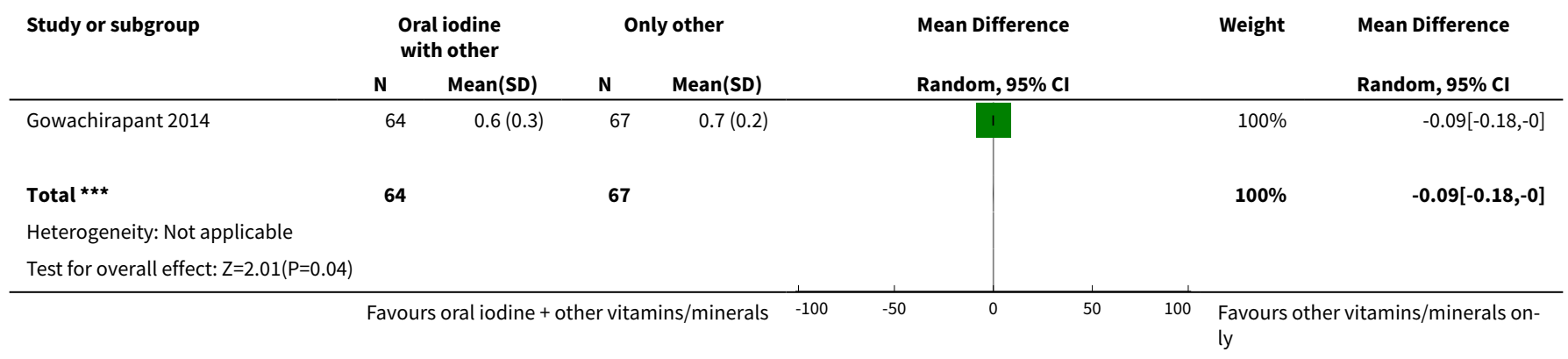

Analysis 4.19. Comparison 4 Oral iodine supplement with other vitamins and/or minerals versus only other vitamins and/or minerals but no iodine, Outcome 19 Neonatal insufficient iodine intake.

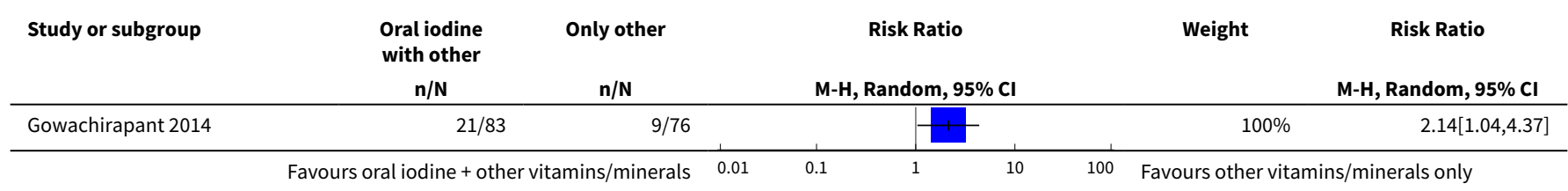




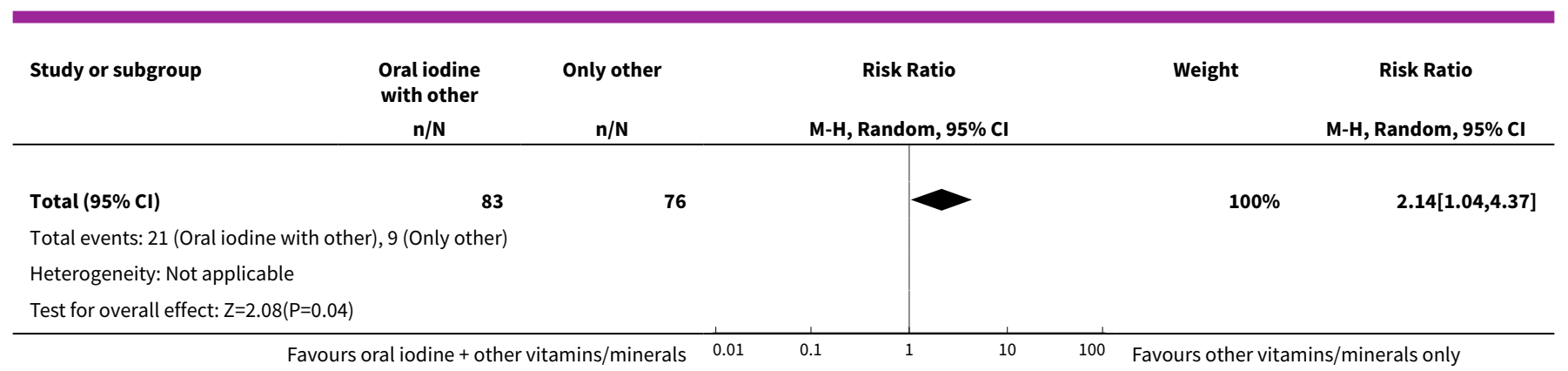

Comparison 5. Any injected iodine supplement versus same supplement without iodine or no treatment/placebo

\begin{tabular}{lllll}
\hline Outcome or subgroup title & No. of studies & $\begin{array}{l}\text { No. of partici- } \\
\text { pants }\end{array}$ & Statistical method & Effect size \\
\hline 1 Perinatal mortality & 1 & 399 & Risk Ratio (M-H, Random, 95\% Cl) & $0.66[0.42,1.03]$ \\
\hline 2 Congenital anomalies & 1 & 818 & Risk Ratio (M-H, Random, 95\% Cl) & $0.27[0.12,0.60]$ \\
\hline 3 Neonatal goitre & 1 & 456 & Risk Ratio (M-H, Random, 95\% Cl) & $0.0[0.0,0.0]$ \\
\hline $\begin{array}{l}4 \text { Child mental or motor de- } \\
\text { velopment (IQ points) }\end{array}$ & 2 & 174 & $\begin{array}{l}\text { Mean Difference (IV, Random, 95\% } \\
\text { Cl) }\end{array}$ & $11.21[7.96,14.46]$ \\
\hline
\end{tabular}

Analysis 5.1. Comparison 5 Any injected iodine supplement versus same supplement without iodine or no treatment/placebo, Outcome 1 Perinatal mortality.

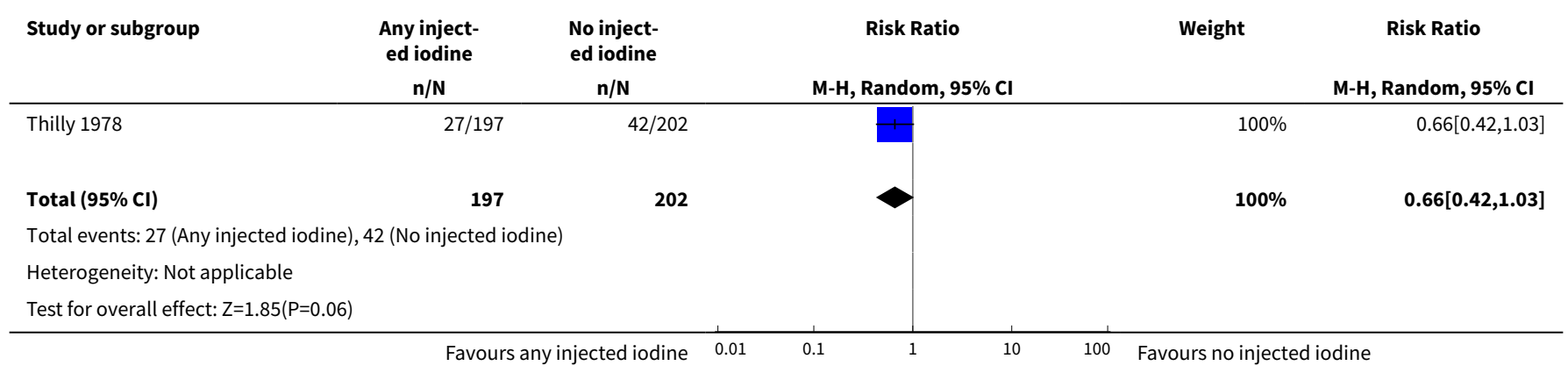

Analysis 5.2. Comparison 5 Any injected iodine supplement versus same supplement without iodine or no treatment/placebo, Outcome 2 Congenital anomalies.

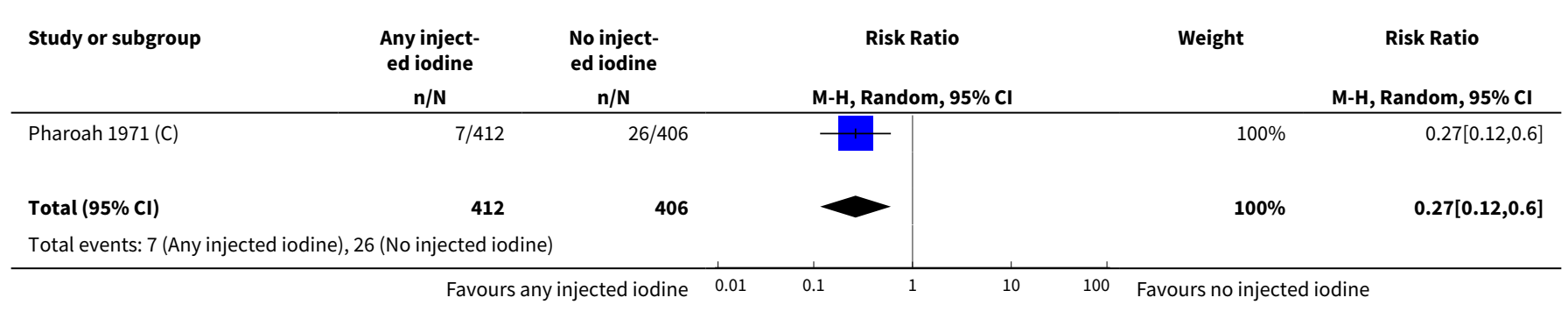




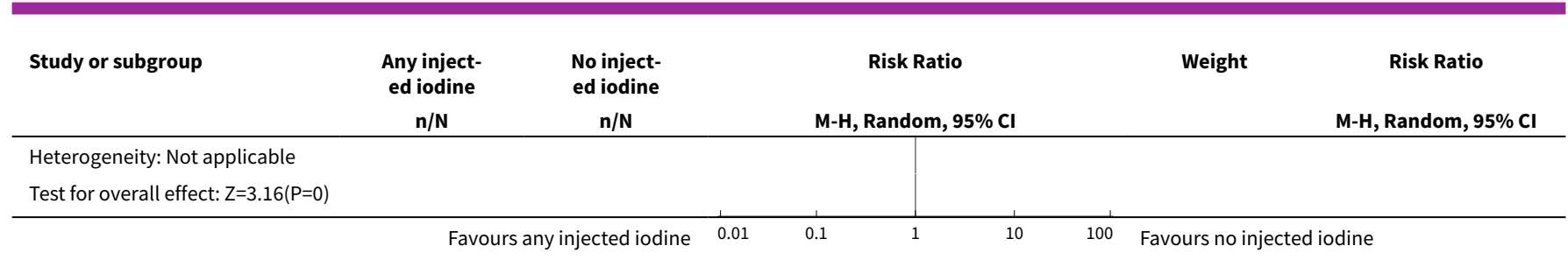

Analysis 5.3. Comparison 5 Any injected iodine supplement versus same supplement without iodine or no treatment/placebo, Outcome 3 Neonatal goitre.

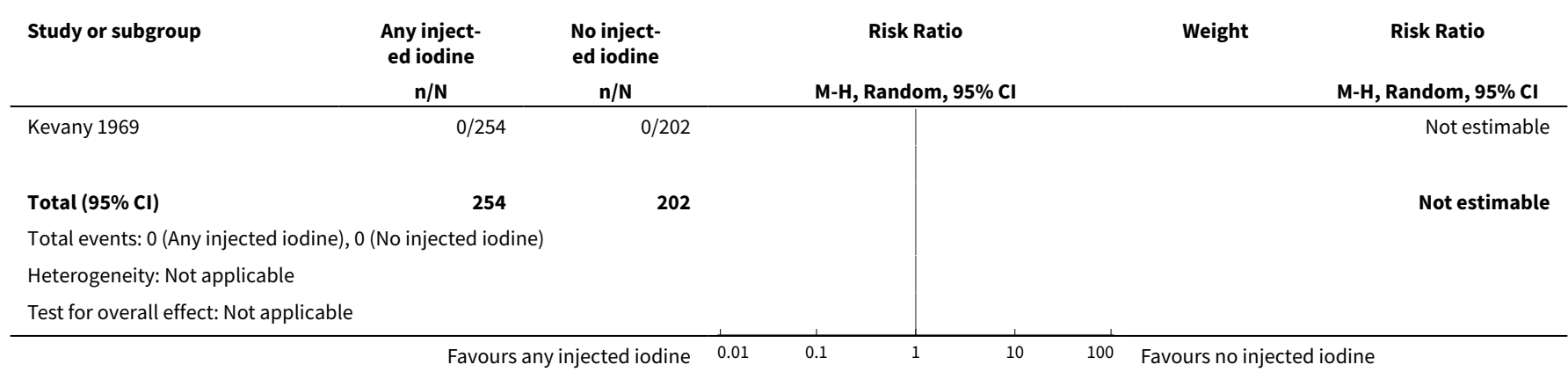

Analysis 5.4. Comparison 5 Any injected iodine supplement versus same supplement without iodine or no treatment/placebo, Outcome 4 Child mental or motor development (IQ points).

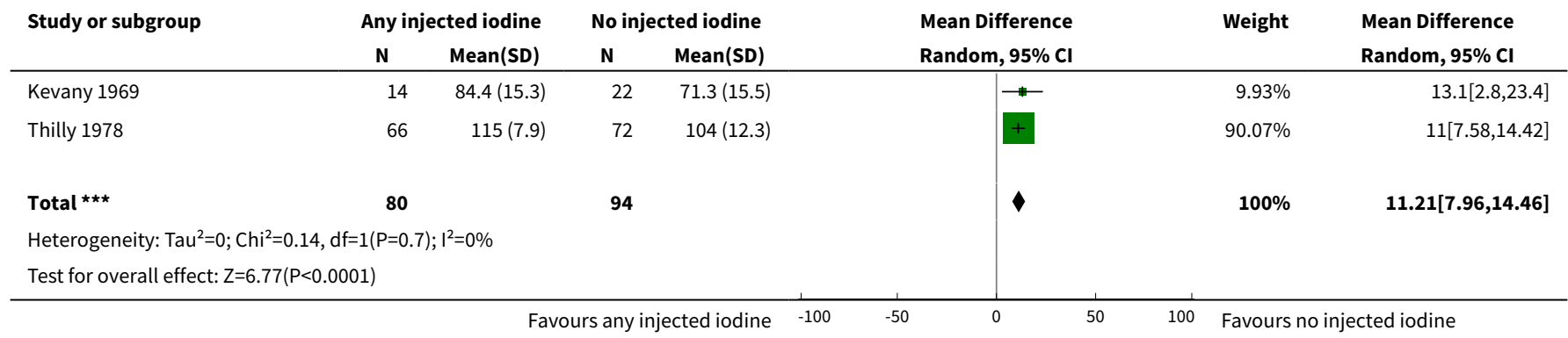




\begin{tabular}{|c|c|c|c|c|c|c|c|c|}
\hline \multirow{3}{*}{ 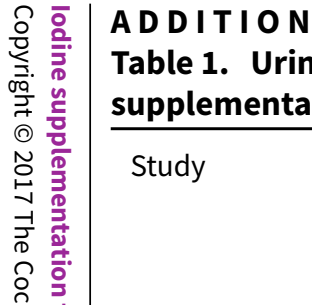 } & $\begin{array}{l}\text { L TAB LE } \\
\text { ry iodine col } \\
\text { ion }\end{array}$ & centration a & breast milk iod & \multicolumn{4}{|c|}{ concentration following prepregnancy, pregnancy or postpartum iodine } & \multirow{2}{*}{ ine concen- } \\
\hline & Setting & $\begin{array}{l}\text { Intervention } \\
\text { timing }\end{array}$ & $\begin{array}{l}\text { Intervention de- } \\
\text { scription }\end{array}$ & $\begin{array}{l}\text { Timing of } \\
\text { assessment }\end{array}$ & \multicolumn{2}{|l|}{ Urinary iodine concentration } & $\begin{array}{l}\text { Breast milk iodine concen- } \\
\text { tration }\end{array}$ & \\
\hline & & & & & lodine & Control & lodine & Control \\
\hline \multirow[t]{2}{*}{$\begin{array}{l}\text { Bouhouch } \\
2014 \text { (C) }\end{array}$} & \multirow[t]{2}{*}{$\begin{array}{l}\text { Southern } \\
\text { Morocco }\end{array}$} & \multirow[t]{2}{*}{ Postpartum } & \multirow{2}{*}{$\begin{array}{l}\text { lodine: single dose } \\
\text { oral } 400 \mathrm{mg} \text {, con- } \\
\text { trol: single dose } \\
\text { placebo }\end{array}$} & Baseline & $\begin{array}{l}\text { Median: } 37 \mu \mathrm{g} / \mathrm{L}, \text { IQR: } 22-77 \\
(\mathrm{n}=119)\end{array}$ & $\begin{array}{l}\text { Median: } 30 \mu \mathrm{g} / \mathrm{L}, \mathrm{IQR}: \\
\text { 18-61 }(\mathrm{n}=115)\end{array}$ & & \\
\hline & & & & $\begin{array}{l}\text { Postpartum: } \\
9 \text { months }\end{array}$ & $\begin{array}{l}\text { Median: } 58 \mu \mathrm{g} / \mathrm{L}, \text { IQR: } \\
34-135(\mathrm{n}=94)\end{array}$ & $\begin{array}{l}\text { Median: } 39 \mu \mathrm{g} / \mathrm{L}, \mathrm{IQR} \\
\text { 24-62 }(\mathrm{n}=81)\end{array}$ & $\begin{array}{l}\text { Median: } 39.4 \\
\mu \mathrm{g} / \mathrm{L}, \mathrm{IQR}: \\
23.5-66.7(\mathrm{n} \\
=94)\end{array}$ & $\begin{array}{l}\text { Median: } 26.2 \\
\mu \mathrm{g} / \mathrm{L}, \mathrm{IQR}: \\
17.7-42.7(\mathrm{n} \\
=81)\end{array}$ \\
\hline \multirow[t]{3}{*}{$\begin{array}{l}\text { Bruck- } \\
\text { er-Davis } \\
2013\end{array}$} & \multirow[t]{3}{*}{ Nice, France } & \multirow[t]{3}{*}{ Pregnancy } & \multirow[t]{3}{*}{$\begin{array}{l}\text { lodine: daily dose } \\
150 \mu \mathrm{g} \text { of iodine, } \\
\text { control: vitamin } \\
\text { mix but no iodine }\end{array}$} & $\begin{array}{l}\text { Baseline: } \\
\text { before } 12 \\
\text { weeks of } \\
\text { amenor- } \\
\text { rhoea }\end{array}$ & $\begin{array}{l}\text { Median: } 111 \mu \mathrm{g} / \mathrm{L}, \mathrm{IQR}: \\
\text { 28-399 }(\mathrm{n}=32)\end{array}$ & $\begin{array}{l}\text { Median: } 103 \mu \mathrm{g} / \mathrm{L}, \text { IQR: } \\
\text { 14-355 }(\mathrm{n}=54)\end{array}$ & & \\
\hline & & & & $\begin{array}{l}\text { Pregnan- } \\
\text { cy: 3rd } \\
\text { trimester }\end{array}$ & $\begin{array}{l}\text { Median: } 160.5 \mu \mathrm{g} / \mathrm{L}, \text { IQR: } \\
\text { 18-358 }(\mathrm{n}=30)\end{array}$ & $\begin{array}{l}\text { Median: } 76 \mu \mathrm{g} / \mathrm{L}, \text { IQR: } \\
\text { 16-303 }(\mathrm{n}=46)\end{array}$ & & \\
\hline & & & & $\begin{array}{l}\text { Postpartum: } \\
3 \text { months }\end{array}$ & $\begin{array}{l}\text { Median: } 58 \mu \mathrm{g} / \mathrm{L}, \text { IQR: } \\
34-135(\mathrm{n}=18)\end{array}$ & $\begin{array}{l}\text { Median: } 58 \mu \mathrm{g} / \mathrm{L}, \mathrm{IQR}: \\
\text { 34-135 }(\mathrm{n}=18)\end{array}$ & & \\
\hline Glinoer 1993 & $\begin{array}{l}\text { Brussels, } \\
\text { Belgium }\end{array}$ & Pregnancy & $\begin{array}{l}\text { lodine: single dose } \\
1 \mathrm{~mL} \text { iodized oil, } \\
\text { control: multivita- } \\
\text { min injection no io- } \\
\text { dine }\end{array}$ & $\begin{array}{l}\text { Neonatal: } \\
\text { 3-6 days }\end{array}$ & $\begin{array}{l}\text { Mean: } 77 \mu \mathrm{g} / \mathrm{L}, \mathrm{SEM}:+/-8 \text { ( } \\
=60)\end{array}$ & $\begin{array}{l}\text { Mean: } 43 \mu \mathrm{g} / \mathrm{L}, \mathrm{SEM}: \\
+/-4(\mathrm{n}=60)\end{array}$ & $\begin{array}{l}\text { Mean: } 61 \\
\mu \mathrm{g} / \mathrm{L}, \mathrm{SEM}: \\
+/-10,(\mathrm{n}= \\
60)\end{array}$ & $\begin{array}{l}\text { Mean: } 29 \\
\mu g / L, S E M: \\
+/-2,(n=60)\end{array}$ \\
\hline \multirow[t]{2}{*}{$\begin{array}{l}\text { Liesenkotter } \\
1996\end{array}$} & \multirow[t]{2}{*}{$\begin{array}{l}\text { Berlin, Ger- } \\
\text { many }\end{array}$} & \multirow[t]{2}{*}{ Pregnancy } & \multirow[t]{2}{*}{$\begin{array}{l}\text { Daily dose oral } 300 \\
\mu \mathrm{g} \mathrm{KI} \text {, control: no } \\
\text { intervention }\end{array}$} & $\begin{array}{l}\text { Postpartum: } \\
\text { mean } 11 \\
\text { days }\end{array}$ & $\begin{array}{l}\text { Median: } 104.5 \mu \mathrm{g} / \mathrm{dl}, \text { IQR: } \\
\text { NR }(\mathrm{n}=\mathrm{NR})\end{array}$ & $\begin{array}{l}\text { Median: In fig only }(\mathrm{n}= \\
\mathrm{NR} \text { ) }\end{array}$ & & \\
\hline & & & & $\begin{array}{l}\text { Neonatal: } 5 \\
\text { days }\end{array}$ & $\begin{array}{l}\text { Median: } 8.3 \mu \mathrm{g} / \mathrm{dl}, \text { IQR: In fig } \\
\text { only ( } \mathrm{n}=\mathrm{NR})\end{array}$ & $\begin{array}{l}\text { Median: } 6.5 \mu \mathrm{g} / \mathrm{dl} \text {, IQR: } \\
\text { In fig only }(\mathrm{n}=\mathrm{NR})\end{array}$ & & \\
\hline
\end{tabular}




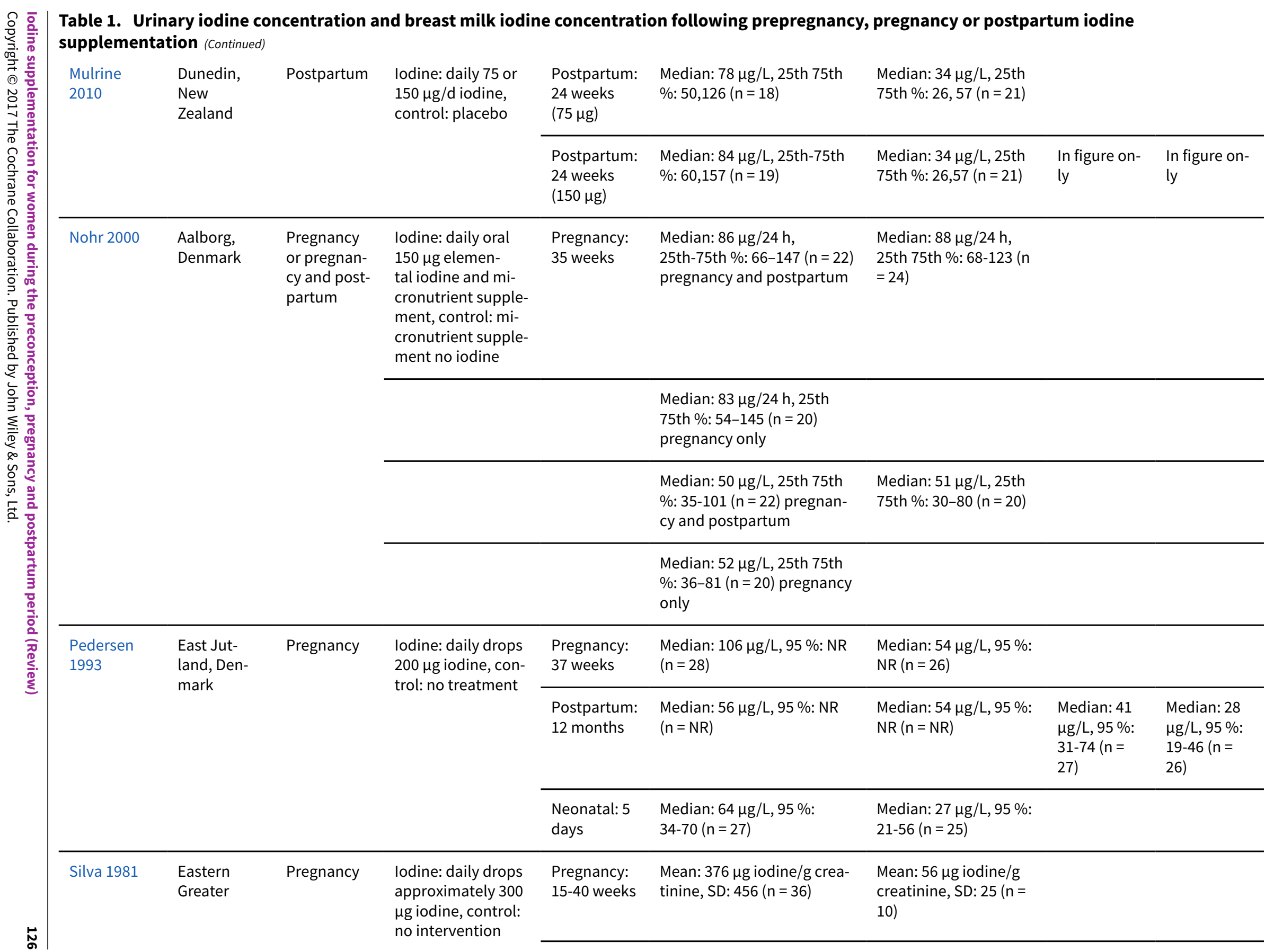




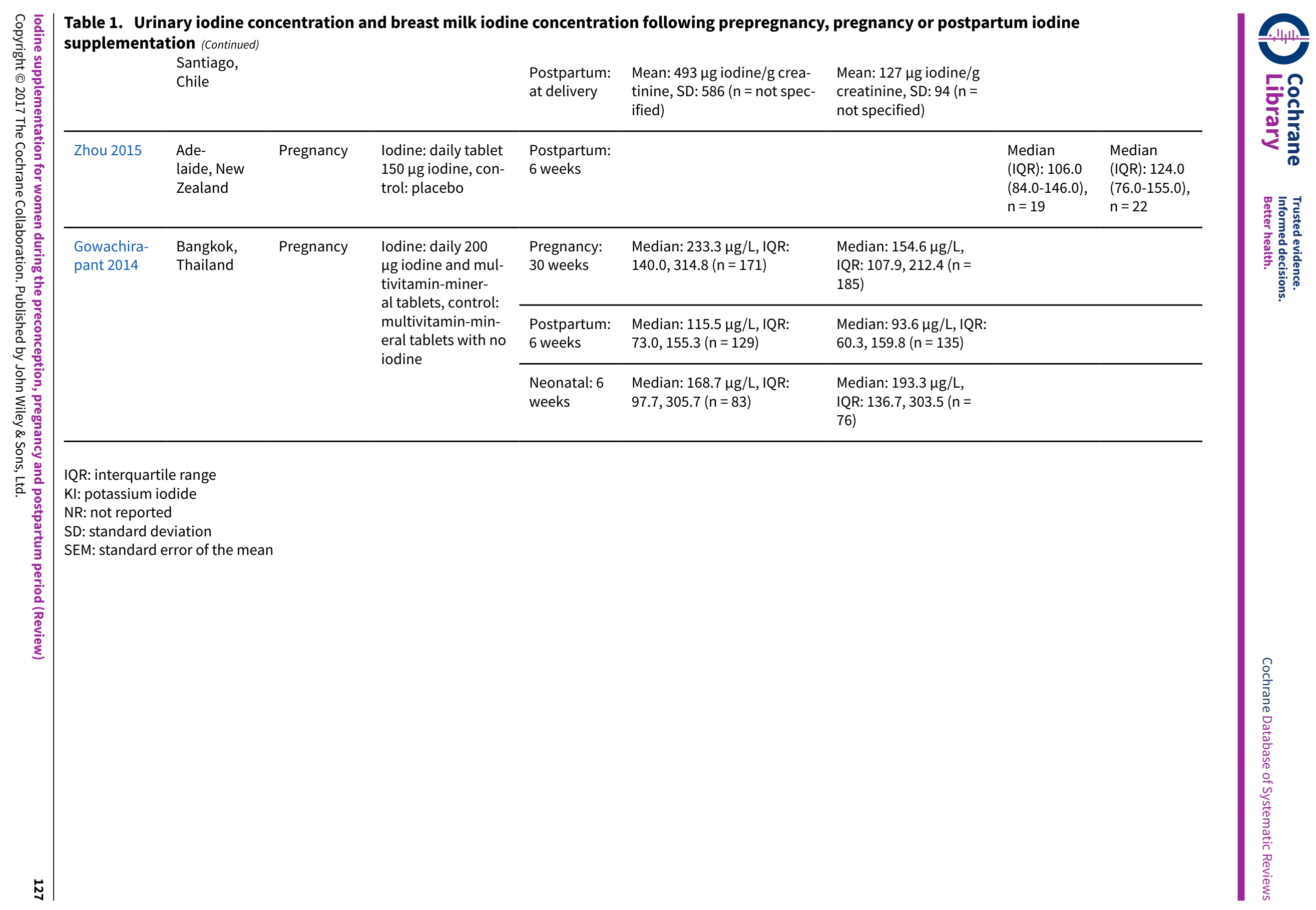


Table 2. Maternal thyroid volume - pregnancy

\begin{tabular}{lll}
\hline Study & \multicolumn{1}{l}{ Thyroid volume $(\mathrm{mL})$} & \\
\cline { 2 - 3 } & lodine & No iodine \\
\hline Brucker-Davis 2013 1 & Median: 9.73, range: 5.4-15.5 $(\mathrm{n}=30)$ & Median: 10.13, range: 4.2-25.5 $(\mathrm{n}=46)$ \\
\hline Pedersen 1993 2 & Median: 11.1 $(\mathrm{n}=28)$ & Median: $12.4(\mathrm{n}=26)$ \\
\hline Gowachirapant 2014 3 & Median: 8.0, IQR: 7.0, 9.1 $(\mathrm{n}=176)$ & Median: 8.1, IQR: 7.1, 9.4 $(\mathrm{n}=190)$ \\
\hline
\end{tabular}

1 Assessed in the 3 rd trimester.

2 Assessed at 37 weeks' gestation. Median estimated from figure. No estimate of range or distribution was provided. Total was not provided so was assumed.

${ }^{3}$ Assessed at 30 weeks' gestation. Intention-to-treat analysis.

Table 3. Maternal thyroid volume - postpartum

\begin{tabular}{lll}
\hline Study & \multicolumn{1}{l}{ Thyroid volume $(\mathrm{mL})$} & \\
\cline { 2 - 3 } & lodine & No iodine \\
\hline Brucker-Davis 2013 1 & Median: 8.5, range: 3.8-13.8 $(\mathrm{n}=18)$ & Median: 9.7, range: 6.6-18.9 $(\mathrm{n}=18)$ \\
\hline Liesenkotter 1996 2 & Mean: 20.5, SD: 8.5 $(\mathrm{n}=38)$ & Mean: 20.0, SD: 10.5 $(\mathrm{n}=70)$ \\
\hline Pedersen 1993 3 & Median: 10.2 $(\mathrm{n}=25)$ & Median: $10(\mathrm{n}=24)$ \\
\hline Gowachirapant 2014 4 & Median: 7.3, IQR: 5.8, 9.0 $(\mathrm{n}=129)$ & Median: 7.2, IQR: 6.1, 8.4 $(\mathrm{n}=135)$ \\
\hline
\end{tabular}

${ }^{1}$ Assessed at 3 months postpartum.

2Assessed by ultrasound on average at 11 days postpartum. Mean and SD extracted from figure.

${ }^{3}$ Assessed at 12 months postpartum. Median estimated from figure. No estimate of range or distribution was provided. Total was not provided so was assumed.

${ }^{4}$ Assessed at 6 weeks postpartum.

\section{Table 4. Maternal thyroglobulin - pregnancy}

\begin{tabular}{|c|c|c|}
\hline \multirow[t]{2}{*}{ Study } & \multicolumn{2}{|l|}{ Thyroglobulin (in $\mu \mathrm{g} / \mathrm{L}$ ) } \\
\hline & lodine & No iodine \\
\hline Brucker-Davis 20131 & Median: 17.5 , range: $2.5-56.2(n=30)$ & Median: 19.6 , range: $3.8-98.6(n=46)$ \\
\hline Nohr 20002 & Median: 14.1, IQR: 5.0, $21.5(n=42)$ & Median: 19.4, IQR: 8.2, $33.5(n=24)$ \\
\hline Pedersen 19933 & Median: $9.2(n=28)$ & Median: $16.7(n=26)$ \\
\hline Gowachirapant 20144 & Median: 9.78, IQR: 5.46, $18.10(n=176)$ & Median 11.90, IQR: 6.35, $22.30(n=190)$ \\
\hline
\end{tabular}

1 Assessed in the 3 rd trimester.

2Assessed at 35 weeks' gestation. 
${ }^{3}$ Assessed at 37 weeks' gestation. Median estimated from figure. No estimate of range or distribution was provided. Total was not provided so was assumed.

${ }^{4}$ Assessed at 30 weeks' gestation.

Table 5. Maternal thyroglobulin - postpartum

\begin{tabular}{|c|c|c|}
\hline \multirow[t]{2}{*}{ Study } & \multicolumn{2}{|l|}{ Thyroglobulin (in $\mu \mathrm{g} / \mathrm{L}$ ) } \\
\hline & lodine & No iodine \\
\hline Brucker-Davis 20131 & Median: 11.5 , range: $4.4-37(n=18)$ & Median: 23.1 , range: $3.0-45.5(n=18)$ \\
\hline Liesenkotter 19962 & Mean: 8.3, SD: $10.9(n=38)$ & Mean: 13.5, SD: $19.3(n=70)$ \\
\hline Pedersen 19933 & Median: $4.7(n=24)$ & Median: $10.3(n=24)$ \\
\hline Gowachirapant 20144 & Median: 7.94, IQR: 4.89, $15.30(n=129)$ & Median: 9.51, IQR: 4.79, $15.90(n=135)$ \\
\hline
\end{tabular}

1Assessed at 3 months postpartum.

${ }^{2}$ Assessed on average at 11 days postpartum.

${ }^{3}$ Assessed at 12 months postpartum. Median estimated from figure. No estimate of range or distribution was provided. Total was not provided so was assumed.

${ }^{4}$ Assessed at 6 weeks postpartum.

Table 6. Neonatal behavioural assessment scales scores assessed at 6 weeks postpartum (Zimmerman 2009)

\begin{tabular}{|c|c|c|c|c|c|c|}
\hline \multirow[t]{2}{*}{ Outcome } & \multicolumn{3}{|l|}{ lodine } & \multicolumn{3}{|l|}{ Control } \\
\hline & Median & IQR & $\mathrm{n}$ & Median & IQR & $\mathrm{n}$ \\
\hline Habituation & 7.0 & $(5.4,8.3)$ & 22 & 7.6 & $(6.8,8.1)$ & 18 \\
\hline Social-interactive & 7.4 & $(6.4,8.0)$ & 66 & 6.9 & $(6.0,8.1)$ & 68 \\
\hline Motor system & 6.0 & $(5.3,6.6)$ & 73 & 5.8 & $(5.2,6.4)$ & 72 \\
\hline State organization & 3.8 & $(2.8,4.0)$ & 48 & 3.8 & $(3.0,4.1)$ & 53 \\
\hline State regulation & 4.0 & $(3.3,4.5)$ & 38 & 4.0 & $(2.6,4.7)$ & 40 \\
\hline Autonomic system & 6.7 & $(6.0,7.3)$ & 61 & 6.7 & $(5.3,7.3)$ & 71 \\
\hline Reflexes & 3.0 & $(1.8,4.0)$ & 74 & 3.0 & $(2.0,4.0)$ & 75 \\
\hline Supplementary items & 6.7 & $(5.3,8.3)$ & 48 & 6.3 & $(5.1,8.1)$ & 55 \\
\hline
\end{tabular}

IQR: interquartile range 


\section{AP P E N DICES}

\section{Appendix 1. Search strategy and terms}

Two review authors (JPR and KBH) searched the WHO International Clinical Trials Registry Platform (ICTRP) for unpublished, ongoing or planned trials using the following terms (last search date: 17 November 2016): "iodine AND pregnancy", "iodine AND pregnant", "iodine AND postnatal", "iodine AND postpartum", "iodine AND breastfeeding", "iodine and lactation"

\section{CONTRIBUTIONS OF AUTHORS}

All authors contributed to the development of this review.

Disclaimer: Juan Pablo Peña-Rosas is currently a staff member of the World Health Organization (WHO). Luz Maria De-Regil and Kimberly Harding are employed full-time by the Micronutrient Initiative (MI). The authors alone are responsible for the views expressed in this publication and they do not necessarily represent the decisions, policy or views of WHO or MI.

\section{DECLARATIONS OF INTEREST}

Luz Maria De-Regil is employed by the Micronutrient Initiative (MI), an international not-for-profit organization that implements salt fortification programmes, to ensure populations have adequate iodine levels. As an employee of MI she recused herself from assessing the eligibility of one study sponsored by MI that was excluded as determined by another author. She is also a board member for the lodine Global Network, a non-profit, non-government organization for the sustainable elimination of iodine deficiency worldwide.

Kimberly Harding is employed by the Micronutrient Initiative (MI), an international not-for-profit organization that implements salt fortification programmes, to ensure populations have adequate iodine levels. As an employee of $\mathrm{MI}$ she recused herself from assessing the eligibility of one study sponsored by MI that was excluded as determined by another author.

Part of this updated review was developed during the World Health Organization (WHO)/Cochrane/Micronutrient Initiative/Cornell University Summer Institute for Systematic Reviews in Nutrition for Global Policy Making hosted at the Division of Nutritional Sciences, Cornell University, Ithaca, USA in 7-18 July, 2014 (Kimberly Harding) and in 27 July - 7 August 2015 (Brian Payne). The World Health Organization supported this programme.

Brian Payne received financial support from the first multidisciplinary training programme on global nutrition policy for sustainable development designed by the Latin American Society of Nutrition (SLAN), World Health Organization (WHO), PanAmerican Health Organization (PAHO), the World Food Programme (WFP) and the Micronutrient Initiative (MI) in 2015.

Juan Pablo Peña-Rosas: The Evidence and Programme Guidance Unit, Department of Nutrition for Health and Development, World Health Organization receives financial resources from several external sources for the biennium 2014-2015 from the Bill \& Melinda Gates Foundation (2013-2016); US Centers for Disease Control and Prevention (CDC) (2014-2019); The Micronutrient Initiative (2014-2017); US Agency for International Development (USAID) (2014-2016) and Harvest Plus (2014-2015). Donors do not fund specific guidelines and do not participate in any decision related to the guideline development process including the composition of policy questions, membership of the guideline groups, the conduct and interpretation of systematic reviews, or the formulation of recommendations.

Angela C Webster: none known.

Constance is employed by a public hospital and in her role she reviews women with gestational diabetes and thyroid dysfunction. In her clinical role she encourages all pregnant women and women contemplating pregnancy to have sufficient iodine supplementation (without any preference for a specific brand) in accordance with local and international recommendations.

Erika Ota received partial financial support from the Evidence and Programme Guidance Unit, Department of Nutrition for Health and Development, World Health Organization to contribute to this review.

\section{SOURCES OF SUPPORT}

\section{Internal sources}

- Micronutrient Initiative (MI), Canada.

Luz Maria De-Regil and Kimberly Harding are full time staff of MI.

- Evidence and Programme Guidance, World Health Organization, Switzerland.

Juan Pablo Peña-Rosas is full time staff of WHO. 


\section{External sources}

- The Bill \& Melinda Gates Foundation, USA.

WHO acknowledges the financial support from the Bill \& Melinda Gates Foundation for the development of systematic reviews on the effects of nutrition-specific and nutrition-sensitive interventions for health and development.

- United States Agency for International Development (USAID), USA.

WHO acknowledges the financial support of USAID for the development of systematic reviews on the effects of micronutrient interventions for health and development.

- UNDP/UNFPA/UNICEF/WHO/World Bank Special Programme of Research, Development and Research Training in Human Reproduction (HRP), Department of Reproductive Health and Research, World Health Organization, Switzerland.

- World Health Organization, Switzerland.

Brian Payne received financial support for this work as part of a short-term consultancy in the Evidence and Programme Guidance, Department of Nutrition for Health and Development. Erika Ota received partial financial support from this department to contribute to this review.

\section{DIFFERENCES BETWEEN PROTOCOLAND REVIEW}

There are some differences between our published protocol (De-Regil 2015) and this review.

The contact person (and guarantor) for this review has changed from Luz Maria De-Regil to Juan Pablo Peña-Rosas. Additional co-authors have also joined the review team at the full review stage.

We added "single" dose to the annual category in the supplementation regimen subgroup.

Instead of combining any maternal adverse effects together, we separated adverse effects into different outcomes based on what was reported in the included studies, in order to avoid losing potentially important information. We changed this outcome from: Any adverse effect (for example iodine-induced hyperthyroidism) to:

- Adverse effects:

* Elevated thyroid peroxidase antibodies (TPO-ab) (as defined by trial authors)

* Hyperthyroidism (as defined by trial authors)

* Digestive intolerance (as defined by trial authors)

Instead of combining any adverse effects (for infants and children up to 23 months of age) together, we separated adverse effects into different outcomes based on what was reported in the included studies, in order to avoid losing potentially important information. We changed this outcome from: Any adverse effect (for example iodine-induced hyperthyroidism) to:

- Adverse effects

* Elevated TPO-ab (as defined by trial authors)

* Hyperthyroidism (as defined by trial authors)

We added subgroups for a given outcome only where there were at least four studies (previously we planned to do this if there were three or more and to report subgroup analyses only if there were at least two studies per included subgroup category). We considered this meaningful, otherwise we would be comparing single studies rather than characteristics of different types of studies.

Methods/types of participants - we have clarified that the study participants were not restricted in terms of the iodine status of the study population or setting.

Methods/measures of treatment effect - in this section we have clarified how we handled data presented as medians.

\section{INDEX TERMS}

\section{Medical Subject Headings (MeSH)}

*Dietary Supplements [adverse effects]; Hyperthyroidism [epidemiology]; Hypothyroidism [epidemiology]; Infant, Newborn, Diseases [epidemiology]; lodine [*administration \& dosage] [adverse effects] [deficiency]; Perinatal Mortality; Postpartum Period; Preconception Care [*methods]; Pregnancy Complications [epidemiology]; Premature Birth [epidemiology]; Prenatal Care [ ${ }^{*}$ methods]; Randomized Controlled Trials as Topic; Thyroid Hormones [blood]; Thyrotropin [blood]

\section{MeSH check words}

Female; Humans; Infant, Newborn; Pregnancy 